\title{
ATMOSPHERIC VARIABILITY AND PRECIPITATION IN THE ROSS SEA REGION, ANTARCTICA
}

\author{
BY
}

\section{LANA COHEN}

\begin{abstract}
A thesis
submitted to the Victoria University of Wellington in fulfillment of the requirements for the degree of Doctor of Philosophy
\end{abstract}

Victoria University of Wellington

(2013) 



\section{Abstract}

Understanding how atmospheric variability in the Pacific sector of Antarctica drives precipitation is essential for understanding current and past climate changes on the West Antarctic Ice Sheet and the Ross Ice Shelf. Precipitation plays a key role in the Antarctic climate system (via mass balance of ice sheets) and is necessary for understanding past climates (via snow and ice proxies). However precipitation is difficult to measure and model and its variability in these regions is still not well understood. This thesis compiles three separate but inter-related studies which provide further understanding of the atmospheric variability of the Ross Sea region and its role in driving precipitation.

Synoptic classifications over the Southern Ocean in the Pacific sector of Antarctica $\left(50^{\circ} \mathrm{S}-\right.$ Antarctic coast, $\left.150^{\circ} \mathrm{E}-90^{\circ} \mathrm{W}\right)$ are derived from NCEP reanalysis data (1979-2011), producing a set of six synoptic types for the region. These six types describe the atmospheric variability of the Ross and Amundsen Seas region for the past 33 years and show how hemispheric scale circulation patterns such as the El Niño-Southern Oscillation and the Southern Annular Mode are reflected in local precipitation and temperature on the Ross Ice Shelf. The synoptic types also provide understanding of how different source regions and transport pathways can influence precipitation on the Ross Ice Shelf, which is important for the interpretation of climate proxies.

Because of the sparseness of in-situ meteorological measurements in Antarctica, many studies (including the two described above) rely on atmospheric reanalyses data. However, assessments of reanalyses precipitation have only been done on annual and longer timescales. An assessment of the ERA-Interim and NCEP-2 reanalyses precipitation data on synoptic timescales is developed using statistical, event-based analysis of snow accumulation data from automatic weather stations around the Ross Ice Shelf. The results show that there are important differences between the two reanalyses products and that ERA-Interim represents precipitation better than NCEP-2 for this region.

Stable isotopes in snow $\left(\delta^{18} \mathrm{O}\right.$ and $\left.\delta \mathrm{D}\right)$ are widely used as temperature proxies, but are also influenced by moisture history, source region conditions, and cloud micro-physical processes. Further understanding of the relative importance of these other factors is provided by modeling the isotopic composition of snow at Roosevelt Island, an ice core site on the Ross Ice Shelf. A Rayleigh fractionation model is used to determine isotope composition on sub-storm (hourly) timescales, and the results are compared to measured isotope composition. The model is able to reproduce the significant variability of measured isotopes and shows the importance of air-mass mixing and moisture trajectories on the isotopic composition of snow at Roosevelt Island.

Together, these studies show how synoptic variability influences precipitation on the Ross Ice Shelf and at Roosevelt Island in particular, and they provide a basis for interpreting stable isotopes and other precipitation-based climate proxies in ice cores from the Roosevelt Island site. 


\section{Acknowledgements}

Many, many thanks to my advisor, Sam Dean, for his excellent guidance and assistance throughout this thesis. His competence, scientific rigor, and willingness to teach, sets an example I aspire to. Many thanks also to my secondary advisor, Kate Sinclair, for the use of her isotope model and assistance with the many challenges of isotope modeling, as well as extensive help with the ICP-MS analysis. Thanks to James Renwick for help with the cluster analysis and the use of his Matlab code and pre-processed reanalyses datasets. Thanks to the isotope lab at GNS for the isotope analysis and Nancy Bertler for providing the opportunity to sample snow at Roosevelt Island and the use of the ice core facilities at GNS. I also very much appreciate the financial and logistical support from Antarctica New Zealand for making this research possible. Thanks to Tim Naish, Shulamit Gordon, Kate, and Sam for their advice and support during a critical period, without which this thesis wouldn't exist. To friends who've provided moral support over the past three years, thanks for helping me keep perspective on many occasions and to Saskia for happily keeping me company. Finally, countless thanks to my parents for their support and mentoring throughout this process (and long before), and for instilling the simple, but essential principle that is my motivation for doing science: because it's fun! 


\section{Table of Contents}

Abstract

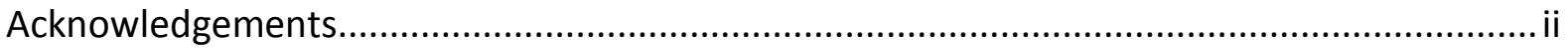

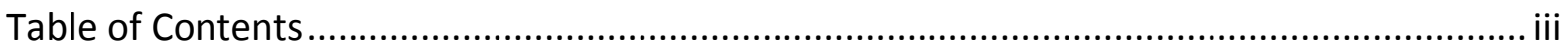

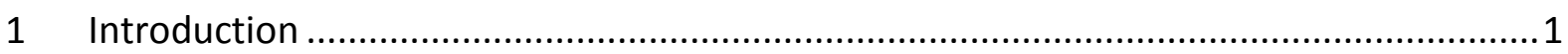

1.1 Atmospheric drivers of precipitation in the Ross Sea region ................................... 8

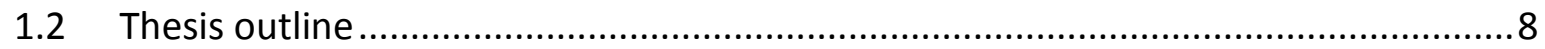

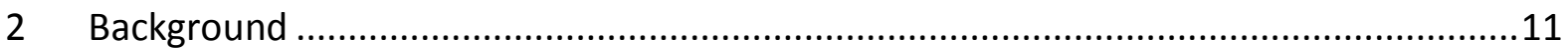

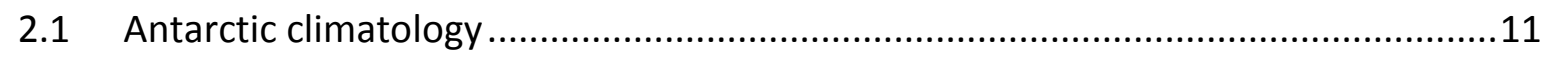

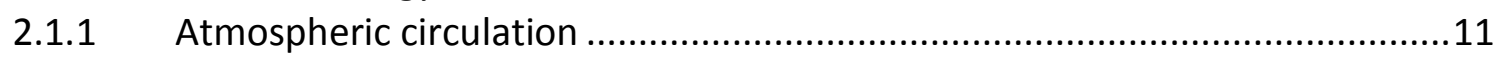

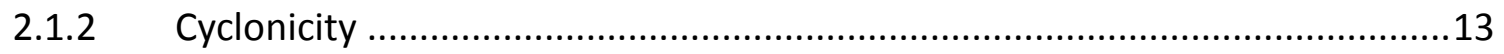

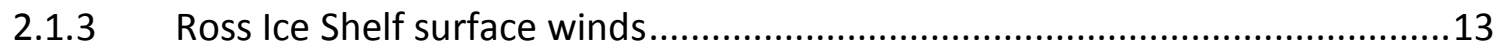

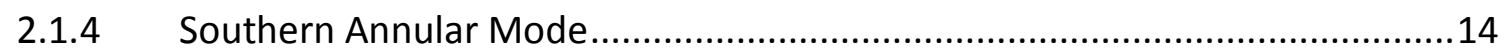

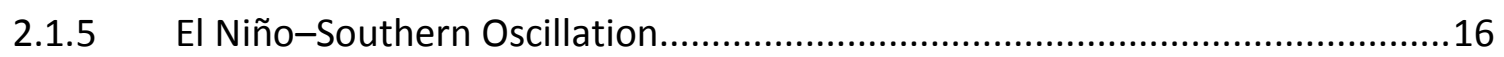

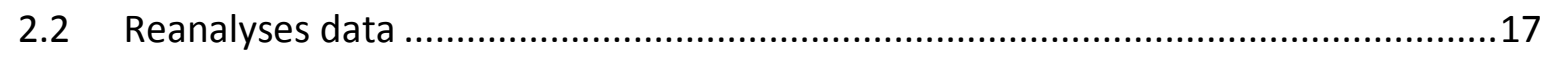

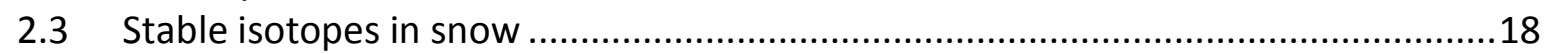

3 Synoptic weather types for the Ross Sea region, Antarctica........................................23

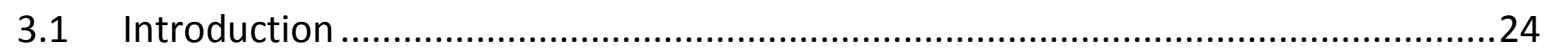

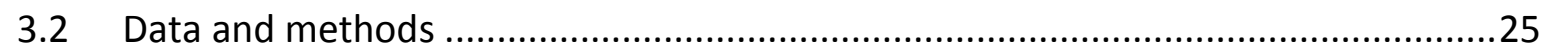

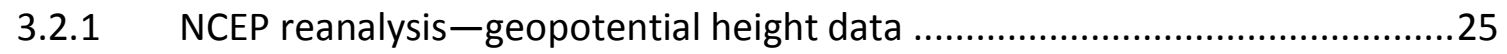

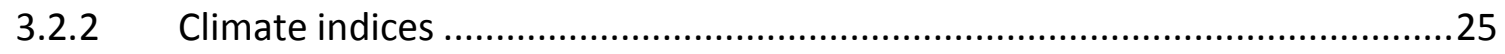

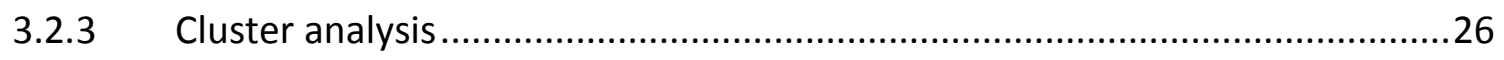

3.2.4 Assessment of NCEP reanalysis precipitation data .......................................28

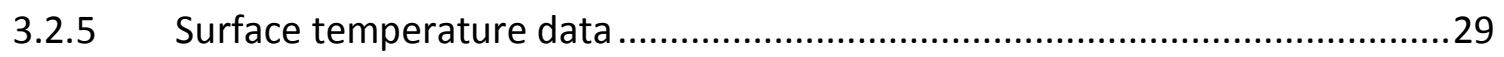

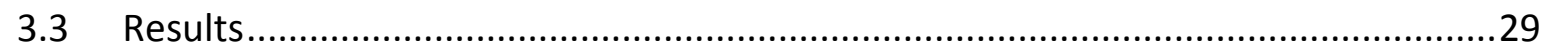

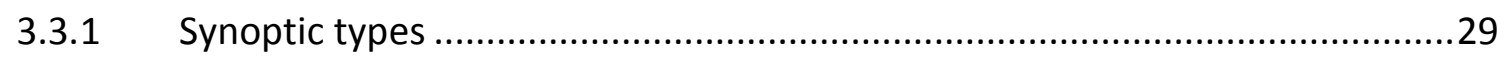

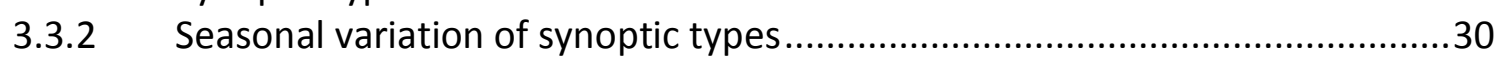

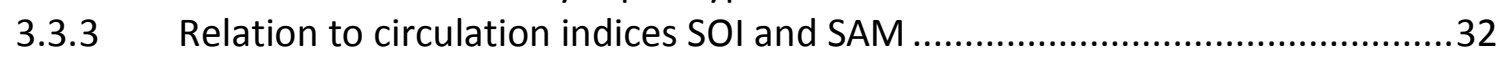

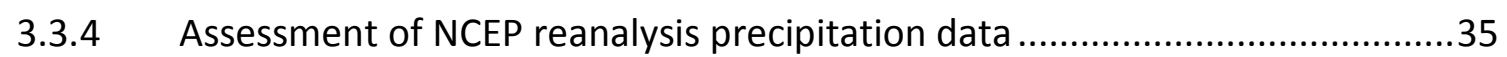

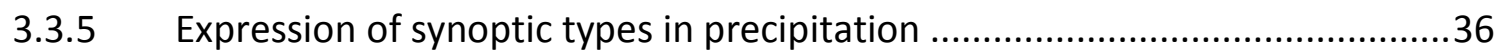

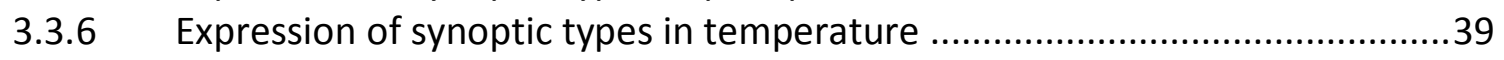

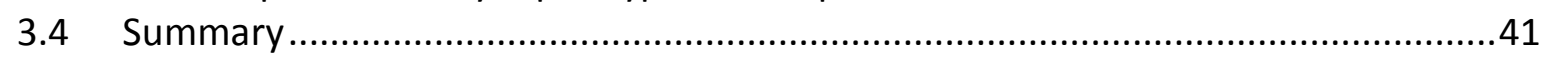

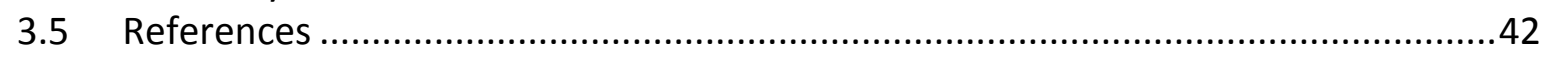

4 Snow on the Ross Ice Shelf: comparison of reanalyses and observations from automatic

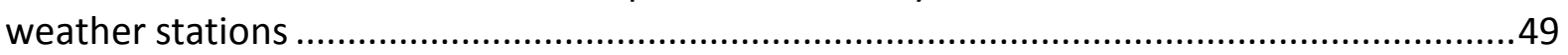

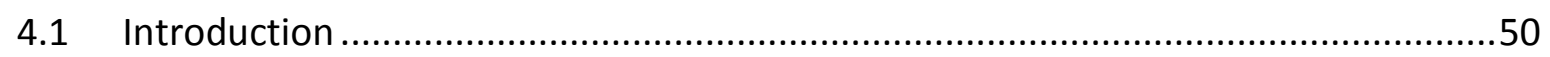

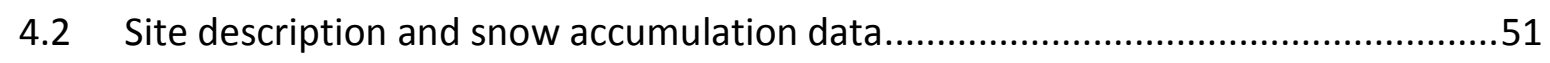

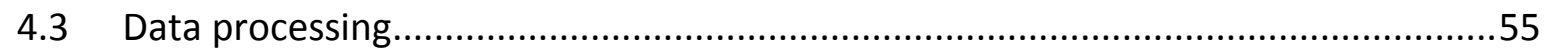

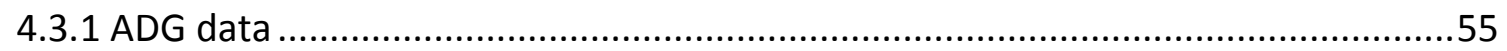

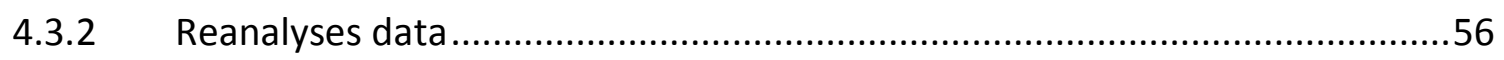

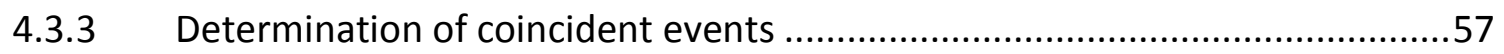

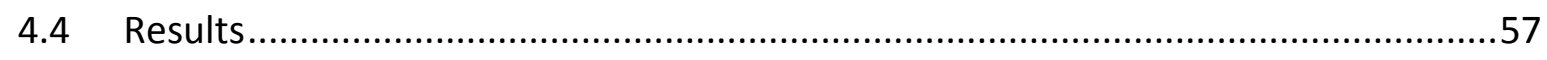

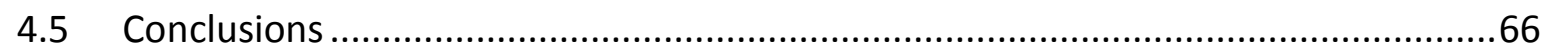

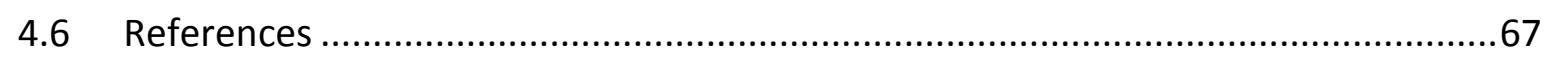

5 Modeling stable isotopes in snow for synoptic events at Roosevelt Island, Antarctica .73

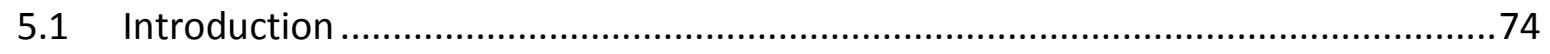




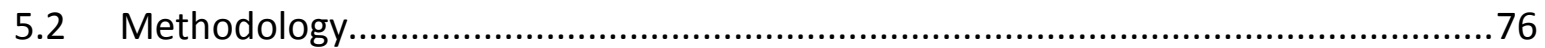

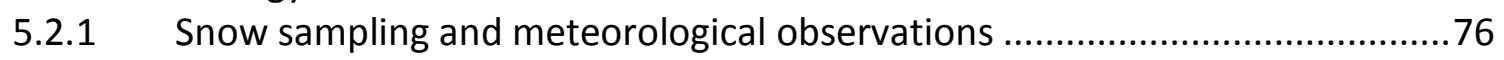

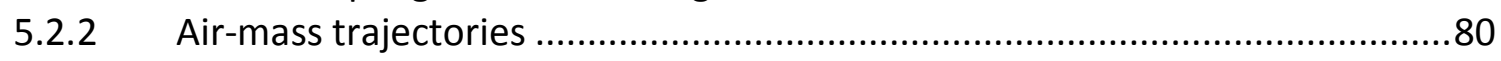

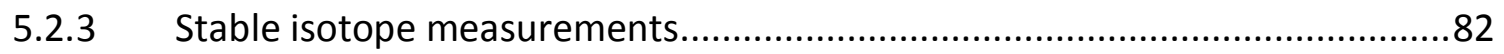

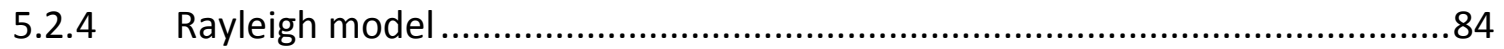

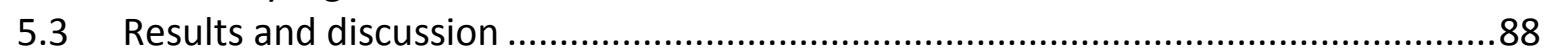

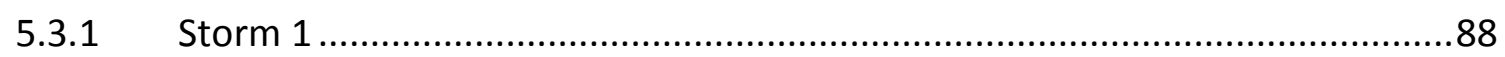

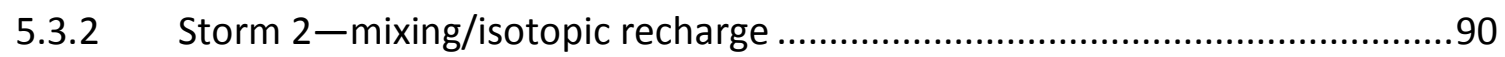

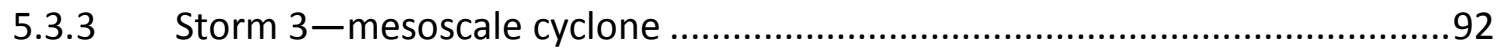

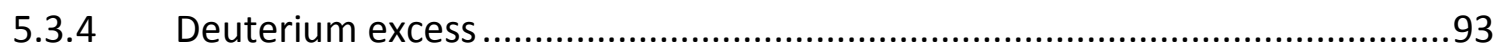

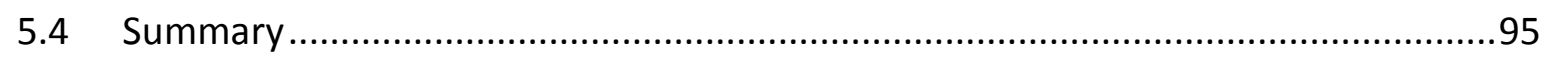

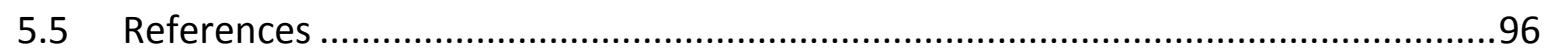

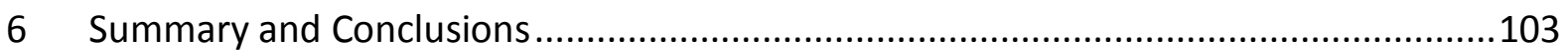

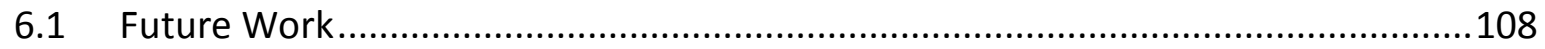

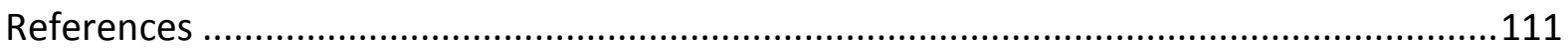

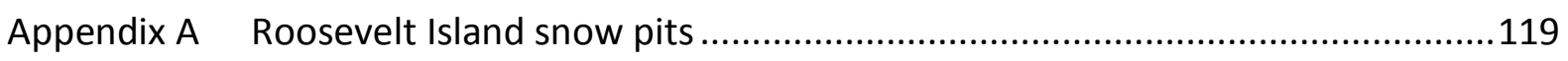

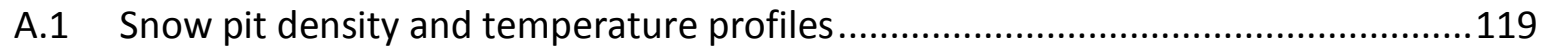

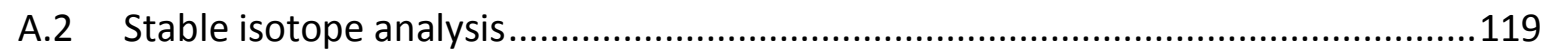

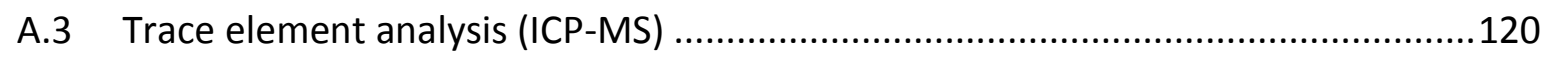

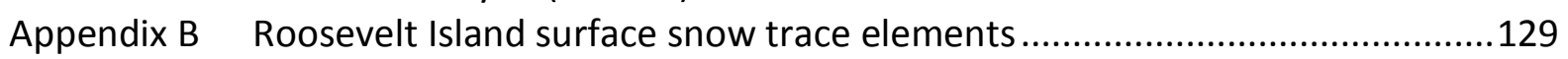




\section{Introduction}

Antarctica is a remote, isolated, ice-covered continent which, in many ways, has only recently begun to be explored. Actual sighting of the continent by Europeans didn't occur until 1820 and significant explorations didn't begin until the 1890s. Scientific exploration has been a key component and motivation of the exploration of Antarctica from the beginning, and the continent has provided a platform for fundamental discoveries across many different scientific disciplines. The International Geophysical Year in 1957-58 triggered the modern era of scientific exploration in Antarctica with the establishment of permanent base stations and regular air support providing the logistics for significant expansion of scientific pursuits.

Despite its isolation and remoteness, Antarctica plays a key role in the global climate system and many studies concerning global climate are conducted there. The polar regions are important for driving and maintaining the global atmospheric and ocean circulation patterns that create global climate regimes such as deserts and tropical regions. These climate regimes and large-scale atmospheric patterns such as the trade-winds and jet streams, are a result of the global temperature gradients which are due to unevenly distributed solar radiation (equator receive more solar radiation than the poles). The large snow- and icecovered areas in both polar regions that reflect significant amounts of solar radiation and radiate heat into space help maintain that global temperature gradient and resulting circulation patterns. Importantly, these snow- and ice-covered regions are more sensitive to global and regional temperature changes due to feedback mechanisms that amplify small changes, and these changes can be detected earlier in the polar regions than elsewhere on the globe.

Though both northern and southern polar regions are mostly snow- and ice- covered, they are fundamentally different, as the northern polar region is an ocean surrounded by land, while the southern polar region is land surrounded by ocean. Antarctica, which is nearly twice the size of Australia (or 52 New Zealands), is almost completely covered (98\%) by glacial ice averaging approximately 1,600 meters thick. There are two geographically (and climatologically) distinct ice sheets: the East Antarctic Ice Sheet (EAIS) and the West Antarctic Ice Sheet (WAIS), which rise to $\sim 4,000$ meters above sea level (a.s.1.) and 2,000 meters a.s.l. respectively (see Figure 1.1). Both of the ice sheets are relatively flat in their interiors (the plateau region, Figure 1.2), and drop steeply to the ocean or ice shelves at the edges. 


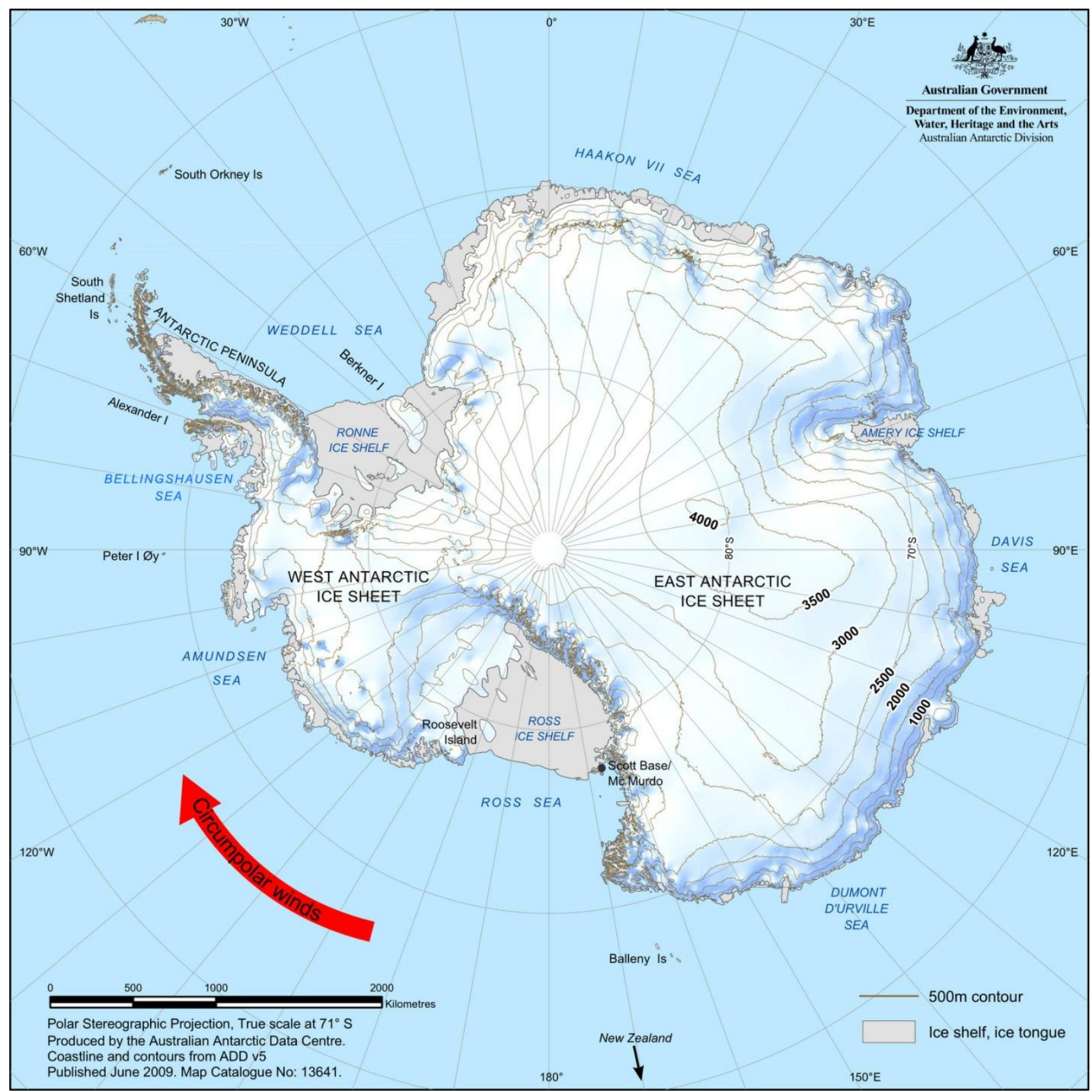

Figure 1.1 Antarctica topography, major geographical features, and direction of the circumpolar winds. Base map courtesy Australian Antarctic Division.

Because Antarctica's ice sheets are significant topographic barriers to storm systems, most of the precipitation falls near the coasts while the interior of the continent remains dry enough to technically be classified as desert ( $<250 \mathrm{~mm}$ water equivalent per year) (Vaughan et al., 1999). The westerly trade winds that circulate around the continent constrain the cold polar air to the Antarctic plateau, while the surrounding Southern Ocean provides a source of relatively warm, moist air for synoptic storm systems that circle the continent. The West Antarctic Ice Sheet, which is smaller and lower than the East Antarctic Ice Sheet, is affected more by the warm, ocean air masses that penetrate from the Southern Ocean. The 
AntarcticPeninsula (AP), which juts further north out into Southern Ocean than the rest of Antarctica is highly affected by these storm systems and receives significantly more precipitation than the rest of the continent.

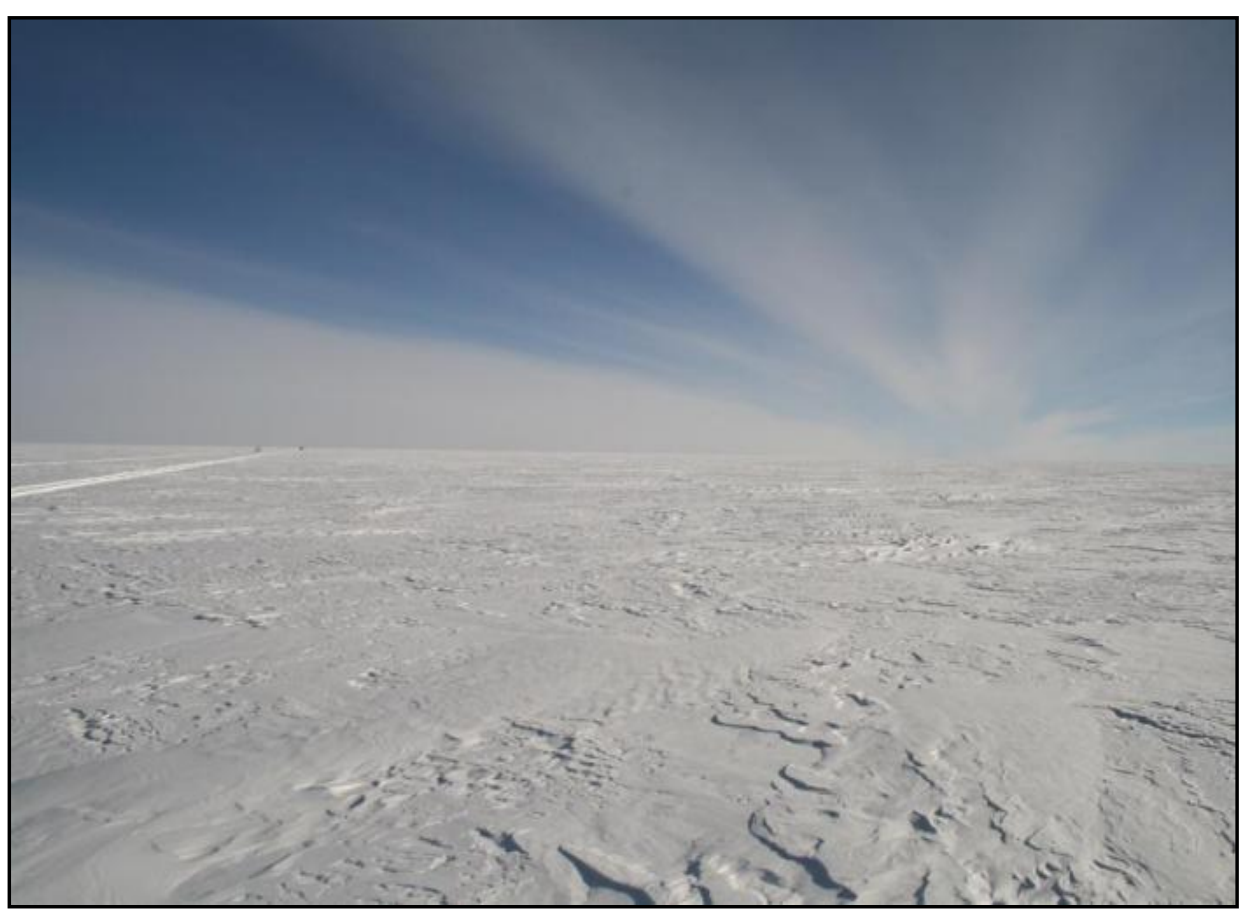

Figure 1.2 The East Antarctic Ice Sheet plateau. Photo courtesy Jan-Gunnar Winther.

Ice shelves, which are an extension of Antarctica's ice sheets, are massive platforms of ice which float on the ocean. The Ross Ice Shelf, which is the largest in Antarctica, is nearly twice the size of New Zealand and several hundred meters thick. The vertical ice front at the ocean edge towers above the ocean surface to heights of 15 to 50 meters and prompted early explorers to call it "the Barrier" (Figure 1.3). The Ross Ice Shelf has played an important role in the early exploration of Antarctica's interior with several explorations starting out at Ross Island, located on the western edge of the Ross Ice Shelf, and continues to be an important logistical hub, housing permanent base stations for New Zealand (Scott Base) and the USA (McMurdo).

Climatologically, ice shelves are very important, playing key roles in both the stability of ice sheets and the global oceanic circulation. Ice shelves, which are formed by the flow of glaciers and ice sheets onto the ocean surface, can act as "plugs" on the flow of ice from these glaciers and ice sheets. Thus, when ice shelves break away, the rate of glacial flow can increase, a process which was illustrated nicely for several glaciers in the Antarctic Peninsula 
after the Larsen B shelf broke off in 2002 (Rignot et al., 2004). Ice shelves are also important for the formation of the cold, saline (dense) Antarctic bottom water (AABW) which is one of the main drivers of the global oceanic circulation. This dense water is formed in massive amounts at the open water regions (polynyas) at the edges of ice shelves and via new ice formation along the bottom of the ice shelves. These processes are intricately linked to atmospheric conditions, both affected by and affecting, wind patterns, heat transfer, and precipitation around Antarctica.

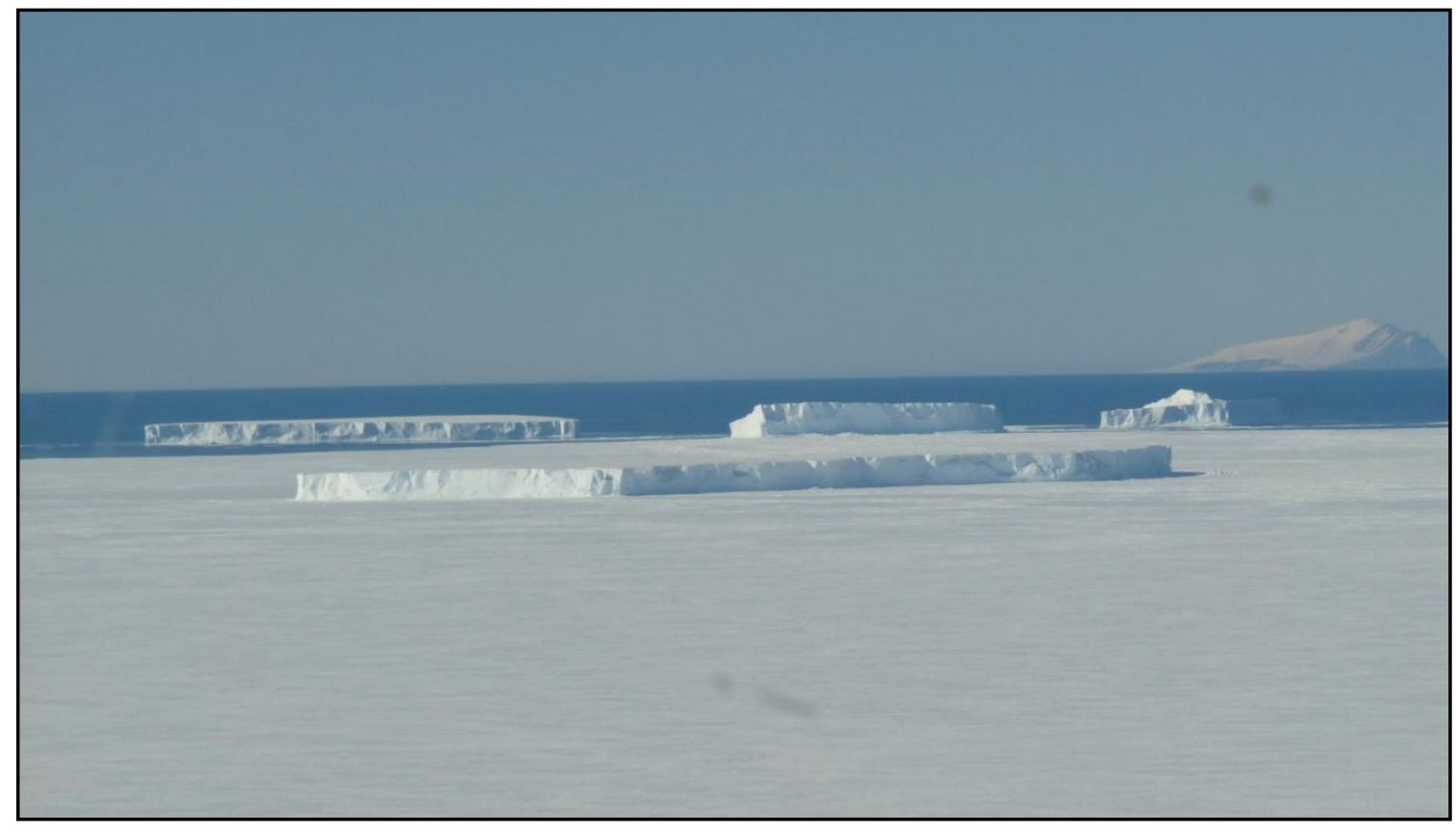

Figure 1.3 Icebergs and sea ice at the edge of the Ross Ice Shelf.

Significant changes have been observed in Antarctica in the last few decades. Melting of the WAIS, first identified in the 1990s, has accelerated recently at rates faster than predicted indicating that we do not fully understand the processes driving this ice mass loss (Rignot et al., 2008). Because West Antarctic ice mass loss can contribute significantly to global sea level rise [potential contribution to sea level rise from the WAIS is $4.8 \mathrm{~m}$ (Bamber et al., 2009)], understanding how the combination of atmospheric and oceanic warming and ice sheet dynamics are driving this ice mass loss is of great interest. Related to this, is the significant warming in West Antarctica and the Antarctic Peninsula $\left(2-3^{\circ} \mathrm{C}\right.$ in the last 50 years, which are among the largest changes seen globally) (Bromwich et al., 2013; Vaughan et al., 2003). Interestingly, this warming is in contrast to a slight cooling on the East Antarctic Ice Sheet (O'Donnell et al., 2011) and increasing sea ice extent in the Ross Sea region 
(Parkinson and Cavalieri, 2012). This emphasizes the importance of understanding the climate and ice processes driving these changes.

The changes in surface temperature and sea ice distribution have partly been attributed to a southerly shift of the belt of westerly winds that encircle the continent over the past few decades (the variability in the position of the westerly jet is known as the Southern Annular Mode (SAM) ). The circumpolar winds have also strengthened in recent decades as a result of the increasing temperature gradient between the mid- and high-latitudes. The strengthening and southerly shift of the circumpolar wind field brings warmer air further south and keeps cold, polar air more constrained (thus explaining the paradox of the East Antarctic Ice Sheet cooling versus West Antarctic Ice Sheet and Antarctic Peninsula warming). In addition, the El Niño-Southern Oscillation (ENSO), a coupled ocean-atmosphere climate cycle based in the Pacific Ocean, is known to affect pressure systems in the Pacific sector of Antarctica (the regions around the Ross, Amundsen, and Bellingshausen Seas). The effects of these two hemispheric-scale modes of climate variability on Antarctic climate are only partly understood and specifically how they affect the climate of the Ross Sea region is one of the primary motivations of this thesis.

One of the main hurdles for understanding climate in Antarctica is the sparseness and short time-span of available meteorological data. A network of Automatic Weather Stations (AWS) scattered throughout Antarctica provides unattended, surface meteorological measurements (Figure 1.4), but the density of stations is sparse. Radiosonde measurements provide local atmospheric measurements of the atmospheric vertical profile, but these are even more sparse than surface measurements. Satellite measurements provide extensive spatial coverage of many surface and atmospheric meteorological parameters, but some key parameters such as precipitation, are not directly measured. Atmospheric reanalyses projects assimilate these observational datasets and, using numerical weather prediction models, provide datasets of atmospheric parameters on a regular spatial grid at regular time intervals. These reanalyses datasets are an extremely valuable tool for studying the recent climate of Antarctica. However, one of the most important parameters, precipitation, is entirely based on model representation due to the difficulty of making accurate precipitation measurements, especially at unattended, remote stations.

What we know about the spatial and temporal variability of Antarctic precipitation is derived primarily from glaciological measurements (i.e. layers of snow accumulation measured in snow pits and ice cores) and not much is known about the sub-annual variability of precipitation. As much of our understanding of present climate comes from knowledge of 
past climate conditions, particularly by studying years of buried snow layers sampled in ice cores, it is critical for studying Antarctic climate to understand how ice core characteristics relate to the climate conditions when the snow was deposited.

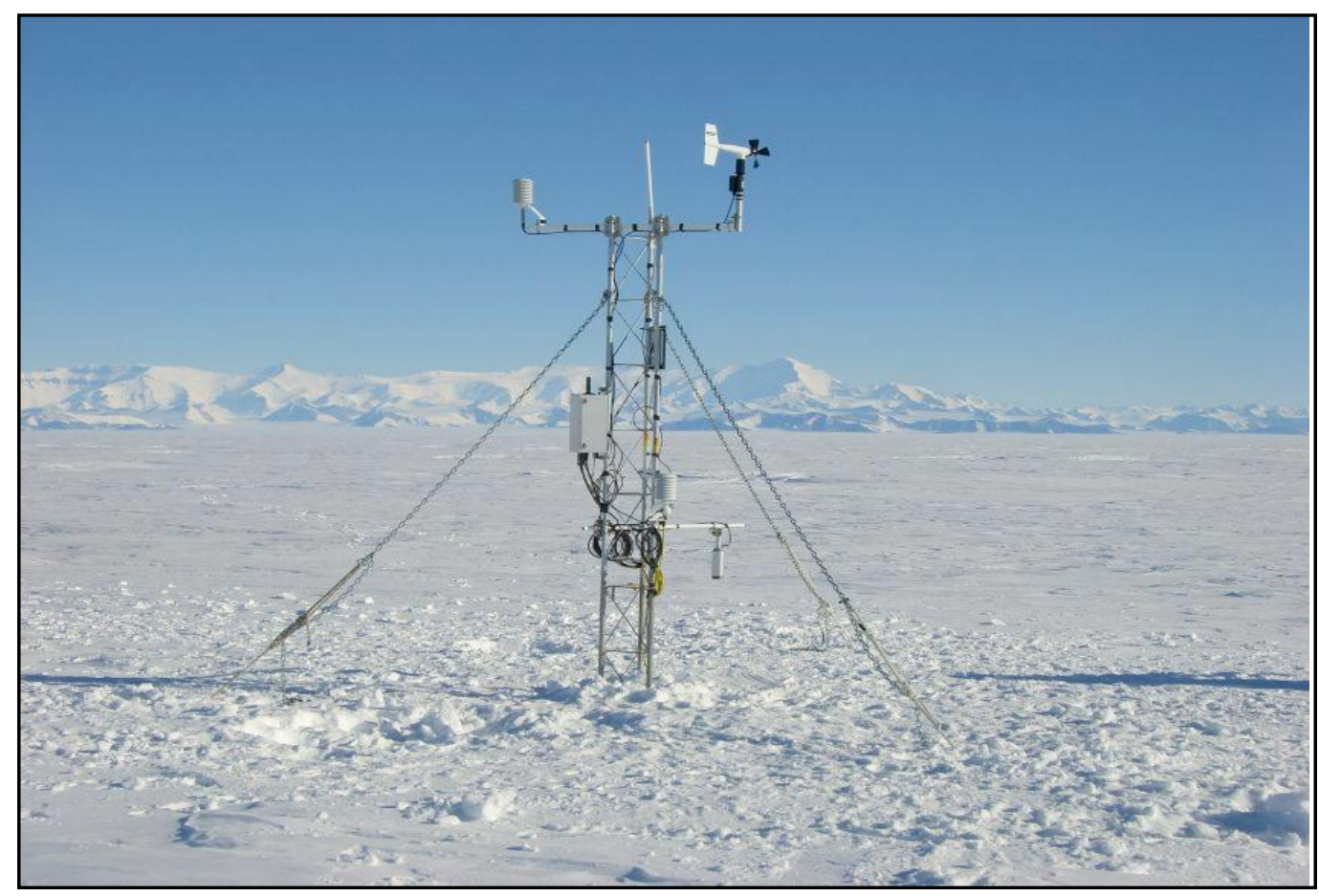

Figure 1.4 Automatic Weather Station (AWS) on the Ross Ice Shelf, Transantarctic Mountains in the background. Photo courtesy UW-Wisconsin AMRC-SSEC, Shelley Knuth.

As snow is deposited, atmospheric conditions are recorded by the layers of snow and this information is stored as the snow layers get buried. Ice cores can provide a record of climate conditions for hundreds of thousands of years before present [EPICA ice core gives an approximately 800,000 year record (Jouzel et al., 2007)]. Climate information is derived by analyzing the ice itself (stable isotopes and chemical composition), dust and ash entrained in the ice, and air bubbles entrained in the ice. Ice cores can provide a myriad of information of past climate conditions including temperature, atmospheric composition, ocean volume, sea ice extent, wind circulation patterns, forest fires, volcanic activity, and solar variability. Past temperatures are one of the more important parameters derived from ice cores. These are derived from measurements of the stable isotopes of oxygen and hydrogen in the ice. The "stable isotope thermometer" is primarily based on empirical relationships between stable isotope ratios and present-day temperatures at the location where the core was taken (Dansgaard, 1964), however there are other factors, such as changes in moisture trajectory 
and moisture source region that can significantly alter that relationship particularly on subannual timescales.

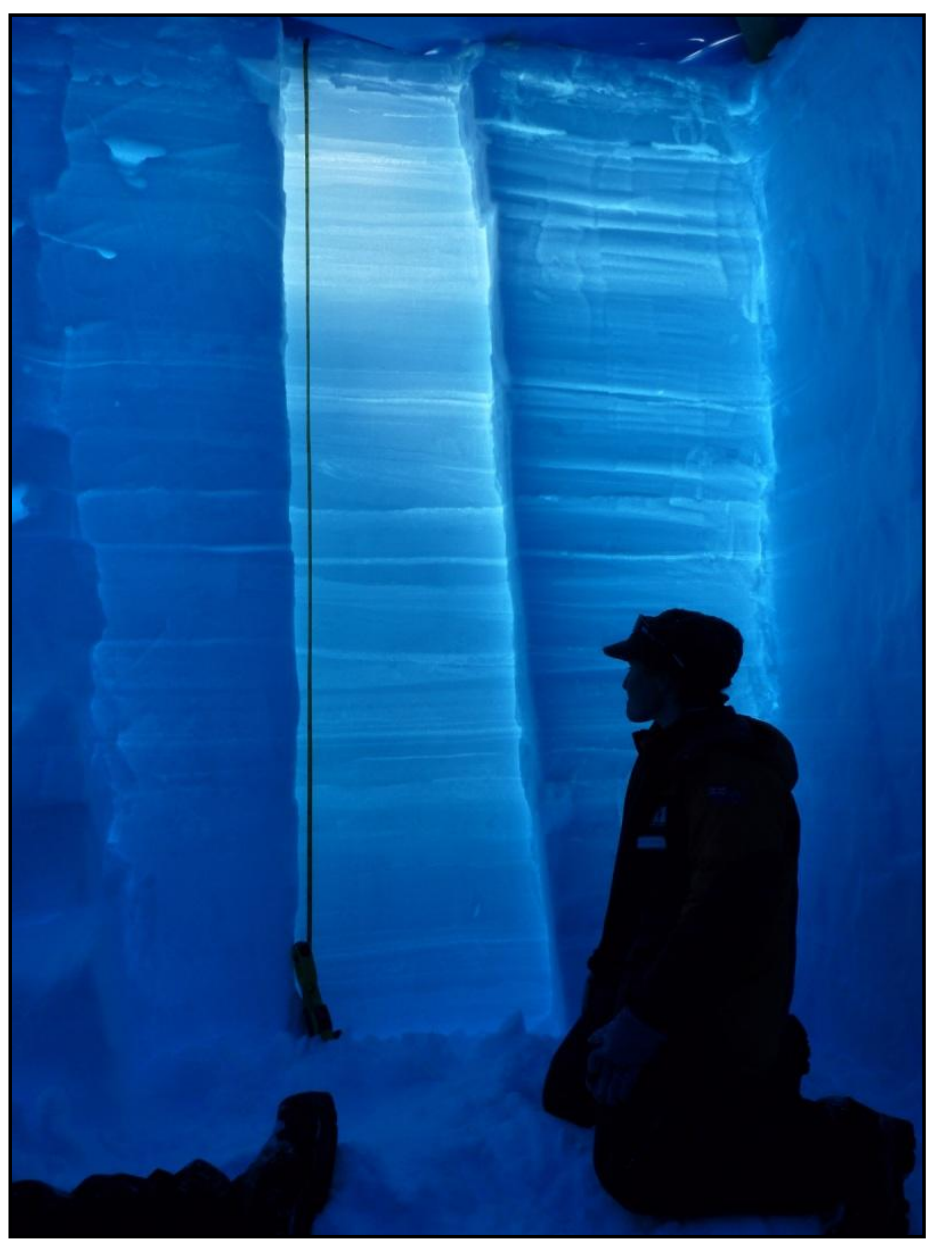

Figure 1.5 The author contemplating layers in a snow pit at Roosevelt Island.

Roosevelt Island, an ice dome located on the eastern side of the Ross Ice Shelf (Figure $1.1)$, is the site of a new intermediate-depth ice core $(760 \mathrm{~m})$ which provides a high resolution (sub-annual) record of the climate over the past $\sim 20,000$ years. Records from the core are expected to provide information about the stability of the Ross Ice Shelf, which acts as a "plug" on several major glacial drainage pathways on the WAIS. In addition, it is located near the coast of Antarctica in the Ross Sea region, where the variability of precipitation would be expected to be highly affected by the hemispheric-scale atmospheric variability mentioned previously (SAM and ENSO). Thus ice core records from this site may provide a record of the variability of these cycles. Interpreting those records requires a more fundamental understanding of how atmospheric variability affects precipitation and precipitation-based proxies in the region, and this is one of the primary motivations of this thesis. 


\subsection{Atmospheric drivers of precipitation in the Ross Sea region}

Understanding how atmospheric variability in the Pacific sector of Antarctica drives precipitation is essential for understanding current and past climate changes on the West Antarctic Ice Sheet and the Ross Ice Shelf. The relationship between atmospheric variability of the region and precipitation is critical for understanding the mass balance of the West Antarctic Ice Sheet and for interpreting climate proxies in snow and ice records. The aim of this research is to provide further understanding of these processes by specifically addressing the following questions:

- How do large-scale atmospheric circulation patterns such as ENSO and SAM affect local meteorological parameters in the Ross Sea region and at the Roosevelt Island site in particular?

- How well do the atmospheric reanalyses datasets represent precipitation on synoptic timescales in the Ross Sea region?

- What are the main atmospheric influences on the stable isotope composition of snow at the Roosevelt Island site?

\subsection{Thesis outline}

Chapter 2 provides further background information relevant to the formation of the three research questions in this thesis, including details on the Antarctic climate and atmospheric circulation patterns, atmospheric reanalyses data, and stable isotopes in snow.

Chapter 3 presents a synoptic-climatology of the Ross-Amundsen Sea region of Antarctica. This work provides a link between large-scale atmospheric variability and regional-scale meteorological parameters such as temperature and precipitation. Six synoptic weather patterns are derived from 32 years of twice daily NCEP reanalysis pressure data by grouping patterns together based on similarity (cluster analysis). The frequency of these six types describe the synoptic variability of the region and reflect large-scale atmospheric phenomenon (El Niño-Southern Oscillation and the Southern Annular Mode) (ENSO and the $\mathrm{SAM}$ ) as well as local meteorological parameters (precipitation and temperature) at Roosevelt Island, a new ice core site on the Ross Ice Shelf.

Chapter 4 provides an analysis of reanalyses precipitation data compared to in-situ snow accumulation records for the Ross Ice Shelf and West Antarctica. Many Antarctic studies rely heavily on reanalyses datasets (including the ones presented in this thesis). This study provides an assessment of the precipitation data provided by the reanalyses products by 
comparing precipitation from two reanalyses datasets (NCEP-2 and ERA-Interim) with snow accumulation records from Automatic Weather Stations (AWS).

Chapter 5 investigates how stable isotopes vary in fresh snow at Roosevelt Island. Stable isotopes are widely used as a temperature proxy in snow and ice records, but the isotope-temperature relationship changes in time and space due to changes in evaporative source region, air-mass trajectory, air-mass mixing, and microphysical processes in clouds. This study provides understanding of the influence of these factors by modeling the isotopic composition of three storm events at Roosevelt Island and comparing the results to measured values. In doing so, this work also illustrates that modeling isotopes on high-resolution timescales (sub-storm) has the potential for providing significant understanding of isotopic fractionation processes.

Chapter 6 summarizes the primary findings of the previous chapters, discusses the implications of this work, and proposes suggestions for future research.

Appendix A provides the results of snow analyzed for stable isotopes and trace elements from two snow pits at Roosevelt Island and Appendix B provides the results from trace element analysis of the surface snow samples taken at Roosevelt Island. These results have not been presented elsewhere in this thesis.

Chapters 3, 4, and 5 have been written as separate manuscripts for publication and can be read independently of each other. To date (December 2013), Chapter 3 has been published in the Journal of Climate (Cohen et al., 2013), Chapter 4 has been published in The Cryosphere (Cohen and Dean, 2013), and Chapter 5 has been reviewed and is undergoing revisions for re-submission to the Journal of Geophysical Research. 



\section{Background}

\subsection{Antarctic climatology}

This section presents an overview of high-latitude Southern Hemisphere atmospheric circulation patterns and dominant modes of variability that are known to affect Antarctic climate with particular focus on the Pacific sector $\left(\sim 150^{\circ} \mathrm{E}\right.$ to $\left.60^{\circ} \mathrm{W}\right)$.

\subsubsection{Atmospheric circulation}

The Earth's global atmospheric circulation patterns are driven by differential heating between the equator and the poles. The equator receives more solar radiation, heating the atmosphere and causing air to rise (hot air is less dense). The air then spreads out at the top of the troposphere, moving away from the equator towards the poles. Near the poles, air cools and descends (cold air is more dense), creating regions of subsidence from $\sim 70^{\circ}$ to the poles. This thermally-driven circulation, which creates three zonally-symmetric cells (the Hadley, Ferrel, and Polar cells), combined with the Earth's spin create the well-known global trade winds and pressure patterns: rising air near the equator, descending air around $30^{\circ}$ latitude and easterlies in the subtropics, ascending air around $60^{\circ}$ latitude and westerlies in the midlatitudes, and descending air near the poles. Because the atmosphere is generally in hydrostatic equilibrium (i.e. the pressure at any point depends on the weight of air above it), regions of less dense, rising air are areas of low pressure and regions of more dense, descending air are areas of high pressure.

The region of low pressure between $60-65^{\circ} \mathrm{S}$ is known as the circumpolar trough and is a very active cyclone-generating area due to the interaction of cold air from the continent and relatively warm, moist air from the Southern Ocean. The westerly winds which prevail throughout the troposphere in the mid-latitudes direct these cyclones, which circulate around the continent with the winds. These features of the atmospheric circulation have pronounced seasonal cycles due to the large differences in incoming radiation between summer and winter and the circumpolar trough is deepest and the westerlies are strongest in the winter when the temperature gradient between the mid- and high-latitudes is the greatest.

The circumpolar trough is an important region for meridional transfer of heat and moisture between mid- and high-latitudes. The trough expands and contracts seasonally (Semi-Annual Oscillation-SAO) due to seasonal differences in temperature gradients between the continent and surrounding ocean and is further south and deeper in the spring 
and autumn and further north and weaker in the summer and winter (van Loon, 1967). The SAO varies considerably on interannual to decadal timescales and affects many aspects of the ocean and atmosphere in the Southern Ocean including the winds, surface ocean currents, cylonicity, and sea ice distribution (Simmonds and Jones, 1998). The circumpolar trough has deepened since the 1970s and the SAO weakened in the 1980s. Both trends are consistent with trends in the Southern Annular Mode (discussed further in section 2.1.4) and have been considered as possible contributors to the Antarctic Peninsula warming and continental cooling pattern seen in recent Antarctic temperature trends (Thompson and Wallace, 2000; Marshall, 2003).

Within the circumpolar trough are several persistent regions of lower pressure that are a result of the atmospheric dynamics (wave number 2-3), the orography of the continent and sea surface temperatures (King and Turner 1997; van den Broeke, 2000; Simmonds et al, 2003). The Amundsen Sea Low (ASL) is the area of low pressure which spans the Bellingshausen, Amundsen and Ross Seas at $\sim 65-70^{\circ} \mathrm{S}$ as shown in Figure 2.1. Climatological averages over the past 30 years indicate that the ASL shifts east-west seasonally and is centered over the Ross Sea in winter and over the Bellingshausen Sea in summer (Turner et al., 2012). Variability in the ASL is of great interest as it has significant effects on the climate of West Antarctica and the Amundsen-Bellingshausen-Ross Sea region (Bromwich, 1988; Cullather et al, 1996; Fogt et al., 2012).

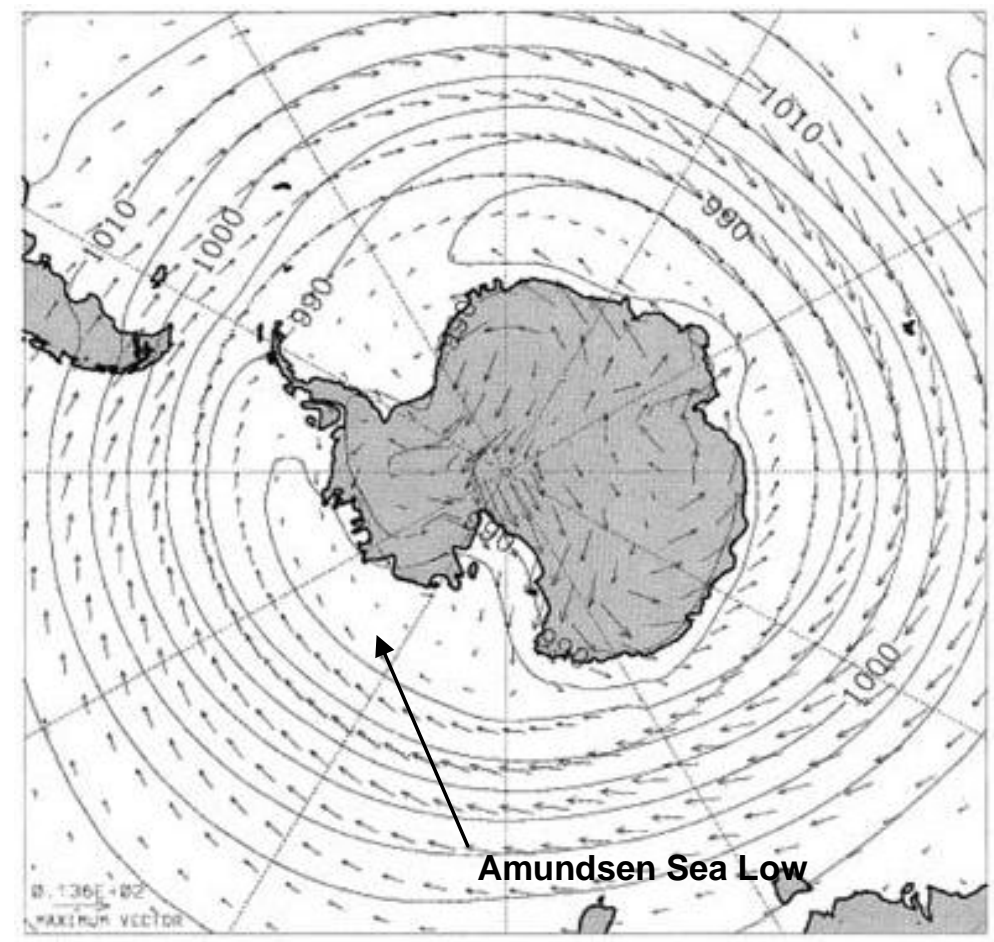

Figure 2.1 Mean sea level pressure climatology and $10 \mathrm{~m}$ winds from NCEP/NCAR Reanalysis for 1979-2002 (contour interval $5 \mathrm{hPa}$ ) showing westerly winds, circumpolar trough and average location of Amundsen Sea Low. Arrow in lower left indicates length of maximum wind vector, $13.6 \mathrm{~m} \mathrm{~s}^{-1}$ (Simmonds and King, 2004). 


\subsubsection{Cyclonicity}

Many of the synoptic-scale $(>1000 \mathrm{~km})$ cyclones that produce precipitation in Antarctica are generated in the circumpolar trough and circulate eastward around the continent with the prevailing winds. These cyclones are the dominant mechanism for transferring moisture and heat poleward. Due to the topography of the continent, much of the moisture gets precipitated out along the coast as these storms encounter steep topography at the edge of the ice caps. Cyclonicity is generally higher in the winter months due to the larger temperature gradient between the mid- and high-latitudes (King and Turner, 1997). The large temperature gradient that exists in the winter between the cold polar plateau and the relatively warm Southern Ocean increases the baroclinic instability, or the misalignment of density and pressure gradients, which in turn increases generation of cyclones (via increased vorticity) in the circumpolar trough. In addition, katabatic winds (cold, dense air which flows downhill due to gravity) flowing off of the Antarctic plateau are more prevalent in winter, which also increases the baroclinicity in certain regions where these wind regimes are prevalent.

The Ross Sea and Ross Ice Shelf has been shown to be an area of particularly active cyclonicity due to the interaction between the topography, katabatic convergence zones off the West Antarctic Ice Sheet and warm marine air from the ocean (Keable et al, 2002; Simmonds et al., 2003; Carrasco, 2003). Cyclones generated in this area are smaller than the synoptic-scale cyclones generated in the circumpolar trough. The generation of these mesocyclones (smaller than $1000 \mathrm{~km}$ in diameter and lasting less than 48 hours) is strongly influenced by the larger scale synoptic flow. Mesocyclones contribute significantly to the precipitation budget at many sites around the Ross Ice Shelf, especially for coastal areas (Carrasco et al, 2003). Both synoptic and mesoscale cyclone activity has been shown to be enhanced in association with anomalously low sea level pressure in the Ross Sea (Carrasco et al, 2003).

\subsubsection{Ross Ice Shelf surface winds}

Katabatic winds, which are the result of cold, dense air draining downslope from the polar plateau, are an important feature of the surface wind regime for many regions of Antarctica. On the Ross Ice Shelf (RIS), the katabatic wind regime is shaped by the topography surrounding the RIS, which is a relatively flat region bordered to the south and west by the Transantarctic Mountains (rising to over 4,000 meters) and to the east by the Siple Coast (rising more gradually to the West Antarctic Ice Sheet at $~ 2,000 \mathrm{~m}$ ) (see Figure 2.2). Katabatic winds drain through outlet valleys in the Transantarctic Mountains and Siple 
Coast and can extend for hundreds of kilometers across the RIS enhanced by low pressure systems in the Ross Sea (Parish and Cassano, 2003). Barrier winds, which are the result of cold, stable air forced along the Transantarctic Mountains, along with katabatic winds, significantly shape the average surface wind flow on the RIS (Carrasco and Bromwich, 1993; O’Connor et al., 1994; Seefeldt et al., 2007). This surface wind flow, also known as the RIS Air Stream (shown in Figure 2.3), is affected by synoptic and mesoscale cyclone activity in the region, which enhances and provides forcing for the katabatic and barrier winds (Parish and Cassano, 2003). The RIS Air Stream has been shown to significantly affect the northward transport of atmospheric mass from the polar plateau (Parish and Bromwich, 2007) and can strongly influence snow accumulation on the RIS (Bromwich, 1988).

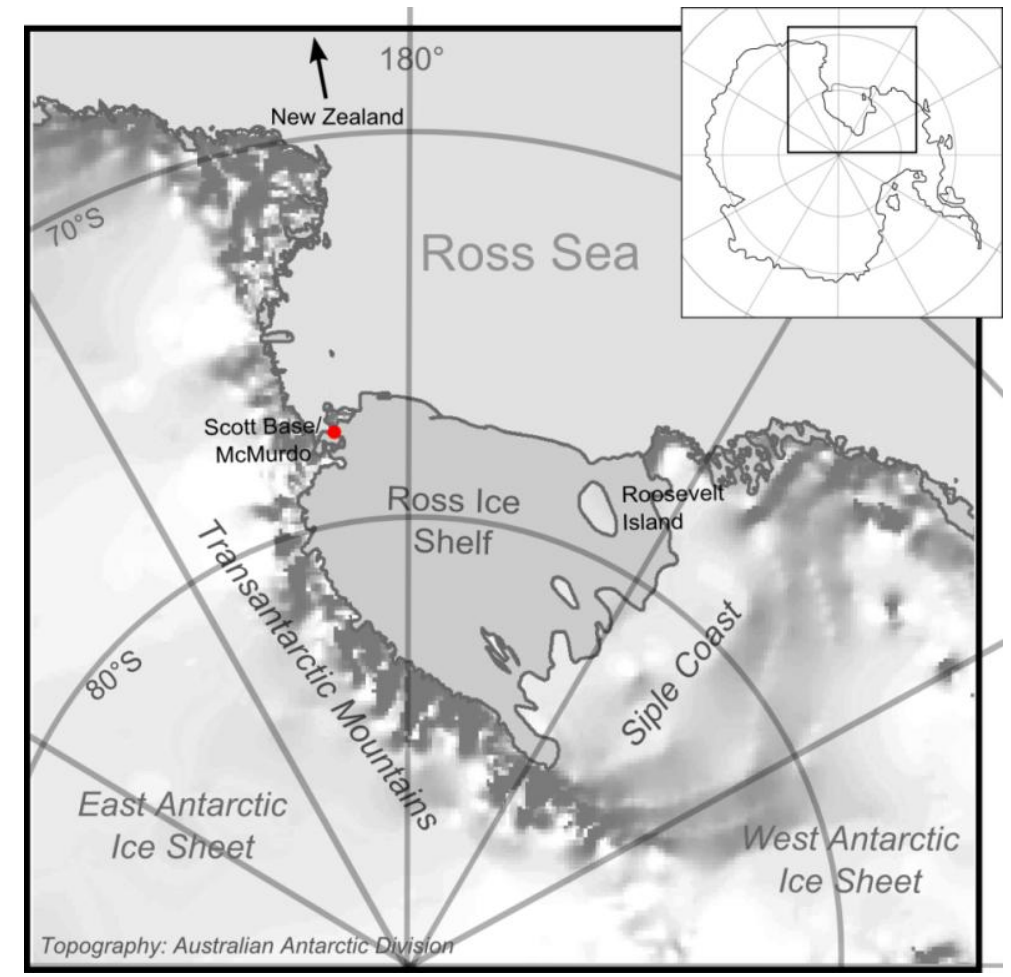

Figure 2.2 Map of the Ross Ice Shelf. Note that the orientation of Antarctica is opposite to that of previous figures.

\subsubsection{Southern Annular Mode}

The Southern Annular Mode (SAM) (also known as the Antarctic Oscillation) describes the (non-seasonal) variability in the annular (ring-shaped) atmospheric circulation pattern in the southern mid- to high-latitudes. The SAM is the most dominant mode of atmospheric variability in the southern high-latitudes and explains most of the southern hemisphere climate variability on both high-frequency and low-frequency timescales (weeks 
to years) (Thompson and Wallace, 2000). Physically, the SAM is the north/south shift of the westerly jet, and involves a mass shift in the atmosphere in the mid- to high-latitudes (Hartmann and Lo, 1998; Thompson and Wallace, 2000). It can be measured as a difference in sea level pressure anomalies between middle and high latitudes (Marshall, 2003). The SAM has shown a positive trend since the 1960s, expressed as lower surface pressures over Antarctica, higher pressures at mid-latitudes and increased westerlies around $60^{\circ} \mathrm{S}$. The trend towards a more positive SAM in recent decades explains the recent Antarctic temperature trends of cooling over the continent and warming on the peninsula as well as increased cyclonic activity in the Amundsen-Bellingshausen Sea (Thompson and Wallace 2000; Simmonds and Keay, 2000; Kwok and Comiso, 2002).

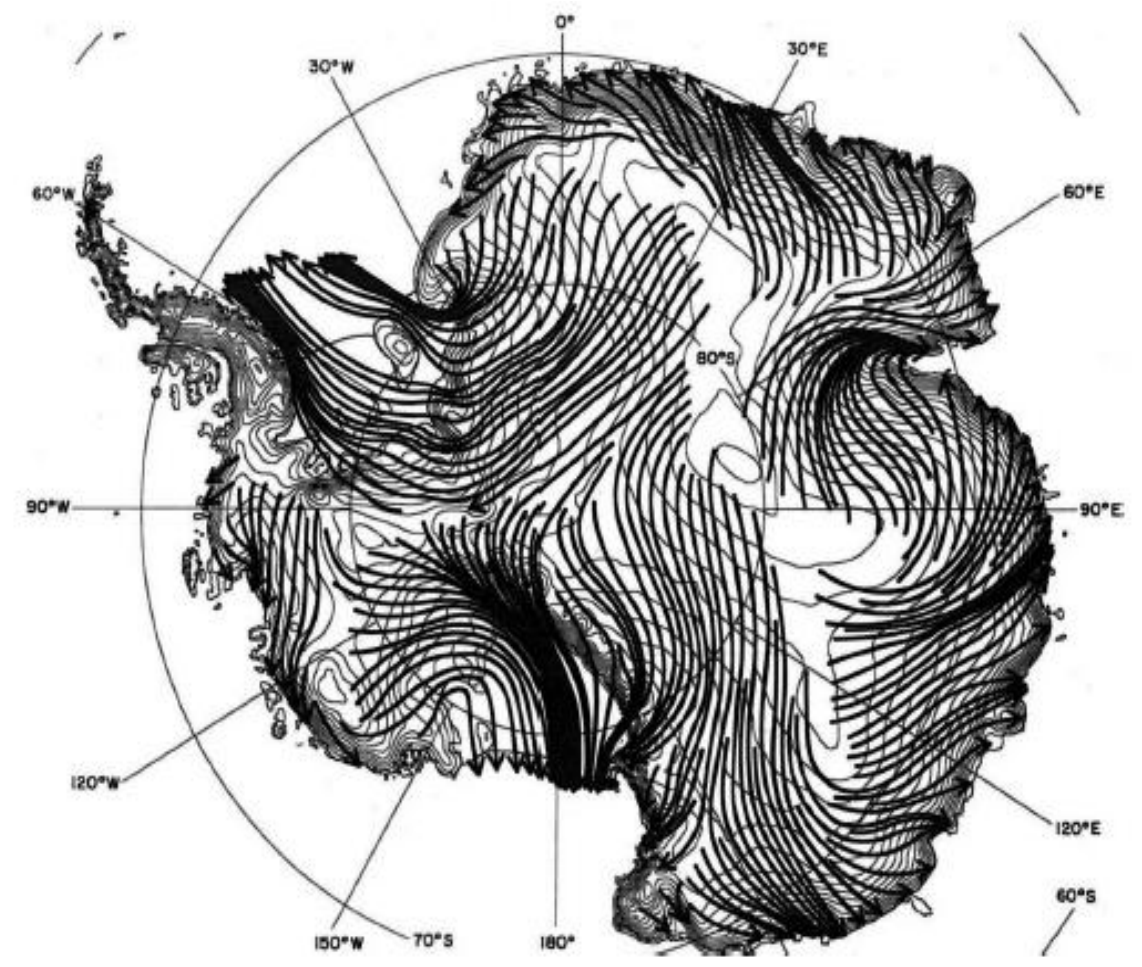

Figure 2.3 Mean surface winds from June 2003-May 2004 AMPS archive (Antarctic Mesoscale Prediction System) showing Ross Ice Shelf air stream (Parish and Bromwich, 2007).

In climate models the SAM is also recognized as one of the main drivers of southern hemisphere climate variability. The positive SAM trend in recent decades has been linked to both stratospheric ozone depletion and increased greenhouse gases (Thompson and Solomon, 2002; Marshall et al, 2004; Arblaster and Meehl, 2006; Polvani et al., 2011) and understanding the influences of both these phenomenon on the SAM is the subject of ongoing investigation (e.g. Arblaster et al., 2011). In addition, influences on the SAM are known to extend to the tropics indicating that there are likely to be complex interactions 
between the SAM and the El Niño/Southern Oscillation (Thompson and Wallace, 2000; L'Heureux and Thompson, 2006; Fogt and Bromwich, 2006).

\subsubsection{El Niño-Southern Oscillation}

The El Niño-Southern Oscillation (ENSO) describes a coupled oceanic-atmospheric climate cycle that is primarily expressed as anomalies in sea-surface temperature, wind, and pressure in the Pacific Ocean. ENSO operates on 2-10 year cycles and is responsible for a significant amount (30\%) of the interannual variability of the surface pressure around Antarctica via poleward propagating Rossby waves (Turner, 2004). The variability of ENSO can be described by the Southern Oscillation Index (SOI) which is the normalized surface pressure difference between Tahiti and Darwin. The pressure difference between these locations indicates the weakening (strengthening) of the easterly tradewinds in the tropical Pacific that is associated with El Niño (La Niña) and reflects the east-west shift of the warm water pool in the Pacific basin. The SOI expresses the strength and phase of ENSO events, where a negative SOI is an El Niño (warm) event and a positive SOI is a La Niña (cold) event (Trenberth, 1997). ENSO signals in Antarctica are primarily manifest in the Pacific sector as high sea level pressure and sea surface temperature anomalies in the AmundsenBellingshausen Sea and zonal wind anomalies at $60^{\circ} \mathrm{S}$ (Karoly, 1989; Turner, 2004; Renwick, 2005). The teleconnection pattern of ENSO in the Southern Ocean and Antarctica is described by the Pacific-South American (PSA) mode, which is the wave train of surface temperature and pressure anomalies which propagate from the subtropics across the southeastern Pacific and into the southwestern Atlantic (Mo and Higgins, 1998).

ENSO teleconnections in Antarctica have been studied using in-situ observations, satellite data, snow and ice proxies, and reanalysis data. In Antarctica, ENSO cycles have been shown to affect sea ice distributions [via the Antarctic Dipole, which is the high-latitude portion of the PSA pattern (Yuan and Martinson, 2001)] and cyclonicity (Pezza et al., 2008) and evidence of ENSO cycles have been seen in Antarctic ice cores (e.g. Meyerson et al, 2002; Steig et al, 2005; Yan et al, 2005). The deepening of the Amundsen Sea Low during La Niña events has been shown to correlate with increased cyclonicity in the Amundsen Sea region (Turner, 2004), but the relationships between atmospheric parameters and ENSO have been shown to be highly variable (Turner et al., 2012). For example, precipitation in West Antarctica was shown to be correlated strongly with ENSO in the 1990s, but only very weakly correlated in the 1980s (Guo et al., 2004). Genthon and Cosme (2003) showed that precipitation in West Antarctica is intermittently correlated with ENSO on 10 to 15 year 
intervals. The effects on the ENSO signal by climate cycles that act on longer timescales, such as the Antarctic Circumpolar Wave (which acts on eight year cycles), and decadal-scale trends in the Semi-Annual Oscillation complicates the understanding of ENSO teleconnections and the effects on Antarctic climate.

Much of the variability of the ENSO signal in the southern high latitudes is associated with SAM variability (Bromwich et al, 2000; Genthon and Cosme, 2003; Fogt and Bromwich, 2006). Schneider et al. (2004) showed Antarctic temperature patterns can be described as a combination of both SAM and ENSO atmospheric circulation patterns and Gregory and Noone (2008) showed ENSO teleconnections are weakened during a positive phase SAM and strengthened during a negative phase SAM. However, focus remains on the atmospheric patterns as they are the primary drivers of the high-frequency, large-scale variability. As such, the first research question of this thesis, which is considered in Chapter 3 is:

\section{How do large-scale atmospheric circulation patterns such as ENSO and SAM affect local meteorological parameters in the Ross Sea region and at the Roosevelt Island site in particular?}

\subsection{Reanalyses data}

Because of the sparseness of measurements Antarctica and the Southern Ocean, reanalyses products have been a key tool for studying atmospheric variability and trends in Antarctica (e.g. Monaghan et al., 2006; Krinner et al., 2007; Marshall et al., 2009;Bromwich et al., 2013). The two most widely used reanalysis datasets are from the National Centers for Environmental Prediction and the National Center for Atmospheric Research (NCEP/NCAR) and from the European Centre for Medium-Range Weather Forecasts (ECMWF). Reanalyses data assimilates and reprocesses in situ meteorological data and satellite data to produce comprehensive global datasets of meteorological parameters at regular vertical and horizontal resolutions throughout the atmosphere. The NCEP/NCAR Reanalysis-2 (NCEP-2) provides parameters at $2.5^{\circ}$ latitude/longitude resolution (Kanamitsu et al., 2002); the ECMWF ERAInterim provides parameters at $1.5^{\circ}$ latitude/longitude resolution (though the underlying models for both are run at higher resolution) (Dee et al, 2011). The NCEP-2 dataset extends from 1948 to the present, but parameters for the high latitudes are only reliable since the 
incorporation of satellite-based observations in 1979 (Bromwich and Fogt, 2004; Bromwich et al., 2007); the ERA-Interim dataset is only available from 1979.

Because of the difficulty of making precipitation measurements and inherent problems in distinguishing wind-blown and precipitated snow, precipitation is not one of the parameters directly constrained by observational data in reanalyses products. Instead, precipitation relies on the forecast models' representation of the hydrological processes which are at six-hourly intervals for NCEP-2 and three-hourly intervals for ERA-Interim. The ERAInterim dataset also incorporates more satellite observations and uses a more sophisticated variational assimilation system (4D-Var versus 3D-Var) which likely results in an improved moisture analysis (Andersson et al., 2007, Simmons et al., 2010).Previous studies on the limitations of reanalyses datasets in Antarctica have shown significant differences between ERA-Interim and NCEP-2 datasets in the trends and variability of a number of parameters. Bromwich et al. (2011) shows spurious trends in NCEP-2 pressure in the Southern Ocean over 1989-2009 which is likely related to differences also seen in NCEP-2 cyclonicity and precipitation (Cullather et al., 1998; Zou et al., 2004; Bromwich et al., 2004). In addition, ERA-Interim is shown to have a dry bias over the East Antarctic Ice Sheet (Bromwich et al., 2011). Differences between ERA-Interim precipitation and other reanalyses that appear in 2006 are attributed to new satellite observations and GPS radio occultation measurements being assimilated (Bromwich et al., 2011). Though these investigations have provided valuable information on the limitations of reanalyses products they all focused on seasonal and longer timescales and little is known about the variability of precipitation in Antarctica on sub-annual timescales. As such, Chapter 4 of this thesis addresses this question:

\section{How well do the atmospheric reanalyses datasets represent precipitation on synoptic timescales in the Ross Sea region?}

\subsection{Stable isotopes in snow}

Stable isotopes measured in snow pits and ice cores are widely used as a proxy for past temperatures. Isotopes, which are elements of the same atomic number, but different atomic mass due to different number of neutrons, occur naturally and at known abundances. In snow and ice, the most commonly measured stable isotopes are oxygen $\left({ }^{18} \mathrm{O}\right)$ and hydrogen $\left({ }^{2} \mathrm{H}\right)$ [also known as deuterium (D)]. Isotopes behave identically to each other 
chemically, but there are slight differences in how isotopes behave in physical and biological systems due to their different masses (the kinetic isotope effect). These slight differences produce different ratios of isotopes which are what is measured and interpreted. For example, the saturation vapour pressure of water, $e_{s}$, is slightly higher for lighter water molecules, (i.e. lighter molecules evaporate more readily). This means that water evaporating in a closed system at equilibrium, will result in a liquid that has a higher ratio of heavy to light isotopes than the original state (enrichment) and a vapour that has a lower ratio of heavy to light isotopes than the original state (depletion).

In order to be able to compare isotope ratios across time and space, all measurements are related to a standard value, the Vienna Standard Mean Ocean Water (VSMOW), which is the proportions of $\mathrm{O}$ and $\mathrm{H}$ isotopes in global sea water. Isotopes measured in snow and ice are reported as the difference from this standard:

$$
\delta=\left(\frac{\text { isotope ratio of sample }}{\text { isotope ratio of VSMOW }}-1\right) \times 1000
$$

The measured differences are usually quite small and $\delta$ is generally given in parts per thousand (\%o) and reported using the notation $\delta^{18} \mathrm{O}$ and $\delta \mathrm{D}$.

Table 2.1 VSMOW-defined sea water abundances of stable isotopes in parts per million (ppm). The more rare oxygen isotope ${ }^{17} \mathrm{O}$ is not commonly used in precipitation studies.

\begin{tabular}{|l|l|}
\hline${ }^{2} \mathrm{H} /{ }^{1} \mathrm{H}$ & $155.76 \pm 0.1 \mathrm{ppm}$ \\
\hline${ }^{18} \mathrm{O} /{ }^{16} \mathrm{O}$ & $2005.20 \pm 0.43 \mathrm{ppm}$ \\
\hline${ }^{17} \mathrm{O} /{ }^{16} \mathrm{O}$ & $379.9 \pm 1.6 \mathrm{ppm}$ \\
\hline
\end{tabular}

In the mid- to high-latitudes, isotopic ratios measured in precipitation $\left(\delta^{18} \mathrm{O}\right.$ and $\left.\delta \mathrm{D}\right)$ generally decrease towards the poles due to the process presented schematically in Figure 2.4. Water vapour evaporated from ocean water in the warm mid-latitudes is transported to higher (cooler) latitudes and progressively depleted as the air mass cools and precipitation condenses out. This model is only applicable for moisture trajectories in which large-scale convective processes do not dominate, which is generally true for extratropical cyclones. In addition, since the net moisture flux in the high-latitudes is poleward and primarily driven by synoptic scale cyclones (Bromwich, 1988; Tsukernik and Lynch, 2013), the spatial distribution of isotopes and its correlation with atmospheric temperature is relatively robust, and isotopes in 
snow and ice can be used as a proxy for temperature.. However, on regional scales, the relationship between isotopes and temperature can be complicated by changes in the source region, seasonality of precipitation, moisture trajectory, and air mass mixing (e.g. Noone and Simmonds, 1998; Delaygue et al., 2000; Werner and Heimann, 2002)which can confuse their interpretation as a paleoclimate proxy.

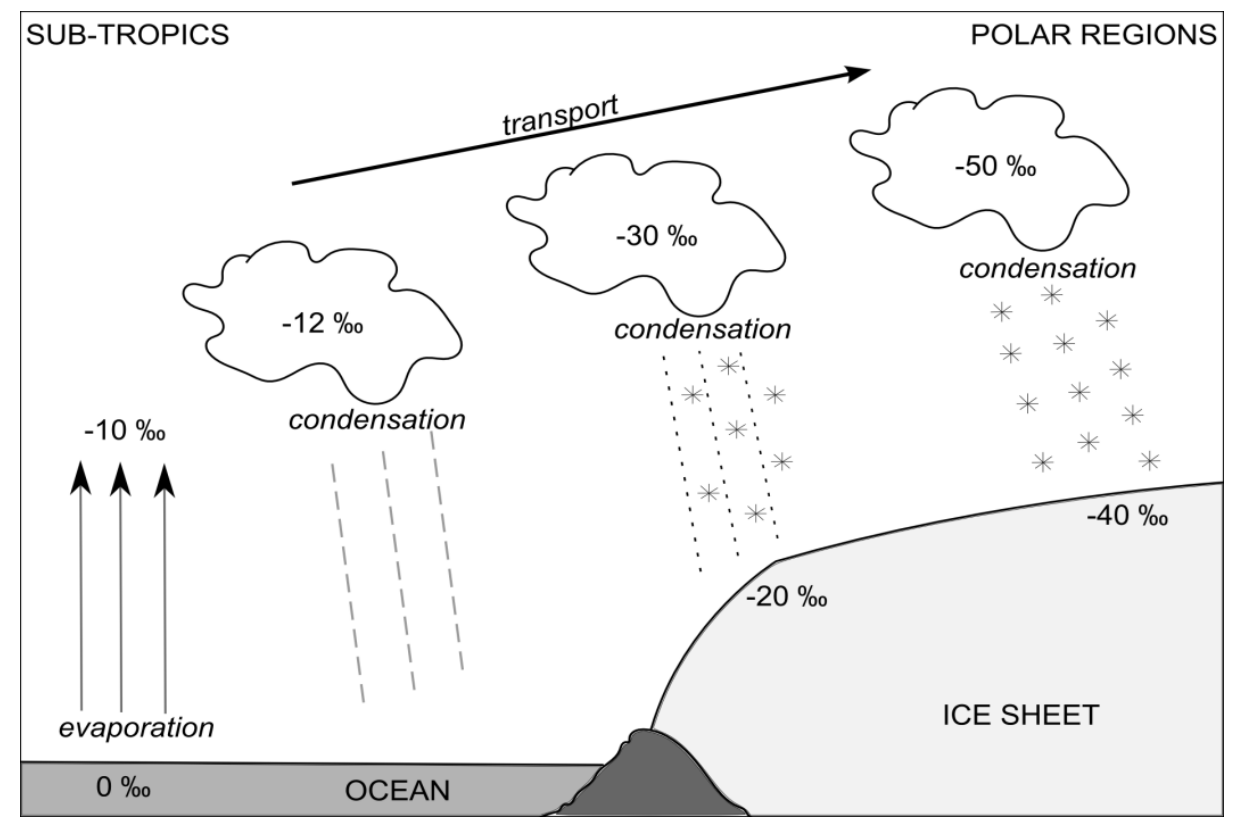

Figure 2.4 Schematic of isotopic fractionation of $\delta^{18} \mathrm{O}$ in the hydrological cycle. The figure conceptually describes the process of Rayleigh distillation which results in the observed distribution of stable isotopes in the mid-to high-latitudes (modified from Helsen, 2006).

The process of isotopic fractionation, where an isolated air mass cools and loses water via condensation is called Rayleigh distillation and provides a theoretical basis for the significant spatial correlation between isotope and temperature on a global scales (Dansgaard, 1964). Rayleigh distillation describes the isotopic ratio of an isolated air mass at each point where condensation occurs and is removed:

$$
\mathrm{d} \ln \mathrm{R}=(\alpha-1) \mathrm{d} \ln f
$$

where $\mathrm{R}$ is the isotopic ratio of the vapor, $f$ is the fraction of vapor remaining in the cloud (from original value, 1 ), and $\alpha$ is the fractionation factor, an empirically-derived value that describes fractionation rates. Integrating over the time and assuming a constant fractionation factor, the isotope ratio of the vapour can be calculated as:

$$
\mathrm{R}=\mathrm{R}_{0} f^{(\alpha-1)}
$$


Note that the initial isotopic values of the vapour are necessary for calculating the final values. The isotopic ratio of precipitation, $\delta_{\mathrm{p}}$, can be calculated from the composition of the vapour, $\delta_{\mathrm{v}}$, using the definition of $\delta$ in equation 2.1 and the fractionation of precipitation from vapour (Fisher and Alt, 1985):

$$
\begin{aligned}
& \delta_{\mathrm{v}}=\left(\delta_{\mathrm{v} 0}+1000\right) f^{(\alpha-1)}-1000 \\
& \delta_{\mathrm{p}}=\alpha\left(\delta_{\mathrm{v}}+1000\right)-1000
\end{aligned}
$$

Equations 2.4 and 2.5 are the basis of a Rayleigh isotopic model which models the isotopic composition of the precipitation from an air mass and can be compared to measured precipitation values. Input parameters are the initial isotopic composition of the vapour (at the source region), the fractionation factor and the fraction of water vapour remaining in the air mass (calculated from initial and final values of specific humidity). Rayleigh-type isotopic models have the advantage of being able to directly assess the sensitivity of the individual input parameters, which cannot be done using global climate models that incorporate isotope models. However, Rayleigh-type models rely heavily on the representation of air mass trajectories in calculating isotope values and there is no way of accounting for air mass mixing.

Another complicating factor in modeling isotopes is in the parameterization of the different isotopic fractionation. There are two different processes that occur: equilibrium fractionation and kinetic fractionation. Equilibrium fractionation describes the fractionation rate of vapour evaporated from liquid due to differences in saturation vapour pressure and is dependent on temperature (i.e. the separation increases with decreasing temperature). Kinetic fractionation is a smaller effect, resulting from the different diffusivity of isotope molecules (i.e. the diffusivity of $\mathrm{HD}^{16} \mathrm{O}$ different from $\mathrm{D}_{2}{ }^{18} \mathrm{O}$ or $\mathrm{D}_{2}{ }^{16} \mathrm{O}$ ) and is primarily a function of relative humidity and to a lesser extent, turbulence. Kinetic fractionation is an important process in the micro-boundary layer above the ocean surface (influencing the initial isotope vapour values) and in clouds when forming snow and ice crystals (Merlivat and Jouzel, 1979). The parameterization of the fractionation in many Rayleigh models is a combination of both equilibrium and kinetic factors.

Kinetic fractionation doesn't produce significant changes to $\delta^{18} \mathrm{O}$ and $\delta \mathrm{D}$ values, but becomes very important when considering the second-order isotopic parameter deuterium- 
excess (d-excess). Deuterium excess is a second-order parameter calculated from the relationship between $\delta \mathrm{D}$ and $\delta^{18} \mathrm{O}$. Based on the Rayleigh theory of equilibrium fractionation and borne out in globally measured values, the relationship between $\delta \mathrm{D}$ and $\delta^{18} \mathrm{O}$ is known as the Global Meteoric Water Line (GMWL) (Craig, 1961):

$$
\delta \mathrm{D}=\left(8 \times \delta^{18} 0\right)+10 \%
$$

Deviations from this relationship, which are primarily due to the kinetic fractionation effects during evaporation at oceanic source region and during snow formation, are defined as the dexcess (Dansgaard, 1964).

$$
\mathrm{d} \text { excess }=\delta \mathrm{D}-\left(8 \times \delta^{18} \mathrm{O}\right)
$$

The effects of kinetic fractionation are accounted for in Rayleigh models by incorporating a kinetic fractionation parameterization during evaporation at the ocean surface (formation of $\delta_{\mathrm{v} 0}$ ), and a supersaturation function during condensation to account for the supersaturation of vapour with respect to ice (Jouzel and Merlivat, 1984).

D-excess is higher for lower relative humidity values and this has been used in ice cores to make inferences about past changes in moisture source region and atmospheric circulation (e.g. Ciais et al., 1995; Vimeux et al., 1999; Stenni et al., 2001; Masson-Delmotte et al., 2004). However the effects of kinetic fractionation on d-excess values in precipitation are still not well known, and further understanding of these processes and those contributing to uncertainties in $\delta^{18} \mathrm{O}$ and $\delta \mathrm{D}$ are the subject of on-going investigation. The study in this thesis uses a Rayleigh isotope model to examine the isotopic fractionation process for individual storms in Antarctica with the aim of providing insight into how other factors such as source region, moisture trajectory and air-mass mixing contribute to isotopic fractionation. The comparison of measured isotopes in Antarctic snow to modeled isotopes on sub-storm timescales is a new approach, and addresses the third research question:

\footnotetext{
What are the main atmospheric influences on the stable isotope composition of snow at the Roosevelt Island site?
} 


\title{
3 Synoptic weather types for the Ross Sea region, Antarctica
}

This chapter presents a synoptic-climatology of the Ross-Amundsen Sea region of Antarctica. It provides a link between large-scale atmospheric variability and regional-scale meteorological parameters. Roosevelt Island, an ice core site on the Ross Ice Shelf, is used as an example to show the effects of synoptic variability on temperature and precipitation at the site. This chapter has been published in Journal of Climate (Cohen et al., 2013).

\begin{abstract}
Synoptic classifications over the Southern Ocean in the Ross Sea region, Antarctica $\left(50^{\circ} \mathrm{S}-\right.$ Antarctic coast, $\left.150-270^{\circ} \mathrm{E}\right)$ have been derived from NCEP reanalysis data (1979-2011) producing a set of six synoptic types for the region. These types describe realistic synoptic conditions for the region, and represent the moisture-bearing low pressure systems that circulate around Antarctica. The types are described as: Low-Bellingshausen/Amundsen (LBA), Low (L), Zonal (Z), Low-Ross (L-R), Ridge (R), and Low-Amundsen (L-A). Seasonal frequencies of the synoptic types reflect the seasonal zonal shift of the Amundsen Sea Low and also correlate well with the Southern Oscillation Index (SOI) and the Southern Annular Mode (SAM). Variability in the occurrences of the synoptic types L-R and L-BA indicate a shifting of the position of the ASL further east (west) towards (away from) the Antarctic Peninsula during La Niña (El Niño) and positive (negative) SAM conditions. A joint linear regression of the SOI and SAM indices show strongest correlations with the types L-BA and L-R in the spring, and quantifies the joint forcing effect of these climate cycles on synoptic variability in the region. As a demonstration of how synoptic classification provides links between large-scale atmospheric circulation and local climate parameters, the synoptic types are related to precipitation and temperature at Roosevelt Island, an ice core site on the Ross Ice Shelf $\left(80^{\circ} \mathrm{S}, 200^{\circ} \mathrm{E}\right)$. The synoptic types provide quantification of distinct precipitation and temperature regimes at this site, which allows for more fundamental understanding of the precipitation source regions and transport pathways that drive the variability in snow and ice proxies.
\end{abstract}




\subsection{Introduction}

Understanding the links between large-scale atmospheric circulation and local meteorological parameters is the subject of many studies (e.g. Smithson 1986; Yarnal et al. 2001; Sheridan and Lee 2010). One technique for investigating these links is synopticclimatological classification, which groups synoptic weather patterns into distinct regimes and relates them to local or regional climate parameters (Yarnal 1993). A synopticclimatological classification (known locally as 'Kidson Types') was developed for New Zealand (Kidson 1994; 2000) which showed relationships between the synoptic regimes and climate parameters such as precipitation and temperature as well as relationships to largescale atmospheric circulation patterns such as those induced by the El Niño/Southern Oscillation (ENSO) and the Southern Annular Mode (SAM) (Kidson 1999; Kidson and Renwick 2002; Renwick 2011). Kidson's synoptic typing has been shown to have many uses both qualitatively and quantitatively, through analysis of paleoclimate proxies (Lorrey et al. 2007), biological systems (Renwick et al. 1998), and glacier mass balance (Purdie et al. 2011).

This study uses Kidson's synoptic classification techniques and applies it to the Ross Sea region of Antarctica. While much work has been done to understand both past and present Antarctic climate using snow and ice reconstructions, station data, satellite and reanalysis data, and climate models, less has been done on synoptic scales. Studies of Antarctic climate indicate that climate variability is not homogeneous over the entire continent (Turner et al. 2005a; Rignot et al. 2008; O'Donnell et al. 2011). Specific interest lies in the Pacific Sector of Antarctica, the region encompassing the Ross Sea, West Antarctica and the Antarctic Peninsula, due to these regions' importance for understanding variability in ENSO and the SAM, the stability of the Ross Ice Shelf, mass balance of the West Antarctic Ice Sheet, and sea ice distribution (Mayewski et al. 2005; Fogt and Bromwich 2006; Krinner et al. 2007; Stammerjohn et al. 2008).

Climatologically, this region is dominated by the Amundsen Sea Low (ASL), a permanent region of low pressure within the circumpolar trough that spans the Bellingshausen, Amundsen and Ross Seas at $\sim 65-70^{\circ} \mathrm{S}$. The ASL is of great interest as it has measurable effects on the climate of West Antarctica and the Amundsen, Bellingshausen, and Ross Sea regions. It is a region of significant cyclonicity and is known to be affected by large-scale atmospheric circulation variability (Bromwich 1988; Cullather et al. 1996; Simmonds et al. 2003; Fogt et al. 2012). 
Synoptic-scale systems have been shown to be very important for determining the amount and distribution of precipitation in Antarctica (Noone et al. 1999; 2002). As such, synoptic-climatological classification can provide further understanding of the synoptic controls on precipitation, which is important for interpreting snow and ice paleoclimate archives. As a case study we investigate how the synoptic types relate to precipitation at Roosevelt Island, the site of a future ice core record, on the eastern side of the Ross Ice Shelf. While previous studies have used back trajectories to understand precipitation delivery for interpreting snow and ice records in Antarctica (e.g. Helsen et al. 2007; Thomas and Bracegirdle 2009; Sinclair et al. 2010), synoptic-climatological classification is a more general approach with the potential to relate precipitation (and other meteorological parameters) over a much larger region and also to provide a link to large-scale atmospheric circulation.

\subsection{Data and methods}

\subsubsection{NCEP reanalysis-geopotential height data}

Reanalysis data have been widely used to analyze Antarctic climate variability, examine atmospheric circulation patterns, and correlate with snow and ice records (King and Turner 1997). This study uses the National Centers for Environmental Prediction/National Center for Atmospheric Research (NCEP/NCAR) reanalysis dataset, which assimilates and reprocesses in-situ meteorological data and satellite data to produce a comprehensive, global dataset of meteorological parameters at $2.5^{\circ}$ latitude/longitude resolution (though the underlying models are run at higher resolution) (Kalnay et al. 1996). The NCEP/NCAR dataset extends from 1948 to present but parameters for the high latitudes are more reliable since the incorporation of satellite-based observations in 1979 (Bromwich and Fogt, 2004; Bromwich et al. 2007). This study uses twice-daily (00 UTC and 12 UTC), land-masked 1000 hectopascal (hPa) geopotential heights for the time period 1 January, 1979 to 30 June, 2011.

\subsubsection{Climate indices}

Climate indices for the El Niño/Southern Oscillation and the Southern Annular Mode are used in this study to investigate how the synoptic types relate to large-scale climate variability. The SAM is the expansion and contraction of the polar vortex, and involves a mass shift in the atmosphere in the mid- to high-latitudes (Thompson and Wallace 2000). We 
use the SAM index from Marshall (2003), which is a proxy for the zonal mean sea-level pressure difference between $40^{\circ} \mathrm{S}$ and $65^{\circ} \mathrm{S}$ and is derived from station data, as opposed to reanalysis data. Positive values of the SAM indicate lower surface pressure over Antarctica and higher pressures at mid-latitudes.

The El Niño/Southern Oscillation describes a coupled oceanic-atmospheric climate cycle that is primarily expressed as anomalies in sea-surface temperature, wind, and pressure in the tropical Pacific Ocean. The variability in ENSO can be measured by the Southern Oscillation Index which expresses the strength and phase of ENSO events, where a negative SOI is an El Niño (warm) event and a positive SOI is a La Niña (cold) event. The SOI is calculated from the difference in monthly mean sea-level pressure anomalies between Tahiti and Darwin (Trenberth 1997).

\subsubsection{Cluster analysis}

Cluster analysis was performed on NCEP reanalysis geopotential height data over the ocean and Ross Ice Shelf for the region encompassing the Ross and Amundsen Seas and part of the Bellingshausen Sea $\left(50^{\circ} \mathrm{S}\right.$ - Antarctic coast, $\left.150^{\circ} \mathrm{E}-270^{\circ} \mathrm{E}\right)$ (Figure 3.1). Slightly larger and smaller areas of analysis were also considered but did not affect the results materially. This region appeared to be the best to represent the synoptic conditions of the region as it is an area small enough to capture synoptic weather patterns but not so large as to have too many patterns to combine into meaningful clusters. The cluster analysis gives similar patterns for $500 \mathrm{hPa}$ and $1000 \mathrm{hPa}$ geopotential heights, but we use the $1000 \mathrm{hPa}$ fields for this study as they show more spatial variability in the pressure fields than the $500 \mathrm{hPa}$ fields. Kidson (2000) showed in his analysis for the New Zealand region that the relationship between synoptic types and meteorological parameters did not differ significantly between the 500 $\mathrm{hPa}$ - and $1000 \mathrm{hPa}$-derived types.

Prior to clustering, the data were detrended (mean subtracted), area-weighted (by the cosine of the latitude), and land-masked to remove the effects of continental topography. Cluster analysis was performed on the dataset of twice-daily geopotential height patterns (for all months of the year combined) based on the convergent k-means procedure (MacQueen, 1967). The initial clusters are generated from a random selection of $N$ 'seed' patterns from the full set of synoptic fields. Each geopotential map state (23738 time points) is then matched to one of the $N$ initial clusters based on the minimum root-mean-square difference (k-means) between the standardized means of each pattern. Every pattern is assigned to one of the initial $N$ clusters. At each iteration, clusters are merged based on the two clusters with 
the highest pattern correlation and the patterns are then re-assigned to the new clusters. Thus, the procedure goes from $N$ to $N-1, N-2$ clusters and so on, eventually to one cluster containing all the data.

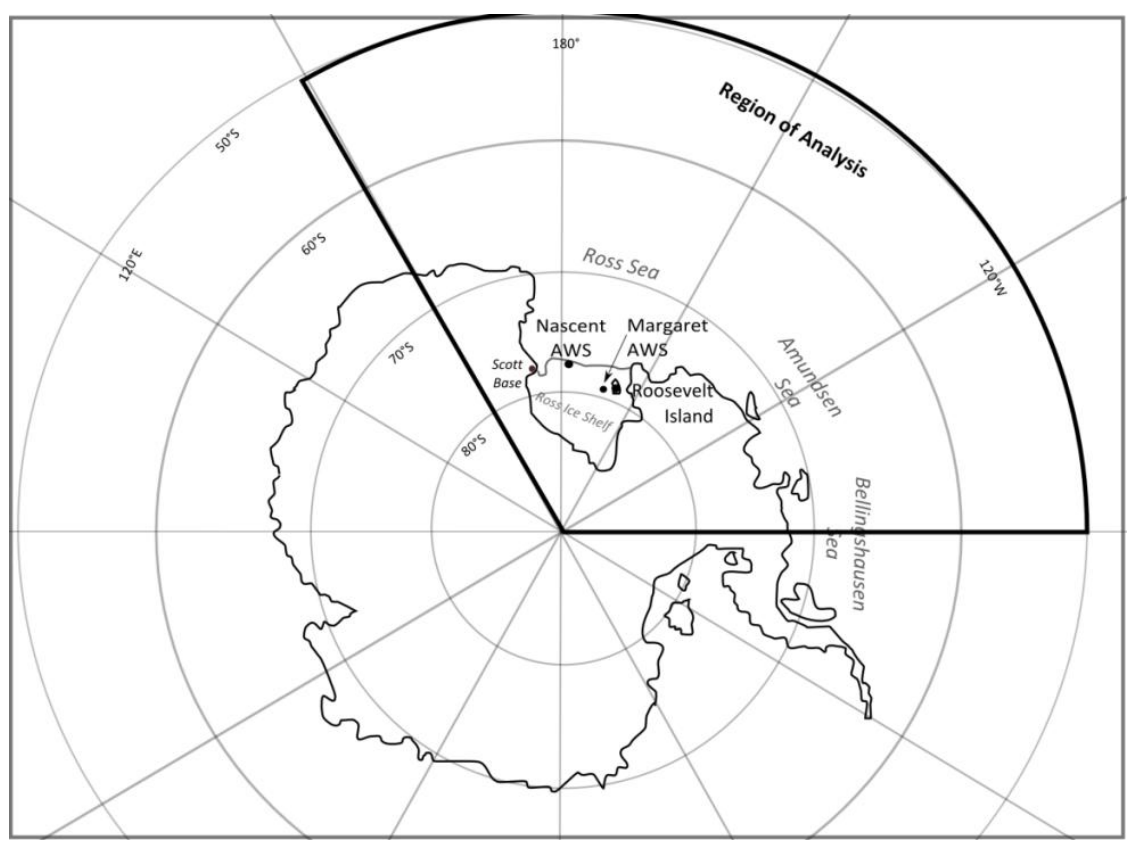

Figure 3.1 Map indicating area of cluster analysis $\left(50^{\circ} \mathrm{S}\right.$ - Antarctic coastline, 150-270 $\left.{ }^{\circ} \mathrm{E}\right)$. Locations of Roosevelt Island ice core site and 'Nascent' and 'Margaret' Automatic Weather Stations (AMRC, SSEC, UW-Madison) are also indicated.

Since the final number of clusters chosen to represent a dataset can be arbitrary, determining this number was done by running the clustering procedure ten times using 50 different randomly-selected seed clusters. This provided an assessment of cluster reproducibility and stability. The final selection of the number of clusters to retain was made by visual inspection. The procedure produced a consistently reproducible set of six clusters for every run. The frequency of cluster occurrence is calculated for each set of clusters. For all ten runs, the frequency of the six clusters varied by only $0.1 \%$.

The clustering procedure was also run using the European Centre for Medium-Range Weather Forecasts (ECMWF) ERA-Interim reanalysis dataset which is now available from 1979 onwards. The ERA-Interim $1000 \mathrm{hPa}$ geopotential height fields for 1979-2011 produced identical clusters to the NCEP data with cluster frequency differing from the NCEP clusters by only $0.4-0.8 \%$. 


\subsubsection{Assessment of NCEP reanalysis precipitation data}

Because there are no in-situ precipitation measurements for our case-study site, Roosevelt Island $\left(80^{\circ} \mathrm{S}, 200^{\circ} \mathrm{E}, 550 \mathrm{~m}\right.$ a.s.l), we will be using precipitation rates from the NCEP reanalysis dataset in conjunction with the synoptic types. Previous assessments of NCEP reanalysis precipitation over Antarctica urge using this data with caution (e.g. Bromwich et al. 2007; Bromwich et al. 2011). We compare a two-year in-situ precipitation record from the Ross Ice Shelf to NCEP reanalysis precipitation fluxes for the nearest gridbox to qualitatively assess how well the reanalysis data represents precipitation on the Ross Ice Shelf.

The recent analysis from Bromwich et al. (2011) indicates that, for the NCEP dataset, the net accumulation (P-E) over Antarctica does not compare well to several other reanalysis products, though they show that the discrepancies lay primarily with the evaporation term and the precipitation actually compares well to the other reanalyses products. The best agreements regionally are for the Ross Ice Shelf and parts of West Antarctica though the precipitation does show a spurious upward trend (since 1979) in the Pacific sector that is not seen in the other reanalyses. The source of this trend is unknown but may be related to the strong negative trend in pressure also seen in this region (Bromwich et al. 2011).

The University of Wisconsin (UW-Madison, AMRC) Automatic Weather Station (AWS) 'Nascent' $\left(78^{\circ} \mathrm{S}, 181.5^{\circ} \mathrm{E}\right)$ is located near the northwestern edge of the Ross Ice Shelf approximately $340 \mathrm{~km}$ west of Roosevelt Island (Figure 3.1). Snow surface height and other meteorological parameters were measured by the Nascent AWS for the period 1 January, 2009 to 30 April, 2011. Snow accumulation (and ablation) was measured with a Campbell Scientific SR50 acoustic depth gauge (ADG) which measures the distance to the snow surface using reflected sonic pulses. Detailed specifications on all of the AWS instrumentation can be found on the University of Wisconsin, AMRC site (http://amrc.ssec.wisc.edu). The Nascent station raw data were retrieved from the University of Wisconsin, AMRC ftp site (ftp://amrc.ssec.wisc.edu).

A snow accumulation record for the Nascent station was produced from the raw data by first removing null measurements and measurements obviously affected by rime, wind, and blowing snow (i.e. spurious data points outside of the two-year range of values). The raw snow-height data were recorded at 20 minute intervals and were averaged to the same 6hourly resolution as the reanalysis data (18-point average). The NCEP reanalysis data is given as an instantaneous precipitation rate: $\mathrm{kg} \mathrm{m}^{-2} \mathrm{~s}^{-1}$ water equivalent (w.e.). In order to 
compare with the snow accumulation that is measured by the ADG, the reanalysis data were converted to mm w.e. per 6 hours and summed.

\subsubsection{Surface temperature data}

The relationship between surface temperature at Roosevelt Island and synoptic types is investigated using air temperature data from a University of Wisconsin AWS located less than 100 kilometers west of Roosevelt Island ('Margaret', $80^{\circ} \mathrm{S}, 195^{\circ} \mathrm{E}, 67 \mathrm{~m}$ a.s.1.) and NCEP reanalysis surface temperature for the gridbox at $80^{\circ} \mathrm{S}, 200^{\circ} \mathrm{E}$. The NCEP reanalysis temperature data is twice-daily for the period 1 January, 1979 to 30 June, 2011. The Margaret AWS dataset is three-hourly for the period 13 November, 2008 to 30 June, 2011.

The Margaret AWS data were retrieved from the University of Wisconsin, AMRC, SSEC ftp site (ftp://amrc.ssec.wisc.edu). Air temperature is measured with a platinum resistance thermometer sensor with accuracy $+/-0.5^{\circ} \mathrm{C}$ (further specifications on the $\mathrm{U}$. Wisconsin AWS instrumentation is at http://amrc.ssec.wisc.edu). The AWS 3-hourly data have been pre-processed to remove erroneous data and were then averaged to 12-hours to match the resolution of the synoptic typing. Monthly means were calculated for the respective datasets and subtracted from each data point before grouping by synoptic type.

\subsection{Results}

\subsubsection{Synoptic types}

Figure 3.2 shows the six synoptic types for the Ross Sea region resulting from the 1000 $\mathrm{hPa}$ geopotential height cluster analysis. These six types are a classification of all synoptic conditions for the period 1979-2011. The patterns have larger spatial extents than typical synoptic pressure systems due to the smoothing that results from averaging many patterns together, but they show realistic synoptic conditions for the region which is dominated by cyclonic, moisture-bearing low pressure systems that travel around the continent with the westerly circumpolar winds. Note that the process of clustering inherently emphasizes the differences in strength and positions between the patterns.

The types are described as: Low-Bellingshausen/Amundsen (L-BA), Low (L), Zonal (Z), Low-Ross (L-R), Ridge (R), and Low-Amundsen (L-A). All of the patterns except Zonal are characterized by low pressure systems with centers of action about $60^{\circ} \mathrm{S}$ located in different parts of the Ross, Amundsen and Bellingshausen Seas. The Zonal pattern is 
characterized by a relatively weak latitudinal pressure gradient. The patterns are in order of frequency, noted on each map, with the type L-BA as the most frequent pattern $(30.8 \%)$ and the remaining 5 patterns occurring significantly less, but about equally (12-15.3\%). Generally, the synoptic patterns are less diverse than those derived for mid-latitude regions such as New Zealand, which reflects the dominance of low pressure systems in the atmospheric circulation around Antarctica.

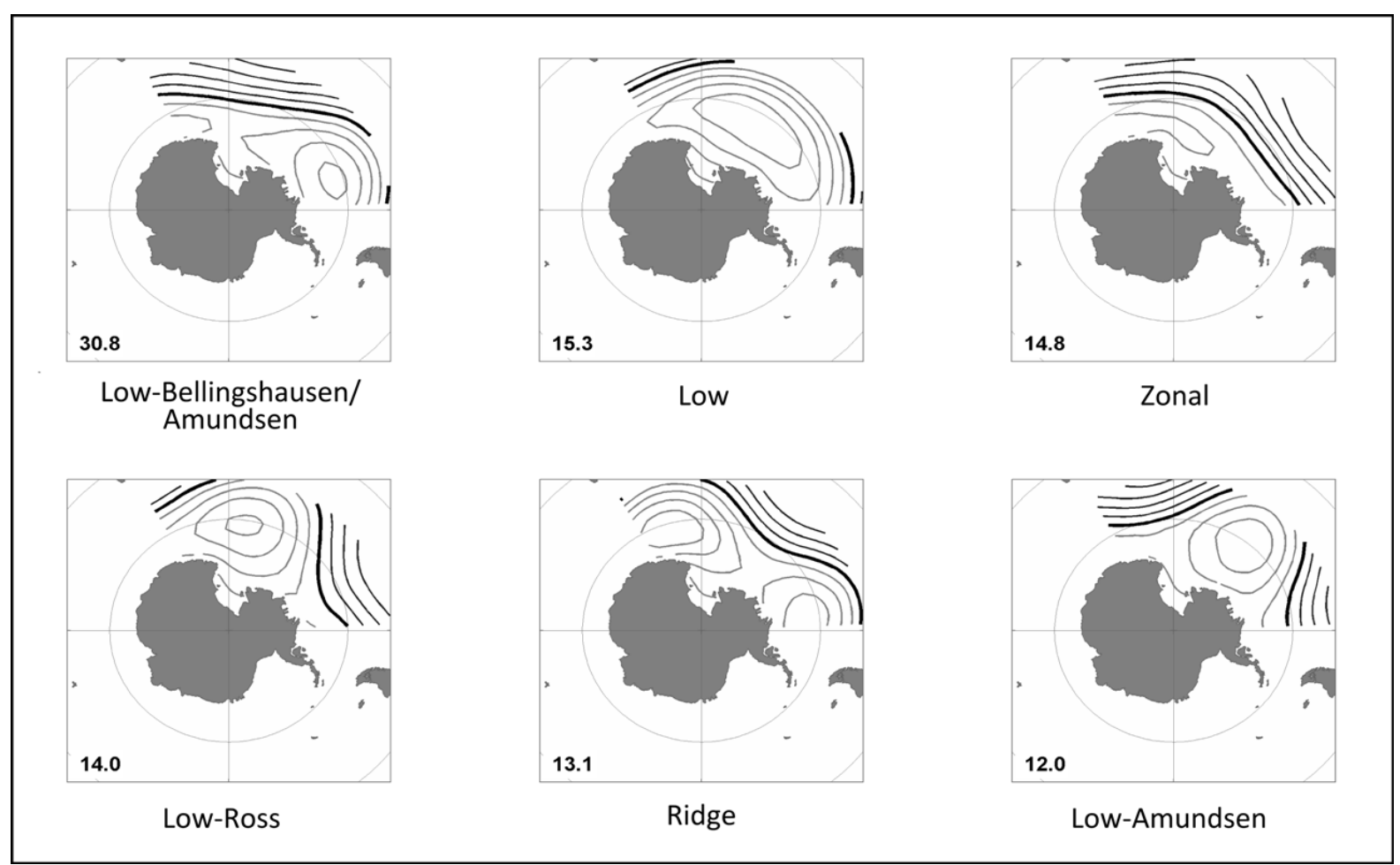

Figure 3.2 Synoptic types for Ross Sea region from NCEP reanalysis 1000 hPa geopotential height data from January 1, 1979 to June 30, 2011. Thick black line is zero meters, light grey is negative, dark grey is positive. Contour interval is 20 meters. Northern limit of the plots are 50 $\mathrm{S}$; inner circle is $60^{\circ} \mathrm{S}$. Frequency of occurrence is shown in lower left corner of each type.

\subsubsection{Seasonal variation of synoptic types}

The seasonal variability of the Ross Sea region synoptic types is shown in Figure 3.3. The most obvious seasonal change reflects the well-known zonal shift of the Amundsen Sea Low, the region of permanent low pressure that spans the Bellingshausen, Amundsen and Ross Seas at $\sim 65-70^{\circ} \mathrm{S}$ (King and Turner 1997; Simmonds et al. 2003; Fogt et al. 2012). The occurrence of the type L-BA is more frequent in summer and autumn (DJF and MAM) while the type L-R is more frequent in spring and winter ( $\mathrm{SON}$ and JJA), indicating that the region of low pressure shifts further east (west) towards the Bellingshausen Sea (Ross Sea) in the summer and autumn (winter and spring). 


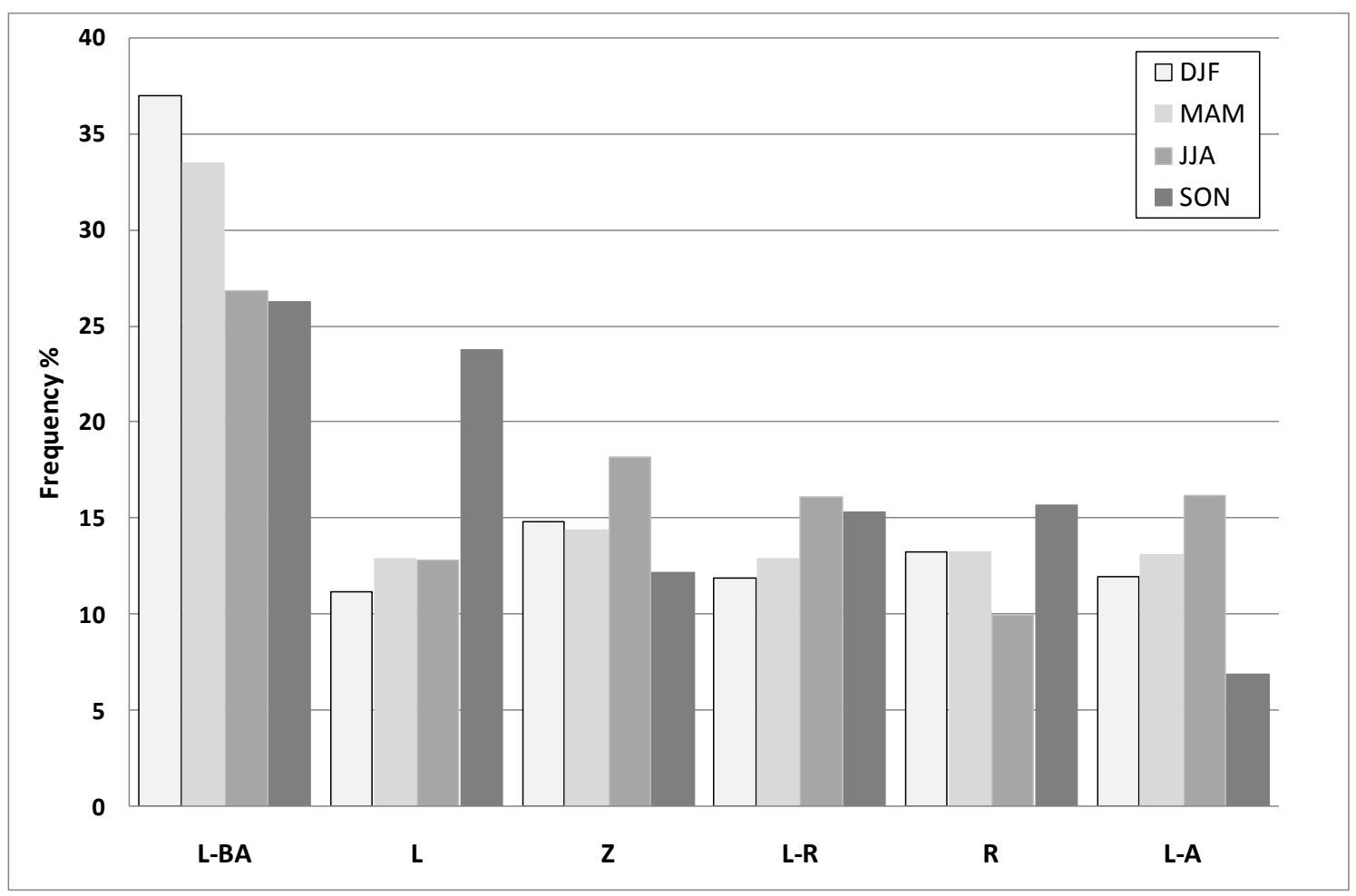

Figure 3.3 Seasonal variability of synoptic types by frequency of occurrence from 1979-2011. The synoptic types correspond to those in Figure 3.2: L-BA (Low-Bellingshausen/Amundsen), L (Low), $Z$ (Zonal), L-R (Low-Ross), R (Ridge), and L-A (Low-Amundsen).

During the spring, the type L has significantly increased occurrence, while the type L-A is decreased in occurrence. Both of the types L and L-A are lows centred at $\sim 60^{\circ} \mathrm{S}, 225^{\circ} \mathrm{E}$, with type L being much broader and deeper than L-A. The seasonal shift between these two types may be a reflection of the Semi-Annual Oscillation (SAO). The SAO is the climatological expansion and contraction of the circumpolar trough during the equinoctial months when temperature and pressure gradients are largest between mid- and high-latitudes. These gradients result in higher baroclinicity and stronger westerlies in the region south of $\sim 50^{\circ} \mathrm{S}$ which give rise to deeper and more southerly (and easterly) pressure systems during the spring and autumn with strongest maxima seen in spring (van Loon 1967; van den Broeke 1998; Simmonds and Jones 1998). The SAO has significant influence on sea ice and meteorological parameters for many regions of Antarctica (Simmonds and Jones 1998; van den Broeke 1998; 2000), but it exhibits its largest variability in pressure in the Amundsen Sea region and demonstrates this variability on interannual to decadal timescales (Simmonds and Jones 1998; Simmonds 2003). 


\subsubsection{Relation to circulation indices SOI and SAM}

Two dominant modes of atmospheric variability that are known to have significant influences on southern high latitudes are the ENSO and the SAM. ENSO influences the high latitude circulation on interannual and longer timescales while the SAM plays a significant role on all time scales from the synoptic to interannual or longer (Thompson and Wallace 2000; Turner 2004). In Antarctica, evidence of these climatic patterns has been found to be strongest in the Ross and Amundsen Sea regions, but the interactions between them are complex and still not well understood and there is no real consensus of how these cycles are manifest in the region (e.g. Bromwich et al. 2000; Renwick 2002; Schneider et al. 2004; L'Heureux and Thompson 2006; Fogt and Bromwich 2006; Gregory and Noone 2008).

Table 3.1 shows seasonal correlations (r) and significance levels (p) of seasonal mean synoptic type occurrence frequency with indices for the SAM (Marshall 2003) and the SOI (from NOAA/CPC). The indices and synoptic type frequencies are averaged seasonally from monthly values. The strongest correlations with synoptic types are with the SAM in all seasons with the exception of a strong negative correlation of the type L-R with the SOI in the spring. The types L-BA and L-R show the strongest correlations with both the SOI and the SAM, with L-BA being positively correlated and L-R negatively correlated. The positive (negative) correlation of L-BA (L-R) with the SAM is in line with previous studies showing the shifting of the position of the Amundsen Sea Low further east (west) towards (away from) the Antarctic Peninsula during positive (negative) SAM conditions (e.g. Kwok and Comiso 2002; Turner et al. 2005b). The correlations of the types L-BA and L-R with the SOI indicate there is similar variability in the ASL with ENSO. Positive correlations of the SOI with L-BA show La Niña conditions shift the position further east towards Bellingshausen Sea while negative correlations of the SOI with L-R show El Niño conditions shift the position further west towards the Ross Sea.

Table 3.2 shows the same seasonal correlations, but uses only the upper and lower quartiles for the SOI and the SAM $(-1 \geq \mathrm{SOI} \geq 1.2 ;-0.79 \geq \mathrm{SAM} \geq 1.43)$ which reduces the number of values to 16 (significance levels $>95 \%$ are bolded). The magnitudes of all the significant correlations in Table 3.1 are increased in Table 3.2 although a few are no longer significant because of the reduction in degrees of freedom. The SAM is strongly negatively correlated with the type L-R (strongest in the spring, $r=-0.68$ ) and strongly positively correlated with the type L-BA (also strongest in the spring, $r=0.84$ ). The correlations in Tables 3.1 and 3.2 also show the type L occurs more frequently for +SAM and +SOI while 
the type L-A occurs more frequently for -SAM and -SOI. This is consistent with results from other studies (e.g. Fogt and Bromwich 2006; Fogt et al. 2011) which indicate a weaker (stronger) ASL during -SAM/El Niño (+SAM/La Niña) conditions.

Table 3.1 Seasonal correlations ( $r$ ) and significance levels $(p)$ for synoptic type occurrence with the Southern Oscillation Index (SOI) and the Southern Annular Mode (SAM) over the period 1979-2011. Bolded values indicate correlations with 95\% significance levels $(p<0.05)$.

\begin{tabular}{|c|c|c|c|c|c|c|c|c|c|c|c|c|c|c|c|c|}
\hline & \multicolumn{4}{|c|}{ DJF } & \multicolumn{4}{|c|}{ MAM } & \multicolumn{4}{|c|}{ JJA } & \multicolumn{4}{|c|}{ SON } \\
\hline & \multicolumn{2}{|c|}{ SOI } & \multicolumn{2}{|c|}{ SAM } & \multicolumn{2}{|c|}{ SOI } & \multicolumn{2}{|c|}{ SAM } & \multicolumn{2}{|c|}{ SOI } & \multicolumn{2}{|c|}{ SAM } & \multicolumn{2}{|c|}{ SOI } & \multicolumn{2}{|c|}{ SAM } \\
\hline & $r$ & $p$ & 1 & $p$ & $r$ & $p$ & & $p$ & $r$ & $p$ & & $p$ & & $p$ & & $p$ \\
\hline L-BA & 0.259 & 0.152 & -0.013 & 0.945 & 0.427 & 0.013 & 0.565 & 0.001 & 0.402 & 0.023 & 0.352 & 0.048 & 0.291 & 0.106 & 0.753 & 0.000 \\
\hline L & 0.439 & 0.012 & 0.439 & 0.012 & -0.055 & 0.761 & -0.099 & 0.585 & 0.189 & 0.300 & 0.476 & 0.006 & 0.329 & 0.066 & -0.024 & 0.897 \\
\hline Z & -0.331 & 0.065 & -0.076 & 0.678 & -0.306 & 0.084 & -0.067 & 0.710 & -0.052 & 0.778 & -0.167 & 0.360 & -0.371 & 0.037 & -0.303 & 0.092 \\
\hline L-R & -0.474 & 0.006 & -0.186 & 0.307 & -0.457 & 0.007 & -0.491 & 0.004 & -0.248 & 0.171 & -0.552 & 0.001 & -0.611 & 0.000 & -0.547 & 0.001 \\
\hline $\mathbf{R}$ & 0.155 & 0.397 & -0.121 & 0.509 & 0.262 & 0.141 & 0.184 & 0.305 & -0.464 & 0.007 & 0.270 & 0.135 & -0.016 & 0.932 & -0.273 & 0.131 \\
\hline L-A & -0.057 & 0.758 & -0.065 & 0.725 & -0.077 & 0.668 & -0.482 & 0.005 & -0.117 & 0.522 & -0.421 & 0.016 & 0.117 & 0.525 & -0.179 & 0.327 \\
\hline
\end{tabular}

Table 3.2 Seasonal correlations ( $r$ ) and significance levels $(p)$ for synoptic type occurrence with the upper and lower quartiles of the Southern Oscillation Index (SOI) and the Southern Annular Mode (SAM) over the period 1979-2011. Bolded values indicate correlations with 95\% significance levels $(p<0.05)$.

\begin{tabular}{|c|c|c|c|c|c|c|c|c|c|c|c|c|c|c|c|c|}
\hline & \multicolumn{4}{|c|}{ DJF } & \multicolumn{4}{|c|}{ MAM } & \multicolumn{4}{|c|}{ JJA } & \multicolumn{4}{|c|}{ SON } \\
\hline & \multicolumn{2}{|c|}{ sol } & \multicolumn{2}{|c|}{ SAM } & \multicolumn{2}{|c|}{ SOI } & \multirow{2}{*}{\multicolumn{2}{|c|}{$r^{\text {SAM }_{p}}$}} & \multicolumn{2}{|c|}{ SOI } & \multicolumn{2}{|c|}{ SAM } & \multicolumn{2}{|c|}{ SOI } & \multicolumn{2}{|c|}{ SAM } \\
\hline & $r$ & $p$ & $r$ & $p$ & $r$ & $p$ & & & $r$ & $p$ & $r$ & $p$ & & $p$ & $r$ & $p$ \\
\hline L-BA & 0.416 & 0.109 & 0.020 & 0.941 & 0.568 & 0.022 & 0.671 & 0.004 & 0.611 & 0.012 & 0.428 & 0.098 & 0.316 & 0.234 & 0.844 & 0.000 \\
\hline L & 0.606 & 0.013 & 0.460 & 0.073 & -0.087 & 0.748 & -0.059 & 0.828 & 0.280 & 0.294 & 0.549 & 0.027 & 0.457 & 0.075 & -0.049 & 0.856 \\
\hline Z & -0.394 & 0.131 & -0.047 & 0.863 & -0.362 & 0.168 & -0.117 & 0.667 & -0.103 & 0.704 & -0.216 & 0.422 & -0.411 & 0.114 & -0.560 & 0.024 \\
\hline L-R & -0.549 & 0.028 & -0.219 & 0.416 & -0.612 & 0.012 & -0.515 & 0.041 & -0.358 & 0.173 & -0.635 & 0.008 & -0.697 & 0.003 & -0.680 & 0.004 \\
\hline $\mathbf{R}$ & 0.166 & 0.539 & -0.009 & 0.974 & 0.383 & 0.143 & 0.028 & 0.917 & -0.507 & 0.045 & 0.340 & 0.198 & -0.101 & 0.709 & -0.239 & 0.373 \\
\hline L-A & -0.203 & 0.451 & -0.222 & 0.409 & -0.062 & 0.819 & -0.509 & 0.044 & -0.212 & 0.431 & -0.497 & 0.050 & 0.166 & 0.538 & -0.232 & 0.388 \\
\hline
\end{tabular}

In order to quantify the relative influences of ENSO and the SAM on the occurrence of these patterns a multiple linear regression was calculated for both L-BA and L-R where,

$$
\mathrm{F}_{\mathrm{L}-\mathrm{BA}}=\mathrm{a}+\mathrm{b}_{\mathrm{SOI}}(\mathrm{SOI})+\mathrm{c}_{\mathrm{SAM}}(\mathrm{SAM})
$$

The regressions were calculated using seasonally averaged values. Correlations and significance values are shown in Table 3.3. The multiple regressions improve on the correlations over either the SAM or SOI alone for all seasons except for summer and support results of previous studies concerning the linear (or near-linear) reinforcing of "in-phase" 
events (i.e. +SAM/La Niña, $-\mathrm{SAM} / \mathrm{El}$ Niño) on the climate of this region (e.g. Fogt and Bromwich 2006; Stammerjohn et al. 2008; Fogt et al. 2011; Markle et al. 2012). Correlations are highest for both L-BA and L-R in the spring ( $r=0.76$ and $r=0.73$, respectively) indicating that the SAM and SOI jointly explain over 50\% of the variance in frequency of these two types for this season.

Table 3.3 Correlations ( $r$ ) and significance levels ( $p$ ) for multiple linear regressions of SOI and SAM with types L-Bellingshausen/Amundsen $(L-B A)$ and $L-R o s s(L-R)$ by season. Bolded values indicate correlations with $95 \%$ significance levels $(p<0.05)$.

\begin{tabular}{rcc|cc|cc|cc}
\hline \multicolumn{2}{c|}{ DJF } & \multicolumn{2}{c|}{ MAM } & \multicolumn{2}{c|}{ JJA } & \multicolumn{2}{c}{ SON } \\
\cline { 2 - 9 } & $r$ & $p$ & $r$ & $p$ & $r$ & $p$ & $r$ & $p$ \\
L-BA & 0.288 & 0.110 & 0.639 & 0.000 & 0.552 & 0.001 & 0.761 & 0.000 \\
L-R & 0.474 & 0.006 & 0.603 & 0.000 & 0.621 & 0.000 & 0.733 & 0.000
\end{tabular}

The relative influences of normalized SOI and SAM indices on the multiple linear regressions are shown in Table 3.4, which gives the ratios of the coefficients, $b_{S O I}$ and $c_{S A M}$ (ratio of unity indicates equal strength of the predictors). For the spring, when there is the highest correlations with the regression, the SAM dominates the variance for L-BA $\left(b_{S O I} / c_{S A M}\right.$ $=0.17)$, while they are more equal for L-R $\left(b_{S O I} / c_{S A M}=1.34\right)$. The dominance of the SOI on L-R in summer is primarily due the influence of the very strong 1982/83 ENSO event (strongest during November to March).

Table 3.4 Coefficients of the SOI and SAM regression with the types L-Bellingshausen/Amundsen ( $L$ $B A)$ and $L-$ Ross $(L-R)$. Ratios of unity indicate equal influence on regression.

\begin{tabular}{cccc|ccc|ccc|ccc}
\hline & \multicolumn{3}{c|}{ DJF } & \multicolumn{3}{c|}{ MAM } & \multicolumn{3}{c|}{ JJA } & \multicolumn{3}{c}{ SON } \\
\hline & $\boldsymbol{b}_{\text {SOI }}$ & $\boldsymbol{c}_{\text {SAM }}$ & $\boldsymbol{b}_{\text {SOI }} / \boldsymbol{c}_{\text {SAM }}$ & $\boldsymbol{b}_{\text {SOI }}$ & $\boldsymbol{c}_{\text {SAM }}$ & $\boldsymbol{b}_{\text {SOI }} / \boldsymbol{c}_{\text {SAM }}$ & $\boldsymbol{b}_{\text {SOI }}$ & $\boldsymbol{c}_{\text {SAM }}$ & $\boldsymbol{b}_{\text {SOI }} / \boldsymbol{c}_{\text {SAM }}$ & $\boldsymbol{b}_{\text {SOI }}$ & $\boldsymbol{c}_{\text {SAM }}$ & $\boldsymbol{b}_{\text {SOI }} / \boldsymbol{c}_{\text {SAM }}$ \\
L-BA & 1.37 & -0.77 & -1.78 & 3.01 & 4.34 & 0.69 & 3.67 & 2.56 & 1.43 & 0.82 & 4.96 & 0.17 \\
L-R & -1.54 & -0.001 & 1540 & -2.20 & -2.24 & 0.98 & -2.11 & -3.32 & 0.64 & -2.51 & -1.87 & 1.34
\end{tabular}

We also investigate whether the trends seen in the SAM and SOI are reflected in the frequency of the synoptic types. Linear trends and significance values are calculated by season for the indices and synoptic type occurrence over the period 1979-2011 as shown in Table 3.5. The positive trends seen in the SOI (significance level $>90 \%$ ) for spring and summer are also seen in the type L for these months. The trends in type L may reflect an increase in the occurrence of the deeper, larger type $\mathrm{L}$ at the expense of the smaller, weaker 
type L-A (negative trend in L-A significant at > 95\% level for MAM). This scenario would be consistent with previous investigations of cyclone activity in the Southern Hemisphere which show increasing size and depth (and decreasing number) of cyclonic systems in this region with positive SOI and positive SAM (e.g. Simmonds and Keay 2000; Simmonds et al. 2003; Pezza et al. 2012). Interestingly, the strongest (and most significant) trend is in type L (3.436 decade $\mathrm{d}^{-1}, p=0.01$ ) during the spring instead of summer when both the SAM and SOI have significant positive trends. We would expect a stronger trend in the summer due to the reinforcing effects of a positive SOI and SAM on cyclonicity (Pezza et al. 2012). Thus the strength of the trend in type $\mathrm{L}$ may be more of a reflection of the positive trend in the SAO since the early 1980s when it was very weak (van den Broeke 2000; Simmonds 2003).

Table 3.5 Linear trends and significances for the SAM, SOI and synoptic type frequencies calculated over the period 1979-June 2011 for each season. Bolded values indicate 95\% significance levels ( $p<$ $0.05)$; italicized values indicate $90 \%$ significance levels $(p<0.10)$.

\begin{tabular}{ccc|cc|cc|cc} 
& \multicolumn{2}{c|}{ DJF } & \multicolumn{2}{c|}{ MAM } & \multicolumn{2}{c|}{ JJA } & \multicolumn{2}{c}{ SON } \\
\cline { 2 - 9 } & $\begin{array}{c}\text { Linear trend } \\
\text { (per decade) }\end{array}$ & $\boldsymbol{p}$ & $\begin{array}{c}\text { Linear trend } \\
\text { (per decade) }\end{array}$ & $\boldsymbol{p}$ & $\begin{array}{c}\text { Linear trend } \\
\text { (per decade) }\end{array}$ & $\boldsymbol{p}$ & $\begin{array}{c}\text { Linear trend } \\
\text { (per decade) }\end{array}$ & $\boldsymbol{p}$ \\
\hline \hline SOI & 0.677 & 0.07 & 0.351 & 0.11 & 0.087 & 0.69 & 0.465 & 0.08 \\
SAM & $\mathbf{0 . 4 6 8}$ & $\mathbf{0 . 0 4}$ & 0.295 & 0.13 & 0.063 & 0.78 & 0.118 & 0.63 \\
\hline L-BA & -0.171 & 0.88 & 1.734 & 0.25 & 0.121 & 0.93 & -0.980 & 0.50 \\
L & 1.417 & 0.08 & 0.231 & 0.82 & 0.906 & 0.36 & $\mathbf{3 . 4 3 6}$ & $\mathbf{0 . 0 1}$ \\
Z & -0.538 & 0.57 & -0.987 & 0.27 & -0.050 & 0.96 & -0.798 & 0.36 \\
L-R & -0.580 & 0.51 & -0.886 & 0.35 & -1.361 & 0.22 & -1.122 & 0.23 \\
R & 0.062 & 0.92 & $\mathbf{1 . 3 5 0}$ & $\mathbf{0 . 0 4}$ & 0.585 & 0.35 & -0.576 & 0.43 \\
L-A & -0.219 & 0.71 & $\mathbf{- 1 . 4 4 2}$ & $\mathbf{0 . 0 4}$ & -0.201 & 0.77 & 0.039 & 0.92
\end{tabular}

\subsubsection{Assessment of NCEP reanalysis precipitation data}

Figure 3.4 shows snow accumulation for the 'Nascent' AWS and precipitation accumulation for the NCEP reanalysis grid point $77.139^{\circ} \mathrm{S}, 181.875^{\circ} \mathrm{E}$ (T62 Gaussian grid) for the period 1 January, 2009 to 30 April, 2011. Since the AWS accumulation data is affected by densification, wind scour and drifting (Knuth et al. 2010), objective identification of small and medium precipitation events is difficult. Large events can be easily identified in a subjective manner and these are shown in Figure 3.4 by the smoothed line overlaying the AWS data. This line highlights the stepped jumps in surface height that indicate large 
precipitation events. Of the 13 large events seen in the AWS data, nine are seen concurrently in the reanalysis data $(\sim 70 \%)$, and there are six large events in the reanalysis data that are not seen in the observed data ( 3 of these are in March-April 2011).

Total accumulation over the period is $0.835 \mathrm{~m}$ snow for Nascent and $71.1 \mathrm{~mm}$ w.e. for NCEP reanalysis. Using an average snow density of $\sim 30 \%$ (Mellor 1964), the reanalysis data underestimates snow accumulation over this time period by a factor of $\sim 3$ ( $0.24 \mathrm{~m}$ total snow accumulation). While there are some previous studies showing that NCEP reanalysis tends to underestimate precipitation for many regions of Antarctica (e.g. Cullather et al 1998; Zou et al 2004) we are not aware of any which compare AWS observations and this discrepancy would be worth further investigation. Even though the magnitudes of reanalysis precipitation do not compare well to observed values we feel the reanalysis data reproduces large precipitation events well enough to use the data in a qualitative sense to investigate how precipitation relates to the synoptic types.

\subsubsection{Expression of synoptic types in precipitation}

The relationship between precipitation at Roosevelt Island and the synoptic types is shown in Figure 3.5. NCEP reanalysis twice-daily precipitation rates for Roosevelt Island are grouped by synoptic type for the same time period as the cluster analysis was run (1 January, 1979-30 June, 2011). The precipitation rates from NCEP reanalysis dataset are shown for each synoptic type by percentage of total accumulation and by distribution of sizes of precipitation events. The values of precipitation from the reanalysis data are only used in a relative sense as they are likely significantly underestimated for the Roosevelt Island site as discussed above.

The type L-R brings $29 \%$ of the total precipitation to the Roosevelt Island site even though it only occurs $14 \%$ of the time while the type L-BA which occurs $30.8 \%$ of the time brings only $19 \%$ of the precipitation to the site. The type L brings the least amount of precipitation (8\%). As expected, the types L-R and L-A bring significant amounts of precipitation to the Roosevelt Island site as these patterns deliver relatively warm moisturebearing air from the Southern Ocean to the Antarctic coastline. The types L and L-BA would be expected to drive moisture-depleted air masses that had travelled over the West Antarctic Ice Sheet to the site. The distinct differences in precipitation delivery shown here are similar 
to those found by Nicolas and Bromwich (2011) using the Antarctic Mesoscale Prediction System (AMPS) archive dataset.

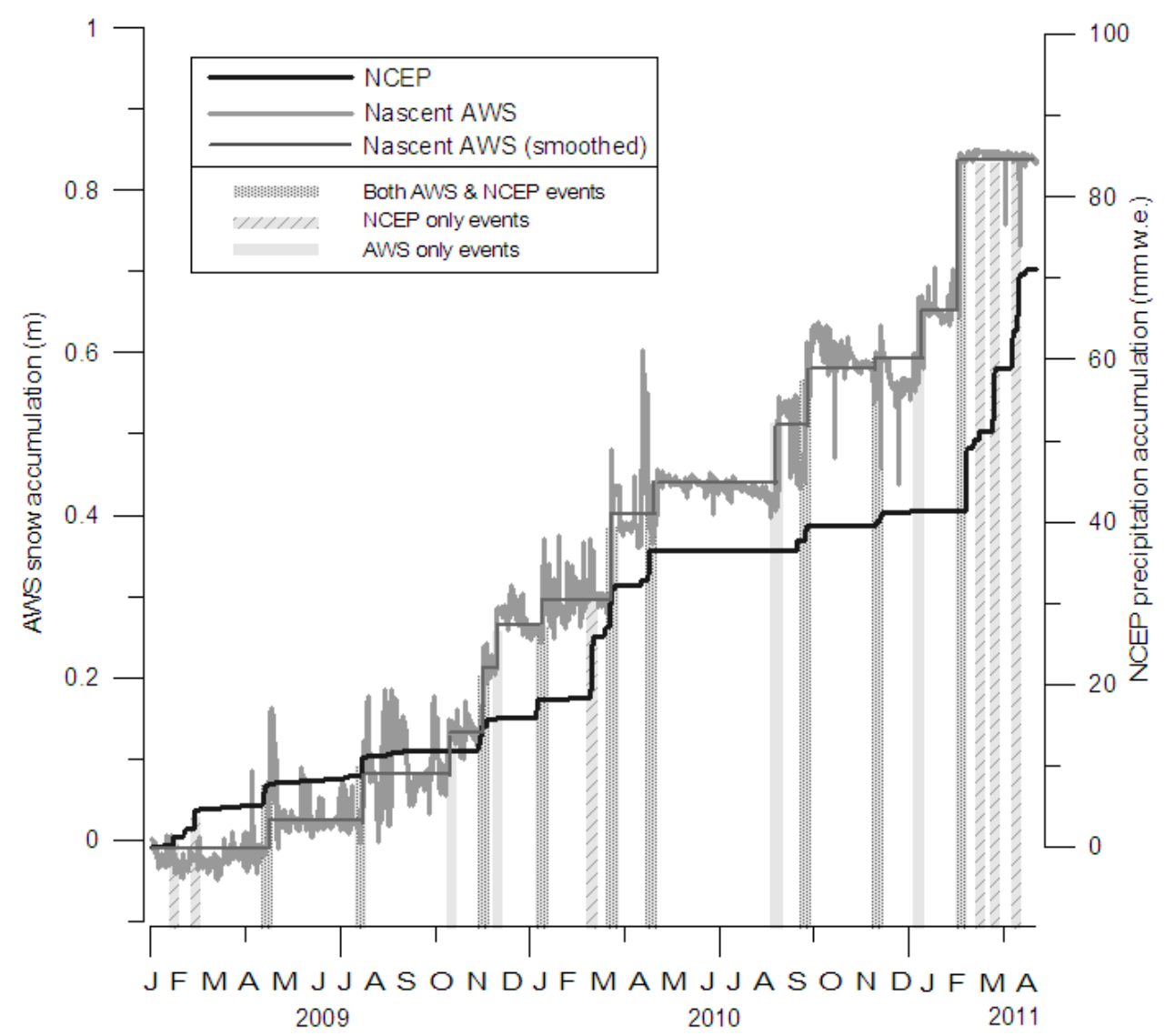

Figure 3.4 Comparison of accumulated precipitation for the 'Nascent' AWS (AMRC, SSEC, UWMadison) with NCEP Reanalysis (77.139 ${ }^{\circ}$ S, 181.875 ${ }^{\circ}$ E) for January 2009-April 2011. Reanalysis precipitation (black line) is in mm water equivalent (w.e.); AWS precipitation (grey lines) is in meters of snow. The dark grey line overlaying the Nascent AWS measurements has been smoothed to show the large precipitation events only. Vertical bands indicate times when both datasets record large events, AWS-only events, and reanalysis-only events.

Further breakdown of the precipitation by the relative size of precipitation "event" is also shown in Figure 3.5. Three groups were chosen based on the overall distribution of the precipitation dataset. Very small and zero precipitation rates (less than $0.05 \mathrm{~mm}$ w.e. per 12 hrs) occurring $96.6 \%$ of the time, account for less than $10 \%$ of the precipitation at the site. Of the remaining non-zero precipitation events, "small" events (less than $0.5 \mathrm{~mm}$ w.e. per 12 hrs) account for $38 \%$ of the total precipitation and "large" (greater than $0.5 \mathrm{~mm}$ w.e. per 12 hours) events account for $53 \%$ of the total precipitation. The type L-R, which dominates as a precipitation source region, brings the majority of its snowfall in large amounts. The types L$\mathrm{A}$ and $\mathrm{Z}$ also contribute significant percentages as large pulses of precipitation. For the type 
L-BA, precipitation is distributed primarily in small events, with the total amount reflecting the fact that this type is the most frequently occurring.

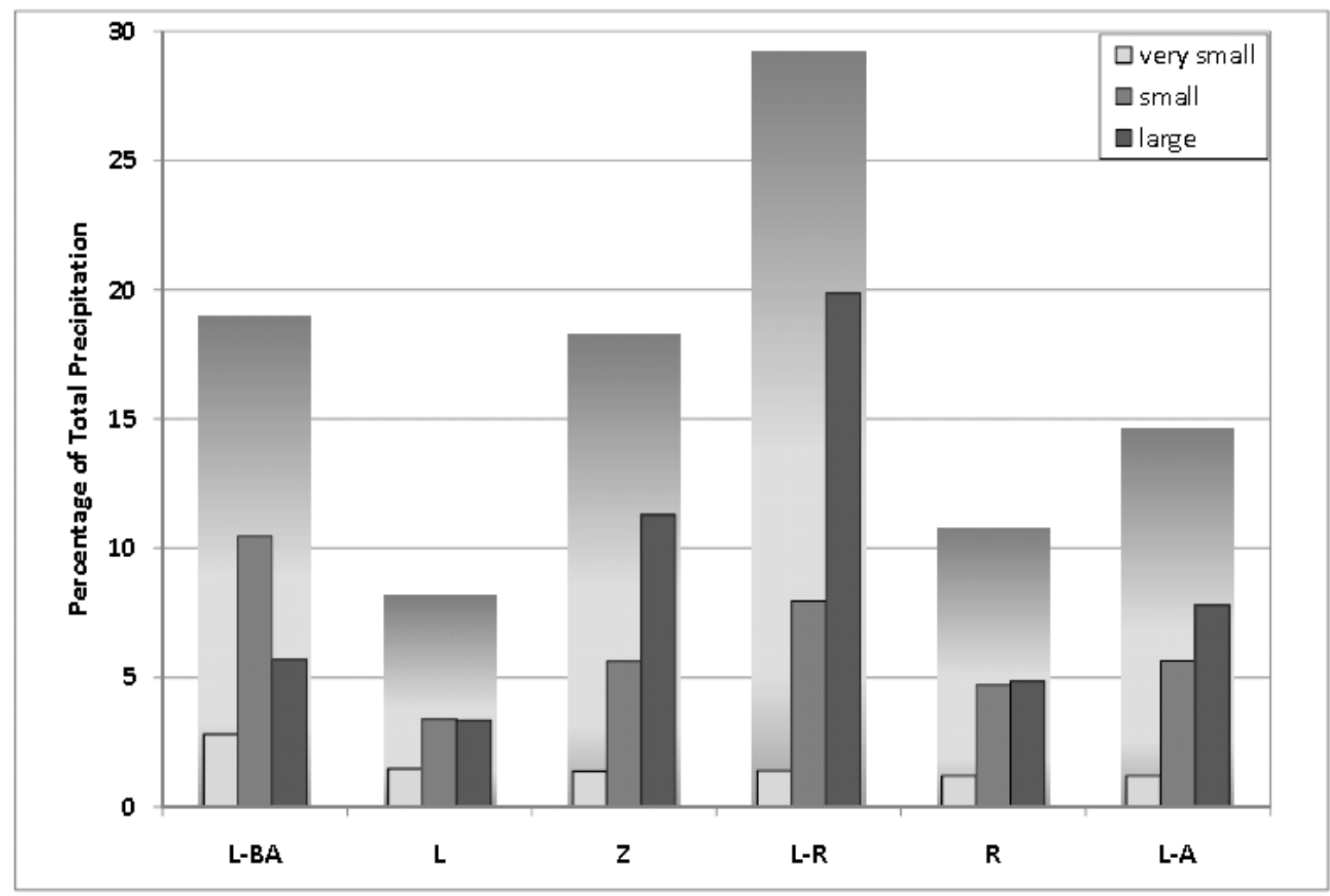

Figure 3.5 Precipitation at Roosevelt Island with relation to the Ross Sea synoptic types for 19792011. Wide bars indicate percentage of total precipitation delivered to the Roosevelt Island site by each type (as in Figure 3.2). Narrow bars indicate the composition of precipitation by size of "event". Groupings are: very small $(<0.05 \mathrm{~mm}$ w.e. per $12 \mathrm{hrs})$, small $(0.05-0.5 \mathrm{~mm}$ w.e. per $12 \mathrm{hrs})$, and large (>0.5 mm w.e. per $12 \mathrm{hrs}$ ).

Because the Zonal (Z) type does not appear to be able to transport moist mid-latitude air to the site, it is surprising to see this type associated with a large amount of precipitation. To consider why this might be so, the $\mathrm{Z}$ type was further divided into three sub-types with distinct synoptic differences (Figure 3.6). The sub-types were derived by re-clustering the $\mathrm{Z}$ type using the same clustering methodology as for the primary clustering. The $\mathrm{Z}$ sub-types are described as: $\mathrm{Z}-\mathrm{Z}$ onal $\left(\mathrm{Z}_{\mathrm{Z}}\right)$ - zonal flow throughout the regions, $\mathrm{Z}$-Low $\left(\mathrm{Z}_{\mathrm{L}}\right)$-a low west of $180^{\circ} \mathrm{E}$, and $\mathrm{Z}$-Trough $\left(\mathrm{Z}_{\mathrm{T}}\right)$ - $\mathrm{a}$ trough in the region. The frequency of these types as a percentage of the Zonal type is shown on each map. While it can be seen that all three types are characterized by relatively weak gradients (as compared to the other main types), the type $\mathrm{Z}_{\mathrm{L}}$ is distinguished by a low west of Roosevelt Island that could drive moist air south to the site and delivers $7.5 \%$ of the total precipitation ( $42 \%$ of the $\mathrm{Z}$ precipitation). The type $\mathrm{Z}_{\mathrm{T}}$, 
distinguished by a trough pattern and weak low just north of the site, delivers $4 \%$ of the total precipitation (23\% of the $\mathrm{Z}$ precipitation). These two types indicate that weaker and/or more southerly positioned systems may play a significant role in precipitation in the Ross Sea region.

Total precipitation for the 32.5 year period is $338 \mathrm{~mm}$ w.e., averaging $\sim 10 \mathrm{~mm}$ w.e. per year for the NCEP reanalysis data. From shallow firn cores and radar measurements across Roosevelt Island (Conway et al. 1999), actual annual precipitation is estimated to be on the order of $200 \mathrm{~mm}$ w.e. per year. However, we do have some confidence in the qualitative ability (timing and relative amounts) of NCEP reanalysis to reconstruct precipitation on the Ross Ice Shelf from the Nascent AWS comparison. Two possible reasons the reanalysis may underestimate precipitation at Roosevelt Island are, 1) the summit of Roosevelt Island gets additional precipitation due to topographic uplift, being approximately 450 meters above the surrounding ice shelf, and 2) mesoscale systems are not well captured by the reanalysis data because of its coarse resolution (Condron et al. 2006). Mesoscale systems are found in high densities in this region, particularly along the eastern Ross Ice Shelf, and have been shown to substantially contribute to precipitation along the Antarctic coast (e.g. Carrasco et al. 2003; Irving et al. 2010). The importance of these factors is of interest for interpreting Roosevelt Island climate data and is the subject of future and ongoing work.

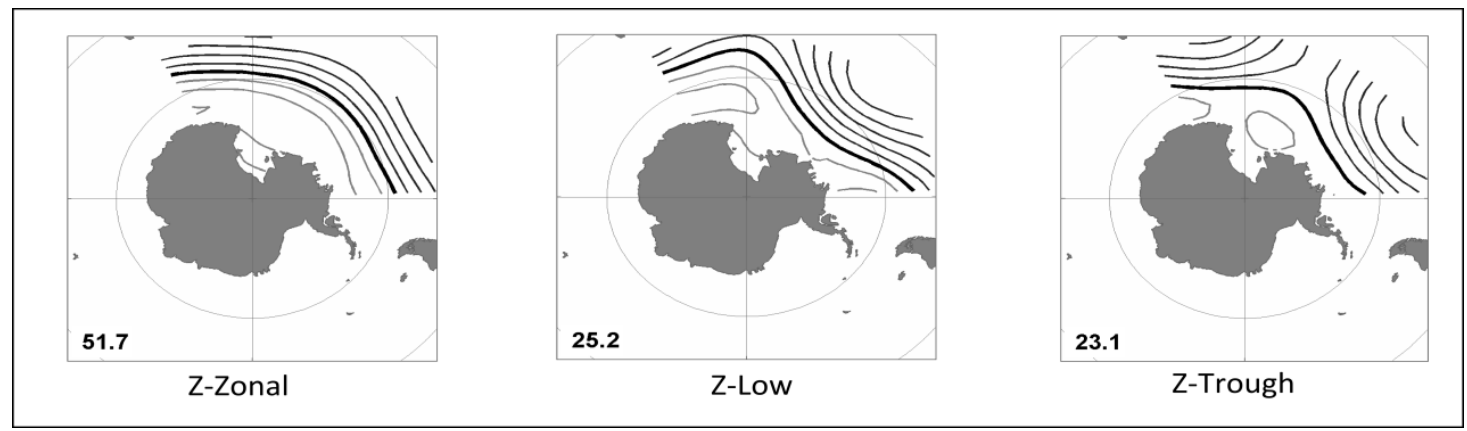

Figure 3.6 Zonal sub-types $\left(Z_{Z}, Z_{L}\right.$ and $\left.Z_{T}\right)$ and frequency of occurrence of each as percentage of the Zonal type.

\subsubsection{Expression of synoptic types in temperature}

The relationship between surface temperature at Roosevelt Island and synoptic types is shown in Figure 3.7. The figure shows departures from monthly means and 95\% confidence intervals for two temperature datasets, one from a University of Wisconsin AWS located less than 100 kilometers west of Roosevelt Island (Margaret AWS) and the other is NCEP reanalysis surface temperature for the gridbox at $80^{\circ} \mathrm{S}, 200^{\circ} \mathrm{E}$. The NCEP data is for the 
period January 1979-June 2011, and the AWS data is for 13 November, 2008-30 June, 2011. The reanalysis data shows significant temperature differences between synoptic types with average departures from monthly means varying between $-1.0^{\circ} \mathrm{C}$ to $+1.7^{\circ} \mathrm{C}$. Because the observed dataset is much shorter ( 2.4 years) than the reanalysis dataset (32.5 years) the differences in temperature are not significant, but it is encouraging that the patterns and magnitudes are similar to those of the reanalysis data. As expected, the types L-R, and L-A bring warmer than average temperatures to the site as these types are associated with the relatively warm, moisture-bearing air from the Southern Ocean.

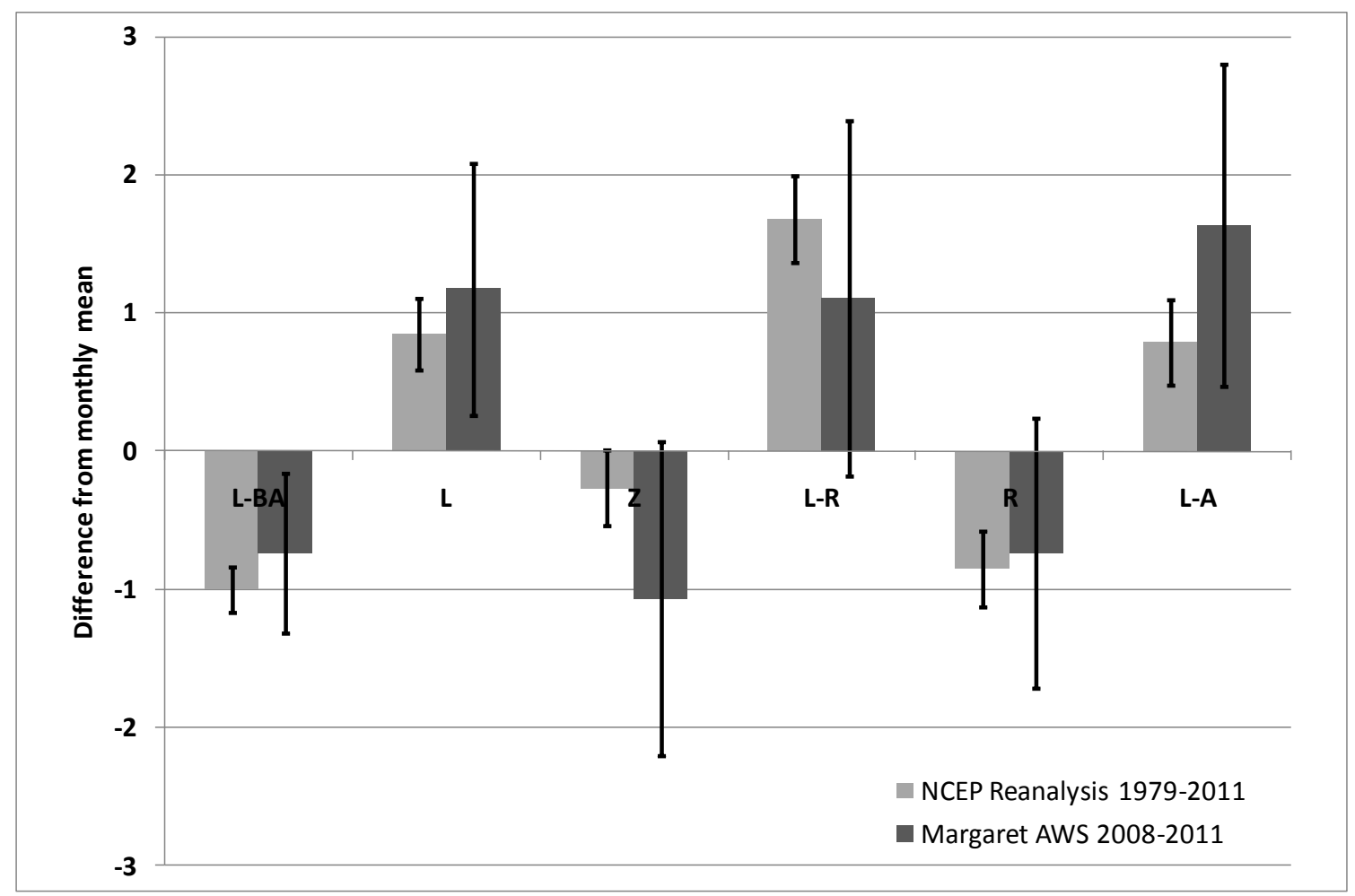

Figure 3.7 Temperature departures from monthly means (with 95\% confidence intervals indicated) at Roosevelt Island grouped by synoptic type (as in Figure 3.2). Two temperature datasets are used: light grey bars are NCEP reanalysis from 1979-2011, dark grey bars are for Margaret AWS (AMRC, SSEC, UW-Madison) from 13 Nov, 2008 through 30 June, 2011.

The type L shows warmer than average temperatures but brings the least amount of precipitation to the site, indicating that this type is associated with moisture-depleted but relatively warm air masses. The types L-BA and $\mathrm{R}$ are also low-precipitation types, but are differentiated by lower than average temperatures, perhaps indicating these types are the primary drivers of the cold, dry drainage winds from the West Antarctic Ice Sheet (King and Turner 1997). The type $\mathrm{Z}$ also brings colder than average temperatures although over the 
longer dataset the average is close to zero $\left(-0.3^{\circ} \mathrm{C}\right)$ indicating there may not be significant variability in temperature associated with this type.

\subsection{Summary}

This work provides the first synoptic-climatological classification of weather systems for Antarctica, focusing on the Ross Sea region and Antarctic coast across the Pacific sector. The six main synoptic types and three sub-types derived from NCEP reanalysis data describe the synoptic conditions for the period 1979-2011. The patterns describe realistic synoptic conditions for the region, representing the variability in the moisture-bearing low pressure systems that circulate around the Antarctic continent.

Seasonal variability of the synoptic types is in line with known patterns of variability such as the seasonal zonal shift of the ASL, and pressure effects of ENSO and the SAM. The type L-R is negatively correlated with the SOI and SAM while L-BA is positively correlated with the SOI and the SAM, indicating shifting of the position of the low further east (west) towards (away from) the Antarctic Peninsula during La Nina (El Niño) and positive (negative) SAM conditions. Correlations of both types (L-BA and L-R) with the SAM are highest in the spring $(r=0.75$ and $r=-0.55$ respectively) and non-existent in the summer. Correlation of L-R with the SOI is also highest in the spring $(r=-0.61)$.

Multiple linear regressions of the SOI and SAM indices improve on these correlations, indicating the reinforcing influence of these two climate cycles on the synoptic conditions of this region. The joint regressions show that the SOI and the SAM explain over $50 \%$ of the variability in L-BA and L-R in the spring and nearly $40 \%$ in autumn. Trends in the indices from 1979-2011 are also seen in trends of the occurrence of the synoptic types. Because the technique is shown to reflect variability in large-scale circulation in physically meaningful ways we expect to see changes in the synoptic types (frequency or patterns) as the climate changes (e.g. as the positive SAM becomes more frequent) (Marshall 2003).

The synoptic types are also shown to reflect variability in measureable climate parameters such as precipitation and temperature suggesting that this approach has some merit for studying surface climate at high-latitudes. Using the Roosevelt Island ice core site as a case-study, it is shown that the synoptic types bring very different amounts and size distributions of precipitation to Roosevelt Island. For example, the L-R synoptic type is shown to have a significant role in delivering precipitation to the site ( $30 \%$ of total precipitation). That the frequency of L-R is strongly correlated with both the SOI and the 
SAM and exhibits a long-term trend, suggests that an ice core record from Roosevelt Island may be able to offer significant insights into the long-term variability of these climate drivers.

There are many potential applications for using synoptic classification to help understand how local climate parameters relate to climate variability in Antarctica. Future work with the Ross Sea synoptic types will focus on investigating the relationship to meteorological parameters at other sites and relating the synoptic types to other climate parameters (e.g. sea ice and snow chemistry).

\section{Acknowledgements}

The authors greatly appreciate the support of the University of Wisconsin-Madison, Automatic Weather Station Program and Antarctic Meteorological Research Center for the AWS data sets and Matthew Lazzara in particular for information provided on the Antarctic AWS datasets. We also appreciate use ofNCEP Reanalysis data provided by the NOAA/OAR/ESRL PSD, Boulder, Colorado. Two of the authors (SD and JR) were partfunded through core funding from the N.Z. Ministry of Science and Innovation.

\subsection{References}

Bromwich, D. H. 1988: Snowfall in high southern latitudes, Rev. Geophys., 26, 149-168.

Bromwich, D.H., A. N. Rogers, P. Kållberg, R. I. Cullather, J. W. C. White, and K. J. Kreutz. 2000: ECMWF analyses and reanalyses Depiction of ENSO signal in Antarctic precipitation. J. Climate, 13, 1406-1420.

Bromwich, D. H., and R. L. Fogt, 2004: Strong trends in the skill of the ERA-40 and NCEPNCAR reanalyses in the high and midlatitudes of the southern hemisphere, 19582001, J. Climate, 17, 4603-4619.

Bromwich, D. H., R. L. Fogt, K. I. Hodges and J. E. Walsh, 2007: A tropospheric assessment of the ERA-40, NCEP, and JRA-25 global reanalyses in the polar regions. J. Geophys. Res.112, D10111.

Bromwich, D. H., J. P. Nicholas, A. J. Monaghan, 2011: An assessment of precipitation changes over Antarctica and the Southern Ocean since 1989 in contemporary global reanalyses. J. Climate, 24, 4189-4209. 
Carrasco, J. F., D. H. Bromwich, A. J. Monaghan, 2003: Distribution and characteristics of mesoscale cyclones in the Antarctic: Ross Sea eastward to the Weddell Sea. Mon. Wea. Rev., 131, 289-301.

Condron, A., G. R. Bigg, and I. A. Renfrew, 2006: Polar mesoscale cyclones in the northeast Atlantic: Comparing climatologies from ERA-40 and satellite imagery. Mon. Wea. Rev., 134, 1518-1533.

Conway, H., B. L. Hall, G. H. Denton, A. M. Gades, E. D. Waddington, 1999: Past and Future Grounding-Line Retreat of the West Antarctic Ice Sheet, Science, 286, 280283.

Cullather, R. I., D. H. Bromwich, and M. L. Van Woert, 1996: Interannual variations in Antarctic precipitation related to El Niño-Southern Oscillation, J. Geophys. Res., 101, 19109-19118.

Cullather, R. I., D. H Bromwich, and M. L Van Woert. 1998: Spatial and Temporal Variability of Antarctic Precipitation from Atmospheric Methods. J. Climate,11, 334367.

Fogt, R. L., and D. H. Bromwich, 2006: Decadal Variability of the ENSO Teleconnection to the High-Latitude South Pacific Governed by Coupling with the Southern Annular Mode. J. Climate, 19, 979-997.

Fogt, R. L., D. H. Bromwich, and K. M. Hines, 2011: Understanding the SAM influence on the South Pacific ENSO teleconnection. Clim. Dyn., 36, 1555-1576.

Fogt, R. L., A. J. Wovrosh, R. A. Langen, and I. Simmonds, 2012: The characteristic variability and connection to the underlying synoptic activity of the AmundsenBellingshausen Seas Low. J. Geophys. Res., 117, D07111, doi:10.1029/2011JD017337.

Gregory, S. and D. Noone. 2008: Variability in the teleconnection between the El NinoSouthern Oscillation and West Antarctic climate deduced from West Antarctic ice core isotope records. J. Geo. Res.,113, D17110.

Helsen, M. M., R. S. W. Van de Wal, M. R. Van den Broeke, 2007: The isotopic composition of present-day Antarctic snow in a Lagrangian atmospheric simulation. J. Climate, 20, 739-756. 
Irving, D., I. Simmonds, K. Keay, 2010: Mesoscale cyclone activity over the ice-free Southern Ocean: 1999-2008. J. Climate, 23, 5404-5420.

Kalnay et al., 1996: The NCEP/NCAR 40-year reanalysis project, Bull. Amer. Meteor. Soc., 77, 437-470.

Kidson, J. W., 1994: An automated procedure for the identification of synoptic types applied to the New Zealand region. Int. J. Climatol., 14, 711-721.

Kidson, J. W., 1999: Principal modes of Southern Hemisphere low frequency variability obtained from NCEP/NCAR reanalyses. J. Climate, 12, 2808-2830.

Kidson, J. W., 2000: An analysis of New Zealand synoptic types and their use in defining weather regimes. Int. J. Climatol., 20, 299-316.

Kidson, J.W. and J. A. Renwick, 2002: The Southern Hemisphere evolution of ENSO during 1981-99. J. Climate, 15, 847-863.

King, J.C. and J. Turner, 1997: Antarctic meteorology and climatology. Cambridge University Press.

Knuth, S. L., G. J. Tripoli, J. E. Thom, G. A. Weidner, 2010: The influence of blowing snow and precipitation on snow depth change across the Ross Ice Shelf and Ross Sea regions of Antarctica. J. App. Met. \& Clim., 49, 1306-1321.

Krinner, G., O. Magand, I. Simmonds, C. Genthon, J. L. Dufresne, 2007: Simulated Antarctic precipitation and surface mass balance at the end of the twentieth and twenty-first centuries. Clim. Dyn., 28, 215-230.

Kwok, R., and J. C. Comiso, 2002: Spatial patterns of variability in Antarctic surface temperature: Connections to the Southern Hemisphere Annular Mode and the Southern Oscillation, Geophys. Res. Lett., 29, 1705.

L'Heureux, M. L., and D. W. J. Thompson, 2006: Observed relationships between the E1 Niño-Southern Oscillation and the extratropical zonal-mean circulation. J. Climate, 19, 276-287.

Lorrey, A., A. M. Fowler, and J. Salinger, 2007: Regional climate regime classification as a qualitative tool for interpreting multi-proxy palaeoclimate data spatial patterns: A New Zealand case study. Palaeogeog. Palaeoclim. Palaeoecol., 253, 407-433. 
MacQueen, J. 1967: Some methods for classification and analysis of multivariate observations. Proc. Fifth Berk. Symp. Math. Stat. Prob., 1, 281-297.

Markle, B. R., N. A. N. Bertler, K. E. Sinclair and S. B. Sneed, 2012: Synoptic variability in the Ross Sea region, Antarctica, as seen from back-trajectory modeling and ice core analysis. J. Geo. Res117, D02113.

Marshall, G. J., 2003: Trends in the southern annular mode from observations and reanalyses. J. Climate, 16, 4134-4143.

Mayewski, P.A., M. Frezzotti, N. Bertler, and 16 others. 2005: The International TransAntarctic Scientific Expedition (ITASE): an overview, 28th Symposium of the Scientific-Committee on Antarctic Research, Jul 28-29, 2004, Ann. Glaciology, 41, 180-185.

Mellor, M. (Ed.), 1964: Antarctic Snow and Ice Studies. Antarct. Res. Ser., vol. 2, 286 pp., AGU, Washington D.C.

Nicolas, J. P. and D. H. Bromwich, 2011: Climate of West Antarctica and influence of marine air intrusions. J. Climate, 24, 49-67.

Noone, D., J. Turner, and R. Mulvaney, 1999: Atmospheric signals and characteristics of accumulation in Dronning Maud Land, Antarctica. J. Geophys. Res., 104(D16), 19,191-19,211.

Noone, D. and I. Simmonds, 2002: Annular variations in moisture transport mechanisms and the abundance of $\delta^{18} \mathrm{O}$ in Antarctic snow. J. Geophys. Res., 107, 4742.

O’Donnell, R., N. Lewis, S. McIntyre and J. Condon, 2011: Improved methods for PCAbased reconstructions: Case study using the Steig et al. (2009) Antarctic temperature reconstruction. J. Climate, 24, 2099-2115.

Pezza A. B., H. A. Rashid, I. Simmonds, 2012: Climate links and recent extremes in Antarctic sea ice, high-latitude cyclones, Southern Annular Mode and ENSO. Clim. Dyn., 38, 57-73.

Purdie, H., A. Mackintosh, W. Lawson, and B. Anderson, 2011: Synoptic influences on snow accumulation on glaciers east and west of a topographic divide: Southern Alps, New Zealand. Arctic, Antarctic and Alpine Res., 43, 82-94. 
Renwick, J. A., R. J. Hurst, and J. W. Kidson, 1998: Climatic influences on the survival of southern Gemfish (Rexea Solandri, Gempylidae) in New Zealand waters. Int. J. Climatol., 18, 1655-1667.

Renwick, J. A., 2002: Southern Hemisphere circulation and relations with sea ice and sea surface temperature. J. Climate, 15, 3058-3068.

Renwick, J. A., 2011: Kidson's synoptic weather types and surface climate variability over New Zealand. Weather and Climate,31, 2-23.

Rignot, E., J.L. Bamber, M.R. Van Den Broeke, C. Davis, Y.H. Li, W.J. Van De Berg, Van Meijgaard, 2008: Recent Antarctic ice mass loss from radar interferometry and regional climate modeling, Nat. Geosci., 1, 106-110.

Schneider D.P., E.J. Steig, J.C. Comiso, 2004: Recent climate variability in Antarctica from satellite-derived temperature data, J. Climate, 17, 1569-1583.

Sheridan, S. C. and C. C. Lee, 2010: Synoptic climatology and the general circulation model. Prog. Phys. Geog., 34, 101-109.

Simmonds, I., 2003: Modes of atmospheric variability over the Southern Ocean. J. Geophys. Res., 108(C4), 8078.

Simmonds, I. and D. A. Jones, 1998: The mean structure and temporal variability of the semiannual oscillation in the southern extratropics. Int. J. Climatology, 18, 473-504.

Simmonds, I. and K. Keay, 2000: Variability of Southern Hemisphere extratropical cyclone behavior, 1958-97. J. Climate, 13, 550-561.

Simmonds, I., K. Keay, and E. Lim. 2003: Synoptic Activity in the Seas around Antarctica. Mon. Wea. Rev.131, 272-287.

Sinclair, K. E., N. A. N. Bertler, and W. J. Trompetter, 2010: Synoptic controls on precipitation pathways and snow delivery to high-accumulation ice core sites in the Ross Sea region, Antarctica. J. Geo. Res., 115, D22112.

Smithson, P. A., 1986: Synoptic and dynamic climatology. Prog. Phys. Geog., 10, 100-110.

Stammerjohn, S. E., D. G. Martinson, R. C. Smith, X. Yuan, and D. Rind, 2008: Trends in Antarctic annual sea ice retreat and advance and their relation to El Niño-Southern Oscillation and Southern Annular Mode variability. J. Geophys. Res., 113, C03S90. 
Thomas, E.R., and T. J Bracegirdle 2009: Improving ice core interpretation using in situ and reanalysis data. J. of Geo. Res.114, D20116.

Thompson, D. W.J, and J. M Wallace. 2000: Annular Modes in the Extratropical Circulation. Part I: Month-to-Month Variability. J. Climate,13, 1000-1016.

Trenberth, K. E., 1997: The definition of El Nino, Bull. Am. Met. Soc., 78, 2771-2777.

Turner, J., 2004. The El Niño-Southern Oscillation and Antarctica. Int. J. Climatology, 24, 131.

Turner, J., S. R. Colwell, G. J. Marshall, T. A. Lachlan-Cope, A. M. Carleton, P. D. Jones, V. Lagun, P. A. Reid, and S. Iagovkina. 2005a: Antarctic climate change during the last 50 years. Int. J. Climatology25, 279-294.

Turner, J., T. Lachlan-Cope, S. Colwell, and G. J. Marshall. 2005b: A positive trend in western Antarctic Peninsula precipitation over the last 50 years reflecting regional and Antarctic-wide atmospheric circulation changes. Ann. Glaciology41, 85-91.

van Loon, H. 1967: The half-yearly oscillations in the middle and high southern latitudes and the coreless winter. J. Atmos. Sci., 24, 472-486.

van den Broeke, M. R., 1998: The semi-annual oscillation and Antarctic climate. Part 1: influence on near surface temperatures (1957-1979). Antarctic Sci., 10(2), 175-183.

van den Broeke, M. R., 2000: On the interpretation of Antarctic temperature trends. $J$. Climate, 13, 3885-3889.

Yarnal, B., 1993: Synoptic climatology in environmental analysis. Bellhaven Press.

Yarnal, B., A. C. Comrie, B. Frakes, D. P. Brown, 2001: Developments and prospects in synoptic climatology. Int. J. Climatol.,21, 1923-1950.

Zou, C. Z., M. L. Van Woert, C. Y. Xu, and K. Syed, 2004: Assessment of the NCEP-DOE reanalysis-2 and TOVS Pathfinder A moisture fields and their use in Antarctic net precipitation estimates. Month. Weath. Rev., 132, 2463-2476. 



\title{
4 Snow on the Ross Ice Shelf: comparison of reanalyses and observations from automatic weather stations
}

In order to provide an assessment of how well reanalyses datasets represent precipitation on synoptic timescales in the Ross Sea region, this chapter compares atmospheric reanalyses precipitation to in-situ snow accumulation records for the Ross Ice Shelf. This manuscript has been published in The Cryosphere (Cohen and Dean, 2013).

\begin{abstract}
Snow accumulation measurements from Automatic Weather Stations (AWS) around the Ross Ice Shelf (RIS), Antarctica are used to provide a new set of ground-based observations which are compared to precipitation from the ECMWF ERA-Interim and NCEP/NCAR Reanalysis2 datasets. The high temporal resolution of the AWS snow accumulation measurements allow for an event-based comparison of reanalyses precipitation to the in-situ observations. Snow accumulation records from nine AWS provide multiple years of accumulation data between 2008-2012 over a relatively large, homogeneous region of Antarctica and provide the basis for a statistical evaluation of accumulation and precipitation events. The complex effects of wind on snow accumulation (which can both limit and enhance accumulation) complicate the use of the accumulation measurements, but this analysis shows that they can provide a valuable source of ground-based observations for comparisons to modeled precipitation on synoptic time scales. The analysis shows that ERA-Interim reproduces more precipitation events than NCEP-2 and these events correspond to an average 8.2\% more precipitation. Significant correlations between reanalyses and AWS event sizes are seen at several stations and show that ERA-Interim consistently produces larger precipitation events than NCEP-2.
\end{abstract}




\subsection{Introduction}

Knowledge of the spatial and temporal variability of precipitation and snow accumulation in Antarctica is essential for further understanding of Antarctic mass balance, ice core interpretation, and atmospheric circulation changes. Because of the sparseness of in-situ and satellite measurements in Antarctica, atmospheric reanalyses products are a key tool for studying precipitation in Antarctica (e.g. Monaghan et al., 2006; Krinner et al., 2007; Marshall et al., 2009; Bromwich et al., 2012). The European Centre for Medium-Range Weather Forecasts (ECMWF) ERA-Interim and National Centers for Environmental Predication/National Center for Atmospheric Research (NCEP/NCAR) Reanalysis-2 datasets are the most easily accessible and provide data over the longest time period (1979-present for the polar regions), and they are therefore widely used in climatological and meteorological studies of Antarctica. Understanding how well precipitation is represented by these reanalyses products (and other Numerical Weather Prediction (NWP) models) is difficult to ascertain because of the difficulty in making precipitation measurements and the sparceness of these measurements in the high latitudes.

Previous studies have focused on annual and longer timescales and primarily use glaciological observations (e.g. Cullather et al., 1998; Bromwich et al., 2004, 2007, 2011). These studies provide valuable information on trends and large-scale variability of precipitation and show that there are significant differences in precipitation representation between various reanalyses datasets. Most recently, Bromwich et al., (2011) showed that the ERA-Interim dataset represents the spatial variability and recent trends in precipitation over most of Antarctica better than the NCEP-2 dataset. However, this assessment is based on annually-averaged precipitation from satellite and glaciological observations and doesn't give insight into how well reanalyses represent precipitation on much shorter timescales. In addition, on-going challenges with use of satellite observations for verification of NWP modeled precipitation (e.g. Lu et al., 2010) indicate that there is still a considerable need for in-situ precipitation observations.

Understanding how well reanalyses precipitation is represented on synoptic scales is of interest primarily for ice core interpretation and atmospheric circulation change studies (e.g. Simmonds et al., 2003; Helsen et al., 2007; Thomas and Bracegirdle 2009; Sinclair et al., 2010; Fogt et al., 2012). Synoptic-scale systems drive much of the temporal and spatial variability of precipitation in Antarctica and understanding how that variability affects climate proxies in ice cores is very important (Noone and Simmonds, 2002). The Ross and 
Amundsen Seas in particular are regions of significant synoptic-scale cyclone activity in the Southern Ocean which are the source of most of the precipitation on the Ross Ice Shelf and West Antarctic Ice Sheet (King and Turner, 1997; Simmonds et al., 2003). The synoptic variability of these regions are of interest and the source of ongoing research as they are known to be influenced by large-scale atmospheric circulation changes such as the Southern Annular Mode and El Niño - Southern Oscillation (Cullather et al., 1996; Fogt and Bromwich, 2006; Fogt et al., 2012; Cohen et al., 2013).

Snow accumulation measurements from the University of Wisconsin Antarctic Meteorological Research Center (UW-AMRC) network of un-manned Automatic Weather Stations (AWS) provide a source of in-situ observations which may be used to assess reanalyses precipitation on synoptic scales. This study compares accumulation measurements from the Ross Ice Shelf, Antarctica to individual precipitation events from the ECMWF ERA-Interim and NCEP/NCAR Reanalysis-2 datasets. The stations provide measurements of snow accumulation via changes in snow height as well as the standard suite of meteorological parameters (temperature, pressure, relative humidity, and wind speed and direction) (Lazzara et al., 2012). Snow height changes are measured with acoustic depth gauge (ADG) instruments which measure amount of snow accumulation and exact timing of accumulation events. ADGs have been widely used in Antarctic studies to characterize precipitation and surface mass balance on sub-annual timescales (e.g. Braaten, 1997, 2000; Qin et al., 2004; Eisen et al., 2008; Reijmer and van den Broeke, 2003; Thiery et al., 2012) and in climate proxy studies to investigate the synoptic origins of individual accumulation events (e.g. Noone et al., 1999; Reijmer et al., 2002; Helsen et al., 2007).

As snow accumulation records are a proxy for precipitation, using them to compare to precipitation is not straightforward. The ADG measurements on the Ross Ice Shelf provide a new dataset of high temporal resolution, ground-based accumulation observations which may provide an important source of measurements to assess modeled precipitation on synoptic timescales.

\subsection{Site description and snow accumulation data}

Figure 4.1 shows the locations of the nine UW-AMRC AWS snow height measurements used in this study and the nearest ERA-Interim and NCEP-2 gridpoints. The eight stations on the Ross Ice Shelf (RIS) provide a relatively dense network of stations in a geographically constrained area. We also use data from a station located on the West Antarctic Ice Sheet (WAIS) because of its proximity to the RIS and the significance of the WAIS for mass 
balance and ice core interpretation. The snow height change measurements are available for varying time periods between January 2008-August 2012. Though there are some measurements prior to 2008, continuous, year-round snow accumulation measurements are only available since 2008. All of the stations except for Linda and Byrd have over two years of continuous accumulation measurements, with Windless Bight having the longest record of four and a half years. Each station's length of record, location, and distances to nearest reanalyses grid points are summarized in Table 4.1 .

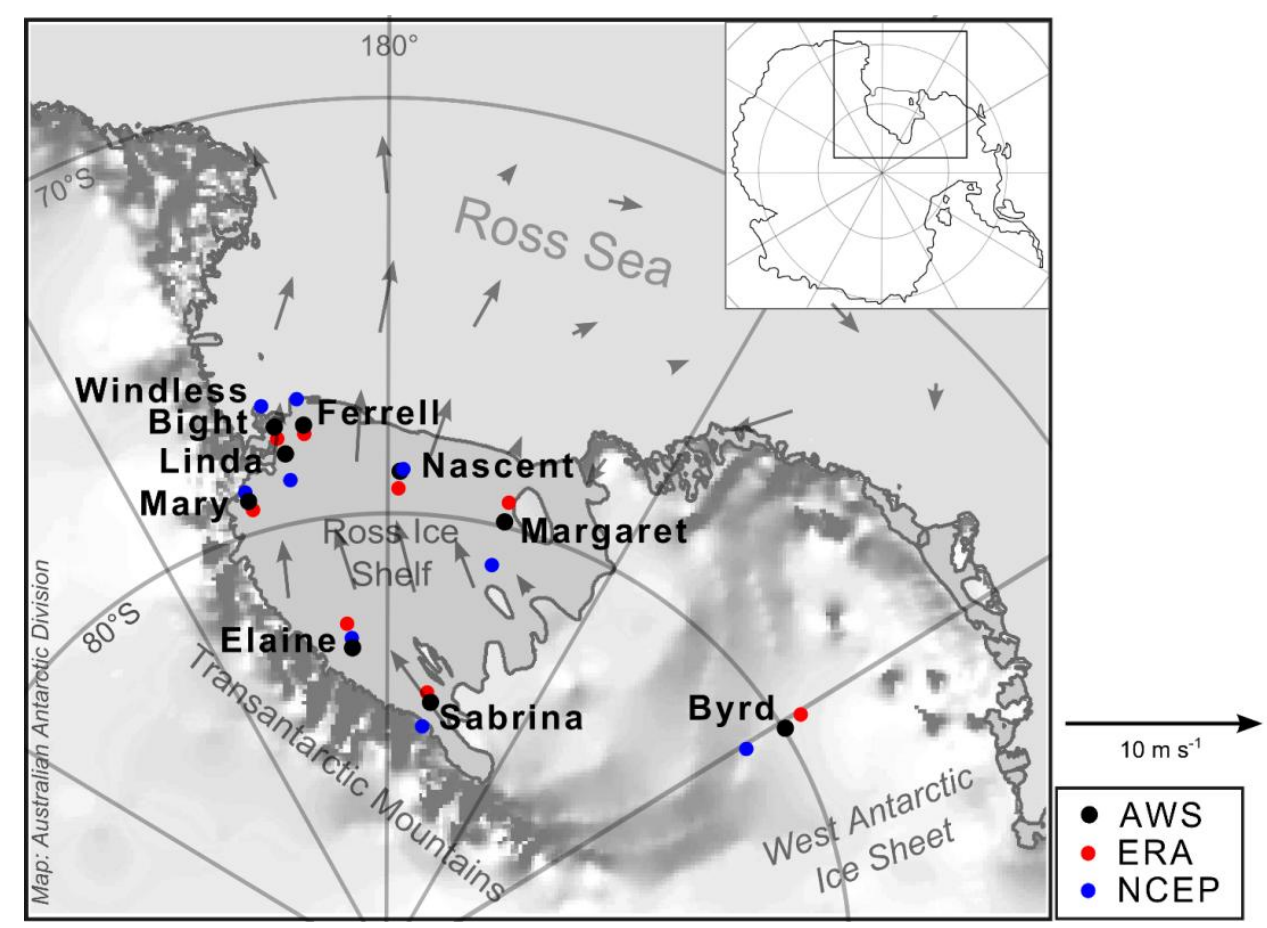

Figure 4.1 Locations of the automatic weather stations (AWS) used in this study and corresponding gridpoint locations for ERA-Interim (red) and NCEP-2 (blue) reanalyses. Wind vectors show the climatological surface wind regime ( $850 \mathrm{hPa}$ ) over the RIS and Ross Sea (from ERA-Interim monthly data averaged over 2008-2012).

Knowledge of the surface wind regime of the RIS is important to help interpret the ADG accumulation measurements, because wind redistribution can be a significant component of snow accumulation (Bromwich, 1988). The RIS is a topographically flat ice shelf bordered to the south and west by the Transantarctic Mountains (TAM), which rise to over 4,000 meters (m), and to the east by the Siple Coast which rises gradually to the WAIS at $\sim 2,000 \mathrm{~m}$ elevation. Katabatic winds, which flow from the ice sheets through the outlet valleys in the TAM and Siple Coast, and barrier winds, which are the result of cold, stable air forced along the TAM, are common features of the surface wind field of the RIS (King and Turner, 1997; Parish et al., 2006). The surface wind regime is also influenced by synoptic scale and 
mesoscale cyclones, which enhance and provide forcing for katabatic and barrier wind regimes (King and Turner, 1997).

Table 4.1 AWS locations, elevations, dates and lengths of ADG records, and distances to nearest ERA-Interim and NCEP-2 gridpoints.

\begin{tabular}{cccccc}
\hline Station & Location & $\begin{array}{c}\text { Elev. } \\
(\mathbf{m})\end{array}$ & $\begin{array}{c}\text { Dates of ADG data \& Length } \\
\text { of Record (yrs) }\end{array}$ & $\begin{array}{c}\text { Distance to } \\
\text { ERA/NCEP } \\
(\mathbf{k m})\end{array}$ \\
\hline Byrd & $80.007 \mathrm{~S}, 119.404 \mathrm{~W}$ & 1530 & Nov 2011-Aug 2012 & 0.8 & $58 / 105$ \\
Sabrina & $84.247 \mathrm{~S}, 170.068 \mathrm{~W}$ & 88 & Jan 2010-Aug 2012 & 3.5 & $29 / 57$ \\
Elaine & $83.094 \mathrm{~S}, 174.285 \mathrm{E}$ & 58 & Jan 2010-Aug 2012 & 2.6 & $66 / 27$ \\
Margaret & $80.000 \mathrm{~S}, 165.000 \mathrm{~W}$ & 67 & Nov 2008-Aug 2012 & 3.8 & $56 / 105$ \\
Nascent & $78.129 \mathrm{~S}, 178.498 \mathrm{~W}$ & 30 & Jan 2009-Apr 2011 & 2.3 & $44 / 10$ \\
Mary & $79.305 \mathrm{~S}, 162.985 \mathrm{E}$ & 58 & Jan 2008-Dec 2011 & 3.8 & $24 / 29$ \\
Linda & $78.426 \mathrm{~S}, 168.418 \mathrm{E}$ & 42 & Nov 2011-Aug 2012 & 0.8 & $50 / 68$ \\
Ferrell & $77.833 \mathrm{~S}, 170.819 \mathrm{E}$ & 45 & Jan 2009-Dec 2010 & 2.0 & $19 / 77$ \\
Windless Bight & $77.725 \mathrm{~S}, 167.687 \mathrm{E}$ & 40 & Jan 2008-Aug 2012 & 4.6 & $31 / 68$ \\
\hline
\end{tabular}

Figure 4.1 shows the climatological near-surface $(850 \mathrm{hPa})$ winds on the Ross Ice Shelf (from the ERA-Interim reanalysis data), which illustrates the varying wind conditions experienced at different stations. Most of the AWS are located in katabatic outflow paths (Mary, Linda, Elaine, Ferrell, Nascent, and Byrd) and barrier wind regimes (Sabrina), and as a result these sites experience strong winds more often than the other sites (Braaten, 1997; Parish et al., 2006; Knuth et al., 2010; Nigro et al., 2011). We expect the snow accumulation at these sites may be more affected by wind redistribution than other sites such as Margaret, which is located on the eastern side of the RIS near Roosevelt Island. The Windless Bight site, located near Ross Island on the northwestern edge of the RIS, is also less affected by strong wind regimes, but is known to experience high accumulation compared to other sites due to its location on the windward side of Ross Island (Monaghan et al., 2005).

Wind redistribution of snow is a significant and on-going challenge for studying precipitation events in Antarctica because the process is complex and dependent on many additional factors such as snow age, air temperature, snow moisture, local topography (down to meter-scale sastrugi), and snow grain size ( $\mathrm{Li}$ and Pomeroy, 1997). Increases in measured snow accumulation at a site can occur due to either precipitation, or blowing snow, or both, as precipitation often occurs in conjunction with high wind speeds. Increases in accumulation due to clear-sky precipitation and hoar frost are not considered significant for this region (Bromwich, 1988). Decreases in accumulation due to ablation, compaction, and 
sublimation are significant contributers to net accumulation but can be largely ignored in this study as the event-based analysis only considers positive changes in accumulation. The densification of the snowpack that occurs on the timescale of an event ( $<100 \mathrm{hrs})$ is less than $1 \mathrm{~mm}$ (Arthern et al., 2010) and can thus be ignored for this study. However, the densification of snow deposited during an event due to wind can significantly increase surface snow densities (Pomeroy and Brun, 2001) and this is considered further in the analysis.

As wind is the primary factor affecting the magnitude of measured accumulation (both positively and negatively), previous studies can help provide some estimate of the frequency of high winds occurring during accumulation events on the RIS and their effects on measured accumulation (Braaten 1997, 2000; Knuth et al., 2010). Based on wind speed measurements for several stations on the RIS, Knuth et al. (2010) showed that most (72\%) measured large accumulation events (> $1 \mathrm{~cm}$ per 30 minutes) were associated with blowing or drifting snow which may or may not have been concurrent with precipitation. In another study on the RIS, Braaten (1997) showed that while most ADG measured accumulation events were associated with human-observed precipitation events (using a much smaller event size threshold of 1.3 $\mathrm{mm})$, less than half of the observed events (38\%) resulted in measurable accumulation by the instrument.

Here we describe a methodology for identifying accumulation events within the ADG records, which allows these measurements to be used to compare with reanalyses precipitation. By utilizing long records from a large number of stations we can construct a statistical comparison, which still acknowledges the imperfections in the observations. This approach allows for a straightforward validation of the timing and duration of individual events in the reanalyses datasets. Comparison of the sizes of these events requires conversion of a snow height change to a mass (water equivalency) and ideally requires a measurement of snow density at each site and event. Since this information is not available we consider a range of snow densities that include the full range of freshly deposited snow $\left(70-120 \mathrm{~kg} \mathrm{~m}^{-3}\right.$ for temperatures $<+1{ }^{\circ} \mathrm{C}$ ) and wind-redistributed snow (from $250 \mathrm{~kg} \mathrm{~m}^{-3}$ and up) (Pomeroy and Brun, 2001). We use an average surface (the top $1-4 \mathrm{~m}$ ) snowpack density of $350 \mathrm{~kg} \mathrm{~m}^{-3}$ to compare the multi-year accumulation records (Kojima, 1964). 


\subsection{Data processing}

\subsubsection{ADG data}

Snow accumulation is measured with a Campbell Scientific SR50 acoustic depth gauge (ADG) which determines the distance to the snow surface using reflected sonic pulses. The SR50 has a resolution of 0.0001 meter $(\mathrm{m})$ and accuracy of $0.01 \mathrm{~m}$ or $0.04 \%$ of sensor height (whichever is larger). The instrument measures the distance to snow surface from the speed of reflected sonic pulses and spurious measurements can occur due to drifting and blowing snow reflecting the acoustic signal, high winds (> $18 \mathrm{~m} \mathrm{~s}^{-1}$ ) (Brazenec and Doesken, 2005), low temperatures $\left(<-35\right.$ to $\left.-40^{\circ} \mathrm{C}\right)$ (Fountain et al., 2010), and rime or ice on the sensor. The temperature-corrected ADG data were retrieved from the University of Wisconsin, AMRC ftp site (ftp://amrc.ssec.wisc.edu). Further information and specifications on the AWS instrumentation and network is described in Lazzara et al. (2012) and on the University of Wisconsin, AMRC site (http://amrc.ssec.wisc.edu).

Snow accumulation records for each station were produced by removing null measurements and measurements that don't represent physical accumulation (i.e. spurious data points outside of the initial and final accumulation values). The ADG data were recorded at a 10 minute sampling rate except for Nascent which is at 20 minute resolution. The ADG sensor heights are periodically adjusted to keep the sensors $\sim 1$ to $2 \mathrm{~m}$ above the snow surface and these height adjustments were applied based on the maintenance logs.

The datasets all contain some high frequency noise which was minimized using the same methodology as Fountain et al. (2010), which removes data outside of one standard deviation of a running daily value. Since snow accumulation due to precipitation is stepped and episodic, the removal of data points outside of the daily standard deviation removes some of the high-frequency noise while retaining the amplitude of an accumulation event, though the timing can be shifted by up to one day. The ADG data were then averaged to a three-hourly resolution in order to compare with the reanalyses datasets.

The ADG records are continuous with no large gaps except for Mary and Windless Bight which have gaps during the winter months of 2011 (June-October). Removal of spurious data, high frequency noise, and gaps in the raw data account for between 1.5 to $6.8 \%$ of the data in all stations except for Mary and Windless Bight which are missing $17.1 \%$ and $22.5 \%$ of their data respectively. 


\subsubsection{Reanalyses data}

Reanalyses assimilate in-situ meteorological data and satellite data into a global circulation model to produce comprehensive global datasets of meteorological parameters at regular vertical and horizontal resolutions throughout the atmosphere. This study investigates the precipitation products from the NCEP-2 (NCEP) and the ERA-Interim (ERA) reanalyses datasets (Kalnay et al., 1996; Dee et al., 2011). The NCEP reanalysis provides parameters at $2.5^{\circ}$ latitude/longitude resolution through 30 June, 2012; ERA provides parameters at $1.5^{\circ}$ latitude/longitude resolution through 31 August, 2012 (though the underlying models for both are run at higher resolution).

Though both reanalyses datasets assimilate meteorological observations from the AWS network, the snow accumulation data is not used. Precipitation products from both reanalyses rely entirely on the model's representation of the hydrological processes as they are not directly constrained by observational data (Dee et al., 2011). The ERA forecast model runs at both higher spatial and temporal resolution than the NCEP model (three-hourly intervals versus six-hourly intervals and $\sim 80 \mathrm{~km}$ versus $\sim 210 \mathrm{~km}$ horizontal resolution). Thus, we expect the ERA precipitation model to perform better in regards to reproducing precipitation on smaller spatial and temporal scales. In addition, ERA reanalysis also incorporates more satellite observations (including GPS radio occultation measurements) and uses a more sophisticated variational assimilation system (4D-Var versus 3D-Var). Differences between ERA and other reanalyses precipitation products since 2006 have been attributed to the assimilation of the new satellite observations (Bromwich et al., 2011) and the more sophisticated variational assimilation system in ERA has also been shown to result in improved moisture analysis (Andersson et al., 2007; Simmons et al., 2010).

The NCEP precipitation is given as an instantaneous precipitation rate, $\mathrm{kg} \mathrm{m}^{-2} \mathrm{~s}^{-1}$ water equivalent (w.e.), averaged over each six hour forecast period which we convert to $\mathrm{m}$ w.e. For ERA, total precipitation is derived from the three-hourly forecast fields and given in $\mathrm{m}$ w.e. Precipitation data from the reanalyses grid points nearest to each AWS location are used for the analysis. Distances from the stations are listed in Table 4.1 and shown in Figure 4.1.

Most of the gridpoints are relatively close to their respective AWS, and all are less than 100 kilometers from the AWS. Stations located in the region that has the highest topographic gradient (near the TAM) are closest to their respective gridpoints, which helps minimize differences due to orographically induced precipitation. Smaller topographic features such as Ross Island and Roosevelt Island are not resolved topographically in either of the reanalyses, and thus, localized precipitation due to these features is not expected to be 
reproduced. For large-scale, synoptically-driven precipitation events, the distances between gridpoints and AWS will not affect the timing or amount of precipitation considerably.

\subsubsection{Determination of coincident events}

Individual accumulation events are identified from the daily accumulation values for each dataset. As with Fountain et al. (2010), we found that the ADG measurements were able to resolve relative changes in snow height as small as 5 millimeters $(\mathrm{mm})$ snow day ${ }^{-1}$, and set that as the event size cutoff for the ADG datasets. For the reanalyses data cutoff value, we use $0.5 \mathrm{~mm}$ w.e. day ${ }^{-1}$, which is equivalent to the ADG cutoff using a mid-range fresh snow density of $100 \mathrm{~kg} \mathrm{~m}^{-3}$. For each dataset, a daily accumulation/precipitation rate is calculated at each time point (three-hourly for ADG and ERA; six-hourly for NCEP) with the day defined as the 12 hours before and 12 hours after the time point. An event is defined for each dataset as the period of time that the accumulation/precipitation rate remains above the cutoff value (ADG: $5 \mathrm{~mm}$ snow day ${ }^{-1}$; reanalyses: $0.5 \mathrm{~mm}$ w.e. day ${ }^{-1}$ ), and only events lasting longer than 6 hours are considered. Coincident events are then determined by identifying the reanalyses events which overlap in time with or are within 24 hours of an ADG event.

\subsection{Results}

Figure 4.2 shows each station's ADG accumulation record along with the ERA and NCEP precipitation. Snow accumulation and precipitation events are seen as stepped increases in the plots. Decreases in accumulation seen in the ADG records indicate the effects of ablation, compaction, or sublimation and are not accounted for in the reanalyses plots, which show only positive changes due to precipitation. Though negative accumulation processes are very important for surface mass balance, they are not considered in this study as we are simply attempting to identify precipitation events. For an approximate comparison of the magnitudes between the datasets (snow accumulation and precipitation), a snow density of $350 \mathrm{~kg} \mathrm{~m}^{-3}$ is used to equate each station's y-axes in Figure 4.2. The reanalyses precipitation shows that ERA produces much more accumulation than NCEP ( two to four times as much over the varying time periods) with the exception of Ferrell, Margaret, and Nascent which have similar total precipitation amounts for ERA and NCEP over these time periods. 

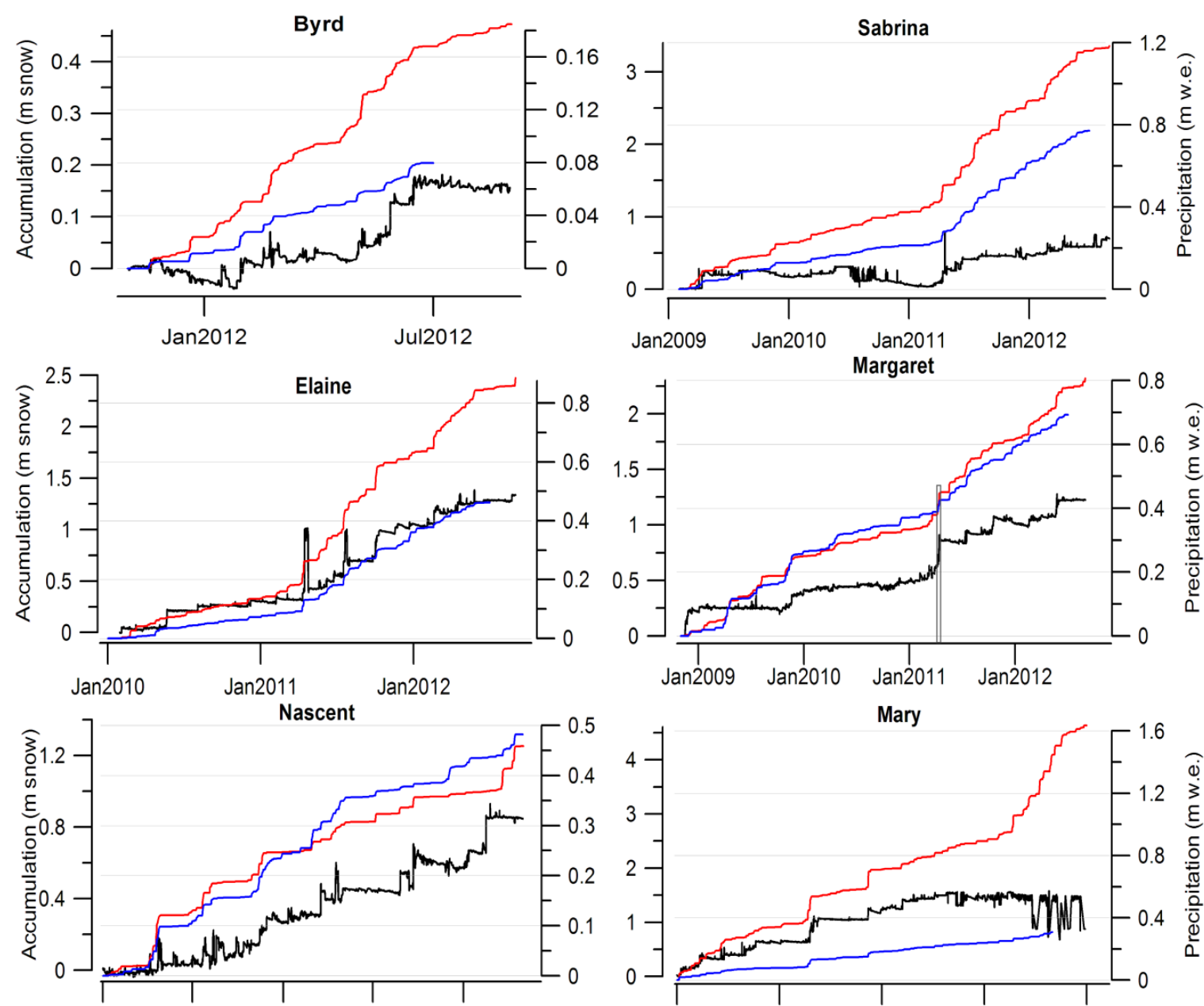

Jan2009 Jul2009 Jan2010 Jul2010 Jan2011

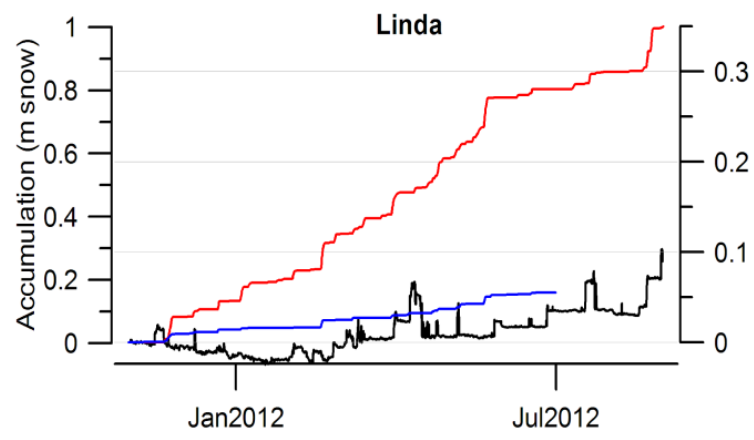

Jan2008 Jan2009 Jan2010 Jan2011 Jan2012
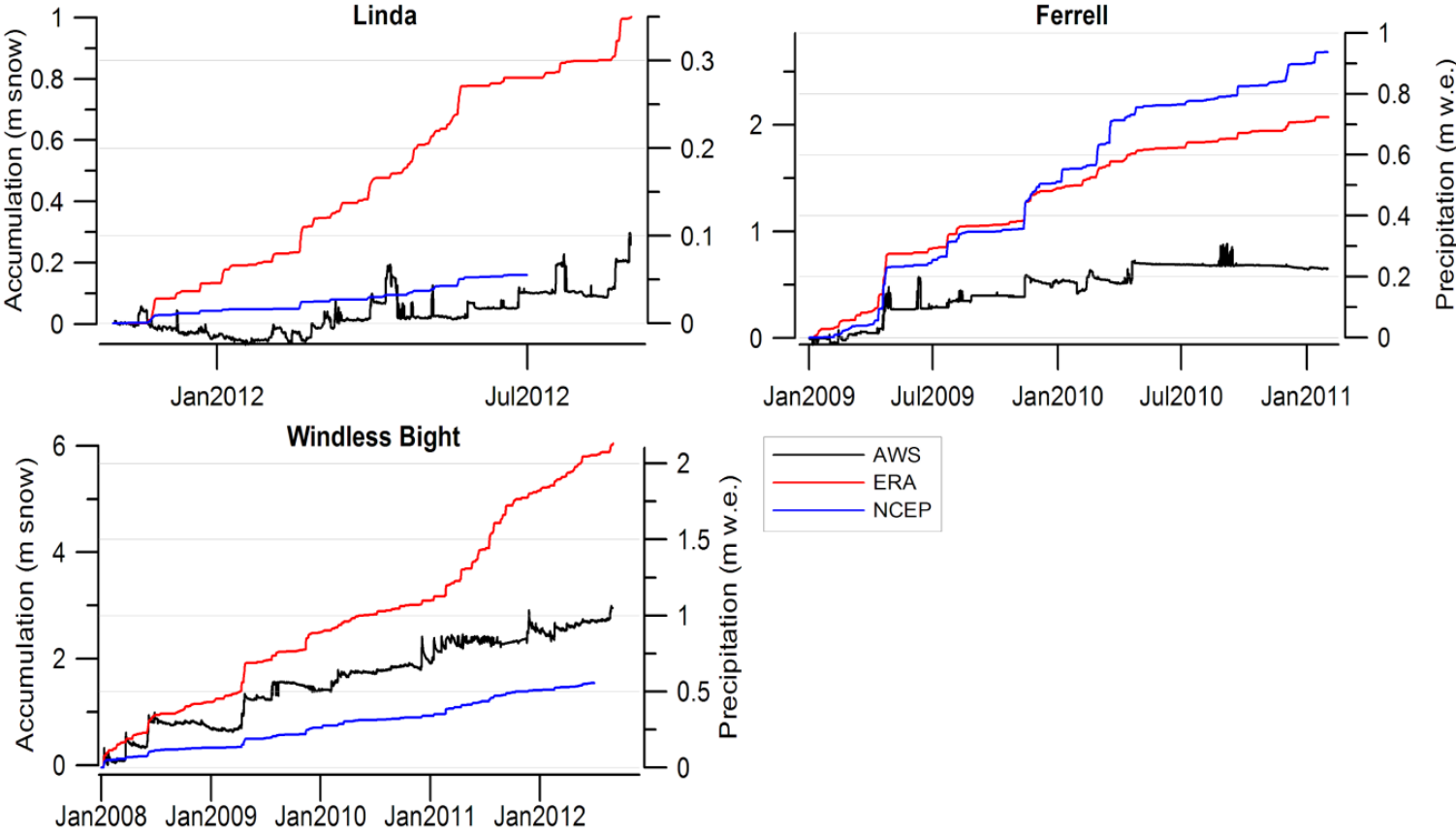

Figure 4.2. Total accumulation and precipitation over time for each station (note different time periods). ADG accumulation is in $m$ snow (left axes) and ERA and NCEP reanalyses is in $m$ w.e. (right axes), with axes offset by 35\% (approximate density of surface snow on RIS). A close up of the time period outlined by the grey box in the Margaret plot is shown in Figure 4.4. 
As precipitation in the reanalyses forecast models are largely driven by the meridional (moisture-bearing) circulation and amount of water available (Kalnay et al., 1996; Dee et al., 2011), we look at the differences between ERA and NCEP for these parameters in order to understand why the precipitation amounts differ so much. Figures $4.3 \mathrm{a}$ and $4.3 \mathrm{~b}$ show the difference between ERA and NCEP (ERA minus NCEP) total precipitable water and nearsurface meridional winds ( $850 \mathrm{hPa}$ ) over the RIS averaged from 2008-2012. Interestingly, Figure 4.3a shows that the ERA reanalysis has less moisture over much of the RIS and Ross Sea, but more along the TAM, which is consistent with the larger amounts of precipitation produced by ERA for stations along the TAM, while the stations further from the TAM (Ferrell, Margaret, and Nascent) produce similar amounts to NCEP. Figure 4.3b shows that ERA has a weaker southerly component (more positive v-wind) for air coming from the Ross Sea (moisture-bearing) onto the RIS, but a stronger southerly component along the TAM. The weaker cyclonic circulation over the RIS in ERA is thus able to explain the differences in total precipitable water. The figures show that the largest differences between ERA and NCEP for both water content and meridional circulation are along the TAM. This is possibly due to the higher spatial resolution of the ERA model being able to more accurately reproduce the effects of the barrier formed by the TAM.

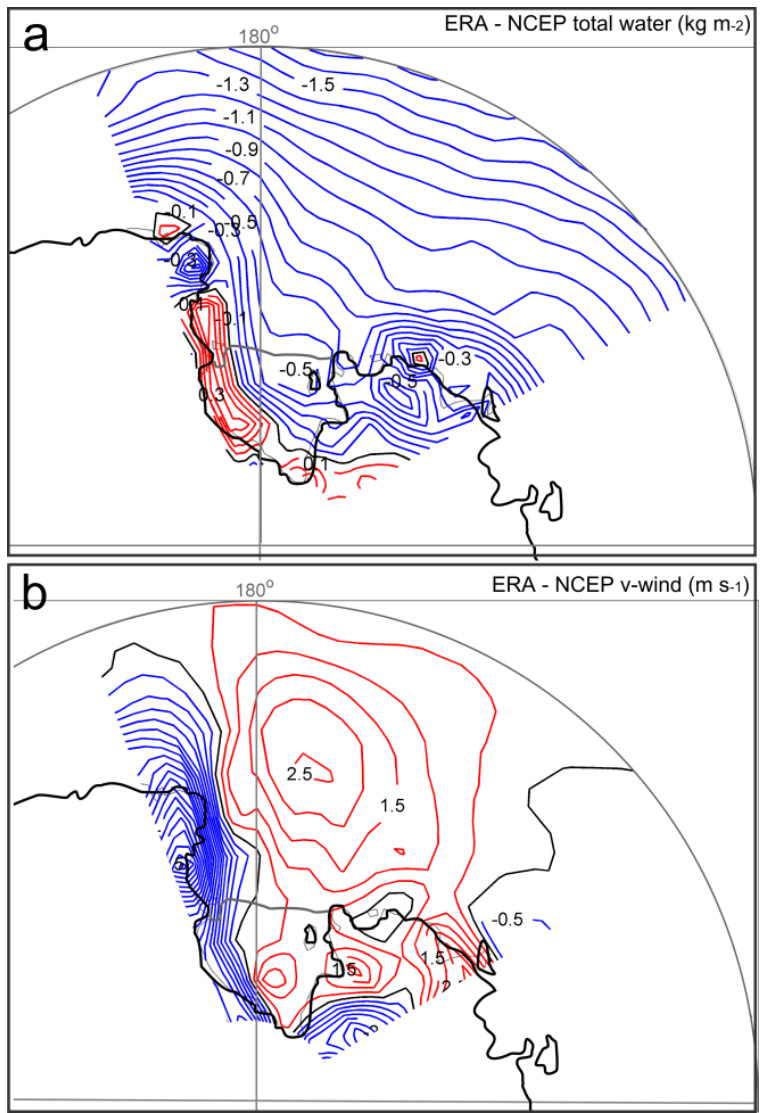

Figure 4.3 Differences between ERA and $N C E P$ reanalyses (ERA minus NCEP) from 2008-2012 over the Ross Sea and RIS region $\left(60^{\circ} \mathrm{S}\right.$ to $85^{\circ} \mathrm{S}, 160^{\circ} \mathrm{E}$ to $\left.240^{\circ} \mathrm{E}\right)$ for a) total precipitable water (total column water) $\left(\mathrm{kg} \mathrm{m}^{-2}\right)$ and $\left.\boldsymbol{b}\right) 850 \mathrm{hPa}$ meridional winds $\left(\mathrm{m} \mathrm{s}^{-1}\right)$. Red contours are positive (ERA larger than NCEP), blue contours are negative (NCEP larger than ERA), grey line is zero. Total precipitable water contours are $0.1 \mathrm{~kg} \mathrm{~m}^{-2}$, wind contours are $0.5 \mathrm{~m} \mathrm{~s}^{-1}$. 
Figure 4.4 shows a close-up of six days in the ADG, ERA, and NCEP records for Margaret station (corresponding to the grey box in Figure 4.2). The figure illustrates the characteristics typical of most of the coincident events identified in all of the stations. The highly stepped nature of ADG accumulation events is clear, as is the more broad nature of reanalyses events. The duration of events are different for each dataset but the events overlap in time (or are within 24 hours as discussed in Section 4.3.3) as illustrated in Figure 4.4.

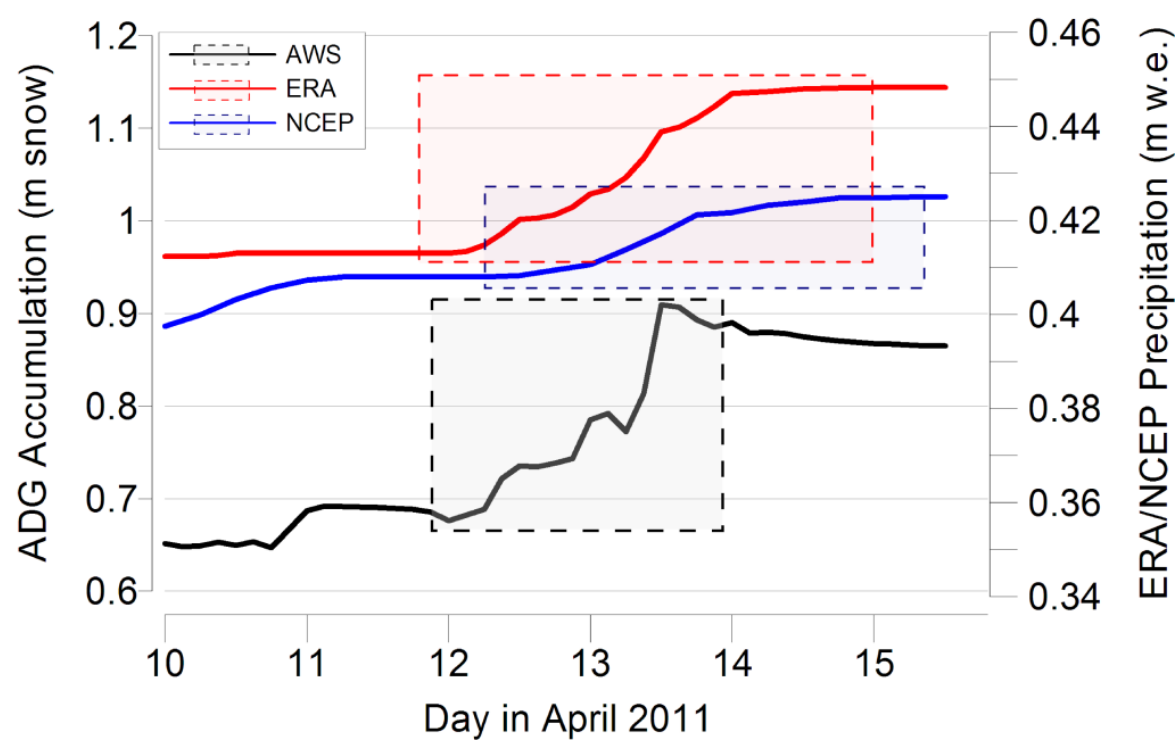

Figure 4.4 Zoomed-in section of the Margaret accumulation plot (corresponding to the grey box in Margaret in Figure 4.2) showing the characteristics typical of a coincident event. $A D G$ snow accumulation is on the left $y$-axis and ERA/NCEP precipitation is on the right $y$ axis as in Figure 4.2 (note axes are different scales for clarity). The dashed boxes indicate the different durations of the coincident event (defined as $>5 \mathrm{~mm}$ snow day ${ }^{-1}$ and $>0.5 \mathrm{~mm}$ w.e. day $^{-1}$ ) for each dataset.

The greater duration of reanalyses events as compared to the ADG events is seen throughout the datasets. The mean duration of coincident events for all ADG events is 27 hours, while the mean durations for ERA and NCEP are 65 and 61 hours respectively. While this may indicate that the cutoff value for the reanalyses data is too low, increasing the cutoff value to a much higher value $\left(2 \mathrm{~mm}\right.$ w.e. day $\left.^{-1}\right)$ decreases the average duration of events to 48 and $46 \mathrm{hrs}$ for ERA and NCEP respectively, which is still much longer than the ADG events and decreases the number of events by $\sim 60 \%$ for both ERA and NCEP. That the reanalyses-derived events are much longer in duration than the ADG-derived events indicates that this is likely a result of the parameterization of synoptically-driven precipitation in reanalyses forecast models and is worth further investigation. 
Table 4.2 shows the number of accumulation events $\left(>5 \mathrm{~mm} \mathrm{day}^{-1}\right.$ for ADG and $>0.5$ mm day ${ }^{-1}$ for reanalyses) identified for each of the ADG, ERA, and NCEP datasets as well as the number of coincident events for each pairing (ADG-ERA and ADG-NCEP). The probability that the number of coincident events in each timeseries is random is determined from the hypergeometric probability density distribution and is much less than 0.01 for all pairings. For all stations except Nascent, ERA produces a much larger number of precipitation events, and except for Sabrina, a higher percentage of these events are coincident with ADG events.

Table 4.2 The number of events for ADG, ERA-Interim, and NCEP-2 datasets and number of coincident events.

\begin{tabular}{rccc|ccc} 
& \multicolumn{7}{c}{$\begin{array}{c}\text { Number of Events } \\
\text { ADG* }\end{array}$} & ERA & ADG-ERA & ADG** & NCEP & ADG-NCEP \\
\hline Byrd & 51 & 50 & 26 & 42 & 22 & 11 \\
Sabrina & 182 & 173 & 73 & 170 & 127 & 68 \\
Elaine & 146 & 98 & 59 & 137 & 84 & 37 \\
Margaret & 237 & 143 & 72 & 235 & 118 & 58 \\
Nascent & 200 & 65 & 44 & 200 & 80 & 40 \\
Mary & 305 & 154 & 97 & 305 & 82 & 42 \\
Linda & 59 & 42 & 27 & 49 & 16 & 8 \\
Ferrell & 94 & 81 & 33 & 94 & 55 & 23 \\
Windless Bight & 369 & 209 & 142 & 353 & 112 & 66 \\
\hline & $*$ to 31-Aug-2012 & & $* *$ to 30-Jun-2012 &
\end{tabular}

Table 4.3 shows the percentage of coincident events captured by reanalyses datasets and the percentage of precipitation derived from these coincident events. ERA events coincide with between $22-51 \%$ of ADG events and NCEP events coincide with 14-40\% of ADG events. On average, ERA captures a higher percentage of ADG events than NCEP (average $37 \%$ versus $23 \%$ ). Because of the known considerable influence of wind-redistributed snow on snow accumulation discussed in Section 4.2, many of the events identified in the ADG data may actually be due to blowing/drifting snow, where no precipitation occurred, and as such we would not necessarily expect these percentages to be very high. Identifying and quantifying these events is very difficult and is a persistent challenge in snow accumulation studies. The coincident events do correspond to sizeable amounts of the total reanalysis precipitation (between $63-86 \%$ and $48-79 \%$ for ERA and NCEP respectively) with ERA producing an average of $8.2 \%$ (significant at the $93 \%$ confidence level) more precipitation than NCEP. That ERA captures on average $14 \%$ more events, but only $8.2 \%$ more 
precipitation indicates that the "extra" events ERA is capturing are smaller precipitation events.

Table 4.3 Percentages of $A D G$ events captured by reanalysis datasets, the amount of precipitation captured by those events (as a percentage of the total reanalysis precipitation), and percentage of reanalysis events that are not seen in ADG data ("false" events) for each reanalysis dataset.

ERA

NCEP

\begin{tabular}{cccc|ccc}
\cline { 2 - 6 } & $\begin{array}{c}\text { ADG } \\
\text { captured } \\
(\boldsymbol{\%})\end{array}$ & $\begin{array}{c}\text { Precipitation } \\
(\boldsymbol{\%})\end{array}$ & $\begin{array}{c}\text { "False" } \\
\text { events } \\
(\boldsymbol{\%})\end{array}$ & $\begin{array}{c}\text { ADG } \\
\text { captured } \\
(\boldsymbol{\%})\end{array}$ & $\begin{array}{c}\text { Precipitation } \\
(\boldsymbol{\%})\end{array}$ & $\begin{array}{c}\text { "False" } \\
\text { events } \\
(\boldsymbol{\%})\end{array}$ \\
\hline Byrd & 51.0 & 70.8 & 48.0 & 26.2 & 67.7 & 50.0 \\
Sabrina & 40.1 & 63.0 & 57.8 & 40.0 & 74.5 & 46.5 \\
Elaine & 40.4 & 81.5 & 39.8 & 27.0 & 72.0 & 56.0 \\
Margaret & 30.4 & 67.3 & 49.7 & 24.7 & 59.7 & 50.8 \\
Nascent & 22.0 & 81.9 & 32.3 & 20.0 & 74.6 & 50.0 \\
Mary & 31.8 & 78.4 & 37.0 & 13.8 & 62.4 & 48.8 \\
Linda & 45.8 & 71.0 & 35.7 & 16.3 & 47.7 & 50.0 \\
Ferrell & 35.1 & 71.6 & 59.3 & 24.5 & 59.9 & 58.2 \\
Windless Bight & 38.5 & 85.8 & 32.1 & 18.7 & 79.0 & 41.1 \\
\hline
\end{tabular}

Table 4.3 also shows the percentage of reanalyses events that aren't seen in the ADG data ("false" events). The NCEP reanalyses dataset has more false events than ERA (average 50\% and $44 \%$ respectively). These events would include cases where snow accumulation is less than the ADG threshold of $5 \mathrm{~mm}^{-1 a y}{ }^{-1}$ (either due to small amounts of precipitation or wind limiting accumulation) or the event does not fall within the 48 -hour window used to define a coincident event. Distinguishing between these circumstances are difficult, but in a study of one ADG record on the RIS, Braaten (1997) found that $38 \%$ of meteorologist-observed precipitation events resulted in no measured accumulation in the ADG record suggesting that identifying whether the additional reanalyses events are in fact real is beyond the capability of the ADG dataset.

To assess the effect of changing the reanalysis event size cutoff on the analysis, we compare the number of coincident events and percentage of precipitation captured by coincident events using different reanalyses cutoff values of $0.35 \mathrm{~mm} \mathrm{day}^{-1}, 0.5 \mathrm{~mm}$ day $^{-1}, 1$ $\mathrm{mm} \mathrm{day}^{-1}$ and $2 \mathrm{~mm} \mathrm{day}^{-1}$ (the values in Tables 4.2 and 4.3 are calculated using $0.5 \mathrm{~mm}$ day ${ }^{-}$ $\left.{ }^{1}\right)$. The two smallest values $\left(0.35\right.$ and $\left.0.5 \mathrm{~mm} \mathrm{day}^{-1}\right)$ are equivalent to the ADG measurement cutoff value $\left(5 \mathrm{~mm} \mathrm{day}^{-1}\right)$ using freshly precipitated snow densities (7\% and $\left.10 \%\right)$. Not surprisingly, increasing the reanalyses cutoff decreases the number of coincident events and amount of precipitation accounted for. Over this range of cutoff values the average 
percentage of coincident events captured for all stations decreases from $40 \%$ to $24 \%$ for ERA and from $27 \%$ to $13 \%$ for NCEP. The average percentage of precipitation accounted for decreases from $77 \%$ to $61 \%$ for ERA and from $70 \%$ to $49 \%$ for NCEP. For the NCEP dataset, though the decrease in number of coincident events is similar to ERA (16\% versus $14 \%)$, a larger change in the amount of precipitation (16\% vs $21 \%)$ is seen. This suggests that the NCEP dataset produces more precipitation at smaller amounts making it more sensitive to the lower cutoff values. The percentage of "false" events also changes much more in the NCEP dataset, decreasing from $51 \%$ to $39 \%$ as the cutoff increases (from 0.35 to $2 \mathrm{~mm}$ day ${ }^{-}$ ${ }^{1}$ ), while ERA "false" events change only slightly from $44 \%$ to $40 \%$.

Further comparison of the coincident events identified between ADG and reanalyses data, Figure 4.5 plots the sizes of coincident events for each station to show the relationships between the ADG and reanalyses events. The sizes are calculated as the total amount of precipitation/accumulation during each coincident event. Although we can not directly compare the sizes (snow versus water equivalent), a range of snow densities for freshly fallen snow $\left(70 \mathrm{~kg} \mathrm{~m}^{-3}\right.$ to $\left.120 \mathrm{~kg} \mathrm{~m}^{-3}\right)$ and wind-redistributed snow $\left(250 \mathrm{~kg} \mathrm{~m}^{-3}\right)$ is shown as dashed lines in Figure 4.5. Least-squares linear regressions and correlations ( $r$ values) are shown for the relationships between ADG and reanalyses event sizes that are significant at $90 \%$ level. Regression lines which lie near the range of fresh snow densities, with zero-intercept and higher correlation coefficients indicate better relationships between reanalyses precipitation and ADG data.

Five of the nine stations have significant relationships with both ERA and NCEP (Elaine, Margaret, Mary, Ferrell, and Windless Bight) and one has a significant relationship with NCEP (Byrd), indicating that many precipitation events are being accurately represented by both reanalyses datasets. The $r$ values vary between 0.26 to 0.69 with neither reanalyses product showing higher correlations over all stations. The regressions show that ERA events are generally larger than NCEP events. The smaller values seen in NCEP would be consistent with previous studies showing that NCEP underestimates precipitation in Antarctica (Cullather et al., 1996; Zou et al., 2004). However the NCEP regressions are not consistent enough to draw any conclusions about biases and none are significantly lower than expected values. The one regression that is significantly higher than expected values (Ferrell) is dominated by several events. 

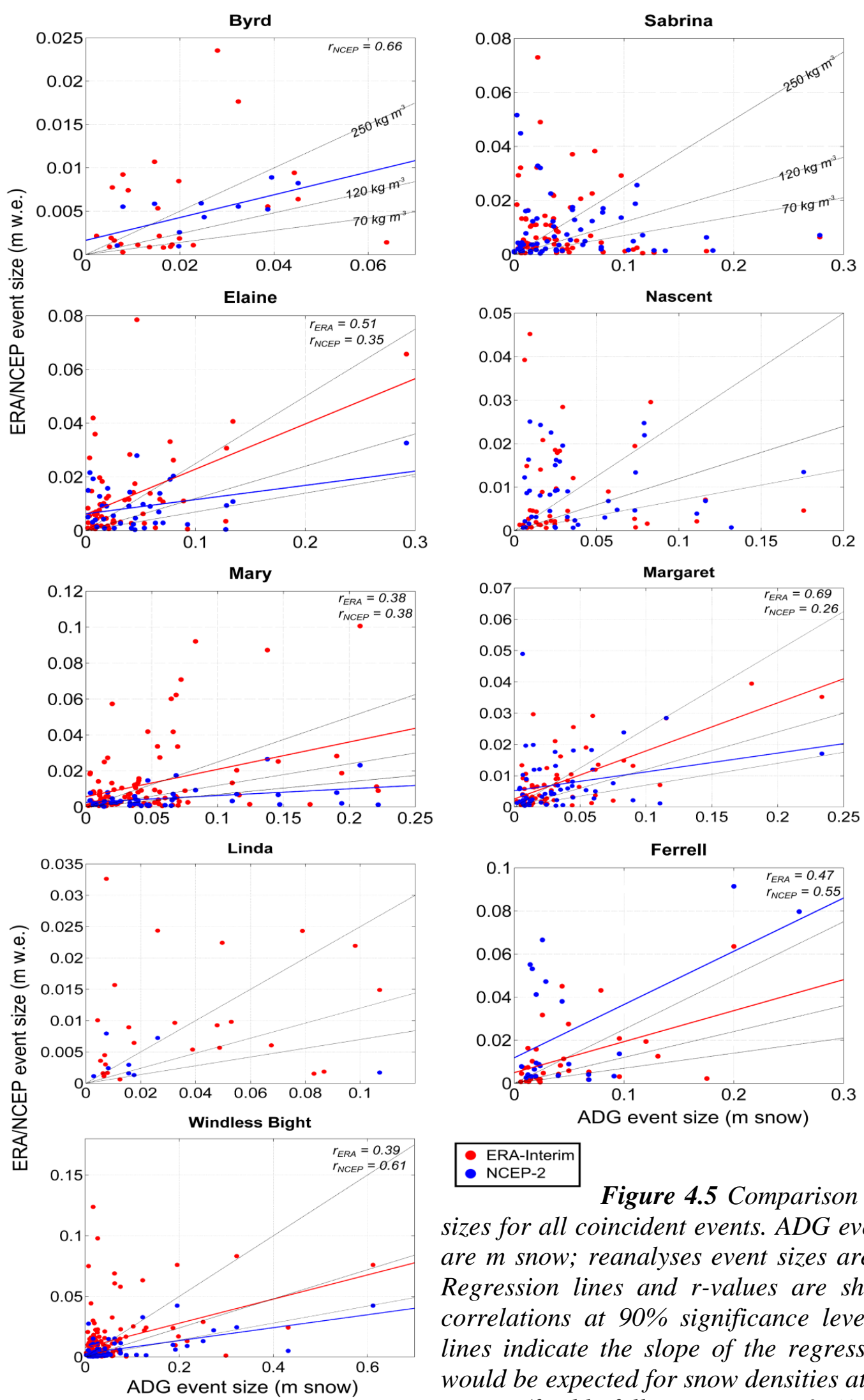

Figure 4.5 Comparison of event sizes for all coincident events. ADG event sizes are $m$ snow; reanalyses event sizes are $m$ w.e. Regression lines and r-values are shown for correlations at $90 \%$ significance level. Black lines indicate the slope of the regression that would be expected for snow densities at various ranges (freshly fallen snow, $\rho=70-120 \mathrm{~kg} \mathrm{~m}^{-3}$; wind-redistributed snow, $\rho=250 \mathrm{~kg} \mathrm{~m}^{-3}$ ). 
The complex effects of wind on ADG snow accumulation means that we cannot determine biases in reanalyses precipitation amounts. In Figure 4.5, events that are in the region above the freshly-fallen snow densities could have several causes: snow accumulation being limited by wind, higher snow densities due to wind-blown snow, or reanalysis overestimating event sizes; events that fall below the range could be either due to excess accumulation due to wind or reanalysis underestimating event sizes. At sites known to exhibit significant ablation such as Ferrell, Mary, Nascent, and Sabrina (Braaten, 1997; Knuth et al., 2010; Nigro et al., 2011), where we would expect a low-bias in the ADG data (i.e. ADG snow accumulation is often limited due to wind), these sites do show a significant number of events where reanalyses are much larger than ADG events (except for the NCEP events with Mary). At Windless Bight, which is a low-wind, high-accumulation site (Knuth et al., 2010) where we would expect a high-bias in the ADG (i.e. ADG snow accumulation is often enhanced by wind conditions), the ERA and NCEP regressions do reflect this (via regression slopes closer to fresh-snow values). However, the ERA data for this site still shows a significant number of events where ERA events are much larger than ADG events. Finally, Margaret, which is located in the least wind-affected region of the RIS (Parish et al., 2006), has the highest correlation and near-zero intercept for the ERA data, but interestingly has the lowest correlation for NCEP. Figure 4.6 illustrates the relationship between average nearsurface wind speed from 2008-2012 and the event-size correlation values from Figure 4.5 (including those that are not significant). The figure supports the notion that the sites located in windier locations tend have the lowest correlations between ADG-measured events and reanalysis events.

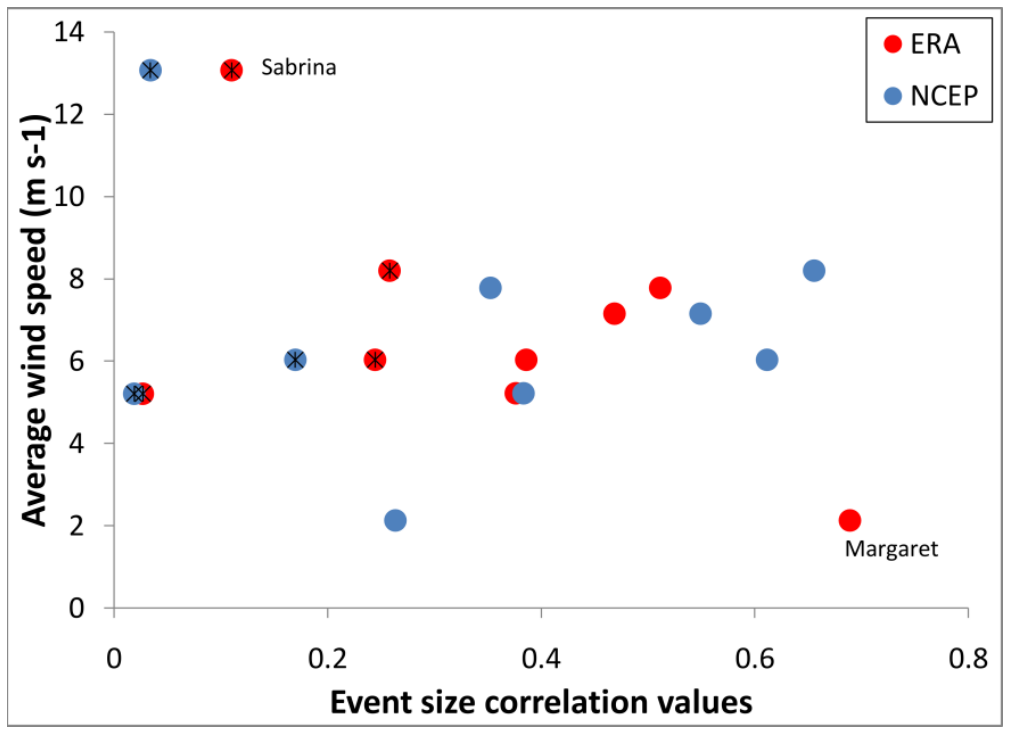

Figure 4.6 Relationship between near-surface wind speed and event size correlation values (from Figure 4.5), including those not significant at $>90 \%$ level (indicated with asterisk). Wind speed values are derived from ERA-Interim $850 \mathrm{hPa}$ monthly averages (750 hPa for Byrd), averaged over the period of this study (2008-2012). Stations with the highest wind speed (Sabrina) and lowest (Margaret) are labeled. 


\subsection{Conclusions}

This study develops an event-based analysis of ADG snow accumulation records from nine AWS located around the Ross Ice Shelf and compares the observations to precipitation from ERA-Interim and NCEP-2 reanalyses. This provides an assessment of the feasibility to use these measurements as validation for precipitation in reanalyses and other NWP models. The high temporal resolution ADG measurements provide a relatively dense network of multi-year accumulation records in a relatively homogeneous region of Antarctica and are shown to provide some insight into reanalyses precipitation on synoptic timescales for recent time periods (2008-2012). Analysis of the number of events in each dataset shows that for all locations, ERA has more matching events with the ADG measurements than NCEP, capturing an average $37 \%$ of ADG accumulation events versus $23 \%$ for NCEP. These coincident events correspond to an average $75 \%$ and $66 \%$ of the total reanalyses precipitation for ERA and NCEP respectively. Quantifying how many of the ADG events are precipitation versus blowing/drifting snow (and thus how many events the reanalyses are missing) is a difficult and on-going challenge in measuring precipitation. Previous estimates of the number of wind-affected accumulation events from ADG data (which may or may not be coincident with precipitation events) on the RIS are on the order of $70 \%$ (Knuth et al., 2010) suggesting that the reanalyses may actually be capturing most precipitation events. Overall this analysis suggests that the ERA data performs better than NCEP, capturing 14\% more events and $8.2 \%$ more precipitation.

Comparisons of the sizes of coincident events between ADG and reanalyses data show that there are significant correlations (at > 90\%) for several of the stations and these correlations are near the range of expected values providing further evidence that the reanalyses are reproducing actual precipitation events. The ERA data consistently produces more precipitation per event than the NCEP which is consistent with capturing more precipitation overall. Neither reanalyses dataset shows consistently higher correlations with the ADG event sizes, but using known biases of wind-limiting snow (Ferrell, Nascent, Mary, Sabrina) or wind-enhancing snow (Windless Bight) helps interpret some of the overall patterns of the event size correlations. ERA consistently shows correlations in the upper range of expected snow densities while NCEP less consistently shows correlations in the lower range of expected snow densities.

Determination of the biases in the reanalyses datasets (i.e. ERA overestimating or NCEP underestimating precipitation) is not possible due to the limitation of the ADG dataset. 
Further work to identify biases and make quantitative estimates would require extensive further analysis of site-specific wind conditions and snow density. In terms of providing snow accumulation measurements, the placement of most of the ADGs on the Ross Ice Shelf is not ideal since they are specifically located in katabatic and barrier wind regimes where snow accumulation is highly affected by winds. Despite this, the analysis shows important differences between the two datasets, and indicates that the ADG measurements could be used more extensively in the future to provide a valuable source of ground-based precipitation observations.

\section{Acknowledgements}

The authors appreciate the support of the University of Wisconsin-Madison Automatic Weather Station Program for the acoustic depth gauge AWS dataset, NSF grant number ANT-0944018. We also appreciate use of the NCEP Reanalysis 2 data provided by the NOAA/OAR/ESRL PSD, Boulder, Colorado and the use of ERA-Interim data provided by the European Centre for Medium-Range Forecasts. Dr Dean's contribution to this manuscript was funded by NIWA under the 'Climate Present and Past' project of the National Climate Centre's Climate Observations Programme (2012/13 SCI).

\subsection{References}

Andersson, E., Holm, E., Bauer, P., Bejaars, A., Kelly, G. A., McNally, A. P., Simmons, A. J., Thepaut, J. N., Tompkins, A. M.: Analysis and forecast impact of the main humidity observing systems. Quart. J. Roy. Met. Soc., 133, 1473-1485, 2007.

Arthern, R. J., Vaughan, D. G., Rankin, A. M., Mulvaney, R., Thomas, E. R.: In situ measurements of Antarctic snow compaction compared with predictions of models, J. Geophys. Res., 115, F03011, doi: 10.1029/2009JF001306, 2010.

Braaten, D.: A detailed assessment of snow accumulation in katabatic wind areas on the Ross Ice Shelf, Antarctica. J. Geophys. Res., 102, 30047-30058, 1997.

Braaten, D.: Direct measurements of episodic snow accumulation on the Antarctic polar plateau. J. Geophys. Res., 105, 10 119-10 128, 2000.

Brazenec, W. A. and Doesken N. J.: An evaluation of two ultrasonic snow depth sensors for potential use at automated surface weather observing sites, 13th Symposium on Meteorological Observations and Instrumentation, American Meteorological Society, Savannah, GA, 2005.

Bromwich, D. H.: Snowfall in high southern latitudes. Rev. Geophys., 26, 149-168, 1988. 
Bromwich, D. H., Guo, Z., Bai, L., and Chen, Q.: Modeled Antarctic Precipitation - Part I: Spatial and Temporal Variability, J. Clim., 17, 427-447, 2004.

Bromwich, D. H., Fogt, R. L., Hodges, K. I., and Walsh, J. E.: A tropospheric assessment of the ERA-40, NCEP, and JRA-25 global reanalyses in the polar regions, J. Geophys. Res., 112, D10111, doi:10.1029/2006JD007859, 2007.

Bromwich, D. H., Nicolas, J. P., and Monaghan, A. J.: An assessment of precipitation changes over Antarctica and the Southern Ocean since 1989 in contemporary global reanalyses, J. Climate, 24, 4189-4209, 2011.

Bromwich, D. H., Nicolas, J. P., Monaghan, A. J., Lazzara, M. A., Keller, L. M., Weidner, G. A., Wilson, A. B.: Central West Antarctica among the most rapidly warming regions on Earth, Nat. Geoscience, 6, 139-145, doi:10.1038/ngeo1671, 2012.

Cohen, L., Dean, S., and Renwick, J.: Synoptic Weather Types for the Ross Sea Region, Antarctica. J. Clim., 26, 636-649, doi: 10.1175/JCLI-D-11-00690.1, 2013.

Cullather, R. I., Bromwich, D. H. and Van Woert, M. L.: Interannual variations in Antarctic precipitation related to El Nino-Southern Oscillation, J. Geophys. Res., 101(19), 109 $-19,118,1996$.

Cullather, R. I., Bromwich, D. H., and van Woert, M. L.: Spatial and temporal variability of Antarctic precipitation from atmospheric methods. J. Climate, 11, 334-367, 1998.

Dee, D. P., S. M. Uppala, A. J. Simmons, P. Berrisford, P. Poli, S. Kobayashi, U. Andrae, M. A. Balmaseda, G. Balsamo, P. Bauer, P. Bechtold, A. C. M. Beljaars, L. van de Berg, J. Bidlot, N. Bormann, C. Delsol, R. Dragani, M. Fuentes, A. J. Geer; L. Haimberger, S. B. Healy, H. Hersbach, E. V. Hólm; L. Isaksen; P. Kållberg, M. Köhler, M. Matricardi, A. P. McNally, B. M. Monge-Sanz, J.-J. Morcrette, B.-K. Park, C. Peubey, P. de Rosnay, C. Tavolato, J.-N. Thépaut, F. Vitart: The ERA-Interim reanalysis: configuration and performance of the data assimilation system. Q.J.R. Meteorol. Soc., 137: 553-597, doi:10.1002/qj.828, 2011.

Eisen, O., Frezzotti, M., Genthon, C., Isaksson, E., Magand, O., van den Broeke, M.R., Dixon, D.A., Ekaykin, A., Holmlund, P., Kameda, T., Karlo, L., Kaspari, S., Lipenkov, V.Y., Oerter, H., Takahashi, S., Vaughan, D.G.: Ground-based measurements of spatial and temporal variability of snow accumulation in East Antarctica, Rev. Geophys., 46, RG2001, doi:10.1029/2006RG000218, 2008.

Fogt, R. L. and Bromwich, D. H.: Decadal Variability of the ENSO Teleconnection to the High-Latitude South Pacific Governed by Coupling with the Southern Annular Mode. J. Climate, 19, 979-997, 2006. 
Fogt, R. L., Wovrosh, A. J., Langen, R. A., Simmonds, I., The characteristic variability and connection to the underlying synoptic activity of the Amundsen-Bellingshausen Seas Low. J. Geo. Res., 117, D07111, doi:10.1029/2011JD017337, 2012.

Fountain, A. G., Nylen, T. H., Monaghan, A., Basaigic, H. J., Bromwich, D.: Snow in the McMurdo Dry Valleys, Antarctica. Int. J. Climatol., 30, 633-642, doi: 10.1002/joc.1933, 2010.

Helsen, M. M., van de Wal R. S. W., and van den Broeke, M. R.: The isotopic composition of present-day Antarctic snow in a Lagrangian atmospheric simulation. J.Climate, 20, 739-756, 2007.

Kalnay, E., M. Kanamitsu, R. Kistler, W. Collins, D. Deaven, L. Gandin, M. Iredell, S. Saha, G.White, J.Woollen, Y. Zhu, A. Leetmaa, R. Reynolds, M. Chelliah, W. Ebisuzaki, W. Higgins, J. Janowiak, K. C. Mo, C. Ropelewski, J. Wang, R. Jenne, D. Joseph: The NCEP/NCAR 40-Year Reanalysis Project. Bull. Amer. Meteor. Soc., 77, 437$470,1996$.

King, J. C. and Turner, J.: Antarctic Meteorology and Climatology. Cambridge University Press, 409 pp, 1997.

Knuth, S. L., Tripoli, G. J., Thom, J. E., and Weidner, G. A.: The influence of blowing snow and precipitation on snow depth change across the Ross Ice Shelf and Ross Sea regions of Antarctica. J. Appl. Meteor. Climatol., 49, 1306-1321, 2010.

Kojima, K.: Densification of snow in Antarctica, in Antarctic Snow and Ice Studies, Antarct. Res. Ser., vol. 2, ed. M. Mellor, pp. 157-218, AGU, Washington, D. C., doi:10.1029/AR002p0157, 1964.

Krinner, G., Magand, O., Simmonds, I., Genthon, C., and Dufresne, J. L.: Simulated Antarctic precipitation and surface mass balance at the end of the twentieth and twenty-first centuries. Climate Dyn., 28, 215-230, 2007.

Lazzara, M. A., Weidner, G. A.; Keller, L. M.; Thom, J. E. and Cassano, J. J.: Antarctic Automatic Weather Station Program: 30 years of polar observations. Bull. Am. Met. Soc., 93, 1519-1537, 2012.

Li, L., and Pomeroy, J. W.: Probability of occurrence of blowing snow. J. Geophys. Res., 102, 21 955-21 964, 1997.

Lu, C., Yuan, H., Tollerud, E. I., Wang, N., Scale-dependent uncertainties in global QPFs and QPEs from NWP model and satellite fields. J. Hydromet., 11, 139-155, 2010.

Marshall, G. J.: On the annual and semi-annual cycles of precipitation across Antarctica, Int. J. Climatol., 29(15), 2298-2308, doi: 10.1002/joc.1810, 2009. 
Monaghan, A. J., Bromwich, D. H., Powers, J. G., and Manning, K. W.: The climate of the McMurdo, Antarctica, region as represented by one year of forecasts from the Antarctic Mesoscale Prediction System. J. Climate, 18, 1174-1189, 2005.

Monaghan, A. J., Bromwich, D. H., Fogt, R. L., Wang, S.H., Mayewski, P.A., Dixon, D.A., Ekaykin, A., Frezzotti, M., Goodwin, I., Isaksson, E., Kaspari, S.D., Morgan, V.I., Oerter, H., van Ommen, T.D., van der Veen. C.J., Wen, J.: Insignificant change in Antarctic snowfall since the International Geophysical Year. Science, 313, 827-831, 2006.

Nigro, M. A.,Cassano, J. J., and Seefeldt, M. W.: A weather-pattern based approach to evaluate Antarctic Mesoscale Prediction System (AMPS) forecasts: Comparison to automatic weather station observations. Wea. Forecasting, 26, 184-198, 2011.

Noone, D., and Simmonds, I.: Annular variations in moisture transport mechanisms and the abundance of d180 in Antarctic snow. J. Geophys. Res., 107, 4742, doi:10.1029/ 2002JD002262, 2002.

Parish, T. R., Cassano, J. J., and Seefeldt, M. W.: Characteristics of the Ross Ice Shelf air stream as depicted in Antarctic Mesoscale Prediction System simulations. J. Geophys. Res., Ill, D12109, doi:10.1029/2005JD006185, 2006.

Pomeroy, J. and Brun, E.: Physical Properties of Snow in: Snow Ecology: An Interdisciplinary Examination of Snow-Covered Ecosystems, Cambridge University Press, 45-126, 2001.

Qin D., Xiao C., I. Allison, Bian L., Stephenson, R., Ren J., and Yan M.: Snow surface height variations on the Antarctic ice sheet in Princess Elizabeth Land, Antarctica: 1 year data from an automatic weather station. Ann. Glaciol., 39, 181-187, 2004.

Reijmer, H., van den Broeke, R., Scheele, M. P.: Air parcel trajectories and snowfall related to five deep drilling locations in Antarctica based on the ERA-15 dataset, J. Clim., 15, 1957-1968, 2002.

Reijmer, C. H. and Van den Broeke, M. R.: Temporal and spatial variability of the surface mass balance in Dronning Maud Land, Antarctica, as derived from automatic weather stations, J. Glaciol., 49, 512-520, doi:10.3189/172756503781830494, 2003.

Simmons, A. J., Willett, K. M., Jones, P. D., Thorne, P. W., Dee, P. D.: Low-frequency variations in surface atmospheric humidity, temperature, and precipitation: Inferences from reanalyses and monthly gridded observational data sets. J. Geophys. Res., 115, doi:10.1029/2009JD012442, 2010. 
Simmonds, I., Keay, K., and Lim, E. P.: Synoptic activity in the seas around Antarctica. Mon. Wea. Rev., 131, 272-288, 2003.

Sinclair, K. E., Bertler, N. A. N., and Trompetter, W. J.: Synoptic controls on precipitation pathways and snow delivery to high-accumulation ice core sites in the Ross Sea region, Antarctica. J. Geophys. Res., 115, D22112, doi:10.1029/ 2010JD014383, 2010.

Thiery, W., Gorodetskaya, I. V., Bintanja, R., van Lipzig, N. P. M., van den Broeke, M. R., Reijmer, C. H., Kuipers Munneke, P.: Surface and snowdrift sublimation at Princess Elisabeth station, East Antarctica, Cryosphere, 6, 841-857, 2012.

Thomas, E. R., and Bracegirdle, T. J.: Improving ice core interpretation using in situ and reanalysis data. J. Geophys. Res., 114, D20116, doi:10.1029/2009JD012263, 2009.

Zou, C. Z., van Woert, M. L., Xu, C. Y., and Syed, K.: Assessment of the NCEP-DOE Reanalysis-2 and TOVS Pathfinder A moisture fields and their use in Antarctic net precipitation estimates. Mon. Wea. Rev., 132, 2463-2476, 2004. 



\title{
$5 \quad$ Modeling stable isotopes in snow for synoptic events at Roosevelt Island, Antarctica
}

The synoptic-climatology described in Chapter 3 shows how precipitation at Roosevelt Island is affected by large-scale climate variability due to different synoptic pathways. This chapter investigates how the synoptically-driven moisture pathways and other atmospheric factors influence isotopic fractionation at Roosevelt Island, with the aim of providing better interpretations of stable isotopes as temperature proxies at the Roosevelt Island site. This chapter has been reviewed and is undergoing revisions for resubmission to the Journal of Geophysical Research Atmospheres.

\begin{abstract}
Stable isotopes in precipitation $\left(\delta^{18} \mathrm{O}\right.$ and $\left.\delta \mathrm{D}\right)$ have a strong relationship with temperature on annual and longer timescales, but are also influenced by moisture history, source region conditions, and cloud micro-physical processes. Here we investigate these secondary influences using a Lagrangian air parcel approach to investigate the isotopic fractionation of three storm events at Roosevelt Island, a coastal Antarctic site on the Ross Ice Shelf, in November-December 2010. We use a Rayleigh distillation mixed cloud isotopic model (MCIM) with air-mass pathways determined using European Centre for Medium-Range Weather Forecasts (ECMWF) ERA-Interim reanalysis data and the National Oceanic and Atmospheric Administration (NOAA) HYSPLIT back-trajectory model. We compare the results to measured isotope values from precipitated snow collected at the site throughout the three storms. This allows us to eliminate uncertainties involving post-depositional effects of snow (diffusion and re-distribution) and determination of the exact timing of precipitation events, and allows us to apply the Rayleigh distillation model on sub-storm timescales. The model is able to reproduce significant intra-storm variability in $\delta^{18} \mathrm{O}$ due to changes in air mass trajectory as well as identifying the effects of mixing (isotopic recharge) on isotopic ratios. The d-excess parameter is shown to be very sensitive to both source region and air mass trajectory.
\end{abstract}




\subsection{Introduction}

Stable isotopes in snow and ice records $\left(\delta \mathrm{D}\right.$ and $\left.\delta^{18} \mathrm{O}\right)$ have been widely used as paleoclimate proxies for temperature based on the empirical, linear relationship between (present-day) mean annual surface temperature $(\mathrm{T})$ and isotopes $(\delta)$ in Antarctic and Greenland snowfall [Lorius and Merlivat 1977; Johnsen et al., 1989]. The $\delta$-T relationship is also supported theoretically by the Rayleigh distillation model of isotopic fractionation [Dansgaard, 1964]. Deuterium excess (d-excess), a second-order parameter calculated from $\delta \mathrm{D}$ and $\delta^{18} \mathrm{O}$ (d-excess $=\delta \mathrm{D}-8 * \delta^{18} \mathrm{O}$ ), has also been used as a paleoclimate proxy for changes in moisture source region and large-scale atmospheric circulation [e.g. Ciais et al., 1995; Vimeux et al., 1999; Stenni et al., 2001; Masson-Delmotte et al., 2004] based on inferences about the non-equilibrium fractionation processes during evaporation [Merlivat and Jouzel, 1979].

The interpretation of isotopes for past climate conditions is complicated by the fact that the $\delta$-T relationship has been shown to vary both spatially and temporally [e.g. Jouzel et al., 1997; Jouzel et al., 2003; Kavanaugh and Cuffey, 2003] and there is on-going work to identify key controls on this relationship. The primary controls on $\delta$ and d-excess in precipitation in polar regions are due to changes in source region conditions and moisture trajectory [e.g. Jouzel et al., 1997; Noone and Simmonds, 2002a; Schlosser et al., 2004], kinetic fractionation processes [Ciais and Jouzel, 1994; Ciais et al., 1995], and postdepositional changes to snow [e.g. Johnsen et al., 2000].

This study investigates isotopes measured from three storm events sampled at Roosevelt Island $\left(80^{\circ} \mathrm{S}, 200^{\circ} \mathrm{E}, 550 \mathrm{~m}\right.$ a.s.l.), the site of an intermediate-depth ice core located on a rise on the eastern Ross Ice Shelf (RIS) (Figure 5.1a). Precipitation at this site is known to be influenced by the Amundsen Sea Low (ASL) via changes in synoptic cyclonicity in West Antarctica and the Amundsen, Bellingshausen and Ross Sea regions [Cohen et al., 2013; Fogt et al., 2012]. The ASL is known to be influenced by large-scale atmospheric circulation changes such as the Southern Annular Mode (SAM) and El Niño - Southern Oscillation (ENSO) and is thought to be related to the spatial and temporal heterogeneity of climate trends in Antarctica [Bromwich, 1988; Cullather et al., 1996; Simmonds et al., 2003; O'Donnell et al., 2011]. Thus, the Roosevelt Island site is of interest for understanding these large-scale atmospheric circulation changes, as well as longer-term climate changes that affect the stability of the RIS, mass balance of the West Antarctic Ice Sheet (WAIS) and sea 
ice distribution [Conway et al. 1999, Mayewski et al., 2005; Fogt and Bromwich, 2006; Stammerjohn et al., 2008].

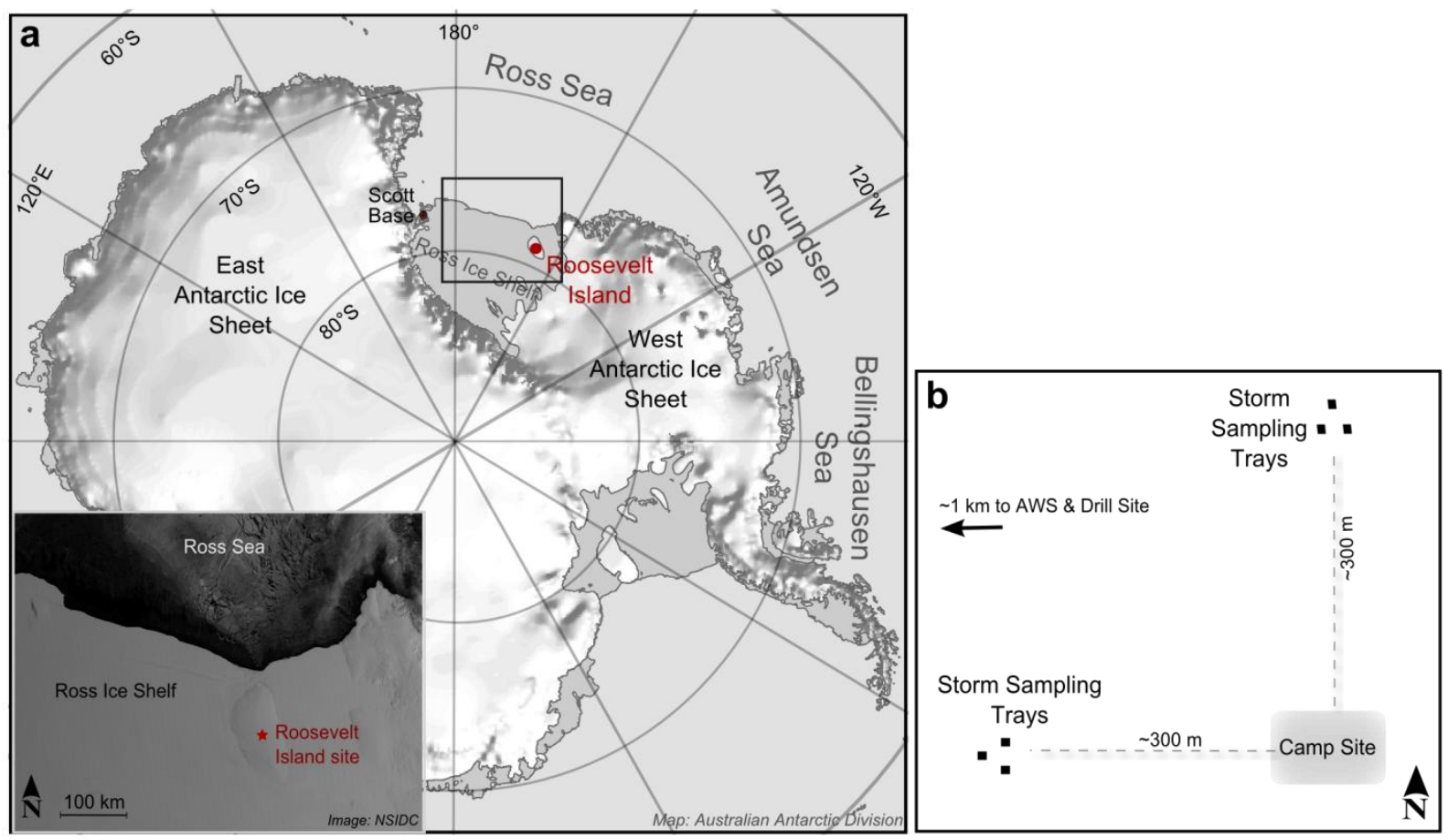

Figure 5.1 a) Location of Roosevelt Island (RI) on the Antarctic continent. The box indicates the extent of the inset satellite image showing the position of RI on the Ross Ice Shelf. b) Location of storm sampling trays in relation to main camp site on RI. MODIS image courtesy National Snow and Ice Data Center [Scambos et al., 1996].

Previous modeling studies which have been used to better understand the limitations of stable isotopes as paleoclimate proxies have employed either general circulation models (GCM) [e.g. Joussaume et al., 1984; Hoffman et al., 1998; Noone and Simmonds, 2002b] or Rayleigh-type distillation models [e.g. Dansgaard, 1964; Jouzel and Merlivat, 1984; Ciais and Jouzel, 1994]. Rayleigh-type models describe the isotopic composition of an air parcel as it cools and loses water through condensation. As such, their ability to accurately represent isotopic fractionation depends heavily on the accuracy of the description of the air parcel pathway and associated meteorological parameters. However, these models have the advantage of being able to directly constrain the meteorology and thus test the models' sensitivity to these parameters.

Rayleigh-type models which use back-trajectories and reanalyses data have provided insight into individual snow events in Antarctic and North American snow pits [Helsen et al., 2004; 2006; Sinclair et al., 2011], and rain events in Australia [e.g. Barras and Simmonds, 
2008] but must also include a parameterization for mixed cloud processes in Antarctic environments [Jouzel and Merlivat, 1984]. We use a mixed-cloud Rayleigh model to investigate stable isotopes from fresh snow samples collected during three distinct storm events that occurred at Roosevelt Island (RI) in November 2010. The storms were sampled throughout their duration, which enables us to better constrain the meteorology and eliminate any influences due to post-depositional changes.

This model uses back-trajectories generated hourly by the NOAA Hybrid Single Particle Lagrangian Integrated Trajectory model (HYSPLIT) with ECMWF ERA-Interim reanalysis data as input. The back-trajectories are used to define broad source regions for each storm, and sea surface temperature (SST) and relative humidity (RH) from the ERAInterim dataset are used to calculate the resulting range of initial isotopic vapor values. Mean profiles of pressure $(\mathrm{P})$, temperature $(\mathrm{T})$, specific humidity $(\mathrm{q})$ and $\mathrm{RH}$ for moisture-bearing trajectories are then used to drive the Rayleigh fractionation model. From this, we model the isotopic evolution of the vapor and precipitation and compare the results to measured isotope values for the three storm events. Calculating initial $\delta$ vapor values explicitly at ocean surface allows us to directly assess the influence of source region variability on isotopic ratios, and using the hourly-resolution back trajectories provides an assessment of the effects of trajectory changes on sub-storm timescales.

The following section describes the methodology of storm sampling and a comparison of meteorological observations with reanalyses data (Section 5.2.1), the generation of backtrajectories (Section 5.2.2), description of measured isotopes (Section 5.2.3) and description of the Rayleigh model parameters (Section 5.2.4). Section 5.3 then discusses the results and implications of modeled $\delta^{18} \mathrm{O}$ values for each of the three storms and d-excess for two of the storms and Section 5.4 summarizes the observations and conclusions from this study.

\subsection{Methodology}

\subsubsection{Snow sampling and meteorological observations}

Fresh snow accumulation was sampled during three storm events in November and December 2010 on RI. Each storm lasted between 55-71 hours from first to last incidence of snowfall (dates/times are summarized in Table 5.1). Accumulated snow was sampled from six white polystyrene trays $(460 \times 360 \times 25 \mathrm{~mm})$ that were placed in two groups approximately $300 \mathrm{~m}$ north and west of the main camp as illustrated in Figure 5.1b. The trays were cleared of snow after samples were taken so that each sample represents a discrete time 
period. The trays were situated about $15 \mathrm{~m}$ apart and were kept flush with the snow surface with small stakes. The snow surface immediately around trays and out to $\sim 300 \mathrm{~m}$ in all directions remained undisturbed (except for a single path to access the site) to minimize artificial snow drifting.

Table 5.1 Summary of storm dates/times, duration, and accumulation amounts.

\begin{tabular}{llll}
$\begin{array}{l}\text { Start-Finish } \\
\text { Date/Time (UTC) }\end{array}$ & $\begin{array}{l}\text { Duration } \\
\text { (hrs) }\end{array}$ & $\begin{array}{l}\text { Accumulation } \\
\text { (cm) }\end{array}$ \\
\hline 9 Nov, 06h & 12 Nov, 04h & 71 & 2 \\
16 Nov, 22h & 19 Nov, 04h & 55 & 3 \\
28 Nov, 21h & 1 Dec, 20h & 69 & 5.5 \\
\hline
\end{tabular}

A summary of the sample date/ time, accumulation amount and snow characteristics are shown in Table 5.2. Each sample represents $0.5 \mathrm{~cm}$ to $2 \mathrm{~cm}$ of snow accumulation and consists of between 3 and 6 discrete sub-samples taken concurrently from different trays in the study area. The time interval between samples varied between 8 and 24 hours. Trays that were covered by small $(<10 \mathrm{~cm}$ high) snow drifts at the time of sampling have been excluded from the analysis (noted in Table 5.2) as they are more likely to represent locallyredistributed snow rather than newly-precipitated snow.

An automatic weather station (AWS) collected the standard suite of meteorological parameters at the RI site from 14 Nov onwards and manual observations of temperature and pressure were recorded at the site for flight operations prior to the installation of the AWS. The AWS was equipped with a sonic anemometer measuring wind speed and direction, a thermistor probe measuring $2 \mathrm{~m}$ air temperature, a pressure transducer, and a snow depth sensor. Data was recorded at 20-minute intervals with a Campbell Scientific CR10X datalogger. In addition, we use European Centre for Medium-Range Weather Forecasts (ECMWF) ERA-Interim reanalysis data, which assimilates and reprocesses in-situ meteorological data and satellite data to produce a comprehensive, global dataset of meteorological parameters [Dee et al., 2011]. This is available at $1.5^{\circ}$ latitude/longitude resolution (though the underlying models are run at higher resolution) at six-hourly time intervals. 
Table 5.2 Summary of surface snow sampling dates/times, the number of samples analyzed ( $n)$, accumulation amount and snow descriptions.

\begin{tabular}{|c|c|c|c|c|}
\hline Sample & $\begin{array}{l}\text { Sample } \\
\text { Date/Time } \\
\text { (UTC) }\end{array}$ & $n$ & $\begin{array}{l}\text { Accumulation } \\
\qquad(\mathrm{cm})\end{array}$ & Snow description ${ }^{1}$ \\
\hline $1 \mathrm{~A}$ & 9-Nov, 0630h & 6 & 0.5 & fine grained, wind-packed \\
\hline $1 \mathrm{~B}$ & 10-Nov, $1930 \mathrm{~h}$ & 6 & 0.5 & fine grained, wind-packed \\
\hline $1 \mathrm{C}$ & 11-Nov, 2000h & 6 & 0.5 & fine grained, wind-packed \\
\hline $1 \mathrm{D}$ & 12-Nov, $0400 \mathrm{~h}$ & 3 & 0.5 & fine grained, wind-packed* $*$ \\
\hline $2 \mathrm{~A}$ & 16-Nov, 2200h & 6 & 0.5 & $\begin{array}{l}\text { medium grained, irregular crystals; fine- } \\
\text { grained, wind packed; surface hoar }\end{array}$ \\
\hline $2 \mathrm{~B}$ & 17-Nov, $0400 \mathrm{~h}$ & 6 & 0.5 & $\begin{array}{l}\text { medium-grained, wind-broken snow and some } \\
\text { fine grained, wind-packed snow }\end{array}$ \\
\hline $2 \mathrm{C}$ & 17-Nov, 2000h & 5 & 0.5 & $\begin{array}{l}\text { medium-grained, wind-broken snow; fine } \\
\text { grained, wind-packed snow* }\end{array}$ \\
\hline $2 \mathrm{D}$ & 18-Nov, 2000h & 6 & 0.5 & $\begin{array}{l}\text { very coarse dendrites \& wind broken snow and } \\
\text { some fine grained wind packed snow }\end{array}$ \\
\hline $2 \mathrm{E}$ & 19-Nov, 0400h & 6 & 1.0 & very coarse dendritic crystals \\
\hline $3 \mathrm{~A}$ & 28-Nov, $2100 \mathrm{~h}$ & 6 & 2.0 & fine grained, wind-broken snow \\
\hline $3 \mathrm{~B}$ & 29-Nov, 2200h & 5 & 0.5 & fine grained, wind-broken snow* \\
\hline $3 \mathrm{C}$ & 30-Nov, 2300h & 5 & 1.0 & $\begin{array}{l}\text { medium grained, wind broken snow \& fine } \\
\text { grained wind packed snow* }\end{array}$ \\
\hline $3 \mathrm{D}$ & 1-Dec, $2000 \mathrm{~h}$ & 5 & 2.0 & $\begin{array}{l}\text { medium grained dendritic crystals; surface } \\
\text { hoar* }\end{array}$ \\
\hline
\end{tabular}

${ }^{l}$ Snow grain size descriptions from Fierz et al [2009].* Snow drift covered one or more trays.

Figure 5.2 compares the RI meteorological data with ERA-Interim data averaged over the area encompassed by the gridpoints $79.5^{\circ} \mathrm{S}$ to $81^{\circ} \mathrm{S}$ by $199.5^{\circ} \mathrm{E}$ to $201^{\circ} \mathrm{E}$. Both pressure and temperature from the ERA-Interim data have been corrected for height as the underlying topography in the reanalysis does not resolve RI (ERA-Interim gives $23 \mathrm{~m}$ a.s.l.; RI elevation is $550 \mathrm{~m}$ a.s.l.). Snow accumulation (and ablation) was measured using an ultrasonic depth sensor (Judd Communications), which measures distance to the snow surface with $1 \mathrm{~cm}$ accuracy. Data from snow depth sensors are affected by blowing snow, densification, and wind scour and drifting [Knuth et al., 2010] making small precipitation events difficult to identify, though large events are easily identified by stepped jumps in the record, and the amounts roughly match the overall observed accumulation amounts (Table 5.1). Snowsurface height measurements are converted to millimeters water equivalent (mm w.e.) for comparison with reanalysis data using a snow density of $100 \mathrm{~kg} \mathrm{~m}^{-3}$ (which is a mid-range fresh snow density for temperatures between $+1^{\circ} \mathrm{C}$ to $-40^{\circ} \mathrm{C}$ [Pomeroy and Brun, 2001]). 


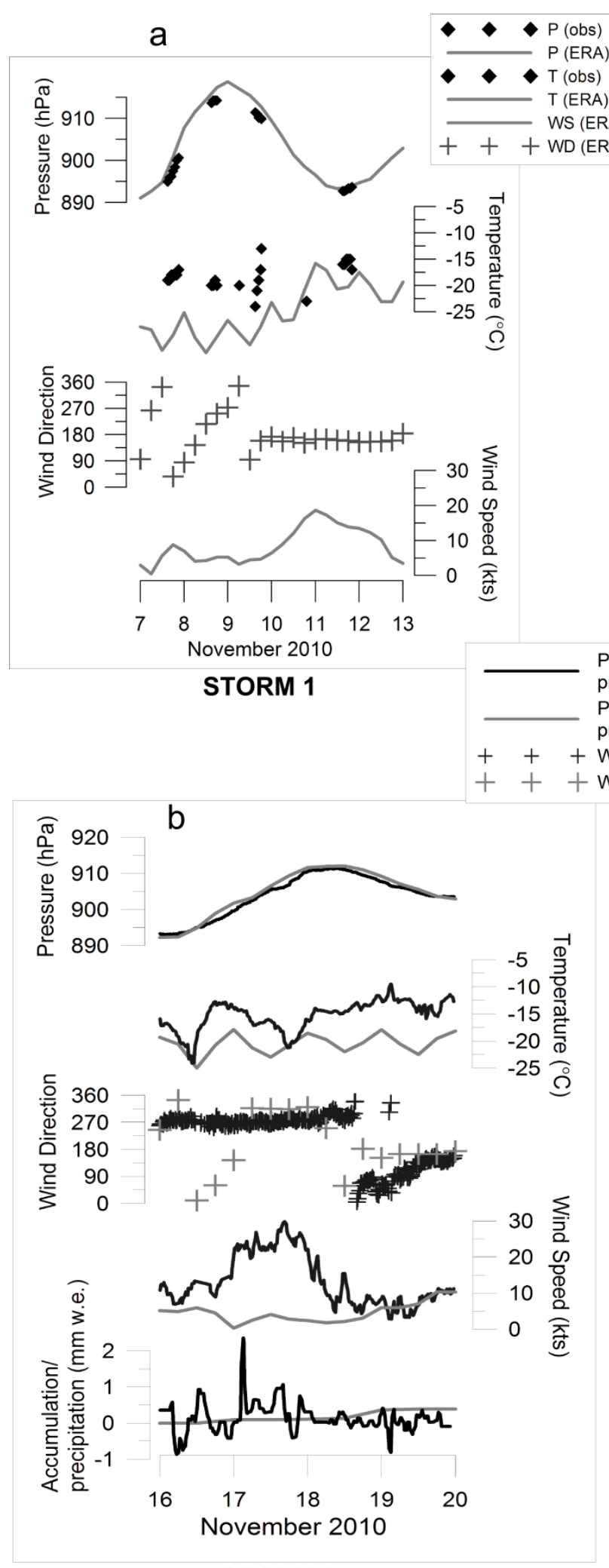

STORM 2
Figure 5.2 a) Comparison of pressure and temperature surface observations and ERA-Interim reanalyses (6-hourly) at RI during Storm 1(no AWS data exists for this time period). Wind speed and wind direction from the ERAInterim are also shown.

b) and c) Comparison of AWS and ERA-Interim pressure, temperature, wind speed and direction, and snow accumulation/precipitation for Storms 2 and 3 respectively.
P, T, WS, precip (AWS) $\mathrm{P}, \mathrm{T}, \mathrm{WS}$, precip (ERA) WD (AWS)

WD (ERA)
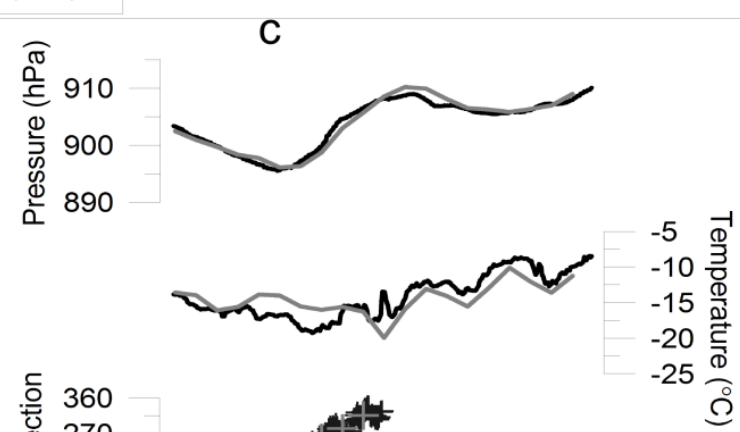

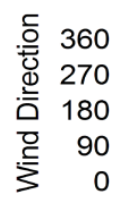
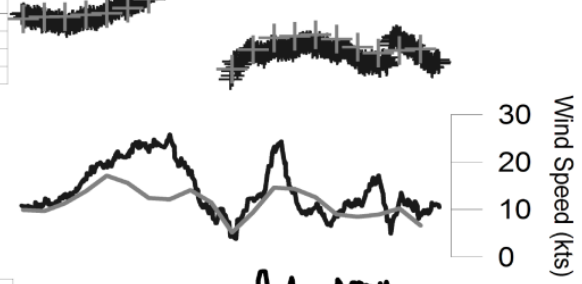

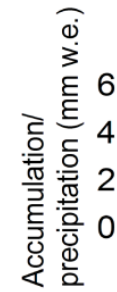

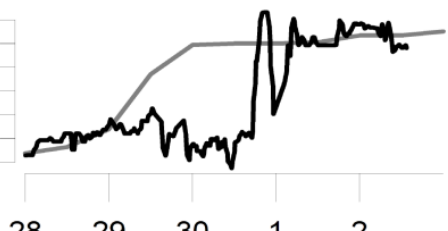

$\begin{array}{lllll}28 & 29 & 30 & 1 & 2\end{array}$

STORM 3

The reanalysis data are in relatively good agreement with observations particularly for Storm 3. For precipitation, the ERA-Interim data reflects similar timing, but a smaller amountfor Storm 2 and similar amount and timing for Storm 3.For Storm 2, for example, the 
reanalysis data gives only $0.4 \mathrm{~mm}$ w.e., while the AWS indicates $\sim 3 \mathrm{~mm}$ w.e. $(3 \mathrm{~cm}$ snow accumulation) for the beginning of that period (17 Nov, 00h-12h) (before wind scour affects the measurements). For Storm 3, the reanalysis data gives a total precipitation of $5 \mathrm{~mm}$ w.e. between $28 \mathrm{Nov}, 12 \mathrm{~h}$ to $3 \mathrm{Dec}, 12 \mathrm{~h}$ with the main pulse on $28 \mathrm{Nov}, 12 \mathrm{~h}$ to $29 \mathrm{Nov}, 12 \mathrm{~h}$, while the AWS indicates similar amount but with the main pulse occurring from 30 Nov to 1 Dec. For Storm 1, ERA-Interim does not produce any precipitation (no snow height data exists for this period, but observations show $\sim 2 \mathrm{~cm}$ accumulation [Table 5.1]), which may in part be due to the lack of RI topography, which would result in local orographically-induced precipitation not being represented in the model data.

\subsubsection{Air-mass trajectories}

Back trajectories for each of the three storms were produced using the NOAA HYSPLIT model version 4.9 [Draxler and Hess, 1997]. We use the ERA-Interim dataset as input for the model, which has best resolution of the available reanalyses products and is thought to be the most accurate for southern high-latitudes [Bromwich et al., 2011]. The accuracy of back trajectories is difficult to quantify as uncertainties increase in time but are on the order of 15 $30 \%$ of the travel distance [Draxler and Hess, 1997]. To minimize uncertainties associated with any single back trajectory, trajectories were run hourly for the duration of each storm (Table 5.1) with 6 hours selected as the time interval before the first sample of each storm. This gives 77 trajectories for Storm 1, 61 for Storm 2 and 75 for Storm 3. Figure 5.3a shows the back-trajectory frequency distributions, or the percentage of hourly trajectories that pass through each $1^{\circ} \times 1^{\circ}$ area.

The back trajectories were initiated at different heights above RI based on the pressure level of the maximum specific humidity values (from the 6-hourly ERA-Interim data) over the site for each of the three storms. These heights are 950 hectopascals (hPa), $925 \mathrm{hPa}$ and $850 \mathrm{hPa}$ for Storms 1, 2 and 3, respectively. The HYSPLIT model was constrained at the upper boundary at $20 \mathrm{~km}$ and wind fields were used to drive vertical motion.

The three storms show distinctly different pathways to the site. Trajectories for Storm 1 and 2 originate over the ocean between 45 to $60^{\circ} \mathrm{S}$ and travel up and over the WAIS before arriving at RI. For Storm 1, trajectories are split between the Pacific and Atlantic Oceans, but for Storm 2 all trajectories originate in the Pacific. Storm 3 consists of slow-moving trajectories that predominantly travel along the Bellingshausen and Amundsen Sea coastlines, although some also originate over the RIS and the East Antarctic Ice Sheet. 

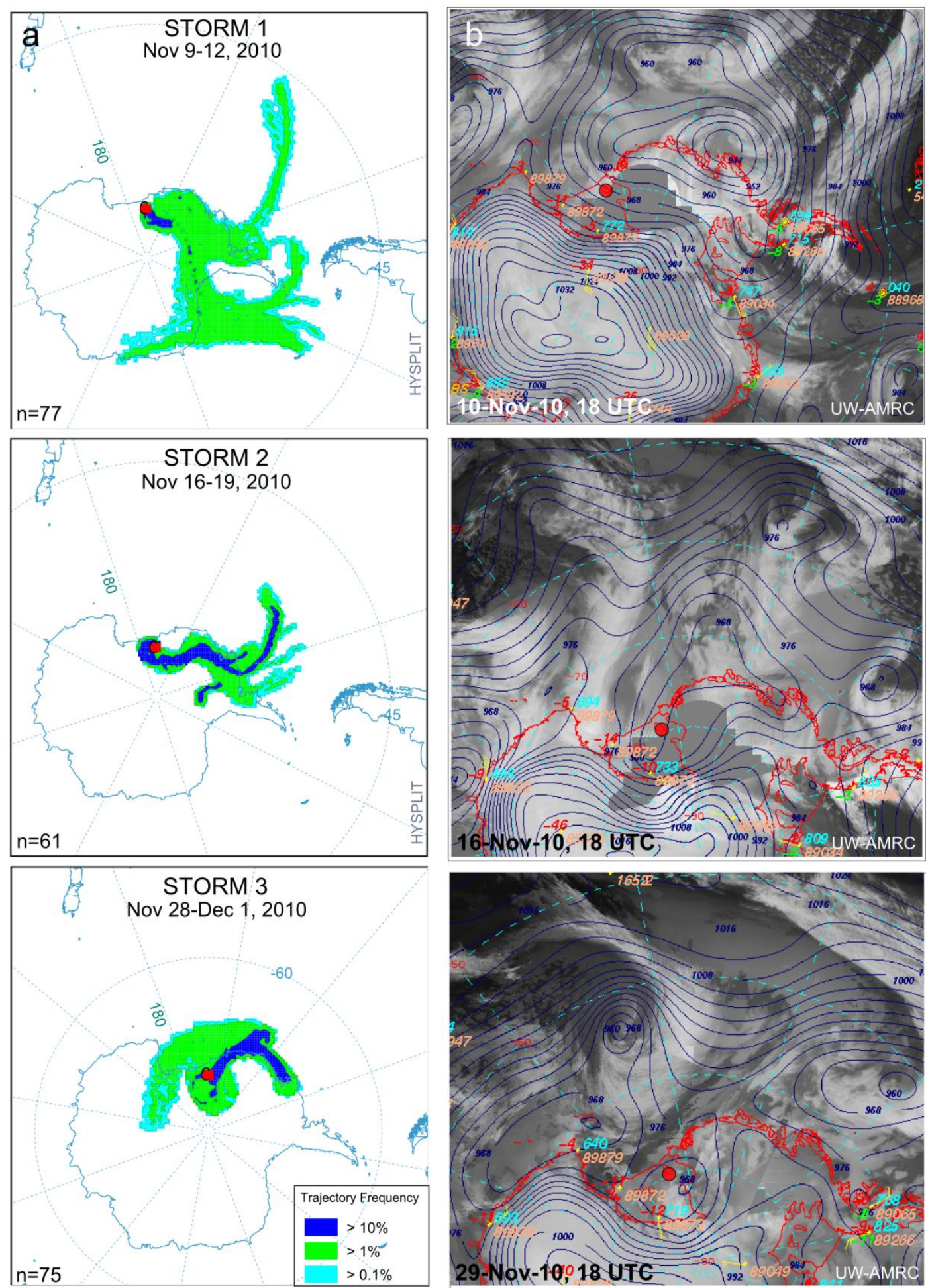

Figure 5.3 a) HYSPLIT frequency distributions of 5-day back trajectories with the number of trajectories (n) marked on each plot b) A representative composite satellite/synoptic image (U. Wisconsin-AMRC) confirming the general trajectory patterns for each storm.

Because we rely on these trajectories to drive the Rayleigh model, we have compared them to composite satellite images and synoptic charts available from the University of Wisconsin Antarctic Meteorological Research Center (http://amrc.ssec.wisc.edu). One 
representative image from each of the three storms is shown in Figure 5.3b. The synoptic charts corroborate the general air-mass movement for all of the storms.

\subsubsection{Stable isotope measurements}

Snow samples collected at RI were kept frozen until they were aliquoted for stable isotope analyses. Oxygen $\left(\delta^{18} \mathrm{O}\right)$ and hydrogen $(\delta \mathrm{D})$ isotope ratios were measured at the Stable Isotope Laboratory at GNS Science and reported with respect to VSMOW. Analytical precision is $0.1 \%$ for $\delta^{18} \mathrm{O}$ and $1.0 \%$ for $\delta \mathrm{D}$, resulting in an uncertainty of $+/-1.3 \%$ for $\mathrm{d}$ excess. Measured $\delta^{18} \mathrm{O}$ and $\delta \mathrm{D}$ values of all sub-samples are shown in Figure 5.4 and Table 5.3. The standard deviation of concurrent sub-samples ranges between 0.11 to $2.29 \%$ for $\delta^{18} \mathrm{O}$ and 1.4 to $19.7 \%$ for $\delta \mathrm{D}$. This is less than the intra-storm variability for all of the storms and we simplify the following analysis by using only the average $\delta$ value for each sample.

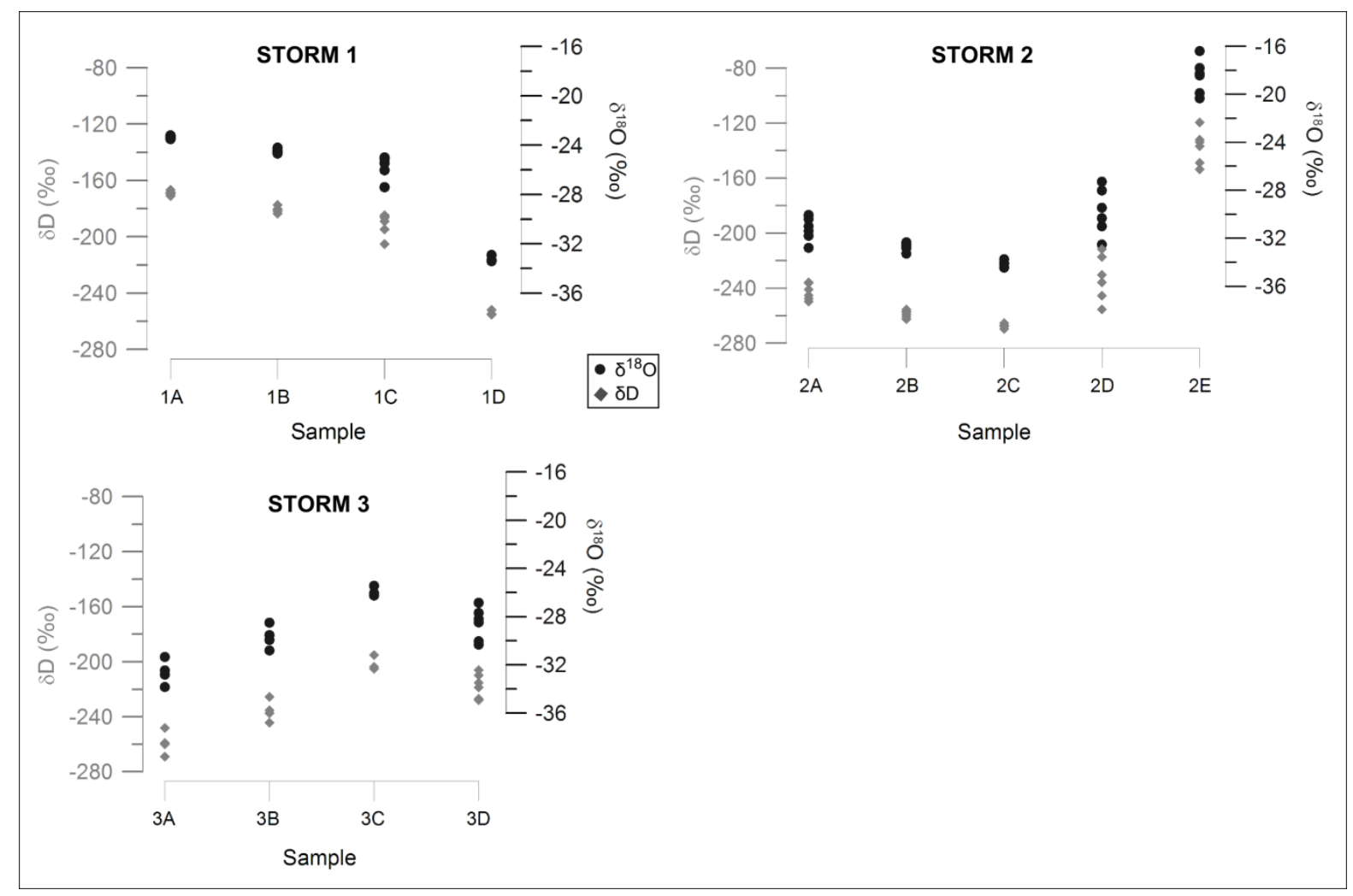

Figure 5.4 Measured $\delta 18 O$ and $\delta D$ values for each storm. Each sample consists of between three and six discrete sub-samples collected concurrently. 
Table 5.3 Stable isotope ratios and standard deviations ( $\sigma)$ for each sample.

\begin{tabular}{l|ll|ll|ll}
\multicolumn{1}{l}{ Sample } & $\boldsymbol{\delta}^{\mathbf{1 8}} \mathbf{O}(\mathbf{\%})$ & $\boldsymbol{\sigma}$ & $\boldsymbol{\delta D} \mathbf{( \% )}$ & $\boldsymbol{\sigma}$ & \multicolumn{1}{c}{ d-excess } & $\boldsymbol{\sigma}$ \\
\hline 1A & -23.4 & 0.11 & -168.9 & 1.42 & 17.9 & 1.38 \\
1B & -24.5 & 0.16 & -181.2 & 2.24 & 14.7 & 2.19 \\
1C & -25.7 & 0.93 & -190.9 & 7.85 & 14.6 & 7.39 \\
1D & -33.2 & 0.26 & -253.9 & 1.86 & 11.8 & 1.71 \\
\hline 2A & -30.8 & 0.71 & -242.7 & 5.91 & 3.8 & 5.56 \\
2B & -32.7 & 0.33 & -258.9 & 2.64 & 2.7 & 2.47 \\
2C & -34.2 & 0.28 & -268.0 & 1.76 & 5.3 & 1.57 \\
2D & -29.8 & 1.94 & -232.8 & 16.62 & 5.4 & 15.68 \\
2E & -18.5 & 1.44 & -137.5 & 12.33 & 10.8 & 11.64 \\
\hline 3A & -31.2 & 2.29 & -247.2 & 19.68 & 2.8 & 18.58 \\
3B & -29.8 & 0.84 & -236.0 & 6.79 & 2.1 & 6.36 \\
3C & -26.7 & 1.81 & -207.6 & 18.47 & 6.4 & 17.75 \\
3D & -28.6 & 1.34 & -217.5 & 8.90 & 11.2 & 8.05 \\
\hline
\end{tabular}

$\delta^{18} \mathrm{O}$ and $\delta \mathrm{D}$ values are generally low compared to the eight-year snow pit isotope record from RI (sampled at a resolution of $\sim 50$ samples $\mathrm{yr}^{-1}$ ) in which $\delta^{18} \mathrm{O}$ ranges from -31.0 to $-16.3 \%$ (mean $=-23.7 \%, \sigma=3.2 \%$ ). This is consistent with the season that surface samples were collected (late spring/early summer). The intra-storm variability of these storms is high $\left(\sigma_{\text {storm1 }}=4.5 \% ; \sigma_{\text {storm } 2}=6.2 \% ; \sigma_{\text {storm3 }}=2.8 \%\right)$, and previous studies have also noted the high variability of stable isotopes in precipitation on these timescales [e.g. Gedzelman and Lawrence, 1982; Jacob and Sonntag, 1991; Barras and Simmonds, 2009]. This has been attributed to evapotranspiration, changes in air-mass trajectories during a storm event, and mixing of more highly-fractionated air from upper layers [Hoffman et al., 1998].

The relationship between $\delta^{18} \mathrm{O}$ and condensation temperature $\left(\mathrm{T}_{\mathrm{c}}\right)$ for all three storms is shown in Figure 5.5. We use $T_{c}$ instead of surface temperature as it a more relevant parameter for isotopic fractionation and avoids surface temperature inversion issues common in polar regions [Jouzel and Merlivat, 1984; van Lipzig et al., 2002]. $T_{c}$ is determined from the ERAInterim dataset at the level of the highest specific humidity above RI (the same height that back trajectories were initiated from; see section 5.2.2). Temperatures are averaged over the time interval between samples, with six hours selected as the time interval before the first sample. There is no significant $\delta$-T relationship for this dataset, and this has also been found in other studies of event-scale snow isotopes in Antarctica [e.g. Schlosser and Oerter 2002; Helsen et al., 2006]. Although temperature is a major control on isotope fractionation processes, it is apparent from the high variability of these storms and lack of temperature 
relationship that other factors (such as moisture history and cloud micro-physical processes) are as important on these timescales.

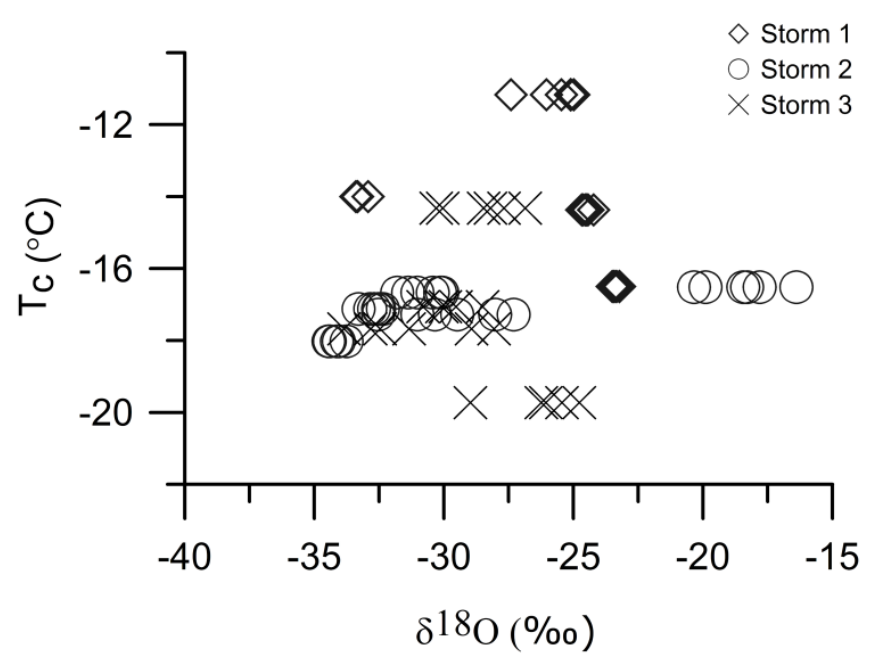

Figure 5.5 Measured $\delta 180$ versus condensation temperature (Tc) for all samples collected during the three storms.

\subsubsection{Rayleigh model}

Rayleigh distillation models have been widely used to better understand isotopic fractionation processes for Antarctic snow [e.g. Jouzel and Merlivat, 1984; Ciais and Jouzel, 1994; Kavanaugh and Cuffey, 2003; Helsen et al., 2006].These models have the advantage of being able to directly constrain meteorological inputs and provide sensitivity analysis of these inputs on isotopic ratios. A Rayleigh fractionation model calculates the isotopic composition of an air parcel as it cools and loses water (or ice) through condensation. The isotopic composition of precipitation $\left(\delta_{\mathrm{p}}\right)$ is a function of the initial isotopic composition of the vapor $\left(\delta_{v 0}\right)$, the fractionation factor $\left(\alpha_{e}\right)$, and the fraction of vapor remaining in an air parcel $(f)$ :

$$
\delta_{\mathrm{p}}=\alpha_{\mathrm{e}}\left(\delta_{\mathrm{v} 0}+1000\right)\left(f^{(\alpha \mathrm{e}-1)}\right)-1000
$$

The fractionation factors, $\alpha_{\mathrm{e}}$, parameterize the depletion of heavy isotopes for $\delta \mathrm{D}$ and $\delta^{18} \mathrm{O}$ within a cloud (assuming equilibrium conditions) as a function of the cloud temperature. This model uses fractionation factors from Horita and Wesolowski [1994] and includes a parameterization for non-equilibrium processes that occur in mixed clouds (i.e. clouds that contain vapor, liquid and ice). The mixed cloud isotopic model (MCIM) uses the supersaturation function $\left(S_{i}\right)$ to parameterize the supersaturation of vapor with respect to ice [Jouzel and Merlivat, 1984; Ciais and Jouzel, 1994]. We use the parameterization: 


$$
S_{i}=1.02-0.0038 * \mathrm{~T}
$$

which is considered the most accurate parameterization for high-latitudes [Schmidt et al., 2005; Helsen et al., 2007]. The determination of the initial isotope value, $\delta_{\mathrm{v} 0}$, and moisture history (from which the fraction of vapor, $f$, is derived) are discussed in further detail below.

\section{Source region delineation and initial isotopic composition of vapor}

The initial isotopic composition of water vapour $\left(\delta^{18} \mathrm{O}_{\mathrm{v} 0}, \delta \mathrm{D}_{\mathrm{v} 0}\right)$ is a major source of uncertainty in isotope modeling [Jouzel and Koster 1996] and there are various methods to determine these parameters. Other similar studies have used isotopes measured near the source region to constrain $\delta_{\mathrm{v} 0}$ values [Sinclair et al., 2011] or defined initial values from GCM-generated isotope fields [Delmotte et al., 2000; Helsen et al., 2006]. We determine the source regions from the back-trajectory analysis and calculate $\delta_{\mathrm{v} 0}$ from ERA-Interim-derived SST and RH values.

The defined source regions for each storm are deliberately broad in order to assess sensitivity of the model to this parameter and are identified based on the q profiles from HYSPLIT back trajectories up to 8 days before precipitation onset at RI. Storm 1 trajectories have maximum $\mathrm{q}$ at 135 hours ( 6 days), Storm 2 at 160 hours ( 6.5 days), and Storm 3 at 95 hours ( $\sim 4$ days). The locations of the highest $10 \%$ and $20 \%$ specific humidity values $\left(\mathrm{q}_{10 \%}\right.$ andq $\left.\mathrm{q}_{20 \%}\right)$ from these trajectories are plotted in Figure 5.6. The specific humidity values for Storm 1 are: $\mathrm{q}_{10 \%}=3.5 \mathrm{~g} \mathrm{~kg}^{-1}, \mathrm{q}_{20 \%}=3.1 \mathrm{~g} \mathrm{~kg}^{-1}$; for Storm $2: \mathrm{q}_{10 \%}=3.1 \mathrm{~g} \mathrm{~kg}^{-1} ; \mathrm{q}_{20 \%}=2.2 \mathrm{~g}$ $\mathrm{kg}^{-1}$; and for Storm 3: $\mathrm{q}_{10 \%}=2.3 \mathrm{~g} \mathrm{~kg}^{-1}, \mathrm{q}_{20 \%}=2.1 \mathrm{~g} \mathrm{~kg}^{-1}$. The source regions for each storm are determined based on the locations of the $\mathrm{q}_{10 \%}$ values, which identifies mid-latitude evaporative source regions at the end of the $\mathrm{q}_{20 \%}$ trajectories. Storm 1 has two distinct source regions, while Storms 2 and 3 are more tightly grouped. For Storms 1 and 2, the highest specific humidities $\left(\mathrm{q}_{10 \%}\right)$ all correspond to pressures above $940 \mathrm{hPa}$, confirming that they originate near the ocean surface. This gives some confidence that these areas represent the evaporative source regions for these storms. The moisture for Storm 3 originates higher above the surface ( 970 to $830 \mathrm{hPa}$ ) indicating that initial isotope values calculated at the ocean surface will not accurately represent initial values for this storm. This is discussed further in Section 5.3.3. 


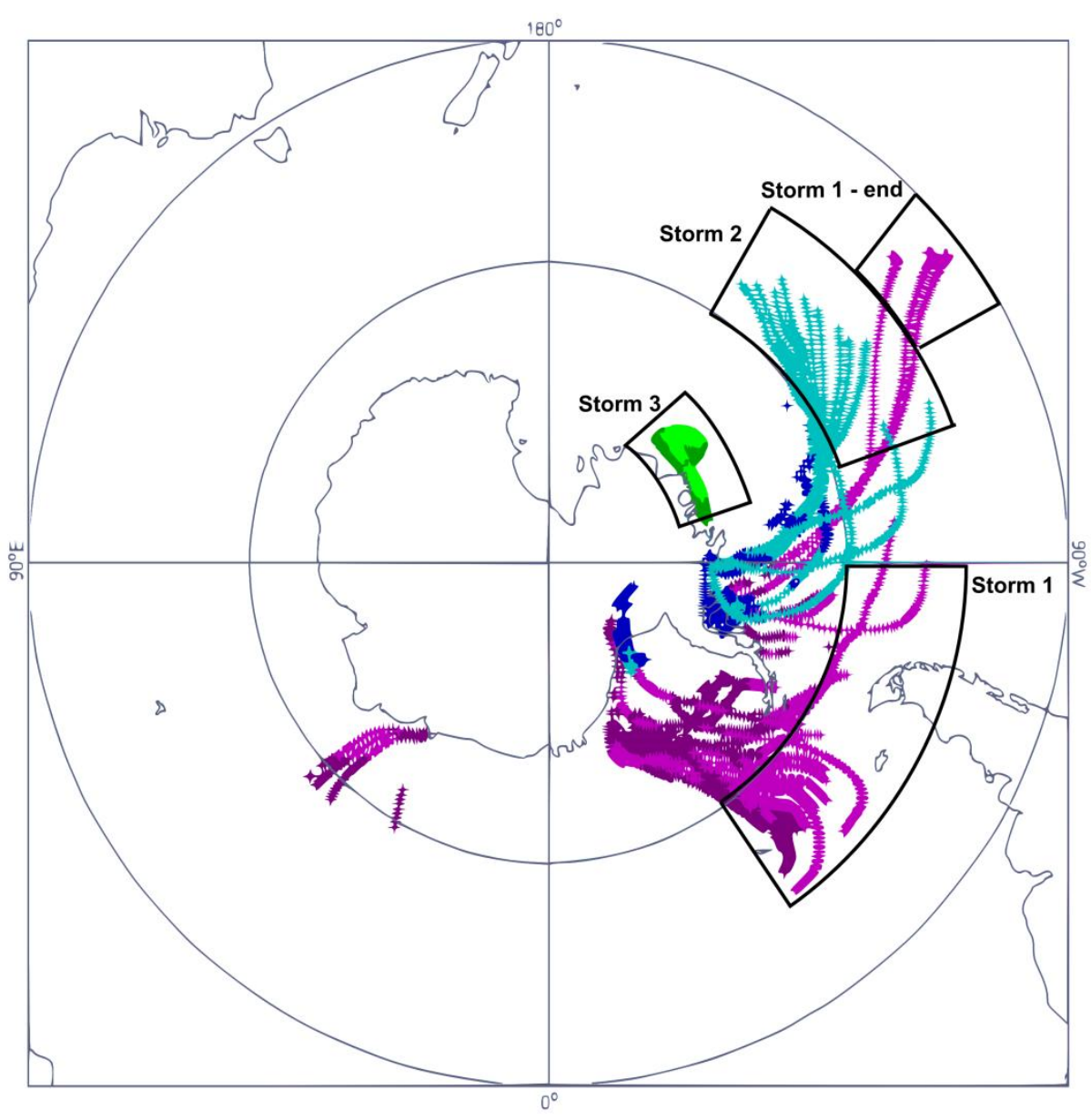

Figure 5.6 Locations of the highest 20\% (dark) and 10\% (light) specific humidity values from HYSPLIT back-trajectories along with delineated source regions for each storm.

The initial isotope values are calculated at the sea surface based on kinetic and equilibrium fractionation processes [Craig and Gordon, 1965]. Kinetic fractionation is primarily dependent on temperature and relative humidity at the air/ocean boundary layer [Merlivat and Jouzel, 1979]. We use equilibrium fractionation factors from Horita and Wesolowski [1994] and kinetic fractionation factors from Cappa et al [2003]. Table 5.4 summarizes the mean, standard deviation, maximum and minimum values of SST and 1000 $\mathrm{hPa} \mathrm{RH}$ for each source region during the period of moisture uptake. These values are used to calculate mean, maximum and minimum values for the initial isotopic composition of vapor for each storm. 
Table 5.4 Source region latitude and longitude bounds, date range and statistical summary of the source region SST, RH and initial isotopic composition of vapor for each storm.

\begin{tabular}{|c|c|c|c|c|c|}
\hline & & Storm 1 & & Storm 2 & Storm 3 \\
\hline & Latitude range & $50-60^{\circ} \mathrm{S}$ & $40-50^{\circ} \mathrm{S}$ & $50-60^{\circ} \mathrm{S}$ & $65-70^{\circ} \mathrm{S}$ \\
\hline & Longitude range & $270-315^{\circ} \mathrm{E}$ & $225-250^{\circ} \mathrm{E}$ & $215-250^{\circ} \mathrm{E}$ & $220-250^{\circ} \mathrm{E}$ \\
\hline & Date range & 3-5 Nov & 5-7 Nov & 9-14 Nov & 23-27 Nov \\
\hline SST (K) & mean & 277 & 283 & 277 & 271 \\
\hline & $\sigma$ & 2.8 & 2.4 & 2.7 & 0.02 \\
\hline & $\min$ & 271 & 279 & 272 & 271 \\
\hline & $\max$ & 282 & 288 & 282 & 271 \\
\hline RH (\%) & mean & 88 & 79 & 79 & 82 \\
\hline & $\sigma$ & 9.7 & 9.7 & 10.6 & 8.8 \\
\hline & $\min$ & 33 & 51 & 47 & 29 \\
\hline & $\max$ & 103 & 102 & 100 & 99 \\
\hline$\delta^{18} \mathrm{O}_{\mathrm{v} 0}(\%)$ & mean & -12.4 & -12.0 & -12.4 & -13.0 \\
\hline & $\min$ & -16.2 & -14.2 & -15.5 & -15.1 \\
\hline & $\max$ & -10.7 & -10.0 & -10.3 & -11.9 \\
\hline$\delta D_{\mathrm{v} 0}(\%)$ & mean & -97.4 & -89.2 & -96.2 & -103.3 \\
\hline & $\min$ & -105.4 & -94.7 & -103.8 & -104.3 \\
\hline & $\max$ & -89.7 & -83.0 & -85.2 & -102.8 \\
\hline d-excess (\%o) & mean & 1.8 & 6.8 & 3.0 & 0.7 \\
\hline & $\min$ & -4.1 & -3.0 & -2.8 & -7.6 \\
\hline & $\max$ & 24.2 & 18.9 & 20.2 & 16.5 \\
\hline
\end{tabular}

\section{Moisture history and fraction of vapor $(f)$}

Figure 5.7 shows the profiles of $\mathrm{q}, \mathrm{P}, \mathrm{T}$, and $\mathrm{RH}$ from the HYSPLIT model for the moisture-bearing back trajectories for each of the three storms. The moisture-bearing trajectories are those that contain the highest $20 \%$ specific humidity values from all of the hourly back-trajectories (as in Figure 5.6). Storms 1 and 2 indicate air-mass trajectories that transport air from the ocean, up and over the WAIS before dropping back down to the RI site (at hour 0), while the Storm 3 profile shows very little change in moisture both over the five days prior to precipitation and when the trajectories are extended further back in time (not shown).

The fraction of vapor remaining in an air parcel is defined as the ratio of specific humidity in the air parcel (q) to the initial specific humidity, $\mathrm{q}_{0}$,

$$
f=\mathrm{q} / \mathrm{q}_{0}
$$


Since the degree of fractionation is highly dependent on the fraction of vapor remaining in the air parcel we model the highest moisture-bearing trajectories $\left(\mathrm{q}_{20 \%}\right.$, shown in Figure 5.6). This reduces the number of trajectories for Storm 1 from 77 to 51 and for Storm 2 from 61 to 42. Rayleigh fractionation is not calculated for Storm 3, and this is discussed further in Section 5.3.3. These moisture history, temperature, and pressure profiles are used to drive the Rayleigh fractionation model. As in Helsen et al. [2006; 2007], fractionation only occurs when the parcel is losing moisture (decreasing q) and is saturated ( $\mathrm{RH}>80 \%)$.
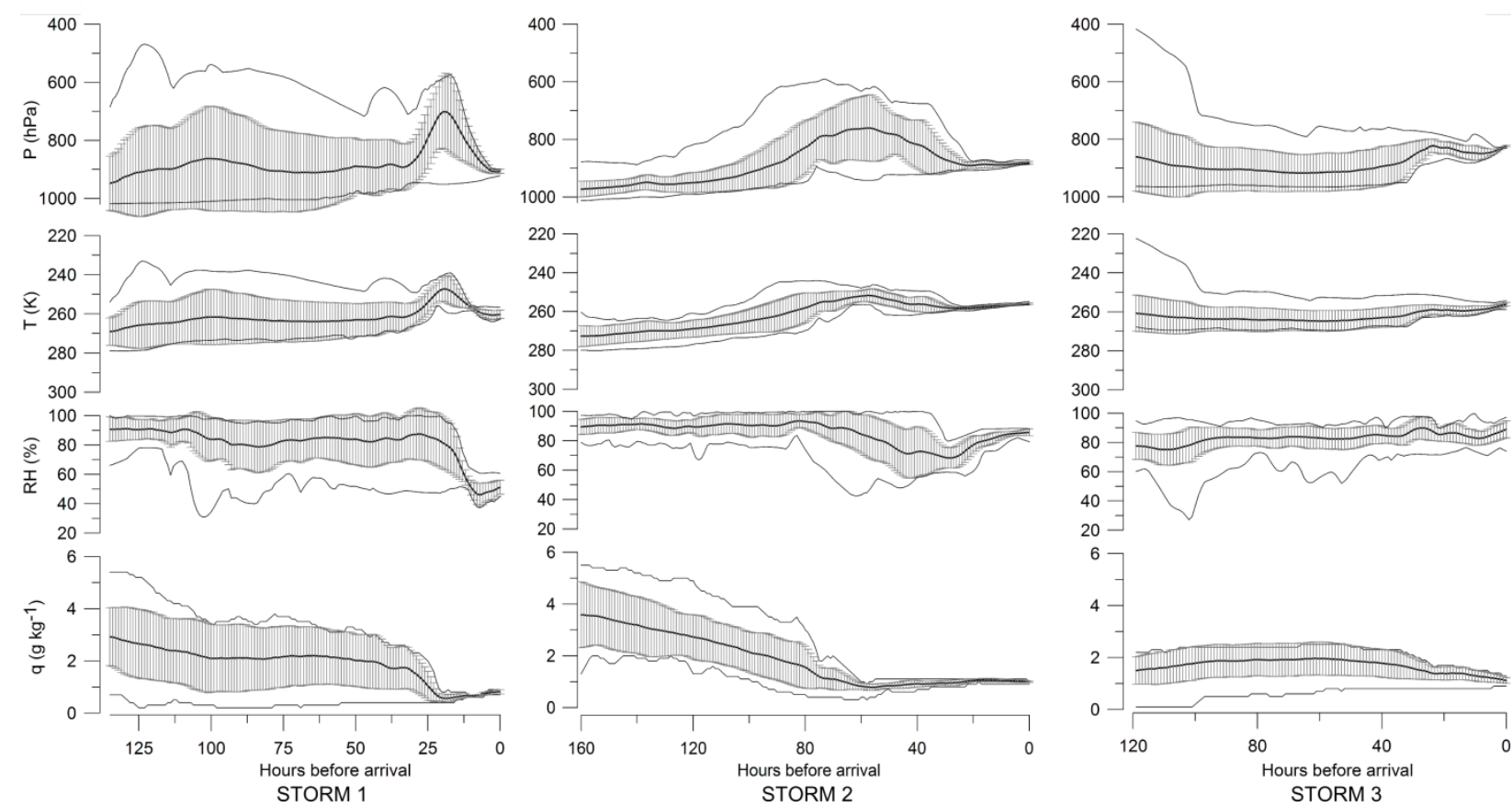

Figure 5.7 Pressure, temperature, relative humidity, and specific humidity profiles of moisturebearing back trajectories (highest $20 \%$ specific humidity values as shown in Fig. 6) for each storm. Upper and lower lines indicate the maximum and minimum values; the middle line and bars are the mean and standard deviation.

\subsection{Results and discussion}

\subsubsection{Storm 1}

Figure 5.8 shows the evolution of modeled $\delta^{18} \mathrm{O}$ in precipitation along the Storm 1 pathway, along with the $\mathrm{T}, \mathrm{RH}$, and q profiles and measured $\delta^{18} \mathrm{O}$ from fresh snow samples. The figure shows the modeled values with the dashed lines indicating the maximum and minimum range of values due to source region uncertainty (from Table 5.4). The RH drops below $80 \%$ from $\sim 20$ hours before arrival at the site, and the grey box indicates where fractionation is suspended. The ERA-Interim dataset does not simulate precipitation over the RI site, but because we know that accumulation did occur at the site during this storm, the 
model is forced to precipitate according the modeled vapor value, $\mathrm{T}$ and $\mathrm{P}$ at hour 0 (when the air parcel is over RI).

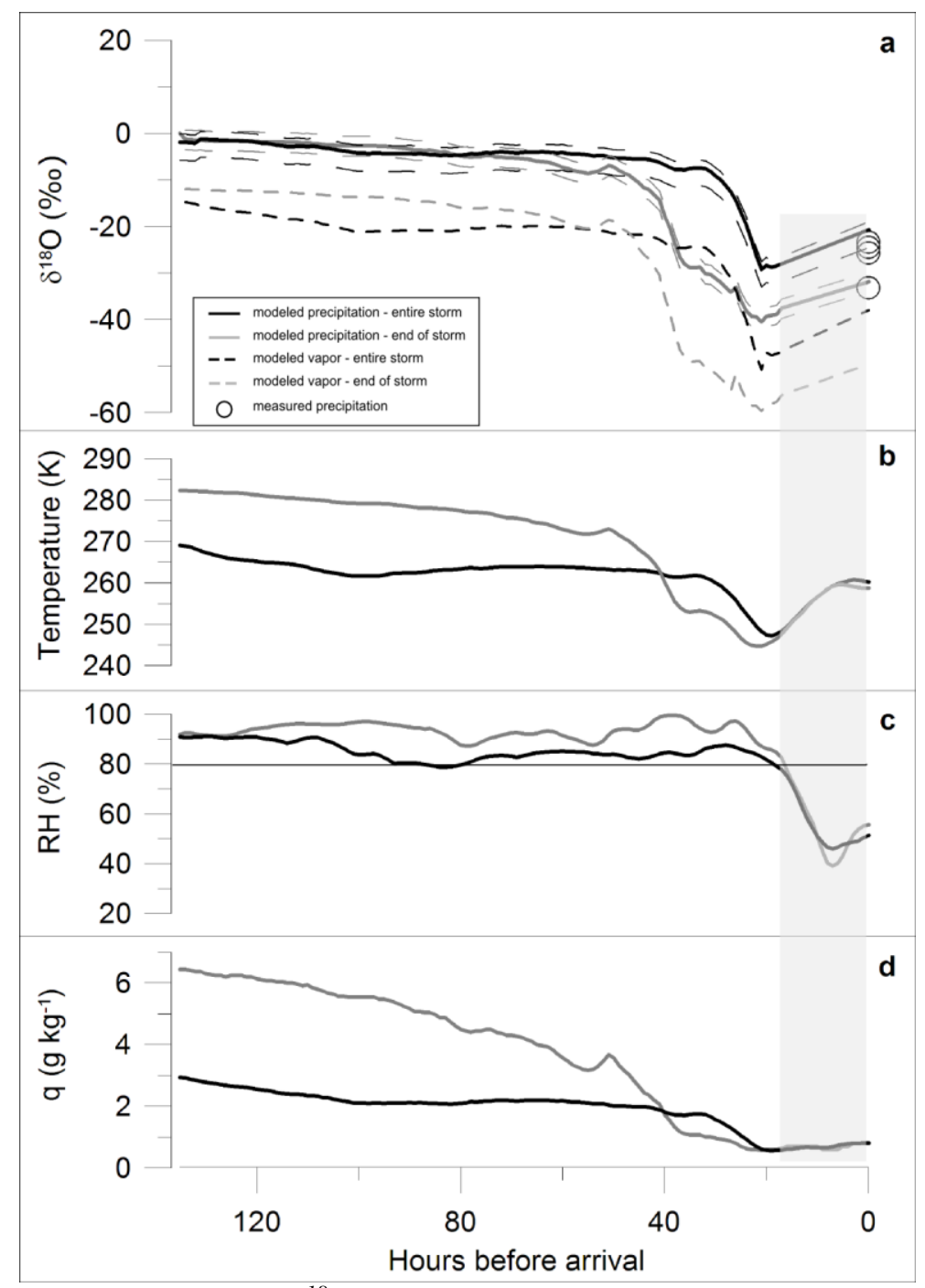

Figure 5.8. a) Evolution of modeled $\delta^{18} O$ precipitation (solid lines) and vapor (short dashed lines) along the Storm 1 pathway for the entire storm (black line) and for trajectories initiated during the final four hours of the storm only (grey line). Long dashed lines show sensitivity of precipitation to different initial vapor values $\left(\delta^{18} \mathrm{O}_{v 0}\right)$ from maximum and minimum source region values given in Table 5.3. Measured $\delta^{18} O$ values (circles) for all four samples are shown (standard deviation of measured values is smaller than the marker). b) Temperature, $\boldsymbol{c}$ ) relative humidity and d) specific humidity profiles for Storm 1 (black lines) and final four hours of Storm 1 (grey lines). The grey box indicates where $\mathrm{RH}<80 \%$ and Rayleigh fractionation is suspended.

The range of modeled values $(-24.5 \%$ to $-19.1 \%$ ) does not reproduce the full range of measured values from the Storm 1 samples $(-33.2 \%$ to $-23.4 \%$ ), but the first two samples (1A and $1 \mathrm{~B}$ ) are at the lower end of the range and sample $1 \mathrm{C}$ is within $5 \%$ of the lowest value. In order to reproduce the $9.8 \%$ drop in $\delta^{18} \mathrm{O}$ from first sample to final sample, errors in estimation of moisture and temperature along storm pathways would have to be significant. 
For example, temperature affects the final precipitation values only moderately, with a $10^{\circ} \mathrm{C}$ decrease in temperature decreasing $\delta^{18} \mathrm{O}$ by only $1.5 \%$. Errors in specific humidity are likely (as ERA-Interim doesn't reproduce the precipitation experienced for this storm), and reproducing the measured drop in $\delta^{18} \mathrm{O}$ would require an increase in $\Delta \mathrm{q}$ of $\sim 40 \%$ over the trajectory pathway (i.e. $40 \%$ decrease in $\mathrm{q}$ at RI or $40 \%$ increase in $\mathrm{q}$ at the source region).

Looking at the trajectories on a sub-storm scale, there is a distinct change in the trajectories initiated during the final four hours of Storm 1 (12 Nov, 01-04h) as shown in Figure 5.9. If these trajectories (corresponding to the final sample for Storm 1, 1D) are modeled separately, the model can reproduce the significant drop in $\delta^{18} \mathrm{O}$ for this part of the storm. Figure 5.8a shows the modeled $\delta^{18} \mathrm{O}$ for this separate pathway with the precipitated value at RI being close to the measured value for this sample $\left(\delta^{18} \mathrm{O}_{\text {modeled }}=-31.9 \% ; \delta^{18} \mathrm{O}_{1 \mathrm{D}}=\right.$ $-33.2 \%$ ). Figure 5.8d illustrates the different moisture history of the final sample which produces the significant drop in $\delta^{18} \mathrm{O}$, with higher initial humidity values and a significant loss of moisture occurring 40-50 hours before arrival at RI.

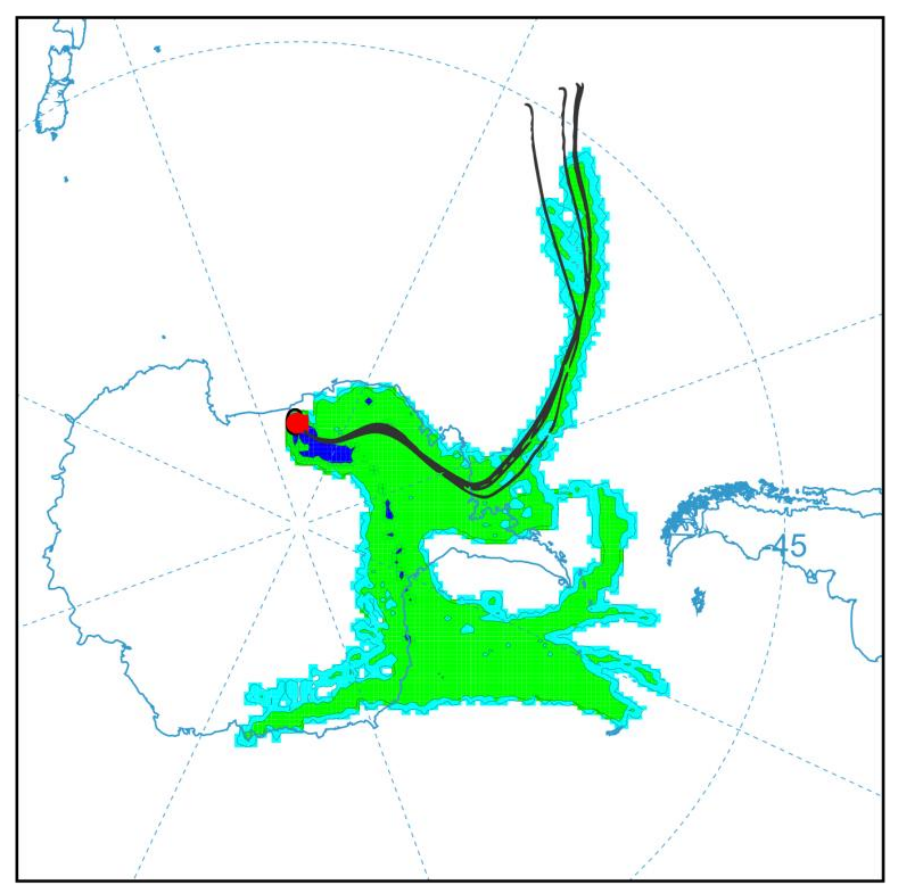

Figure 5.9 Frequency plot of all back-trajectories for Storm 1 with back-trajectories initiated during the final four hours of Storm 1 (Nov 12, 01h to 04h) indicated by the black lines.

\subsubsection{Storm 2-mixing/isotopic recharge}

While the variability of the trajectories in Storm 1 can explain the intra-storm variability in measured $\delta^{18} \mathrm{O}$, Storm 2 back-trajectories, which are more consistent (Figures 5.3 and 5.7), have larger variability in measured isotope ratios. The $\delta^{18} \mathrm{O}$ of the final sample $\left(\delta^{18} \mathrm{O}_{2 \mathrm{E}}=\right.$ 
$-18.5 \%$ ) is higher than the previous four samples (2A-2D), which range from $-34.2 \%$ to $-29.8 \%$ (Figure 5.4 and Table 5.3). Figure 5.10 shows the modeled $\delta^{18} \mathrm{O}$ values for Storm 2 with the dashed lines indicating the maximum and minimum range of values due to source region uncertainty (from Table 5.4), along with the T, RH, and q profiles. They grey box indicates the time period over which $\mathrm{RH}<80 \%$ and Rayleigh fractionation is suspended.

Modeled $\delta^{18} \mathrm{O}$ values $(-22.0 \%$ to $-16.9 \%$ ) only compare well to the final measured sample $(-18.5 \%)$. There is no change in trajectory or moisture history that would produce lower $\delta^{18} \mathrm{O}$ values in the early part of the storm, and variability in source region conditions is not large enough to account for the variability. Although the back-trajectories are associated with some error both spatially and in terms of the reanalysis data used to estimate the loss of moisture along storm pathways, the changes required to reproduce a $>10 \%$ increase in $\delta^{18} \mathrm{O}$ are significant. A $10^{\circ} \mathrm{C}$ decrease in temperature decreases $\delta^{18} \mathrm{O}$ by only $1.5 \%$, and reproducing the measured drop in $\delta^{18} \mathrm{O}$ would require an increase in $\Delta \mathrm{q}$ of $\sim 50 \%$ over the trajectory pathway (i.e. $50 \%$ decrease in q at RI or $50 \%$ increase in q at the source region).

To understand the cause of the variability in isotopes during Storm 2, we consider a scenario that mixes varying amounts of highly-fractionated moisture into the original air parcel. The trajectory profiles indicate an increase in specific humidity between approximately 60 and 20 hours before arrival at RI. This corresponds to the time the parcel spends at higher level in the atmosphere (760-890 hPa) while over the RIS (Figure 5.3 and Figure 5.7). Similar increases in q have been addressed in other Rayleigh models, and are thought to result in "isotopic recharge." In other words, new moisture from the atmosphere is incorporated to produce a new, mixed stable isotope signal [Helsen et al., 2006]. Mixing new moisture into an air mass changes not only the isotopic composition of the vapor but also the vapor fraction, which is a function of the specific humidity.

This is illustrated in Figure 5.10a, which shows $\delta^{18} \mathrm{O}$ as a function of varying the vapor fraction, $f$, from 0.5 to 1 . We use $-45.0 \%$ as the new $\delta^{18} \mathrm{O}$, which is the value of the vapor calculated by the model at hour 60 (before the increase in q begins). At this point $f$ is estimated to be 0.2 . The new modeled $\delta^{18} \mathrm{O}$ values vary from $-40.5 \%$ or $f=0.5$ to $-27.0 \%$ for $f=1$, and the measured intra-storm variability for Storm 2 is reproduced for a range in $f$ of 0.7 to 0.9 . This corresponds to a significant increase in moisture of between 300 to $500 \%$ to be added to the air parcel to reproduce the measured $\delta^{18} \mathrm{O}$ values. Although this magnitude of moisture increase is not captured by the reanalysis data (which indicates a moisture 
increase of only $\sim 12 \%$ ), incorporating less moisture requires much more highly-fractionated air (on the order of $-100 \%$ ).

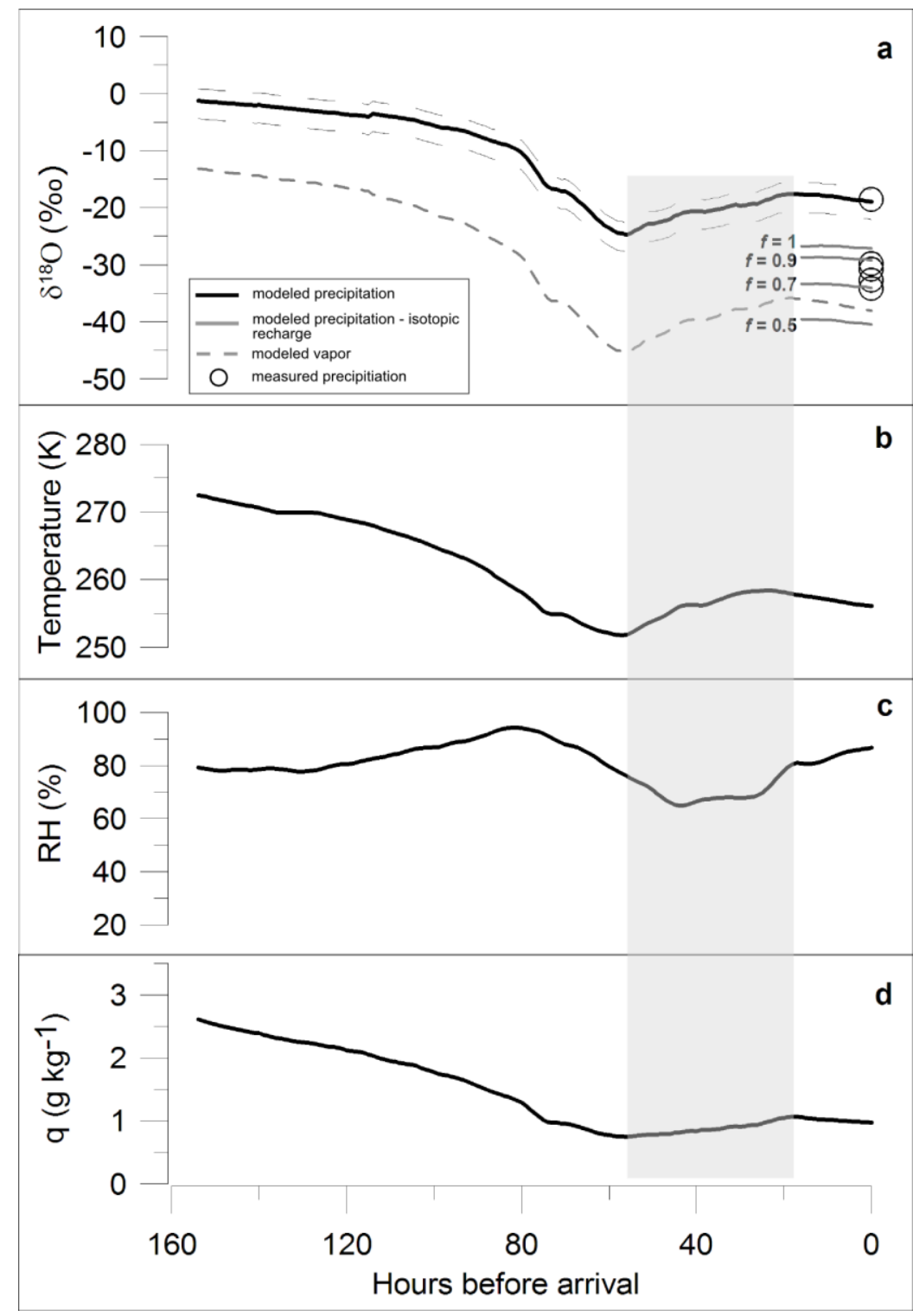

Figure 5.10 a) Evolution of modeled $\delta^{18} O$ precipitation (solid line) and vapor (short dashed line) along the Storm 2 pathway. Long dashed lines show sensitivity of precipitation to different initial vapor values $\left(\delta^{18} O_{v 0}\right)$ from maximum and minimum source region values given in Table 5.3. Measured $\delta^{18} O$ values (circles) for all four samples are shown (standard deviation of measured values is smaller than the marker). Precipitation as a result of isotopic recharge $\left(\delta^{18} \mathrm{O}_{v 0}=-45 \%\right.$ ) is modeled (solid grey lines) for varying amounts of vapor, $f=0.5$ to 1 . b) Temperature, c) relative humidity and $\boldsymbol{d}$ ) specific humidity profiles for Storm 2. The grey box indicates where $R H<80 \%$ and Rayleigh fractionation is suspended.

\subsubsection{Storm 3-mesoscale cyclone}

Based on the back-trajectories and satellite/synoptic images, Storm 3 can be characterized as a mesocyclone. As such, it will not be well represented by the Rayleigh model, which 
describes fractionation due to progressive cooling and condensation, processes which do not occur during these types of storms. The temperature, pressure, and humidity profiles show that these parameters change very little throughout the storm and the moisture arrives higher in the atmosphere than for the other two storms $(\sim 850 \mathrm{hPa})$. The trajectories and satellite images indicate that the precipitation was likely triggered by the introduction of cold, dry air coming across the RIS from East Antarctica interacting with the mesocyclonic system over the RIS.

Of the three storms in this study, Storm 3 produced the most precipitation $(5.5 \mathrm{~cm})$ and although the measured $\delta^{18} \mathrm{O}$ values are similar to those of the two synoptic storms, they show the least intra-storm variability (mean $\delta^{18} \mathrm{O}=-29.2 \%$, $\sigma=2.8 \%$ ). Although we do not model this storm, we apply the Rayleigh model to estimate the isotopic composition of the vapor required to precipitate the measured $\delta^{18} \mathrm{O}$. Interestingly, these values $\left(\delta^{18} \mathrm{O}_{\mathrm{v}}=-39.5 \%\right.$ o to $-46.1 \%$ ) are similar to the value calculated for the isotopic recharge scenario for Storm 2 $\left(\delta^{18} \mathrm{O}_{\mathrm{v}}=-45 \%\right.$ ), and correspond to similar heights in the atmosphere (760 to $890 \mathrm{hPa}$ for Storm 2 and $850 \mathrm{hPa}$ for Storm 3). Further, because mesoscale storms deliver precipitation that is not a function of cloud temperature or air mass trajectory, their influence on long-term (ice core) isotope records could be significant and is certainly worth further consideration.

\subsubsection{Deuterium excess}

As d-excess is based on the equilibrium fractionation relationship between $\delta^{18} \mathrm{O}$ and $\delta \mathrm{D}$ [Dansgaard, 1964], deviations from this relationship reveal kinetic fractionation effects that occur at oceanic source regions and provide information on initial evaporation conditions (primarily SST and RH, and to a lesser extent, wind speed) [Merlivat and Jouzel, 1979]. Based on this, d-excess records have been used to interpret source region and air mass trajectory changes on decadal to millennial timescales [e.g. Vimeux et al., 1999; Stenni et al., 2001; Masson-Delmotte et al., 2004]. On shorter timescales, it is difficult to model d-excess at high latitudes primarily because kinetic fractionation processes in low-temperature clouds are not well understood [Hoffmann et al., 1998; Jouzel et al., 2000; Helsen et al., 2006].

The d-excess values for the three storms vary considerably (Table 5.3). Storm 1 values are high (ranging from $11.8 \%$ - 17.9\%o), with values similar to those at elevations above $3000 \mathrm{~m}$ in Antarctica [Masson-Delmotte et al., 2008], which is consistent with the air mass having traversed the WAIS before precipitating at the site. For Storms 2 and 3, measured d-excess ranges from $2.7 \%$ to $10.8 \%$ and $2.1 \%$ to $11.2 \%$, respectively. The lower 
d-excess values may relate to the higher-latitude source regions (Figure 5.6), as lower SST and higher RH would impart a lower initial d-excess value.

The evolution of modeled d-excess precipitation of Storm 1 for both the entire storm and for the end of the storm is shown in Figure 5.11a. Sensitivity of d-excess due to source region variability is shown with dashed lines using maximum and minimum values initial isotopic values from Table 5.3. The resulting range in final precipitated d-excess is large ($7.9 \%$ to $21.3 \%$ for all storm trajectories; $4.9 \%$ to $27.8 \%$ for end-of-storm trajectories) and encompasses the measured d-excess values for both Storm 1 pathways, with values near the upper range for all storm trajectories, and near the mean for the end-of-storm trajectories. The d-excess is also modeled for Storm 2 and results in a comparatively large range $(-8.7 \%$ to $14.9 \%$; Figure 5.11b). The measured d-excess value for the sample that corresponds to this (non-mixed) pathway is near the upper bound of the modeled range $(10.8 \%$ ).

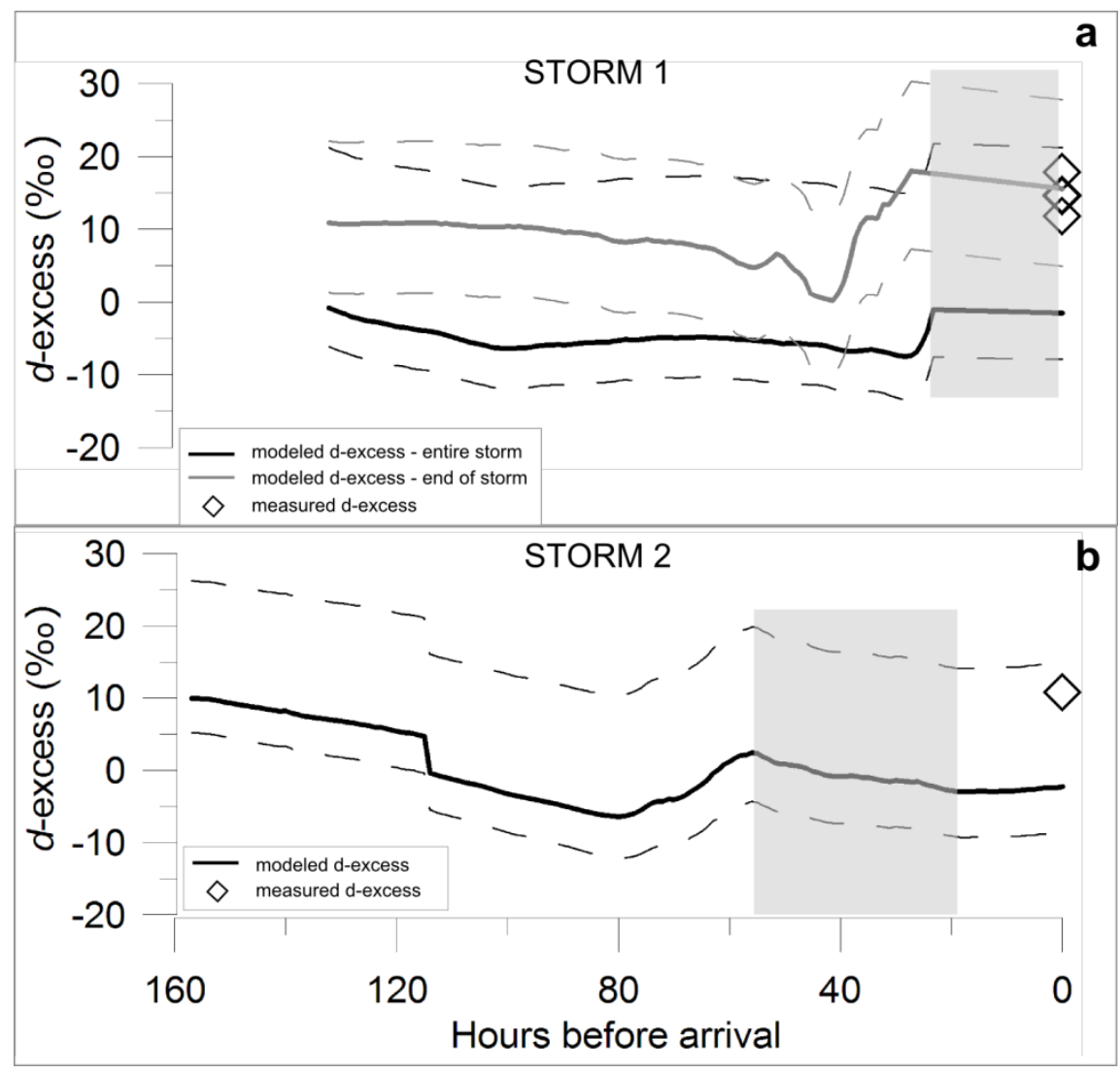

Figure 5.11 a) Evolution of modeled d-excess precipitation along the Storm 1 pathway for the entire storm (black line) and for trajectories initiated for the final four hours of the storm (grey line). Dashed lines show sensitivity of d-excess precipitation to different initial vapor values from maximum and minimum source region values given in Table 5.3. Measured d-excess values (diamonds) for all four samples are shown for comparison. b) Evolution of modeled d-excess for Storm 2 (solid line) with sensitivity to maximum and minimum source region values from Table 5.3 (dashed lines). Measured d-excess for the sample not affected by isotopic recharge (diamond) is shown for comparison. The grey box indicates where $R H<80 \%$ and Rayleigh fractionation is suspended. 
The evolution of d-excess precipitation in Figure 5.11 indicates that d-excess is highly sensitive to both source region variability and moisture pathway, as other previous studies have also shown [e.g. Helsen et al., 2006; 2007]. Further work with more storm observations is necessary to better understand the effects of source region, moisture pathways, and the parameterization of kinetic fractionation.

\subsection{Summary}

A Rayleigh distillation model with mixed cloud isotopic processes is used to investigate stable isotopes on sub-storm timescales for synoptic storms producing precipitation at a coastal Antarctic site. Three storm events were sampled during NovemberDecember 2010. For each of the storm events, freshly precipitated snow was sampled four to five times throughout the storm allowing elimination of uncertainties involving postdepositional effects. Air-mass trajectories derived from the HYSPLIT model and ERAInterim reanalysis data are used to drive the Rayleigh model. An assessment of ERA-Interim meteorological parameters for the three storms compares well with observed conditions giving confidence that the back-trajectories are producing realistic air-mass pathways.

Measured stables isotopes, $\delta^{18} \mathrm{O}$ and $\delta \mathrm{D}$, show high intra-storm variability. Overall, the Rayleigh distillation model (driven by ERA-Interim reanalyses data) is able to reproduce the stable isotope composition of precipitation on sub-storm timescales and over simple topographic terrain. We show that uncertainty in source region conditions accounts for some, but not all of the intra-storm variability and changes in air-mass trajectory and mixing account for the largest changes in $\delta^{18} \mathrm{O}$ values. For Storm 1, air-mass trajectories show significant change in moisture pathway that accounts for the variability and high-resolution modeling along specific trajectories is required to reproduce the full range of isotopic values in precipitation. For Storm 2, the intra-storm variability is shown to be reproduced only by mixing in varying amounts of already highly-fractionated air. Storm 3 is a mesocyclone which is not able to be modeled using Rayleigh distillation processes, but points to the importance of understanding how precipitation from mesoscale cyclones impact the interpretation of paleoclimate records at sites known to have significant mesocyclone activity.

The modeled d-excess illustrates the sensitivity of this parameter to source regions and moisture pathways. More observations are needed to assess whether the kinetic fractionation processes in the model are sufficiently represented and to better understand the extent to which the source region conditions are imprinted on the d-excess signal in 
precipitation. Further study on a more diverse range of storm events could provide more understanding of how source region and trajectory changes affect the d-excess parameter.

\section{Acknowledgements}

The authors greatly appreciate funding and logistics support from Antarctica New Zealand. Project funding was also received from the New Zealand Ministry for Science and Innovation via contracts awarded to Victoria University of Wellington, GNS Science (VICX0704, CO5X0202, RDF-VUW1103) and a N.Z. Foundation for Research, Science and Technology Postdoctoral Fellowship (contract CO5X0902). We also appreciate the access to and use of the ECMWF ERA-Interim reanalysis data, the NOAA HYSPLIT model and the data products and support provided by the U. Wisconsin-Madison, AMRC. Thanks also to Sam Dean for valuable help with the analysis and manuscript.

\subsection{References}

Barras, V. J. I., and I. Simmonds (2008) Synoptic controls upon $\delta^{18} \mathrm{O}$ in southern Tasmanian precipitation, Geophys. Res. Lett., 35, L02707, doi: 10.1029/2007GL031835.

Barras, V. and I. Simmonds (2009) Observation and modeling of stable water isotopes as diagnostics of rainfall dynamics over southeastern Australia, J. Geophys. Res.,114, D23308, doi: 10.1029/2009JD012132.

Bromwich, D. H. (1988) Snowfall in high southern latitudes, Rev. Geophys.,26(1), 149-168.

Bromwich, D. H., J. P. Nicholas, A. J. Monaghan (2011) An assessment of precipitation changes over Antarctica and the Southern Ocean since 1989 in contemporary global reanalyses. J.Climate, 24, 4189-4209.

Cappa, C. D., M. B. Hendricks, D. J. DePaolo, and R. C. Cohen (2003) Isotopic fractionation of water during evaporation, J. Geophys. Res., 108(D16), 4525, doi:10.1029/2003JD003597.

Ciais P, J. Jouzel (1994) Deuterium and oxygen 18 in precipitation: Isotopic model, including mixed cloud processes. J. Geophys. Res. 99(D8): 16,793-16,803.

Ciais P., J. W. C. White, J. Jouzel, and J. R. Petit (1995) The origin of present-day Antarctic precipitation from surface snow deuterium excess data.J. Geophys. Res., 100, $18917-$ 18927.

Cohen, L., S. Dean, and J. Renwick (2012) Synoptic Weather Types for the Ross Sea Region, Antarctica.J. Climate. in press, doi:10.1175/JCLI-D-11-00690.1. 
Conway, H., B. L. Hall, G. H. Denton, A. M. Gades, E. D. Waddington (1999) Past and Future Grounding-Line Retreat of the West Antarctic Ice Sheet, Science, 286, 280283.

Craig, H. and A. Gordon (1965) Deuterium and oxygen 18 variations in the ocean and the marine atmosphere.In Stable Isotopes in Oceanic Studies and Paleotemperatures, 9130. Lab. Di Geol. Nucl., Pisa, Italy.

Cullather, R. I., D. H. Bromwich, and M. L. Van Woert (1996) Interannual variations in Antarctic precipitation related to El Nino-Southern Oscillation, J. Geophys. Res., 101(19), $109-19,118$.

Dansgaard, W., 1964. Stable isotopes in precipitation, Tellus, 16, 436-468.

Dee, D. P., S. M. Uppala, A.J. Simmons, P. Berrisford, P. Poli, S. Kobayashi, and 30 others (2011) The ERA-Interim reanalysis: configuration and performance of the data assimilation system. Q.J.R. Meteorol. Soc., 137: 553-597.doi:10.1002/qj.828

Delmotte, M., V. Masson, J. Jouzel, V. and Morgan (2000) A seasonal deuterium excess signal at Law Dome, coastal eastern Antarctica: A southern ocean signature. $J$. Geophys. Res, 105(D6), 7187-7197.

Draxler, R.R., and G.D. Hess (1997) Description of the HYSPLIT_4 modeling system. NOAA Tech. Memo. ERL ARL-224, NOAA Air Resources Laboratory, Silver Spring, MD, $24 \mathrm{pp}$.

Ersek V., A. C. Mix, P. U. Clark (2010) Variations of ${ }^{18} \mathrm{O}$ in rainwater from southwestern Oregon. J. Geophys. Res. 115, D09109. DOI: 10.1029/2009JD013345.

Fierz, C., R. L. Armstrong, Y. Durand, P. Etchevers, E. Greene, D. M. McClung, K. Nishimura, P.K. Satyawali, S. A. Sokratov (2009) The International Classification for Seasonal Snow on the Ground.IHP-VII Technical Documents in Hydrology Nº3, IACS Contribution $\mathrm{N}^{\circ} 1$, UNESCO-IHP, Paris.

Fogt, R. L. and D. H. Bromwich (2006) Decadal Variability of the ENSO Teleconnection to the High-Latitude South Pacific Governed by Coupling with the Southern Annular Mode. J. Climate, 19, 979-997.

Fogt, R. L., A. J. Wovrosh, R. A. Langen, and I. Simmonds (2012) The characteristic variability and connection to the underlying synoptic activity of the AmundsenBellingshausen Seas Low. J. Geophys. Res., 117, D07111, doi:10.1029/2011JD017337.

Gedzelman, S.D. and J.R. Lawrence (1982) The isotopic composition of cyclonic precipitation, J. Appl. Meteorol, 21, 1385-1404. 
Helsen, M. M., R. S. W. Van de Wal, M. R. Van den Broeke, E.R. T. Kerstel, V. MassonDelmotte, H. A. J. Meijer, C. H. Reijmer, and M. P. Scheele (2004) Modelling the isotopic composition of snow using backward trajectories: A particular accumulation event in Dronning Maud Land, Antarctica. Ann. Glaciol.,39, 293-299.

Helsen, M. M., R. S. W. Van de Wal, M. R. Van den Broeke, D. Van As, H. A. J. Meijer, and C. H. Reijmer (2005) Oxygen isotope variability in snow from western Dronning Maud Land, Antarctica and its relation to temperature. Tellus, 57B, 423-435.

Helsen M.M., R. S. W. van de Wal, M. R. van den Broeke, V. Masson-Delmotte, H. A. J. Meijer, M. P. Scheele, M. Werner (2006) Modeling the isotopic composition of Antarctic snow using backward trajectories: Simulation of snow pit records. $J$. Geophys. Res. 111, D15109. DOI: 10.1029/2005JD006524.

Helsen M.M., R. S. W. van de Wal, M. R. van den Broeke (2007) The isotopic composition of present-day Antarctic snow in a langrangian atmospheric simulation. J. Climate, 20(4): 739- 756. DOI: 10.1175/JCLI4027.1.

Hoffmann, G., M. Werner, and M. Heimann (1998) Water isotope module of the ECHAM atmospheric general circulation model: A study on time scales from days to several years. J. Geophys. Res., 103 (D14), 16 871-16 896.

Horita J. and D. J. Wesolowski (1994) Liquid-vapour fractionation of oxygen and hydrogen isotopes of water from the freezing to the critical temperature. Geochimica Et Cosmochimica Acta 58(16): 3425-3437. DOI: 10.1016/0016-7037(94)90096-5.

Jacob, H. and C. Sonntag (1991) An 8-year record of the seasonal ratio of ${ }^{2} \mathrm{H}$ and ${ }^{18} \mathrm{O}$ in atmospheric water vapour and precipitation at Heidelberg, Tellus Ser. B,43, 291-300.

Johnsen, S. J., W. Dansgaard, and J. W. White (1989) The origin of Arctic precipitation under present and glacial conditions, Tellus, Ser. B, 41, $452-469$.

Johnsen, S. J., H. B. Clausen, K. M. Cuffey, G. Hoffmann, J. Schwander, and T. Creyts (2000) Diffusion of stable isotopes in polar firn and ice: The isotope effect in firn diffusion, in Physics of Ice Core Records, edited by T. Hondoh, pp. 121-140, Hokkaido Univ. Press, Sapporo, Japan.

Joussaume, J., R. Sadourny, and J. Jouzel (1984) A general circulation model of water isotope cycles in the atmosphere.Nature, 311, 24-29.

Jouzel J and L. Merlivat (1984) Deuterium and oxygen 18 in precipitation: Modeling of the isotopic effects during snow formation. J. Geophys. Res. 89(D7): 11,749-11,757. DOI:10.1029/JD089iD07p11749. 
Jouzel, J. and R.D. Koster (1996) A reconsideration of the initial conditions used for stable water isotope models. J. Geophys. Res., 101(D17), 22,933-22,938.

Jouzel, J., R. B. Alley, C.M. Cuffey, W. Dansgaard, P. Grootes, G. Hoffmann, S.J. Johnsen, R.D. Koster, D. Peel, C.A. Shuman, M. Stievenard, M. Stuiver, and J. White (1997) Validity of the temperature reconstruction from water isotopes in ice cores.J. Geophys. Res., 102(C12), 26,471-26,487.

Jouzel, J., F. Vimeux, N. Caillon, G. Delaygue, G. Hoffmann, V. Masson-Delmotte, and F. Parrenin (2003) Magnitude of isotope/temperature scaling for interpretation of central Antarctic ice cores, J. Geophys. Res., 108(D12), 4361, doi:10.1029/2002JD002677.

Kavanaugh, J. L., and K. M. Cuffey (2003) Space and time variation of $\mathrm{d}^{18} \mathrm{O}$ and $\mathrm{dD}$ in Antarctic precipitation revisited, Global Biogeochem. Cycles, 17(1), 1017, doi:10.1029/2002GB001910.

Knuth, S. L., G. J. Tripoli, J. E. Thom, G. A. Weidner (2010) The influence of blowing snow and precipitation on snow depth change across the Ross Ice Shelf and Ross Sea regions of Antarctica. J. App. Met. \& Clim., 49, 1306-1321.

Lorius, C., and L. Merlivat (1977) Distribution of mean surface stable isotope values in East Antarctica. Observed changes with depth in a coastal area, in Isotopes and Impurities in Snow and Ice, Proceedings of the Grenoble Symposium Aug./Sep. 1975, IAHS Publ., 118, $127-137$.

Marshall, G. J. (2007) Half-century seasonal relationships between the Southern Annular Mode and Antarctic temperatures, International J. Climatology, 27, 3, 373-383.

Masson-Delmotte, V., M. Delmotte, V. Morgan, D. Etheridge, T. V. Ommen, S. Tartarin, and G. Hoffmann (2003) Recent southern Indian Ocean climate variability inferred from a Law Dome ice core: New insights for the interpretation of coastal Antarctic isotopic records, Clim. Dyn.,21(2), 153-166.

Masson-Delmotte, V., B. Stenni, and J. Jouzel (2004) Common millennial-scale variability of Antarctic and Southern Ocean temperatures during the past 5000 years reconstructed from the EPICA Dome C ice core. Holocene, 14, 145-151.

Masson-Delmotte, V, Hou, S., Ekaykin, A., Jouzel, J., and 32 others (2008) A review of Antarctic surface snow isotopic composition: Observations, atmospheric circulation, and isotopic modeling. J. Climate, 21(13), 3359-3387. DOI: 10.1175/2007JCLI2139.1.

Mayewski, P.A., M. Frezzotti, N. Bertler, and 16 others (2005) The International TransAntarctic Scientific Expedition (ITASE): an overview, 28th Symposium of the 
Scientific-Committee on Antarctic Research, Jul 28-29, 2004, Ann. Glaciology, 41, 180-185.

Mellor, M. (Ed.) (1964) Antarctic Snow and Ice Studies. Antarct. Res. Ser., vol. 2, 286 pp., AGU, Washington D.C.

Merlivat L. and J. Jouzel (1979) Global climatic interpretation of the deuterium-oxygen 18 relationship for precipitation.J. Geophys. Res 84(C8): 5029-5033. DOI:10.1029/JC084iC08p05029.

Noone, D. C. and I. A. Simmonds (2002a) Annular variations in moisture transport mechanisms and the abundance of $\mathrm{d} 180$ in Antarctic snow, J. Geophys. Res., 107(D24), 4742, doi:10.1029/2002JD002262.

Noone, D., and I. Simmonds (2002b) Associations between 180 of water and climate parameters in a simulation of atmospheric circulation for 1979-95. J. Climate, 15, 3150-3169.

Scambos, T., J. Bohlander, and B. Raup (1996) Images of Antarctic ice shelves. [2010 Nov 10, 1700h] Boulder, Colorado, USA: National Snow and Ice Data Center. Digital media. http://nsidc.org/data/iceshelves_images/

Schlosser, E. and H. Oerter (2002) Seasonal variations of accumulation and the isotope record in ice cores: a study with surface snow samples and firn cores from Neumayer station, Antarctica. Ann. Glac.,35, 97-101.

Schlosser, E., C. Reijmer, H. Oerter, and W. Graf (2004) The influence of origin of precipitation on the 180-T relationship at Neumayer Station, Ekströmisen, Antarctica.Ann. Glaciol.,39, 41-48.

Schmidt, G. A., G. Hoffmann, D. T. Shindell, and Y. Hu (2005) Modeling atmospheric stable water isotopes and the potential for constraining cloud processes and stratospheretroposphere water exchange, J. Geophys. Res., 110, D21314, doi:10.1029/2005JD005790.

Simmonds, I., K. Keay, and E. Lim (2003) Synoptic Activity in the Seas around Antarctica. Mon. Wea. Rev.131, 272-287.

Sinclair, K. E., S. J. Marshall, T. A. Moran (2011) A Lagrangian approach to modelling stable isotopes in precipitation over mountainous terrain. Hydrol. Process. DOI: 10.1002/hyp.7973.

Stammerjohn, S. E., D. G. Martinson, R. C. Smith, X. Yuan, and D. Rind (2008) Trends in Antarctic annual sea ice retreat and advance and their relation to El Niño-Southern Oscillation and Southern Annular Mode variability. J. Geophys. Res., 113, C03S90. 
Stenni, B., V. Masson-Delmotte, S. Johnsen, J. Jouzel, A. Longinelli, E. Monnin, R. Röthlisberger, and E. Selmo (2001) An oceanic cold reversal during the last deglaciation.Science, 293, 2074-2077.

van Lipzig, N. P. M., E. Van Meijgaard, and J. Oerlemans (2002) The effect of temporal variations in the surface mass balance and temperature-inversion strength on the interpretation of ice-core signals.J. Glaciol.,48, 611-621.

Vimeux, F., V. Masson, J. Jouzel, and M. Stievenard (1999) Glacial-interglacial changes in ocean surface conditions in the Southern Hemisphere. Nature, 398, 410-413. 



\section{Summary and Conclusions}

The research presented in this thesis explores the atmospheric drivers of precipitation in the Ross Sea region of Antarctica from three different perspectives. Precipitation plays a key role in the Antarctic (and thus global) climate system and there are still many unknowns in our knowledge of how it varies in both time and space. In addition, precipitation-based proxies are one of the most important tools we have for reconstructing past climate and climate variability, and better understanding of the fundamental relationships that lead to those reconstructions is extremely important.

Atmospheric variability in the Pacific sector of Antarctica is of interest because the ENSO and SAM are known to affect the climates of the West Antarctic Ice Sheet, Antarctic Peninsula, and Ross Sea region. Understanding current and past climate conditions in these regions requires specific knowledge of how the atmospheric affects the variability of parameters such as precipitation and temperature. This leads to the research question:

How do large-scale atmospheric circulation patterns such as ENSO and SAM affect local meteorological parameters in the Ross Sea region and at the Roosevelt Island site in particular?

Chapter 3 addresses this question by developing a new synoptic-climatology for the Pacific sector of Antarctica which provides a link between large-scale atmospheric circulation patterns and local meteorological parameters in the region. The analysis produced six synoptic types, which describe the synoptic conditions of the region over the last 32 years (1979-2011). The synoptic types are shown to reflect known atmospheric variability in the region, such as the seasonal shift of the Amundsen Sea Low, and changes in depth due to ENSO and SAM.

The synoptic types also correlate with local-scale variability of climate parameters temperature and precipitation (using the Roosevelt Island site as a test case), and thus provide a link between hemispheric-scale atmospheric variability and local climate variability. Comparison of the precipitation and temperature regimes at Roosevelt Island (RI) with the synoptic types illustrates the primary precipitation delivery pathways and associated seasonality, providing key information for interpretation of snow pits and ice cores from the site. Most of the precipitation at RI is associated with lows in the Ross Sea, a situation which also tends to bring warmer air to the site. The higher frequency of the Low-Ross type in the 
winter suggests that synoptically-driven snow accumulation may be more frequent in the winter, although preliminary analysis of two snow pits at RI does not show considerable seasonality of the snow accumulation (Appendix A).

The synoptic types show that there are changes in the synoptic conditions of the region associated with different SAM and ENSO phases and those changing synoptic conditions affect the temperature and precipitation variability at RI, suggesting that these climate cycles may be recorded in snow and ice proxy records at the site. For example, El Niño and negative SAM conditions are correlated with the Low-Ross type (a low situated in the Ross Sea) which is associated with larger amounts of precipitation and warmer temperatures at RI.

However, it is important to keep in mind that the process of synoptic classification is inherently simplifying. Precipitation is a result of complex processes that operate on a wide range of spatial and temporal scales, and at RI precipitation is likely complicated by a wide variety of phenomenon such as mesoscale storms, the topography of the Siple Coast and RI itself, other climate cycles (e.g. the Semiannual Oscillation and Antarctic Circumpolar Wave), and the variability of sea ice. Thus it is necessary to consider the influences of these phenomenon on precipitation at RI in order to accurately interpret possible ENSO or SAM signals in the snow and ice data from the site.

In addition, some of the specifics concerning the teleconnections of ENSO and SAM with the Amundsen Sea Low (ASL) remain under debate. A climatology of the ASL developed by Turner et al. (2012) using reanalyses data, finds a zonal shift of the ASL due to ENSO that is opposite to the shift seen in the synoptic types (though not statistically significant), and finds no zonal shift associated with the SAM. Though Turner et al. (2012) do find similar strengthening (weakening) of the ASL with +SAM and La Niña (-SAM and El Niño) conditions. Further studies to determine the cause of the differences in these analyses would be of considerable interest and would provide better understanding of the climatology of the region.

One way of approaching this would be to use self organizing maps over the region. Self organizing maps (SOMs) are another synoptic classification technique which has been used to investigate synoptic conditions (primarily wind regimes) on the Ross Ice Shelf. The pressure maps produced by Seefeldt and Cassano (2012) for the Ross Ice Shelf and Ross Sea region used higher resolution model data (Antarctic Mesoscale Prediction System) over a smaller region, but show very similar patterns to those derived in the analysis presented in this thesis (i.e. low pressures of varying depth that shift zonally across the Ross Sea region). 
For SOMs, the number of patterns chosen to represent a dataset is more subjective than for cluster analysis, but they provide more information on the relationships between patterns than is provided directly from a cluster analysis. Studies using SOMs for the New Zealand region showed that they reproduced the synoptic types derived from cluster analysis for the same region (Kidson types), indicating that the techniques are complementary (e.g. Jiang et al., 2013). Further discussion of future research motivated by the synoptic types work is presented in Section 6.1.

Reanalyses products are an important and widely-used tool for understanding the climate variability of Antarctica, but precipitation in reanalyses datasets is not well constrained by observations particularly on synoptic timescales. In addition, because observations of precipitation in Antarctica are sparse, assessments of precipitation in reanalyses have only been made on annual and longer timescales. This leads to the research question:

How well do atmospheric reanalyses datasets represent precipitation on synoptic timescales in the Ross Sea region?

Chapter 4 addresses this question by developing a new event-based method for assessing ERA-Interim and NCEP-2 reanalyses precipitation around the Ross Ice Shelf using in-situ snow accumulation measurements from nine Automatic Weather Stations (AWS) between 2008-2012. By using only the positive accumulation events in the snow accumulation record (which are easily identified as stepped changes in height), the event-based analysis is able to ignore the effects of compaction, sublimation, and ablation. However, accumulation events are highly affected by wind which can both limit and enhance snow accumulation. This is an on-going challenge in precipitation studies, and is addressed in this study by considering the general effects of the Ross Ice Shelf surface wind regime on snow accumulation and by using as many measurements as possible in order to provide a statistical assessment. Overall, the results show that for both reanalyses datasets most of the precipitation (66-75\%) is associated with actual snow accumulation events measured by the acoustic depth gauges (ADGs).

In comparing the two reanalyses products, ERA-Interim reproduces considerably more observed precipitation events than NCEP-2, and consistently produces more precipitation per event than NCEP-2. The largest disparities between ERA-Interim and NCEP-2 precipitation is for sites near the Transantarctic Mountains, and this study showed that this is primarily due to differences in water content and meridional circulation over the RIS between the two models. The may be due to the higher spatial resolution of ERA-Interim 
being able to better reproduce the effects of the barrier formed by the Transantarctic Mountains on circulation around the RIS.

While qualitative differences between the two reanalyses representation of precipitation is described, quantification of systematic biases in the size of precipitation events in either of the reanalyses products is not possible using only the ADG data. This is because: 1) the effects of wind on the snow accumulation measurements on an event-byevent basis is unknown and 2) in order to convert snow accumulation values to water equivalency, the snow density must be known. Based on the range of fresh and wind-blown snow densities ( 70 to $250 \mathrm{~kg} \mathrm{~m}^{-3}$ ), statistical relationships between the coincident events show that NCEP-2 event sizes are at the lower range of the expected values and ERA-Interim are at the upper range of expected values. This suggests that NCEP-2 may be underestimating the size of events while ERA-Interim may be overestimating events. Although the ADG snow accumulation measurements cannot provide qualitative information on precipitation amounts, they are a valuable source of data and have been shown here to provide some insight into the representation of precipitation in reanalyses products. Further discussion of future research motivated by this work is presented in Section 6.1.

The work in Chapter 3 provides understanding of how hemispheric-scale atmospheric variability influences precipitation at Roosevelt Island via the synoptic variability of the Ross and Amundsen Sea regions. This is an important contribution to the interpretation of climate proxies at the Roosevelt Island site as they are largely driven by that synoptic variability. However, specifically how the synoptic variability (i.e. changes in moisture trajectory and source region) influences the stable isotope composition of precipitation that falls at Roosevelt Island is critical for interpretation of these proxies in ice cores from the site. This prompts the question:

What are the atmospheric influences on the stable isotope composition of snow at the Roosevelt Island site?

Chapter 5 addresses this question by using an isotopic fractionation model to investigate the atmospheric influences on the composition of stable isotopes in snow at Roosevelt Island on sub-storm timescales. The modelled isotope values are compared to measured isotope values from samples collected during three storm events at Roosevelt Island. One of the key advantages of this study is the sampling of snow during storm events which eliminates the uncertainties involved in estimating dates of snow deposition and post-depositional effects. In 
addition, modelling fractionation on these timescales (sub-storm) provides a technique that hasn't been used for Antarctic snowfall before.

The isotopic modelling uses a Rayleigh distillation model with mixed-cloud processes incorporated. Air mass trajectories for each storm are derived from the NOAA HYSPLIT model using ERA-Interim reanalyses data. The Rayleigh model is driven using the ERAInterim meteorological parameters along the derived air mass trajectories from the source region to precipitating at Roosevelt Island.

The Rayleigh model is able to reproduce the variability of measured $\delta^{18} \mathrm{O}$ well for one of the storms by following the changes in moisture along trajectories derived from the HYSPLIT model. For the second storm, the measured intra-storm variability could only be reproduced by mixing in already highly fractionated air. The third storm cannot be modeled using this method because the storm doesn't follow a Rayleigh-type trajectory (i.e. progressive condensation as the air parcel cools).

An important result from the analysis of Storm 1 is that, while the measured $\delta^{18} \mathrm{O}$ values vary during the storm due to the change in air mass trajectory and source region, the measured d-excess values for this storm do not change considerably. The modelled d-excess for this storm, despite the large uncertainties (due to uncertainties in source region SST and $\mathrm{RH}$ ), indicates that there should be a change in the d-excess values. This indicates a significant lack of understanding of the physical processes driving d-excess values at this site (i.e. the model is wrong), or may demonstrates that d-excess records from RI do not reflect source region changes at all. Sensitivity studies using the Rayleigh model would provide insight into whether this discrepancy is primarily due to poor parameterization of mixedcloud processes or due to uncertainties in the back-trajectories and source region determination. Further discussion of future research motivated by this isotope modelling work is presented in Section 6.1.

Arguably, our current understanding of the spatial and temporal variability of precipitation in Antarctica is less than that of many other meteorological parameters such as temperature, pressure, radiation, humidity, and wind. However, as observation networks are expanded, new observation techniques are developed, and modelling is improved, that understanding is growing. Advances in our knowledge of how atmospheric conditions relate to precipitation in current climate conditions can, in turn, provide further understanding of past climate conditions via the interpretation of ice cores. As we still know surprisingly little 
about the fundamental relationships between atmospheric conditions and precipitation-based proxies, there is much further work to be done in order to produce more robust interpretations of past climates.

\subsection{Future Work}

The synoptic climatology developed for the Ross/Amundsen Sea region in Chapter 3 provides an understanding of the (current) synoptic conditions at Roosevelt Island and establishes a basis for interpreting snow and ice climate proxies from the site. As the RI site provides a relatively high temporal resolution record (sub-annual) proxy record at a location that is shown to be sensitive to changes in the ASL (and thus ENSO and SAM), the synoptic types could be used to complement proxy reconstructions of these cycles in the recent past.

The first step would be to ascertain if there are any correlations between RI climate proxies (e.g. isotopes, accumulation, or trace elements) and frequency of the synoptic types for the recent record (since 1979). If there are correlations, analysis similar to Lorrey et al. (2007) could then be made. They used the NZ synoptic types to interpret precipitationsensitive paleoclimate proxy data from distinct regions of NZ. Obviously this technique would not replace qualitative proxy reconstructions for RI, but could supplement them. The main caveat in studying paleoclimate records in this way is that the paleoclimate is assumed to be similar to present day (i.e. it has a modern analogue), so extending the records too far back and inferring circulation changes should be done with caution.

More robust interpretations of the proxies could use ice records from multiple locations within the Ross/Amundsen Sea region in conjunction with the synoptic types. For example, the synoptic types reflect the increasing occurrence of larger, deeper cyclones in the Pacific sector for La Niña and positive SAM (with the increase in the type 'Low') which may deliver more precipitation and higher temperatures to West Antarctica. Correlations of temperature and precipitation from other sites on the West Antarctic Ice Sheet and Ross Ice Shelf with the synoptic types could provide more robust reconstructions of atmospheric circulation changes and associated variability in the ASL for recent decades and possibly further in the past. This would require drilling of relatively shallow cores in multiple locations in the region, and has the potential to provide valuable understanding of variability of global climate cycles and impacts on Antarctic climate. 
Chapter 4 describes the use of in-situ snow accumulation measurements to assess reanalyses precipitation data on synoptic timescales, and the acoustic depth gauge (ADG) measurements used in this study were shown to be a valuable source of in-situ snow accumulation data. However, as snow accumulation is known to be highly spatially variable and the ADG instruments can only measure at a single point, proper characterization of snowfall and accumulation over larger regions requires a more extensive network of these measurements. A network of such instruments across the WAIS and Ross Ice Shelf would be invaluable for understanding the temporal and spatial variability of precipitation in this region. In addition, the development of new, low-power sensors that measure snow water equivalency (SWE) in addition to snow height changes would be highly valuable. Sensors that use sonic reflectivity to determine snow density are currently being developed (e.g. Kinar and Pomeroy, 2009), and this is this an on-going area of research. The potential impact of these measurements is considerable, as knowledge of snow density and SWE is a key parameter for a wide range of studies from quantifying the hydrological cycle to understanding micro-physical snowpack processes.

Another important factor that this study identifies is the challenge of measuring and accounting for wind redistribution of snow. Much work has been done in the past and this continues to be an active area of research due to the highly variable and complex nature of the processes (e.g. Li and Pomeroy, 1997; Knuth et al., 2010; Rasmussen et al., 2012). Sitespecific field measurements which measure snow accumulation at different heights above the surface have been used to characterize wind redistribution of snow and provide insight into contribution of wind redistributed snow to the snowpack (e.g. Zwaaftink et al., 2013; X. Feng, Dartmouth College, personal communication, October 2013). Similar field measurements at Roosevelt Island would be valuable for understanding the impacts of wind redistribution of snow on the interpretation of snow-based proxies.

Finally, the methodology developed to compare reanalyses precipitation to the ADG snow accumulation data could also be used with other reanalyses products [e.g. Modern-Era Retrospective analysis for Research and Applications (MERRA)] or with higher resolution models such as the Antarctic Mesoscale Prediction System (AMPS) or the Regional Atmospheric Climate Model (RACMO). Such comparisons may help provide better understanding of these models' representation of the hydrological cycle. 
The results of the isotope modelling study presented in Chapter 5 provide substantial motivation for further storm sampling and further application of the model to investigate isotopes on sub-storm timescales. For Roosevelt Island, modelling storms that are more representative of the primary precipitation delivery trajectories and source regions (i.e. those that come directly from the Ross Sea rather than over the WAIS) would provide a more robust understanding of the primary controls on the variability of isotopes at the site, as well as providing quantification of the some of the uncertainty in temperature reconstructions from the RI ice core.

Based on the modelling of d-excess for Storm 1, it is clear that the primary controls on d-excess at RI are not well understood. It is known that d-excess variability is driven by both source region conditions and in-cloud kinetic fractionation processes (Ciais and Jouzel, 1994), and further application of the modelling techniques developed in Chap 5 would likely provide better constraints of the relative contributions of these processes to the d-excess signal. This is highly important not only for the interpretation of d-excess at RI, but for understanding of Rayleigh fractionation processes in general. Better parameterization of incloud isotopic fractionation processes and quantification of the influence of source region conditions versus in-cloud microphysical processes is crucial for progressing our ability to use the d-excess parameter as a climate proxy.

In addition, the three storms described in Chapter 5 show that the contribution of precipitation from non-Rayleigh-type storms (i.e. moisture trajectories that do not progressively condense out heavier isotopes as the air parcel cools) may be important factor at RI. For example, it is known that mesoscale storms are prevalent on the Ross Ice Shelf (Carrasco et al., 2003). The influence of these storms on snow accumulation at RI and their impact on isotopes at the site is an important consideration. Some understanding of this could be derived from the synoptic types work (Chapter 3) which shows considerable amounts of precipitation delivered to RI from the 'Zonal' type. This type may reflect the behavior of mesoscale and small synoptic-scale systems, and this would be worth further analysis. 


\section{References}

Andersson, E., E. Holm, P. Bauer, A. Bejaars, G. A. Kelly, A. P. McNally, A. J. Simmons, J. N. Thepaut, A. M. Tompkins, 2007: Analysis and forecast impact of the main humidity observing systems. Quart. J. Roy. Met. Soc.,133, 1473-1485.

Arblaster, J.M. And G.A. Meehl, 2006: Contributions of external forcings to southern annular mode trends. J. Climate, 19, 2896-2905, doi: 10.1175/JCLI3774.1.

Arblaster, J.M., G.A. Meehl, D.J. Karoly, 2011: Future climate change in the Southern Hemisphere: Competing effects of ozone and greenhouse gases. Geophys. Res. Lett., 38, L02701, doi:10.1029/2010GL045384.

Bamber J.L., Riva R.E.M., Vermeersen B.L.A., LeBroq A.M., 2009: Reassessment of the potential sea-level rise from a collapse of the West Antarctic Ice Sheet, Science,324, 5929, doi:10.1126/science.1169335.

Bertler, N.A.N., P.J. Barrett, P.A. Mayewski, R.L. Fogt, K.J. Kreutz, J. Shulmeister, 2004: El Nino suppresses Antarctic warming, Geophysical Research Letters, 31, 15.

Bromwich, D. H., 1988: Snowfall in high southern latitudes, Rev. Geophys.,26, 1, 149-168.

Bromwich, D. H. and Fogt R.L, 2004: Strong trends in the skill of the ERA-40 and NCEP-NCAR reanalyses in the high and midlatitudes of the southern hemisphere, 1958-2001, J. Climate, 17, 4603-4619.

Bromwich, D. H., A. N Rogers, P. Kaallberg, R. I Cullather, J. W.C White, and K. J Kreutz, 2000: ECMWF Analyses and Reanalyses Depiction of ENSO Signal in Antarctic Precipitation. $J$. Climate13, 1406-1420.

Bromwich, D. H., Guo, Z., Bai, L. and Chen, Q. 2004: Modeled Antarctic Precipitation. Part I: Spatial and Temporal Variability. J. Climate17, 427-447.

Bromwich, D. H., Fogt, R. L., Hodges, K. I., and Walsh, J. E., 2007: A tropospheric assessment of the ERA-40, NCEP, and JRA-25 global reanalyses in the polar regions, J. Geophys. Res., 112, D10111, doi:10.1029/2006JD007859.

Bromwich, D. H., Nicolas, J. P., and Monaghan, A. J., 2011: An assessment of precipitation changes over Antarctica and the Southern Ocean since 1989 in contemporary global reanalyses, J. Climate, 24, 4189-4209.

Bromwich, D. H., J. P. Nicolas, A. J. Monaghan, M. A. Lazzara, L. M. Keller, G. A. Weidner, and A. B. Wilson, 2013: Central West Antarctica among the most rapidly warming regions on Earth. Nature Geoscience, 6, doi:10.1038/ngeo1671.

Bull, J. 2009. "Stable isotope, major and trace element chemistry of modern snow from Evans Piedmont glacier, Antarctica: insights into potential source regions and relationship of 
glaciochemistry to atmospheric circulation and vigour", Victoria University Wellington Masters thesis.

Carrasco, J. F., and D. H. Bromwich,1993: Satellite and automatic weather station analyses of katabatic surges across the Ross Ice Shelf, in Antarctic Meteorology and Climatology: Studies Based on Automatic Weather Stations, Antarct. Res. Ser., vol. 61, edited by D. H. Bromwich and C. R. Stearns, pp. 93-108, AGU, Washington, D. C., doi:10.1029/AR061p0093.

Carrasco, J. F, D. H Bromwich, and A. J Monaghan, 2003: Distribution and Characteristics of Mesoscale Cyclones in the Antarctic: Ross Sea Eastward to the Weddell Sea. Monthly Weather Rev.,131, 289-301.

Chritin, V., R. Bolognesi, and H. Gubler, 1999: FlowCapt: A new acoustic sensor to measure snow drift and wind velocity for avalanche forecasting. Cold Reg. Sci. Technol., 30, 125-133.

Ciais P. and J. Jouzel, 1994: Deuterium and oxygen 18 in precipitation: Isotopic model, including mixed cloud processes. J. Geophys. Res. 99(D8), 16793-16803, doi: 10.1029/94JD00412.

Ciais P., J. W. C. White, J. Jouzel, and J. R. Petit, 1995: The origin of present-day Antarctic precipitation from surface snow deuterium excess data .J. Geophys. Res., 100, 1891718927, doi: 10.1029/95JD01169.

Cohen, L., Dean, S., and Renwick, J., 2013: Synoptic Weather Types for the Ross Sea Region, Antarctica. J. Clim., 26, 636-649, doi: 10.1175/JCLI-D-11-00690.1.

Cohen, L. and Dean, S., 2013: Snow on the Ross Ice Shelf: comparison of reanalyses and observations from automatic weather station. The Cryosphere, 7, 1399-1410, doi: 10.5194/tc-7-1399-2013.

Craig, H., 1961: Isotopic variations in meteoric waters. Science, 133, 1702-1703.

Cullather, R. I., D. H. Bromwich, and M. L. Van Woert, 1996: Interannual variations in Antarctic precipitation related to El Nino-Southern Oscillation, J. Geophys. Res., 101, $19109-19118$, doi: 10.1029/96JD01769.

Cullather, R. I., D. H Bromwich, and M. L Van Woert. 1998: Spatial and Temporal Variability of Antarctic Precipitation from Atmospheric Methods. J. Climate11, 334-367.

Dansgaard, W., 1964: Stable isotopes in precipitation.Tellus, 16, doi:10.1111/j.21533490.1964.tb00181.

Dee, D. P., S. M. Uppala, A.J. Simmons, P. Berrisford, P. Poli, S. Kobayashi, and 30 others, 2011: The ERA-Interim reanalysis: configuration and performance of the data assimilation system. Q.J.R. Meteorol. Soc., 137: 553-597, doi:10.1002/qj.828. 
Delaygue, G., J. Jouzel, V. Masson, R. D. Koster, and E. Bard, 2000: Validity of the isotopic thermometer in central Antarctica: Limited impact of glacial precipitation seasonality and moisture origin, Geophys. Res. Lett., 27, $2677-2680$.

Fisher, D. A. and B. A. Alt, 1985: A global oxygen-isotope model: Semi-empirical, zonallyaveraged. Ann. Glaciol., 7, 117-124.

Fischer, A. P., 2011: The Measurement Factors in Estimating Snowfall Derived from Snow Cover Surfaces Using Acoustic Snow Depth Sensors, J. App. Met. and Climat. 50.3, 681-699.

Fogt, R. and Bromwich, D., 2006: Decadal variability of the ENSO telecocnnection to the highlatitude South Pacific governed by coupling with the Southern Annular Mode. J. Climate, 19, 979-997.

Fogt, R. L., A. J. Wovrosh, R. A. Langen, and I. Simmonds, 2012: The characteristic variability and connection to the underlying synoptic activity of the Amundsen-Bellingshausen Seas Low. J. Geo. Res., 117, doi:10.1029/2011JD017337.

Genthon, C., and E. Cosme, 2003: Intermittent signature of ENSO in west-Antarctic precipitation. Geophys. Res. Lett., 30, 2081, doi: 10.1029/2003GL018280.

Gregory, S. and D. Noone, 2008: Variability in the teleconnection between the El Nino-Southern Oscillation and West Antarctic climate deduced from West Antarctic ice core isotope records. J. Geophys. Res., 113, D17110, doi: 10.1029/2007JD009107.

Guo, Z., D. H. Bromwich, and K. M. Hines, 2004: Modeled Antarctic Precipitation. Part II: ENSO Modulation over West Antarctica. J. Climate17, 448-465.

Hartmann, D.L. and F. Lo, 1998: Wave-driven zonal flow vacillation in the Southern, $J$. Atmospheric Sciences, 55, 1303-1315.

Helsen, M. M., 2006: On the interpretation of stable isotopes in Antarctic precipitation. PhD Thesis: Institute for Marine and Atmospheric Research, Utrecht University.

Hur, S., Cunde, X., Hong, S., Barbante, C., Gabrielli, P., Lee, K., Bouton, C., and Ming, Y., 2007: Seasonal patterns of heavy metal deposition ot the snow on Lambert Glacier basin, East Antarctica, Atmospheric Environment, 41, 8567-8578.

Ingólfsson, Ó. 2004: The Quaternary Glacial and Climate History of Antarctica. In: Ehlers, J. \& Gibbard, P.L. (eds.), Quaternary Glaciations of the World, Part III. Dordrecht, Kluwer, 343.

Jiang, N., K.N. Dirks, K. Luo, 2013: Classification of synoptic weather types using the selforganising map and its application to climate and air quality data visualisation. Weather and Climate, 33, 52-75. 
Jouzel J and L. Merlivat, 1984: Deuterium and oxygen 18 in precipitation: Modeling of the isotopic effects during snow formation. J. Geophys. Res. 89(D7), $11 \quad 749-11757$. doi:10.1029/JD089iD07p11749.

Jouzel, J., V. Masson-Delmotte, and 30 Coauthors, 2007: Orbital and millennial Antarctic climate variability over the past 800,000 years, Science, 317(5839), 793-796, doi:10.1126/science. 1141038 .

Kanamitsu, M., W. Ebisuzaki, J. Woollen, S.-K. Yang, J. J. Hnilo, M. Fiorino, and G. L. Potter, 2002: NCEP-DOE AMIP-II Re- analysis (R-2). Bull. Amer. Meteor. Soc., 83, 1631-1643.

Karoly, D., 1989: Southern Hemisphere Circulation Features Associated with El Nino-Southern Oscillation Events. J. Climate, 2, 1239-1252.

Keable, M, I. Simmonds, K. Keay, 2002: Distribution and temporal variability of $500 \mathrm{hPa}$ cyclone characteristics in the Southern Hemisphere, Int. J. Climat., 22, 131-150.

Kinar, N. J. and J.W. Pomeroy, 2009: Automated Determination of Snow Water Equivalent by Acoustic Reflectometry, IEEE Geoscience and Remote Sensing Society, 47, 3161-3167, doi: 10.1109/TGRS.2009.2019730.

King, J.C. and J. Turner, 1997. "Antarctic meteorology and climatology." Cambridge University Press.

Knuth, S. L., G. J. Tripoli, J. E. Thom, G. A. Weidner, 2010: The influence of blowing snow and precipitation on snow depth change across the Ross Ice Shelf and Ross Sea regions of Antarctica. J. App. Met. \& Clim., 49, 1306-1321.

Krinner, G.,Magand, O.,Simmonds, I.,Genthon, C., and Dufresne, J. L., 2007: Simulated Antarctic precipitation and surface mass balance at the end of the twentieth and twenty-first centuries. Climate Dyn., 28, 215-230.

Kwok, R. and J.C. Comiso, 2002: Spatial patterns of variability in Antarctic surface temperature: connections to the Southern Hemisphere Annular Mode and the Southern Oscillation, Geophys. Res. Let., 29, 1705, doi: 10.1029/2002GL015415.

L'Heureux, M. L, and D. W.J Thompson, 2006: Observed relationships between the El NinoSouthern Oscillation and the extratropical zonal-mean circulation. J. Climate, 19, 276-287.

Legrand, M., and P. A. Mayewski, 1997: Glaciochemistry of polar ice cores: A review, Rev. Geophys., 35(3), 219-243, doi: 10.1029/96RG03527.

Li, L., and J. W. Pomeroy, 1997: Probability of blowing snow occurrence by wind. J. Geophys. Res., 102, 21955-21964, doi: 10.1029/97JD01522. 
Lorrey, A., A. M. Fowler, and J. Salinger, 2007: Regional climate regime classification as a qualitative tool for interpreting multi-proxy palaeoclimate data spatial patterns: A New Zealand case study. Palaeogeog. Palaeoclim. Palaeoecol., 253, 407-433.

Marshall, G.J., 2003: Trends in the southern annular mode from observations and reanalyses, $J$. Climate, 16, 4134-4143.

Marshall, G. J., P. A. Stott, J. Turner, W. M. Connolley, J. C. King, T. A. Lachlan-Cope, 2004: Causes of exceptional atmospheric circulation changes in the Southern Hemisphere. Geophys. Res. Lett., 31, L14205, doi: 10.1029/2004GL019952.

Marshall, G. J., 2009: On the annual and semi-annual cycles of precipitation across Antarctica. Intl. J. Climatology, 29, doi:10.1002/joc.1810.

Masson-Delmotte, V., B. Stenni, and J. Jouzel, 2004: Common millennial-scale variability of Antarctic and Southern Ocean temperatures during the past 5000 years reconstructed from the EPICA Dome C ice core. Holocene, 14, 145-151.

Merlivat, L. and J. Jouzel, 1979: Global climatic interpretation of the deuterium oxygen 18 relationship for precipitation. J. Geophys. Res., 84(C8), 5029-5033.

Meyerson, E.A., P.A. Mayewski, K.J. Kreutz, L.D. Meeker, S.I. Whitlow and M.S. Twickler, 2002: The polar expression of ENSO and sea-ice variability as recorded in a South Pole ice core. Ann. Glaciol., 35, 430-436.

Mo, K.C. And R.W. Higgins, 1998: The Pacific-South American modes and tropical convection during the Southern Hemisphere winter, Monthly Weather Rev., 126, 1581-1596.

Monaghan, A. J., Bromwich, D. H., Fogt, R. L., Wang, S.H., Mayewski, P.A., Dixon, D.A., Ekaykin, A., Frezzotti, M., Goodwin, I., Isaksson, E., Kaspari, S.D., Morgan, V.I., Oerter, H., van Ommen, T.D., van der Veen. C.J., Wen, J., 2006: Insignificant change in Antarctic snowfall since the International Geophysical Year. Science, 313, 827-831.

Noone, D., and I. Simmonds, 1998: Implications for the interpretation of ice-core isotope data from analysis of modelled Antarctic precipitation, Ann. Glaciol., 28, 398 - 402.

O’Connor, W. P., D. H. Bromwich, and J. F. Carrasco, 1994: Cyclonically forced barrier winds along the Transantarctic Mountains near Ross Island, Mon. Weather Rev., 122, 137-150.

O'Donnell, R., N. Lewis, S. McIntyre and J. Condon, 2011: Improved methods for PCA-based reconstructions: Case study using the Steig et al. (2009) Antarctic temperature reconstruction. J. Climate, 24, 2099-2115.

Osterberg, E., Handley, M., Sneed, S., Mayewski, P., Kreutz, K., 2006: Continuous Ice Core Melter System with Discrete Sampling for Major Ion, Trace Element and Stable Isotope Analysis, Environmental Science and Technology, 40, 3344-3361. 
Parish, T.R. and J.J. Cassano, 2003: The role of katabatic winds on the Antarctic surface wind regime, Monthly Weather Rev., 131, 317-333.

Parish, T.R. and D. H. Bromwich, 2007: Reexamination of the Near-Surface Airflow over the Antarctic Continent and Implications on Atmospheric Circulations at High Southern Latitudes. Monthly Weather Rev.,135, 1961-1973.

Parkinson, C. L., and D. J. Cavalieri, 2012: Antarctic sea ice variability and trends, 1979-2010. The Cryosphere, 6, 871-880.

Pezza, A. B., T. Durrant, I. Simmonds, I. Smith, 2008: Southern Hemisphere synoptic behavior in extreme phases of SAM, ENSO, sea ice extent, and Southern Australia rainfall. J. Climate, 21, 5566-5584.

Planchon, F.A.M, Boutron, C.F., Barbante, C., Cozzi, G., Gaspari, V., Wolff, E.W., Ferrari, C.P., and Cescon, P., 2002: Short-term variations in the occurrence of heavy metals in Antarctic snow from Coats Land since the 1920s, Science of the Total Environment, 300, 129-142.

Polvani, L.M., D.W. Waugh, G.J.P, Correa, S.W. Son, 2011: Stratospheric ozone depletion: the main driver of twentieth-century atmospheric circulation changes in the southern hemisphere. J. Climate, 24, 795-812, doi: 10.1175/2010JCLI3772.1.

Rasmussen, R., B. Baker, J. Kochendorfer, T. Meyers, S. Landolt, A.P. Fischer, J. Black, J.M. Theriault, P. Kucera, D. Gochis, C. Smith, R. Nitu, M. Hall, K. Ikeda, E. Gutmann, 2012: How Well Are We Measuring Snow: The NOAA/FAA/NCAR Winter Precipitation Test Bed, Bull. Amer. Meteor. Soc., 93, 811-829, doi:10.1175/BAMS-D-11-00052.1.

Renwick, J.A., 2005: Persistent positive anomalies in the Southern Hemisphere circulation, Monthly Weather Review, 133, 977-988.

Rhodes, R. H., N. A. N. Bertler, J. A. Baker, H. C. Steen-Larsen, S. B. Sneed, U. Morgenstern, and S. J. Johnsen, 2012: Little Ice Age climate and oceanic conditions of the Ross Sea, Antarctica from a coastal ice core record. Climate of the Past, 8, doi:10.5194/cp-8-12232012.

Rignot, E., Casassa, G., Gogineni, P., Krabill, W., Rivera, A., Thomas, R. 2004: Accelerated ice discharge from the Antarctic Peninsula following the collapse of Larsen B ice shelf. Geo. Res. Let., 31, L18401, doi:10.1029/2004GL020697.

Rignot, E., Bamber, J. L., Van Den Broeke, M. R., Davis, C., Li, Y., Van De Berg, W. J., Van Meijgaard, E., 2008: Recent Antarctic ice mass loss from radar interferometry and regional climate modelling, Nat. Geo. 1, 106, doi:10.1038/ngeo102.

Schneider D.P., E.J. Steig, J.C. Comiso, 2004: Recent climate variability in Antarctica from satellite-derived temperature data, J. Climate, 17, 1569-1583. 
Seefeldt, M. W., J. J. Cassano, and T. R. Parish, 2007: Dominant Regimes of the Ross Ice Shelf Surface Wind Field during Austral Autumn 2005. J. Applied Met. and Climat., 46, doi:10.1175/2007JAMC1442.1.

Seefeldt, M.W. And J.J. Cassano, 2012: A description of the Ross Ice Shelf air stream (RAS) through the use of self-organising maps (SOMs). J. Geophys. Res., 117, D09112, doi:10.1029/2011JD016857.

Simmonds, I. and D. A. Jones, 1998: The mean structure and temporal variability of the semiannual oscillation in the southern extratropics. Int. J. Climatology, 18, 473-504.

Simmonds, I., and K. Keay, 2000: Variability of Southern Hemisphere extratropical cyclone behavior, 1958-97. J. Climate., 13, 550-561.

Simmonds, I., and J. C. King, 2004: Global and hemispheric climate variations affecting the Southern Ocean. Antarctic Science, 16, doi:10.1017/S0954102004002226.

Simmonds, I., K. Keay, and E. Lim., 2003: Synoptic Activity in the Seas around Antarctica. Monthly Weather Review131, 272-287.

Simmons, A. J., K. M. Willett, P. D. Jones, P. W. Thorne, and D. P. Dee, 2010: Low-frequency variations in surface atmospheric humidity, temperature, and precipitation: Inferences from reanalyses and monthly gridded observational data sets. J. Geophys. Res., 115, doi:10.1029/2009JD012442.

Steig, E. J, P. A Mayewski, D. A Dixon, S. D Kaspari, M. M Frey, D. P Schneider, S. A Arcone, et al., 2005: High-resolution ice cores from US ITASE (West Antarctica): Development and validation of chronologies and determination of precision and accuracy, Ann.Glaciol.,41, 77-84.

Stenni, B., V. Masson-Delmotte, S. Johnsen, J. Jouzel, A. Longinelli, E. Monnin, R. Röthlisberger, and E. Selmo, 2001: An oceanic cold reversal during the last deglaciation.Science, 293, 2074-2077.

Thompson, D. W. J, and J. M Wallace, 2000: Annular Modes in the Extratropical Circulation. Part I: Month-to-Month Variability. J. Climate,13, 1000-1016.

Thompson, D. W. J., and S. Solomon, 2002: Interpretation of Recent Southern Hemisphere Climate Change, Science296, 895-899.

Trenberth, K.E., 1997: The definition of El Nino, Bull. Am. Met. Soc., 78(12), 2771-2777.

Tsukernik, M. and A.H. Lynch, 2013: Atmospheric meridional moisture flux over the Southern Ocean: a story of the Amundsen Sea, J. Climate, 26, 8055-8064, doi:10.1175/JCLI-D-1200381.1.

Turner, J., 2004: The El Niño-southern oscillation and Antarctica. Internat. J. Climat., 24, 1-31. 
Turner, J., T. Phillips, J. S. Hosking, G. J. Marshall, and A. Orr, 2012: The Amundsen Sea low. Int. J. Climat., doi:10.1002/joc.3558.

van den Broeke, M.R., 2000: The semi-annual oscillation and Antarctic climate. Part 4: a note on sea ice cover in the Amundsen and Bellingshausen Seas. Int. J. Climat.,20, 455-462.

van Loon, H., 1967: The Half-Yearly Oscillations in Middle and High Southern Latitudes and the Coreless Winter, J. Atmos. Sci., 24, 472-486.

Vaughan, D. G., J. L. Bamber, M. Giovinetto, J. Russell, and A. P. R. Cooper, 1999: Reassessment of net surface mass balance in Antarctica. J. Climate, 12, 933-946.

Vaughan, D. G., G. J. Marshall, W. M. Connolley, C. Parkinson, R. Mulvaney, D. A. Hodgson, J. C. King, C. J. Pudsey, J. Turner, 2003: Recent rapid regional climate warming on the Antarctic Peninsula, Clim. Change,60, 243-274.

Vimeux, F., V. Masson, J. Jouzel, and M. Stievenard, 1999: Glacial-interglacial changes in ocean surface conditions in the Southern Hemisphere. Nature, 398, 410-413.

Werner, M., and M. Heimann, 2002: Modeling interannual variability of water isotopes in Greenland and Antarctica, J. Geophys. Res., 107, 4001, doi: 10.1029/2001JD900253.

Yan, Y., P. A Mayewski, S. Kang, and E. Meyerson., 2005: An ice-core proxy for Antarctic circumpolar zonal wind intensity. Ann. Glaciol.,41, 121-130.

Yuan, X.J. and D.G. Martinson, 2001: The Antarctic Dipole and its predictability, Geophys. Res. Lett., 28, 3609-3612, doi: 10.1029/2001GL012969.

Zou, C., M. Van Woert, C. Xu, S. Kamran, 2004: Assessment of the NCEP-DOE reanalysis-2 and TOVS Pathfinder a moisture fields and their use in Antarctic net precipitation estimates. Monthly Wea. Rev., 132, 2463-2476.

Zwaaftink, C.D.G., A. Cagnati, A. Crepaz, C. Fierz, G. Macelloni, M. Valt, and M. Lehning, 2013: Event-driven deposition of snow on the Antarctic Plateau: analyzing field measurements with SNOWPACK, The Cryosphere, 7, 333-347, doi:10.5194/tc-7-333-2013. 


\section{Appendix A Roosevelt Island snow pits}

Two snow pits were sampled at Roosevelt Island in November 2010, providing an approximately eight-year, high resolution ( $\sim 50$ samples per year) record of climate proxies from the site. The snow pit samples were analyzed forstable isotopes and trace elements andcould be used to further investigate high-frequency changes in atmospheric source regions and circulation patterns in the Ross Sea region. This data has not been presented elsewhere in this thesis. The following sections describe the snow pit sampling methodology, data analysis and preliminary results.

\section{A.1 Snow pit density and temperature profiles}

Two snow pits were dug at the Roosevelt Island site approximately 600 meters apart, one twometers deep and the other four meters deep. The density and temperature of both snow pits were measured and the stratigraphy was recorded, particularly noting hoar layers. The density and temperature measurements were taken immediately after pit surfaces were cleared and the profiles are shown in figure A.1. Density was measured using $5 \mathrm{~cm}$ diameter cylinders inserted horizontally in the snow wall at $2.5 \mathrm{~cm}$ overlapping intervals and weighed. Temperature was measured at $10 \mathrm{~cm}$ intervals.

The density profile for the top 2 meters match well between the two pits to about 80 $\mathrm{cm}$ depth and there is about $10 \mathrm{~cm}$ offset below that. The density ranges between 310 to $520 \mathrm{~kg} \mathrm{~m}^{-3}$. The top $1.5 \mathrm{~m}$ of the $4 \mathrm{~m}$ pit was open for over a day, which is evident in the temperatures (and not shown in figure A.1). The temperature at the bottom of the $4 \mathrm{~m}$ pit was $-27.5^{\circ} \mathrm{C}$; the temperature of the $2 \mathrm{~m}$ pit varied from $-15.6^{\circ} \mathrm{C}$ at the top to $-27.7^{\circ} \mathrm{C}$ at the bottom.

\section{A.2 Stable isotope analysis}

Snow samples were collected at $1 \mathrm{~cm}$ resolution and were kept frozen until they were aliquoted for stable isotope analyses. Oxygen and hydrogen isotope ratios $\left(\delta^{18} \mathrm{O}\right.$ and $\left.\delta \mathrm{D}\right)$ were measured at the Stable Isotope Laboratory at GNS Science and reported with respect to VSMOW. Analytical precision is $0.1 \%$ for $\delta^{18} \mathrm{O}$ and $1.0 \%$ for $\delta \mathrm{D}$, resulting in an uncertainty of $+/-1.3 \%$ for d-excess. 


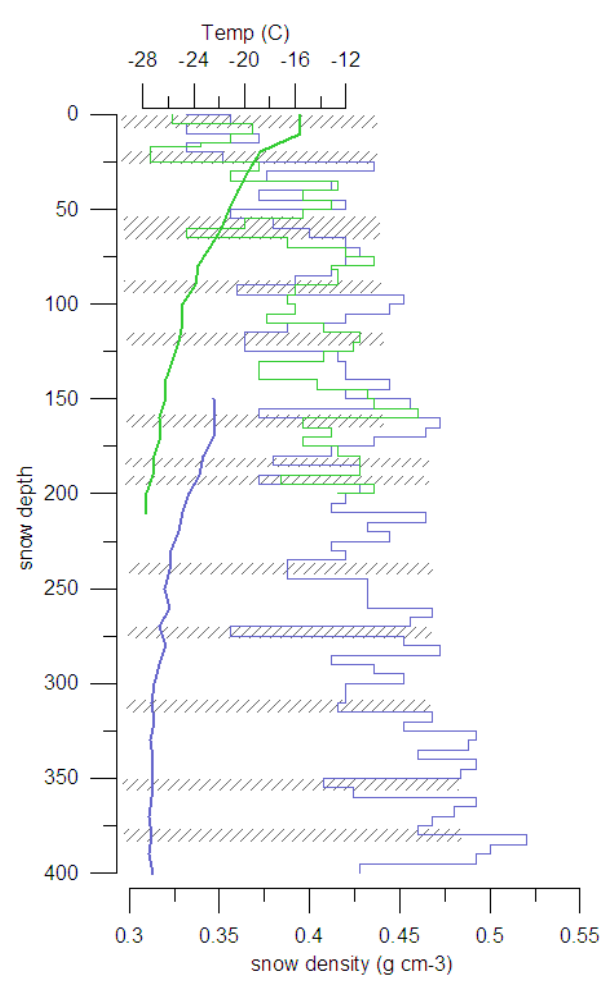

Figure A.1 Density and temperature profiles for the $2 m$ and $4 m$ pits. Shaded horizontal lines indicate visible hoar layers in the $4 \mathrm{~m}$ pit.

The measured stable isotope values and d-excess (d-excess $\left.=\delta \mathrm{D}-8 * \delta^{18} \mathrm{O}\right)$ for the 4 meter pit is shown in figure A.2. The snow pit provides an approximately eight year record based on matching the isotope peaks with the surface temperature from NCEP-2 reanalysis data. Note the variability of the relationship between d-excess and $\delta^{18} \mathrm{O}$ and $\delta \mathrm{D}$ which is in sync between 2002-2009, then out of sync from 2009 to 2010.

\section{A.3 Trace element analysis (ICP-MS)}

Trace elements measured in snow and ice are widely used as climate proxies to indicate changes in wind strength and direction, source region, and atmospheric circulation patterns. Marine aerosols such as $\mathrm{Na}$ and $\mathrm{Mg}$ have been used as proxies for sea-ice extent (distance to open water), cyclonic activity and meridional wind strength. Trace elements such as $\mathrm{Pb}, \mathrm{Cu}, \mathrm{Mn}, \mathrm{Fe}, \mathrm{Bi}, \mathrm{Cd}$, and $\mathrm{U}$ have also shown the potential to identify atmospheric pathways and source regions (Planchon et al, 2002; Hur et al, 2007; Bull, 2009; Rhodes et al., 2012). Elements such as $\mathrm{Al}$ and $\mathrm{Ca}$ are usually from mineral dusts and indicators of terrestrial source regions, though Ca can also indicate marine sources (Legrand and Mayewski, 1997). The Roosevelt Island site would not be expected to have as large a terrestrial signal as sites on the western side of the Ross Ice Shelf, where the Transantarctic Mountains are a nearby source of terrestrial elements. 


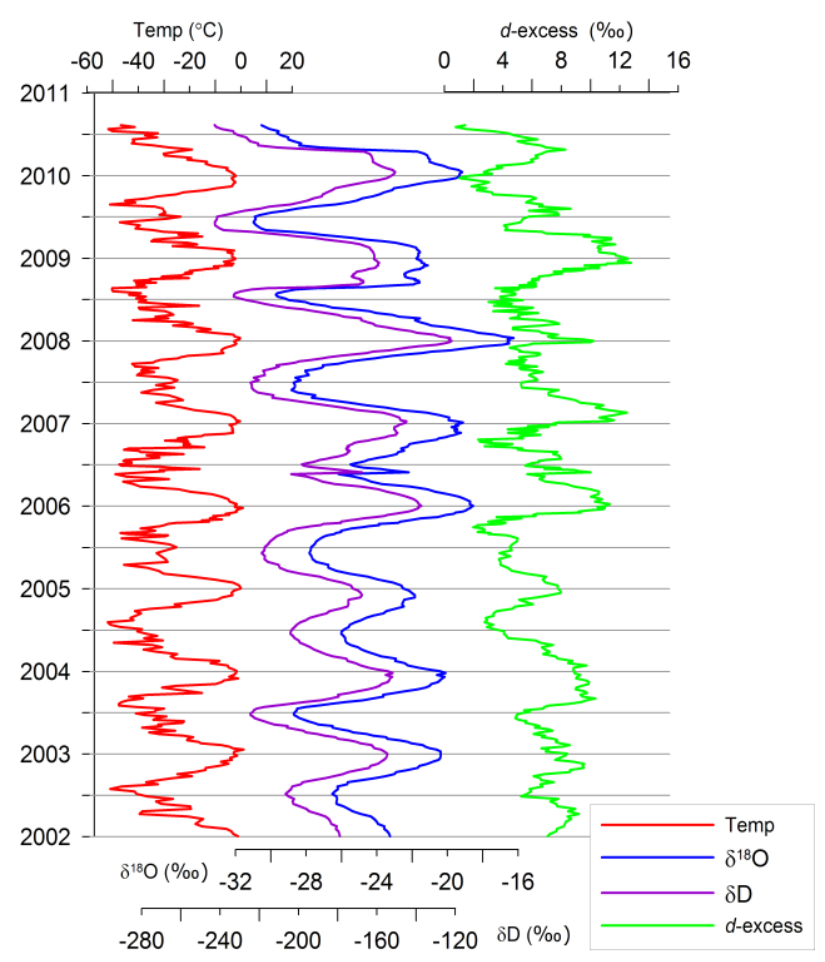

Figure A.2 Stable isotopes ( $\delta 18 O$ and $\delta D)$ and d-excess measured in the 4 meter pit. Dates are based on matching isotope peaks with high temperature from NCEP-2 reanalysis surface temperature record (also shown).

Both pits were sampled at $1 \mathrm{~cm}$ resolution using ultra clean snow sampling methods following previous similar studies (e.g. Bertler et al, 2004; Osterberg et al, 2006; Bull, 2009). Samples were kept frozen until aliquoted into vials in preparation for analysis ( $\sim 24$ hours prior to analysis). Samples were analyzed for major, minor and trace elements ( $\mathrm{Na}, \mathrm{Mg}, \mathrm{Al}$, $\mathrm{Ca}, \mathrm{Mn}, \mathrm{Ba}, \mathrm{Ti}, \mathrm{V}, \mathrm{As}, \mathrm{Rb}, \mathrm{Sr}, \mathrm{Y}, \mathrm{Zr}, \mathrm{Cs}, \mathrm{La}, \mathrm{Ce}, \mathrm{Pr}, \mathrm{Tl}, \mathrm{Pb}, \mathrm{Bi}$, Th, and U) using the Agilet inductively coupled plasma mass spectrometer (ICP-MS) at the geochemistry laboratory at Victoria University of Wellington. Laboratory sample preparation procedures and ICP-MS operation followed the ultra-clean methodology described in Bull (2009) and Rhodes et al. (2012). Procedural blanks analyzed with the samples provided measure of any systematic contamination that occurred in the preparation or during analysis and are used to provide quality control of sample results.

Preliminary results from the ICP-MS analysis show distinct terrestrial (Al) and marine signals $(\mathrm{Na})$ as shown by the $\mathrm{Al} / \mathrm{Na}$ ratio in figure A.3. The $\delta^{18} \mathrm{O}$ curve and location of hoar layers (which are generally formed in summer) are also shown (along with approximate dates). As expected, both $\mathrm{Al}$ and $\mathrm{Na}$ values are much lower than those found at Evans Piedmont Glacier (EPG) (Bull, 2009) which is located in the Transantarctic Mountains and is much closer to the ocean (mean values: $\mathrm{EPG}-\mathrm{Al}=85 \mathrm{ppb}, \mathrm{RI}-\mathrm{Al}=0.31 \mathrm{ppb}$; EPG-Na $=1646$ 
ppb, RI-Na = $327 \mathrm{ppb}$ ). The Al/Na ratios are also much smaller for this site [average 0.002 versus $\sim 0.1$ for the EPG site (Bull, 2009)]. The peaks showing a stronger Al (terrestrial) component are often coincident with the summer hoar layers. The full sets of trace element data for both pits are shown in Tables A.1 and A.2.

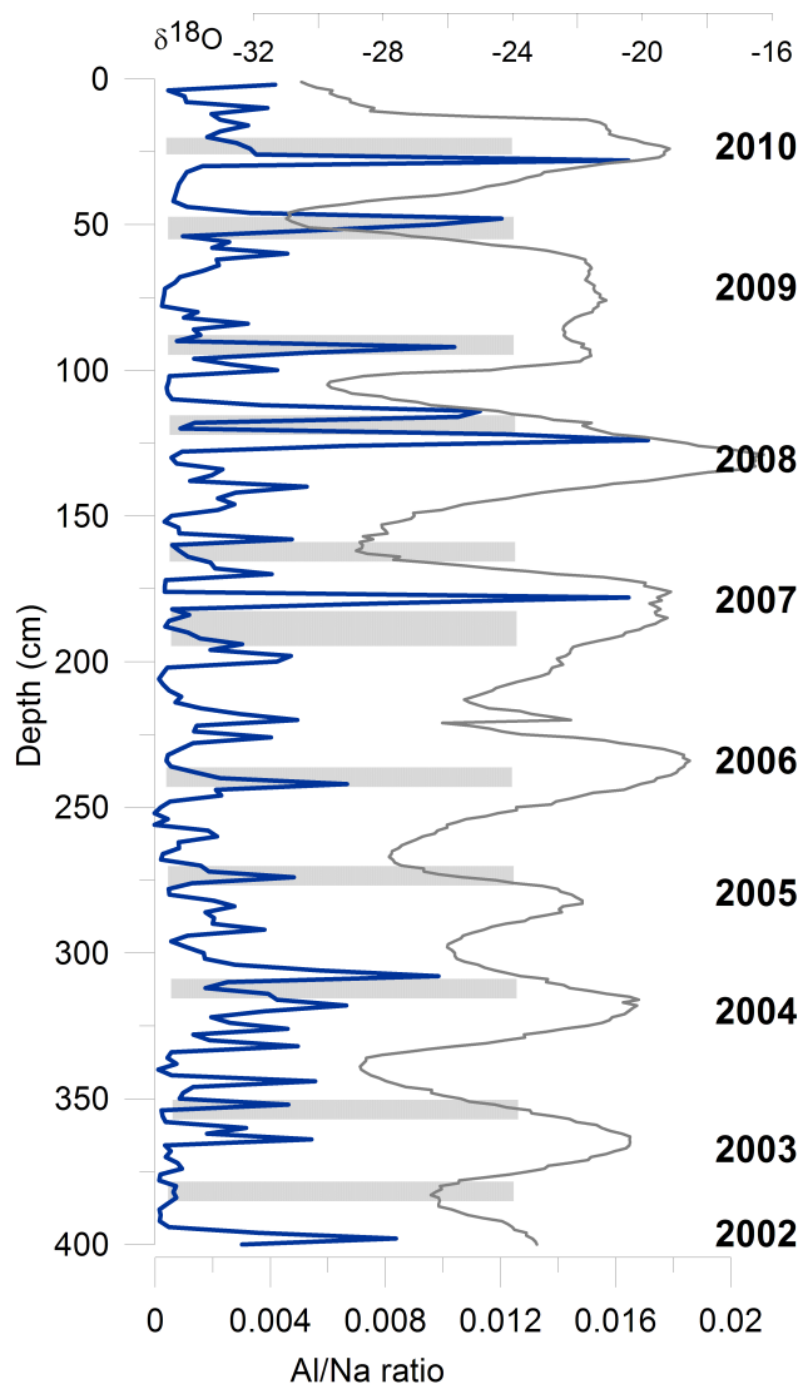

Figure A.3 Al/Na ratio (terrestrial/marine) (blue curve), hoar layers (grey bars), and $\delta^{18} \mathrm{O}$ values (grey curve) with approximate dates from the 4 meter pit. 
Table A.1 Trace element values for the $2 \mathrm{~m}$ pit. Asterisks indicate values below the detection limit.

\begin{tabular}{|c|c|c|c|c|c|c|c|c|c|c|c|c|c|c|c|c|c|c|c|c|c|c|c|}
\hline Depth $(\mathrm{cm}) \mathrm{S}$ & imple & ${ }_{20 p \mathrm{Na}}^{\mathrm{ppb}}$ & $24 \mathrm{Mg}$ & $27 \mathrm{Al}$ & $43 \mathrm{Ca}$ & $55 \mathrm{Mn}$ & $138 \mathrm{Ba}$ & $47 \mathrm{Ti}$ & $51 \mathrm{~V}$ & 75 As & $85 \mathrm{Rb}$ & $86 \mathrm{Sr}$ & $89 \mathrm{Y}$ & $90 \mathrm{Zr}$ & $133 \mathrm{Cs}$ & $139 \mathrm{La}$ & $140 \mathrm{Ce}$ & $141 \mathrm{Pr}$ & & & $209 \mathrm{Bi}$ & & \\
\hline 200 & 002 & \begin{tabular}{|l|l|}
102.2034 \\
\end{tabular} & $\begin{array}{l}12.29497 \\
\end{array}$ & 0.514954 & 6.782449 & 0.003126 & 0.023995 & \begin{tabular}{|l|l|}
7.143323 \\
\end{tabular} & 2.823086 & 1.698346 & 2.608441 & 86.93509 & 9.471592 & 435.9176 & 0.033252 & 0.236607 & 0.570046 & 0 & 0.006443 & 2.485233 & 0.145812 & 0.075009 & 0.057431 \\
\hline 198 & 004 & \begin{tabular}{|l|}
92.64128 \\
102027
\end{tabular} & 12.55762 & 0.731405 & 8.74937 & 0.005611 & 0.005945 & 12.95047 & 5.312424 & 1.369911 & 3.236389 & 80.10195 & 31.16071 & 1032.821 & 0.061535 & 0.192189 & 0.51124 & 0 & 0.08744 & 3.116222 & 0.252845 & 0.134275 & 0.100689 \\
\hline 196 & $\begin{array}{l}006 \\
008\end{array}$ & \begin{tabular}{|l|l|}
109.2427 \\
215.4912
\end{tabular} & $\begin{array}{l}10.96166 \\
26079\end{array}$ & $\begin{array}{l}0.436536 \\
0.555266\end{array}$ & 6.179912 & $\begin{array}{l}0.002047 \\
0.077377\end{array}$ & 0.007695 & $\begin{array}{l}5.226628 \\
1.935784\end{array}$ & $\begin{array}{l}2.773149 \\
5.569923\end{array}$ & $\begin{array}{l}1.499555 \\
.377095\end{array}$ & $\begin{array}{r}2.10965 \\
0.107652\end{array}$ & $\begin{array}{l}87.73496 \\
1709057\end{array}$ & 13.21162 & $\begin{aligned} 388.1799 \\
577.675\end{aligned}$ & 0.028665 & 0.104673 & 0.257284 & 0 & 0.138982 & $\begin{array}{l}1.103008 \\
1070128\end{array}$ & 0.122545 & 0.03982 & 009696 \\
\hline 194 & & 215.4912 & 26.0079 & 0.505266 & 14.77993 & 0.017317 & 0.007594 & 19.35784 & 5.561923 & 3.375085 & 4.107624 & 170.8857 & 17.30835 & 577.675 & 0.101284 & 376624 & 0.799405 & & 0.197889 & 77.0128 & 0.480872 & 0.104642 & 157775 \\
\hline 192 & 010 & 186.7102 & 22.08674 & 0.397811 & 11.01532 & 0.005866 & 0.003081 & 10.06554 & 4.699681 & 3.850448 & 3.914499 & 138.3881 & 1.592397 & 150.8163 & .098227 & 0.240646 & 0.537281 & & 0.162913 & 794816 & 0.111686 & 0.008334 & 152899 \\
\hline 190 & 012 & 208.9244 & 24.09109 & 0.318022 & 16.28298 & 0.008183 & 0.003794 & 14.54197 * & 6.11637 & 3.845131 & 4.833885 & 147.7825 & 2.428466 & 54.72211 & .109419 & 0.213824 & 0.487651 & 0 & 0.072931 * & 4.308402 & 0.094771 & 0.1245 & 0.125464 * \\
\hline 188 & 014 & \begin{tabular}{|l|}
563.78 \\
\end{tabular} & 62.51532 & 0.353935 & 27.35266 & 0.006235 & 0.003153 & 37.62016 & 16.07034 & 5.69145 & 6.847588 & 421.7007 & 7.735836 & 217.0985 & 0.059253 * & 0.232115 & 0.387462 & & 0.453796 & 4.352518 & $0.158881 *$ & 0.1305 * & 0.207759 * \\
\hline 186 & 016 & \begin{tabular}{|l|l|}
584.9737 \\
\end{tabular} & 64.0955 & 0.846619 & 28.77243 & 0.006059 & 0.062793 & 27.51599 & 14.90585 & 6.087094 & 7.280881 & 435.1264 & 8.814131 & 68.04375 & $0.116688 *$ & 0.26113 & 0.492426 & 0 & 0.583449 & 13.97736 & $0.129613 *$ & $0.042 *$ & 0.206409 * \\
\hline 184 & 018 & $\mid 389.5298$ & 45.59061 & 0.49303 & 19.00027 & 0.007303 & 0.006262 & 27.22806 & 10.54359 & 4.249006 & 5.480397 & 301.8924 & 10.6304 & 335.49 & 0.116688 * & 0.362681 & 0.678486 & 0 & 0.311173 * & 3.530548 & $0.129614 *$ & 0.0645 * & $0.16189^{*}$ \\
\hline 182 & 020 & 15.32738 & 1.80438 & 0.268161 & 4.765203 & 0.001143 * & 0.008549 & 14.12976 * & 1.071104 & 0.935528 * & 1.389031 & 11.50224 & 10.97653 & 308.8838 & 0.009815 * & $0.056137 *$ & 0.118935 * & 0 & 0.215552 * & 1.48953 & $0.066897 *$ & $-0.012 *$ & 551265 * \\
\hline 180 & 022 & 191.0266 & 23.37063 & 0.296482 & 15.56392 & 0.003402 & 0.004017 & 13.00377 * & 5.329596 & 3.103297 & 9.160585 & 154.0162 & 2.388383 & 87.43536 & 0.171942 * & 0.238108 & 0.411324 & 0 & 0.186379 * & 2.780542 & $0.0885^{*}$ & $-0.012 *$ & $0.105228^{*}$ \\
\hline & 024 & & 23.67287 & 0.379008 & & 0.01839 & 0.009357 & 49.68536 & 7.085955 & 3.482455 & 8.158378 & 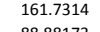 & 4.128521 & $\begin{array}{l}41.59491 \\
0720008\end{array}$ & 0.146496 * & 0.380658 & & 0 & 0.102104 * & & 4563 * & $0.183 *$ & 82918 * \\
\hline $\begin{array}{l}176 \\
174\end{array}$ & 026 & \begin{tabular}{|l|}
110.0272 \\
1647398
\end{tabular} & $\begin{array}{l}14.00065 \\
1942634\end{array}$ & 0.245195 & $\begin{array}{l}9.839622 \\
1049154\end{array}$ & 0.002261 * & 0.001631 & 7.793237 * & 3.228492 & $2.262564 *$ & $\begin{array}{l}2.329673 \\
3.561909\end{array}$ & 88.88173 & $\begin{array}{l}4.852415 \\
\end{array}$ & $\begin{array}{l}97.28908 \\
8070515\end{array}$ & 0.033807 * & 0.165572 & 0.122338 * & 0 & 0.072932 * & 1.988752 & $0.078744^{*}$ & 0.0285 * & 0.028331 * \\
\hline $\begin{array}{l}174 \\
172\end{array}$ & $\begin{array}{l}028 \\
030\end{array}$ & \begin{tabular}{|l|l|}
1645.3798 \\
350.3648
\end{tabular} & $\begin{array}{l}19.42634 \\
5983644\end{array}$ & $\begin{array}{l}0.172828 \\
0.45364\end{array}$ & $\begin{array}{l}\begin{array}{l}10.49154 \\
1871177\end{array} \\
\end{array}$ & $\begin{array}{l}0.008208 \\
0.008055\end{array}$ & $\begin{array}{l}0.002794 \\
0.009266\end{array}$ & $\begin{array}{l}8.743122{ }^{*} \\
2283415\end{array}$ & $\begin{array}{l}4.6911393 \\
10.01647\end{array}$ & $\begin{array}{l}2.6005006 \\
5.130955\end{array}$ & $\begin{array}{l}3.561959 \\
5.771194\end{array}$ & 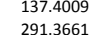 & $\begin{array}{l}3.438838 \\
1.760274\end{array}$ & $\begin{array}{l}88.70545 \\
34.15362\end{array}$ & $\begin{array}{l}0.028717 * * \\
0.111872 *\end{array}$ & $\begin{array}{l}0.056452{ }^{*} \\
0.0666373\end{array}$ & 0.128472 * & 0 & $\begin{array}{l}0.110207 * \\
0.29687^{*}\end{array}$ & $\begin{array}{l}1.777452 \\
364845\end{array}$ & $0.038326^{*} *$ & $=0.0105$ * & 044519 * \\
\hline $\begin{array}{l}172 \\
170\end{array}$ & $\begin{array}{l}030 \\
032 \\
032\end{array}$ & $\begin{array}{l}355.36488 \\
627.7861\end{array}$ & $\begin{array}{l}59.836444 \\
76.10515\end{array}$ & $\begin{array}{l}0.485364 \\
0.428298\end{array}$ & $\begin{array}{l}\begin{array}{l}18.711777 \\
32.89632\end{array}\end{array}$ & $\begin{array}{r}0.0080055 \\
0.00906\end{array}$ & $\begin{array}{l}0.000266 \\
0.003525\end{array}$ & $\begin{array}{l}22.838445 \\
36.04212\end{array}$ & $\begin{array}{l}10.016647 \\
16.67252\end{array}$ & $\begin{array}{l}5.1309555 \\
6.489439\end{array}$ & $\begin{array}{l}5.7771194 \\
9.498748\end{array}$ & $\begin{array}{l}291.16661 \\
641.8884\end{array}$ & $\begin{array}{l}1.760274 \\
4.191739\end{array}$ & $\begin{array}{l}34.153626 \\
62.68007\end{array}$ & $\begin{array}{l}0.11180722^{2} \\
0.167963\end{array}$ & $\begin{array}{l}0.666373 \\
0.470939\end{array}$ & $\begin{array}{r}0.66281 \\
0.814321\end{array}$ & $\begin{array}{l}0 \\
0 \\
0\end{array}$ & $\begin{array}{l}0.296587^{*} \\
0.60833\end{array}$ & $\begin{array}{l}3.604845 \\
2.794046\end{array}$ & $\begin{array}{c}0.140066 * \\
0.16579\end{array}$ & $\begin{array}{l}0.066^{*} \\
0.156553\end{array}$ & $\begin{array}{c}0.1600544^{*} \\
0.301206\end{array}$ \\
\hline 168 & 034 & \begin{tabular}{|l|l|} 
ol2. & 803.99631 \\
\end{tabular} & $\begin{array}{l}7.10515 \\
87.08343\end{array}$ & $\begin{array}{l}0.482858 \\
0.435651\end{array}$ & $\begin{array}{l}32.80652 \\
41.87387\end{array}$ & $\begin{array}{l}0.0099060 \\
0.009231\end{array}$ & $\begin{array}{l}0.0003525 \\
0.004728\end{array}$ & $\begin{array}{l}30.04211 \\
34.20326\end{array}$ & $\begin{array}{l}1.60 / 332 \\
21.33503\end{array}$ & $\begin{array}{l}6.4894439 \\
6.669589\end{array}$ & $\begin{array}{l}9.488 / 48 \\
11.49848\end{array}$ & $\begin{array}{l}604.1 .8884 \\
793.7867\end{array}$ & $\begin{array}{l}4.1 .717 / 199 \\
2.700405\end{array}$ & $\begin{array}{l}35.39637 \\
352.037\end{array}$ & $0.145765 *$ & $\begin{array}{l}0.400599 \\
0.500829\end{array}$ & $\begin{array}{l}0.714321 \\
0.743301\end{array}$ & 0 & $\begin{array}{l}0.008339 \\
0.760209\end{array}$ & $\begin{array}{l}2.1940446 \\
3.999323\end{array}$ & 0.012168 * & $\begin{array}{l}0.15953551 \text { * } \\
0.0591\end{array}$ & $\begin{array}{l}0.3012060^{\circ} \\
0.395088^{2}\end{array}$ \\
\hline 166 & 036 & $\begin{array}{r}030.59530 .286 \\
956.20\end{array}$ & $\begin{array}{l}111.8136 \\
1.134\end{array}$ & $\begin{array}{l}0.4324423 \\
0.3243\end{array}$ & 43.1541 & $\begin{array}{l}.0 .09521 \\
0.009262\end{array}$ & $\begin{array}{l}0.0058728 \\
0.00583\end{array}$ & $\begin{array}{l}3.420260 \\
37.7177\end{array}$ & 24.35954 & $\begin{array}{l}8.005305967 \\
8.0697\end{array}$ & $\begin{array}{l}1.45840 \\
12.38109\end{array}$ & 661.7597 & $\begin{array}{l}3.1904453 \\
3.953\end{array}$ & $\begin{array}{l}131.9126 \\
13106\end{array}$ & 0.10137 * & $\begin{array}{l}0.335436 \\
0.5083\end{array}$ & $\begin{array}{l}0.619877 \\
0.6137\end{array}$ & & 0.944501 & 2.848832 & $0.114075 *$ & $0.033907 *$ & 380745 \\
\hline 164 & 038 & 911.3095 & 97.91279 & 0.30078 & $\begin{array}{r}43.050503 \\
43.0653\end{array}$ & 0.008308 & 0.0054 & 25.19167 & $\begin{array}{l}2.52 .6423 \\
223\end{array}$ & 7.963406 & 49256 & 635.7013 & 4.5507259 & 62.89091 & 0.108029 * & $\begin{array}{l}0.285618 \\
0.5350\end{array}$ & 0.477835 & & 0.828467 & $\begin{array}{l}2.040032 \\
3.051299\end{array}$ & $0.057798 *$ & $-0.00072 *$ & 00304 \\
\hline 162 & 040 & 233.3391 & 47.93573 & 4729 & 14.46187 & 0.012654 & 0.002389 & 31.37865 & 7.138932 & 2.60806 & 333883 & 251.7201 & 2.904846 & 46.3152 & 0.088051 * & 0.470275 & 0.67302 & & 0.139073 * & 57931 & & 137795 & 46039 \\
\hline & & 611.2316 & 71.11423 & & 30.17329 & & & 1.919934 * & 21.35996 & 5.203839 & 226532 & & & 11.95759 & $132556 *$ & 0.090003 * & & & & & & & \\
\hline & & 768.4623 & & & 42.83173 & 0492 & & & 21.87661 & 7.674918 & & 679.7826 & 3.71401 & 15.48949 & & & & & & & & & 19059 * \\
\hline & & 696.8067 & 105.0 & & & 0.003126 & 0.002 & $8.277 \mathrm{CP}$ & 18.72 & & & 3073 & & 75201 & & & & & & & & 8537 & 04716 * \\
\hline & & 835.3016 & 116.0189 & & & & 0.001 & 7392 * & & & & & & & & & & & & & & & \\
\hline & & 870.3396 & 106.3443 & 0.249839 & 40.098 & 0.00483 & 0.002 & & & & 11.63 & & 1.157503 & 22.55 & & $0.133843 *$ & 0.21 & & & 424 & & & 391177 \\
\hline 150 & & 174.1426 & 54.81248 & & 19.76892 & 0.043095 & 0.020 & & 5.607078 & & & & & & & & & & & 20.51213 & & & \\
\hline 148 & 05 & 75.41486 & 12.23778 & & 8.277416 & 0.007409 & 0.002 & & 2.199416 & & & 67.36576 & $1.07 \mathrm{I}$ & & & & 0.3 & & & 3.6363 & & & 0.028312 * \\
\hline 146 & 056 & 149.8 & 16.18 & & & & & & 3.646715 & & 2.884 & & & & & & & & & & & & 0.122685 * \\
\hline & 058 & 110.9 & $16.5 \mathrm{~S}$ & & & & & & & & & & & & & & & & & & & & \\
\hline 1 & 06 & & 43.08 & & & & & & & & & & & & & & & & & & & & \\
\hline & 062 & & & & & & & & & & & & & & & & & & & & & & \\
\hline & 06 & & & & & & & & 5.218 & & & & & & & & & & & & & & \\
\hline $\begin{array}{l}15 \\
13 \\
4\end{array}$ & $\begin{array}{l}06 \\
06\end{array}$ & $\begin{array}{l}46.8 .5 \\
229.8\end{array}$ & $\begin{array}{l}6.062402 \\
2785491\end{array}$ & & $\begin{array}{c}5.26 \\
11.4\end{array}$ & & & & & $899^{*}$ & & & & & & & & & & & & & \\
\hline $\begin{array}{l}134 \\
132\end{array}$ & $\begin{array}{l}068 \\
070 \\
070\end{array}$ & $\begin{array}{r}229.8853 \\
143.263\end{array}$ & $\begin{array}{l}27.85491 \\
17.51297\end{array}$ & $\begin{array}{r}0.2 \\
0.278\end{array}$ & $\begin{array}{l}11.40 \\
9.721\end{array}$ & & $\begin{array}{l}0.001 \\
0.001\end{array}$ & $\begin{array}{l}9.669271 \\
7.62884\end{array}$ & $\begin{array}{l}5.093057 \\
3.570205\end{array}$ & 1374 & & & $\begin{array}{l}0.5559599 \\
4.448559\end{array}$ & & & & & & & & & $\begin{array}{l}96954 \% \text { * } \\
01222 \text { * }\end{array}$ & $3806{ }^{3}$ * $^{\circ}$ \\
\hline $\begin{array}{l}\begin{array}{l}132 \\
130\end{array}\end{array}$ & $\begin{array}{l}070 \\
072\end{array}$ & \begin{tabular}{|l}
1433.263 \\
197.8795
\end{tabular} & $\begin{array}{l}17.51297 \\
23.82603\end{array}$ & $\begin{array}{l}0.277129 \\
0.176424\end{array}$ & $\begin{array}{l}9.721864 \\
9.689755\end{array}$ & $\begin{array}{l}0.001817 *^{*} \\
0.001248\end{array}$ & $\begin{array}{l}0.0001584 \\
0.000903\end{array}$ & $\begin{array}{l}7.62884^{*} \\
0.364067\end{array}$ & $\begin{array}{r}3.570205 \\
4.7346\end{array}$ & $\begin{array}{r}\begin{array}{r}3.388804 \\
3.463467\end{array}\end{array}$ & $\begin{array}{l}2.1 .191091 \\
3.104979\end{array}$ & $\begin{array}{l}1112.24441 \\
152.1152\end{array}$ & $\begin{array}{l}4.448659 \\
1.64028\end{array}$ & $\begin{array}{l}\begin{array}{l}45.209043 \\
31.55164\end{array} \\
3\end{array}$ & $\begin{array}{c}0.017077^{*} \\
0.075132\end{array}$ & $\begin{array}{l}0.05000771 * \\
-0.00357 *\end{array}$ & $\begin{array}{c}0.10962^{*} \\
0.07286\end{array}$ & $\begin{array}{l}0 \\
0\end{array}$ & 368 * & & $\begin{array}{l}0.0800884^{*} \\
0.08400\end{array}$ & $\begin{array}{l}-0.01221 *^{*} \\
0.062225 *^{*}\end{array}$ & $\begin{array}{l}0.10004 *^{*} \\
0.0637794 *\end{array}$ \\
\hline & 074 & 324.8064 & $\begin{array}{l}23.86003 \\
38.43059\end{array}$ & $\begin{array}{l}0.170424 \\
0.207818\end{array}$ & $\begin{array}{l}9.688955 \\
21.93251\end{array}$ & $\begin{array}{l}.00146 \\
0.004849\end{array}$ & & $\begin{array}{l}0.364068 \% \\
6.184847 *\end{array}$ & $\begin{array}{r}4.13364 \\
7.515416\end{array}$ & $\begin{array}{l}3.463466 / \\
3.654548\end{array}$ & $\begin{array}{l}3.1 .057169 \\
7.059\end{array}$ & & $\begin{array}{l}1.1404028 \\
6.576264\end{array}$ & & & 0.091197 * & & & & $\begin{array}{l}2.35429 \\
4.138642\end{array}$ & $0.02780731 *$ & $0.084201 *$ & 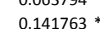 \\
\hline & 076 & & & & & & & & & & & & & & & & & & & & 0.022998 * & & \\
\hline & 07 & & & & & & & & & & & & & & & & & & & & & & \\
\hline 122 & 08 & & & & & & & & & & & & & & & & & & & & & & \\
\hline 120 & 082 & & & & & & & & & & & & & & & & & & & & & & \\
\hline & 08 & & & & & & & & & & & & & & & & & & & & & & \\
\hline & & & 14.08 & & & & & & & & & & & & & & & & & & & & \\
\hline & & & & & & & & & & & & & & & & & & & & & & & \\
\hline & & & & & & & & & & & & & & & & & & & & & & & \\
\hline & & & & & & & & & & & & & & & & & & & & & & & \\
\hline & & & & & & & & & & & & & & & & & & & & & & & \\
\hline 106 & & & & & & & & & & & & & & & & & & & & & & & \\
\hline $\begin{array}{l}104 \\
102\end{array}$ & $\begin{array}{l}098 \\
100\end{array}$ & $\begin{array}{l}533.5903 \\
506.6002\end{array}$ & $\begin{array}{l}63.076677 \\
58.79389\end{array}$ & $\begin{array}{r}1.1858 \\
1.312382\end{array}$ & $\begin{array}{l}24.5491313 \\
29.87604\end{array}$ & $\begin{array}{l}0.0333022 \\
0.036619\end{array}$ & $\begin{array}{l}0.008589 \\
0.016202\end{array}$ & $\begin{array}{l}101.8284 \\
144.8465\end{array}$ & $\begin{array}{l}\text { 15.886899 } \\
13.82181\end{array}$ & $\begin{array}{l}5.840443 \\
6.169927 \\
\end{array}$ & $\begin{array}{l}8.666856 \\
9.377087\end{array}$ & $\begin{array}{r}4163.501 \\
393.6701\end{array}$ & $\begin{array}{l}0.973632 \\
.023916\end{array}$ & $\begin{array}{l}\begin{array}{l}4.7880286 \\
54.82183\end{array} \\
5\end{array}$ & $\begin{array}{l}0.214254 * \\
0.235943 *\end{array}$ & $\begin{array}{l}1.5194415 \\
1.5737477\end{array}$ & $\begin{array}{l}3.078137 \\
3.023875\end{array}$ & & $\begin{array}{l}0.436515 \\
0.488154\end{array}$ & $\begin{array}{l}2.8998005 \\
5.539233\end{array}$ & $\begin{array}{l}0.158774 * \\
0.304902 *\end{array}$ & $\begin{array}{l}0.355657 \text { * } \\
0.0340618 \text { * }\end{array}$ & $\begin{array}{r}0.38091 \\
0.396864\end{array}$ \\
\hline & & & & & & & & & & & & & & & & & & & & & & & \\
\hline
\end{tabular}


Table A.1 continued

\begin{tabular}{|c|c|c|c|c|c|c|c|c|c|c|c|c|c|c|c|c|c|c|c|c|c|c|c|}
\hline & & ppb & & & & & & & & & & & & & & & & & & & & & \\
\hline Depth (cm) & Sample & $23 \mathrm{Na}$ & $24 \mathrm{Mg}$ & $27 \mathrm{Al}$ & $43 \mathrm{Ca}$ & $55 \mathrm{Mn}$ & $138 \mathrm{Ba}$ & $47 \mathrm{Ti}$ & $51 \mathrm{~V}$ & $75 \mathrm{As}$ & $85 \mathrm{Rb}$ & $86 \mathrm{Sr}$ & $89 \mathrm{Y}$ & $90 \mathrm{Zr}$ & $133 \mathrm{Cs}$ & $139 \mathrm{La}$ & $140 \mathrm{Ce}$ & $141 \mathrm{Pr}$ & $205 \mathrm{TI}$ & $208 \mathrm{~Pb}$ & $209 \mathrm{Bi}$ & $232 \mathrm{Th}$ & $238 \mathrm{U}$ \\
\hline 100 & & 271.5775 & 32.51211 & 0.773872 & $\begin{array}{l}13.48854 \\
\end{array}$ & 0.025175 & 0.026303 & \begin{tabular}{|l|l|}
64.51069 \\
\end{tabular} & 8.475387 & 5.212851 & 5.458278 & 213.9032 & 0.716186 & 19.05692 & $0.184816 *$ & 0.971384 & 1.732217 & 0 & 0.200909 * & 6.665174 & 0.333706 * & $0.22708^{*}$ & 0.242639 \\
\hline 98 & & 122.167 & 15.04722 & 0.221558 & 5.897073 & 002178 * & 0.002638 & 28.99766 & 2.949632 & 1.63563 * & 1.872135 & 95.66302 & 1.17053 & 7.037602 & 0.036963 * & 0.12068 * & 0.259745 & 0 & 0.086335 * & 0.94638 & 1.045665 * & 0.094742 * & \\
\hline 96 & & 90.76399 & 11.17716 & 0.58039 & 5.942037 & 009437 & 0.00313 & 22.06693 * & 3.776381 & 2.875105 & 2.700279 & 72.08678 & 0.69416 & 4.121769 & 124017 & 0.413479 & 0.82936 & & 084721 * & 3.371796 & .211464 & 0.183467 & 0.184139 * \\
\hline 94 & $10 \varepsilon$ & 233.689 & 26.33725 & 0.224005 & 10.53236 & $0.002431 *$ & 0.001451 & $7.951839 *$ & 5.444719 & 4.190346 & 2.810416 & 178.6611 & 0.423702 & 5.144422 & 0.021072 & 0.135848 & 0.233332 & & 68636 & 3.183946 & $0.016159 *$ & 0.085719 & 0.116334 * \\
\hline 92 & & 5.028463 & 0.715276 & 0.117548 & 8.172354 & 0.001831 * & 0.000881 & 33.78363 & 0.399033 & 0.88253 & 1.68331 & 8.245153 & 0.233987 & 2.73053 & 0.036272 & 0.041546 & $0.084324 *$ & & 65355 & 7.155016 & 0.11592 * & 0.03158 & 0.04188 * \\
\hline 90 & 11 & 253.7085 & 36.52512 & 0.301804 & 13.77784 & 0.003872 & 0.002425 & 32.24676 & 5.961912 & 5.471369 & 3.718601 & 198.1509 & 0.490796 & 1.363739 & $0.065092 *$ & 0.222864 & 0.359678 & 0 & .083652 * & 4.701151 & 0.029756 * & $0.061936 *$ & $0.188175 *$ \\
\hline 88 & 11 & 383.2299 & 43.90569 & 0.293589 & 16.90284 & $0.001404 *$ & 0.001503 & $5.268952 *$ & 8.517224 & 3.437542 & 4.766708 & 301.9077 & 0.230747 & 2.002188 & $0.041819^{*}$ & 0.151145 * & 0.207172 & 0 & $0.351995 *$ & 2.212721 & $0.095075 *$ & 0.013936 * & 0.13515 * \\
\hline 86 & 116 & 378.3495 & 45.71002 & 0.318347 & 19.75103 & 0.006896 & 0.002419 & $12.89641^{*}$ & 19.03261 & 3.970121 & 5.414854 & 298.9309 & 0.661936 & 7.793092 & 0.089092 * & $0.086129^{*}$ & 0.133356 * & 0 & 0.265859 * & 3.629541 & 0.022498 * & $0.046452 *$ & 135151 * \\
\hline 84 & 118 & 381.883 & 46.83093 & 0.181114 & 17.59643 & 0.00754 & 0.005193 & $4.72102 *$ & 8.806472 & 3.921708 & 4.696781 & 298.0999 & 1.010748 & 1.214495 & $0.032364 *$ & 0.018432 * & 0.067896 * & 0 & 356963 * & 2.919928 & 002177 * & $0.054194 *$ & 996351 * \\
\hline 82 & & & 41.35617 & 0.294047 & 21.40268 & 0.004278 & 0.00539 & 11.562 * & 7.634519 & 4.276754 & 5.286933 & 264.4504 & 0.307162 & 2.546525 & 0.112365 * & $0.129697 *$ & 0.233634 & 0 & $2062277^{*}$ & 5.715242 & 0.045722 * & 0.00464 * & 0.100231 * \\
\hline 80 & 122 & 228.3559 & $\begin{array}{l}28.65987 \\
1.79627\end{array}$ & 0.193392 & 10.57109 & $0.001261 *$ & 0.014137 & $\begin{array}{c}25.7442 \\
\end{array}$ & 5.222501 & 2.969518 & $\begin{array}{r}2.877765 \\
10151\end{array}$ & $\begin{array}{r}180.345 \\
115.506\end{array}$ & 0.407547 & $\begin{array}{l}9.054976 \\
9029115\end{array}$ & $0.05091 *$ & $0.060008^{*}$ & $0.118384 *$ & 0 & 054662 * & 2.801262 & $0.077656 *$ & 0.037161 * & \\
\hline 78 & 122 & $4 \quad 144.0336$ & $\begin{array}{l}17.86627 \\
9479027\end{array}$ & $\begin{array}{l}0.168089 \\
0.27644\end{array}$ & $\begin{array}{l}8.338015 \\
6.1118377\end{array}$ & $\begin{array}{l}0.003768 \\
0.05588\end{array}$ & $\begin{array}{l}0.001139 \\
0.001489\end{array}$ & $5.259556^{*} *$ & $\begin{array}{r}3.293435 \\
1.958865\end{array}$ & $\begin{array}{r}2.18679^{*} * \\
157738\end{array}$ & $\begin{array}{l}1.911513 \\
1.244634\end{array}$ & 115.6268 & $\begin{array}{r}0.53643 \\
\end{array}$ & $\begin{array}{l}6.028145 \\
375255\end{array}$ & $0.019637^{*}$ & $0.053286^{*}$ & 0.11351 * & 0 & .0944177* * & $\begin{array}{r}1.4252 \\
\end{array}$ & $0.031207 *$ & $-0.01703 *$ & 77598 * \\
\hline $\begin{array}{l}76 \\
74\end{array}$ & 126 & \begin{tabular}{l|l|l|}
68.9672 \\
7
\end{tabular} & $\begin{array}{l}9.474922 \\
89929237\end{array}$ & $\begin{array}{l}0.276649 \\
0.2481829\end{array}$ & $\begin{array}{l}6.118376 \\
4.344842\end{array}$ & $\begin{array}{l}0.005581 \\
0.005581\end{array}$ & $\begin{array}{l}0.001481 \\
0.001043\end{array}$ & $\begin{array}{l}8.697599 * \\
11955313 *\end{array}$ & $\begin{array}{l}1.958161 \\
207675\end{array}$ & $\begin{array}{l}1.557381^{*} \\
1.46558\end{array}$ & $\begin{array}{l}1.244634 \\
1.2649\end{array}$ & $\begin{array}{l}56.81083 \\
58.4827\end{array}$ & $\begin{array}{l}2.577696 \\
1.642727\end{array}$ & $\begin{array}{r}37.53554 \\
73.15808\end{array}$ & $0.058183^{*}$ * & $\begin{array}{l}0.068702 \text { * } \\
0.1775959\end{array}$ & $\begin{array}{l}0.236072 \\
0.272228\end{array}$ & 0 & $\begin{array}{l}0.019877 * \\
0.64691 *\end{array}$ & $\begin{array}{l}1.691302 \\
1.379649\end{array}$ & $\begin{array}{l}0.169101 * \\
-0.01814\end{array}$ & $\begin{array}{l}0.035612 * \\
0.039067^{*}\end{array}$ & $\begin{array}{l}0.049145 \text { * * } \\
0.05543\end{array}$ \\
\hline $\begin{array}{l}74 \\
72\end{array}$ & $\begin{array}{l}128 \\
136\end{array}$ & $\begin{array}{l}74.60154 \\
75.0999\end{array}$ & $\begin{array}{l}8.942937 \\
10.11146\end{array}$ & $\begin{array}{l}0.241826 \\
0.324448\end{array}$ & 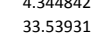 & $\begin{array}{l}0.00015185 \\
0.016063\end{array}$ & & $\begin{array}{l}19.553133^{*} \\
40.819194\end{array}$ & $\begin{array}{r}2.076654 \\
2.26913\end{array}$ & $\begin{array}{l}1.4605588^{*} \\
1.7038\end{array}$ & $\begin{array}{r}1.211449 \\
9.504262\end{array}$ & $\begin{array}{l}58.44822 \\
74.16276\end{array}$ & $\begin{array}{l}1.642723 \\
0.675331\end{array}$ & & $\begin{array}{l}0.029811^{*} \\
0.07303^{*}\end{array}$ & $\begin{array}{l}0.172594 \\
0.217502\end{array}$ & $\begin{array}{l}0.272283 \\
0.422005\end{array}$ & $\begin{array}{l}0 \\
0 \\
0\end{array}$ & & & $\begin{array}{l}-0.018144^{*} \\
0.021047\end{array}$ & $\begin{array}{l}0.0309677^{*} \\
0.04025\end{array}$ & $0.0504399^{*} *$ \\
\hline $\begin{array}{l}12 \\
70\end{array}$ & 13. & \begin{tabular}{|l}
15.09991 \\
76.03535
\end{tabular} & $\begin{array}{l}10.11146 \\
9.644512\end{array}$ & $\begin{array}{r}0.344448 \\
0.37146\end{array}$ & $\begin{array}{l}33.59311 \\
9.311941\end{array}$ & $\begin{array}{l}0.016063 \\
0.013274\end{array}$ & $\begin{array}{l}0.0003592 \\
0.001505\end{array}$ & $\begin{array}{l}\begin{array}{l}0.81941 \\
35.69052\end{array}\end{array}$ & $\begin{array}{r}2.269613 \\
2.536551\end{array}$ & $\begin{array}{l}1.600398 \\
1.225982 *\end{array}$ & $\begin{array}{l}9.304462 \\
2.401839\end{array}$ & $\begin{array}{l}74.16276 \\
63.21884\end{array}$ & $\begin{array}{r}0.6753331 \\
2.07176\end{array}$ & $\begin{array}{l}\begin{array}{l}4.8877299 \\
18.38065\end{array} \\
105\end{array}$ & $\begin{array}{l}0.173093^{*} \\
0.04064 \text { * }\end{array}$ & $\begin{array}{l}0.217502 \\
0.434172\end{array}$ & $\begin{array}{l}0.422005 \\
0.809919\end{array}$ & 0 & $\begin{array}{l}0.0546633^{*} \\
0.046341 *\end{array}$ & $\begin{array}{r}10.506411 \\
7.4141\end{array}$ & $\begin{array}{l}0.0210407 * \\
0.102152 *\end{array}$ & $\begin{array}{l}0.0402588^{*} \\
0.125896\end{array}$ & $\begin{array}{c}0.023388^{*} \\
0.04072\end{array}$ \\
\hline 68 & 13 & $\begin{array}{l}7.0 .03535 \\
73.24325\end{array}$ & $\begin{array}{r}9.6445112 \\
8.87109\end{array}$ & $\begin{array}{l}0.256317 \\
0.25317\end{array}$ & $\begin{array}{l}9.311941 \\
4.273822\end{array}$ & $\begin{array}{l}0.0111874 \\
0.011834\end{array}$ & 0.001422 & $\begin{array}{r}3.596052 \\
29.647\end{array}$ & $\begin{array}{l}2.3535351 \\
2.423111\end{array}$ & $\begin{array}{l}1.2259802 \% \\
1.693022\end{array}$ & $\begin{array}{l}2.401839 \\
1.278761\end{array}$ & $\begin{array}{l}0.23 .1884 \\
57.56126\end{array}$ & $\begin{array}{l}2.0176969 \\
0.54969\end{array}$ & $\begin{array}{l}18.380605 \\
22.86777\end{array}$ & $\begin{array}{l}0.0206928 * \\
0.02598\end{array}$ & $\begin{array}{l}0.434172 \\
0.109268\end{array}$ & $\begin{array}{l}0.8279919 \\
0.27997\end{array}$ & & $\begin{array}{l}0.046541 \\
0.057035 *\end{array}$ & $\begin{array}{r}.1441 \\
1.339521\end{array}$ & $0.018641 *$ & 0.114853 * & $\begin{array}{l}0.040877 \text { * } \\
0.040\end{array}$ \\
\hline 66 & 136 & 67.1362 & 8.516145 & 0.209276 & 10.99865 & 0.012975 & 0.002476 & 28.04997 & 2.216585 & $1.605459 *$ & 5.779284 & & 0.27125 & 7.983744 & 08199 * & 0.114426 & & & & & & & \\
\hline & & $\begin{array}{l}101 \\
101027\end{array}$ & 13.15931 & $\begin{array}{l}0.217419 \\
0.21719\end{array}$ & 6.772381 & 0.011763 & 01527 & 26.77988 & 2.958829 & $\begin{array}{l}1.0385150 \\
2.13896\end{array}$ & $\begin{array}{l}1.674253 \\
1\end{array}$ & 79.36107 & 1466 & 3813722 & 39944 & 0.115718 & & & 20 & 68814 & & & \\
\hline & & 606.1732 & & & & & & & & & & & & & & & & & & & & & \\
\hline 60 & 142 & $\begin{array}{r}816.4 \\
\end{array}$ & 142.7072 & 554529 & 0.01003 & 0.031716 & & 45.54002 & 23.01308 & 7.027535 & 15.75555 & & 0.635566 & 9.276325 & 0.216888 * & 0.855857 & & & & & & & \\
\hline & & 847.6398 & 144.8382 & 0.619078 & & & & 55 & & & 15.94753 & 890.082 & 1.202885 & 48.85363 & & & 253 & & & & & & 0.649861 \\
\hline & 14 & 720.9435 & 105.6245 & 0.643232 & & & & & & & & 747.4405 & & & & 0.756505 & & & & & & & \\
\hline & & 44.49258 & & 0.234 & & 0.013 & & 23.80976 & 1.97 & & & & & & & & & & & & & 0497 * & $0.088555 *$ \\
\hline 52 & 156 & 37.12822 & 5.338837 & & & 0.011554 & & 28.05966 & 1.891974 & $0.890298 *$ & 0.703247 & & 0.511124 & 32.13962 & $0.046601 *$ & $0.0693^{\circ}$ & 0.193156 & & -0.00624 * & 0.420731 * & $-0.02013 *$ & -0.05632 * & \\
\hline 50 & 15 & & 5.2645 & $0.19\}$ & & & & & 1.289723 & 1.210001 * & & & & & & $0.087048 *$ & & & & 0.60336 * & $0.100241 *$ & $0.075027 *$ & \\
\hline 48 & 15 & 112.1 & 15.704 & 0.2972 & 7.458 & 0.014 & & 23.08 & 3.324 & 1.414 & 1.979 & & & & 65 * & 0.166 & & & & & & & \\
\hline & 15 & & & & & & & & & 2.186 & & & & & & & & & & & & & \\
\hline & 158 & $3 \mid 114.2082$ & 15.46662 & 0.293155 & 7.726043 & & 0.003464 & 32.73 & 3.322406 & 2.709377 & 2.086889 & 93.35051 & 1.383708 & 143.3516 & $0.04873 *$ & 0.248518 & 05 & & .066444 * & 24.32352 & & & 467 * \\
\hline 42 & 166 & 26.65446 & 4.014381 & 0.203024 & & & & & 7.193027 & & 0.768936 & & & 6.841319 & & & & & & $0,596336 *$ & & & \\
\hline & & 15.85956 & 2.022237 & & 2.89 & & & & 5.295854 & 0.328014 & 0.513452 & 13.2 & 0.172462 & & & & & & & & & & \\
\hline & & 16.5 & & & & & & & 0.849887 & & 0.687904 & & & & & & & & & & & & \\
\hline & & & & & & & & & 0.546032 & & 0.300131 & & & & & 0.027244 & & & -0.03235 & 0.08 & & & \\
\hline & & & & & & & & & & & & & & & & & & & & & & & \\
\hline & 17 & 50.38 & & & & & & & & & & & & & & & & & & & & & \\
\hline 3 & $17:$ & & & & & & & & & & & & & & & & & & & & & & \\
\hline $2 \varepsilon$ & 17 & & & & & & & & & & & & & & & & & 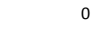 & & & & & \\
\hline & 17 & & & & & & & & & & & & & & & & & & & & & & \\
\hline & & & & & & & & & & & & & & & & & & & & & & & \\
\hline & $18 \mathrm{C}$ & & $\begin{array}{l}14.382 \\
1.371\end{array}$ & & & & & & & & & & & & & & & & & & 1 * & & \\
\hline 20 & 188 & & & & $\begin{array}{r}6.9148 \\
1078827\end{array}$ & & $\begin{array}{l}0.003197 \\
0.0022924\end{array}$ & & $\begin{array}{l}4.666363 \\
4.462889\end{array}$ & & $\begin{array}{l}2.802345 \\
2.132515\end{array}$ & & & & & & & & & $\begin{array}{l}2.730622 \\
2.253999\end{array}$ & 0.004218 * & 872 * * & $\begin{array}{l}0.038172 \text { * * } \\
0.042265\end{array}$ \\
\hline & 188 & $\begin{array}{l}120.71777 \\
123.5576\end{array}$ & $\begin{array}{l}12.533445 \\
1270623\end{array}$ & $\begin{array}{l}0.324062 \\
0.296173\end{array}$ & $\begin{array}{l}10.78827 \\
8.072677\end{array}$ & $\begin{array}{l}0.016621 \\
0.012989\end{array}$ & & & & $\begin{array}{l}2.042889^{*} * \\
2.2621 *^{2}\end{array}$ & & & & $\begin{array}{l}2.1377456 \\
1055101\end{array}$ & & & & & & & & & $0.042262 * *$ \\
\hline & & & & & & & & & & & & & & & & & & & & & & & \\
\hline 12 & $19 c$ & & & & & & & & & & & & & & & & & & & & & & \\
\hline 10 & 192 & & & & & & & & & & & & & & & & & & & & & & \\
\hline 8 & 19 & & & & & & & & & & & & & & & & & & & & & & \\
\hline 6 & 196 & & & & & & & & & & & & & & & & & & & & & & \\
\hline 4 & & & & & & & & & & & & & & & & & & & & & & & \\
\hline & & & & & 1.59007 & 0.070065 & 0.040881 & 133.4618 & 9.07988 & 4.25884 & 10.22962 & 215.6921 & 1.05721 & 4.484458 & & & 224858 & & & & & & \\
\hline
\end{tabular}


Table A.2 Trace element values for the $4 m$ pit. Asterisks indicate values below the detection limit.

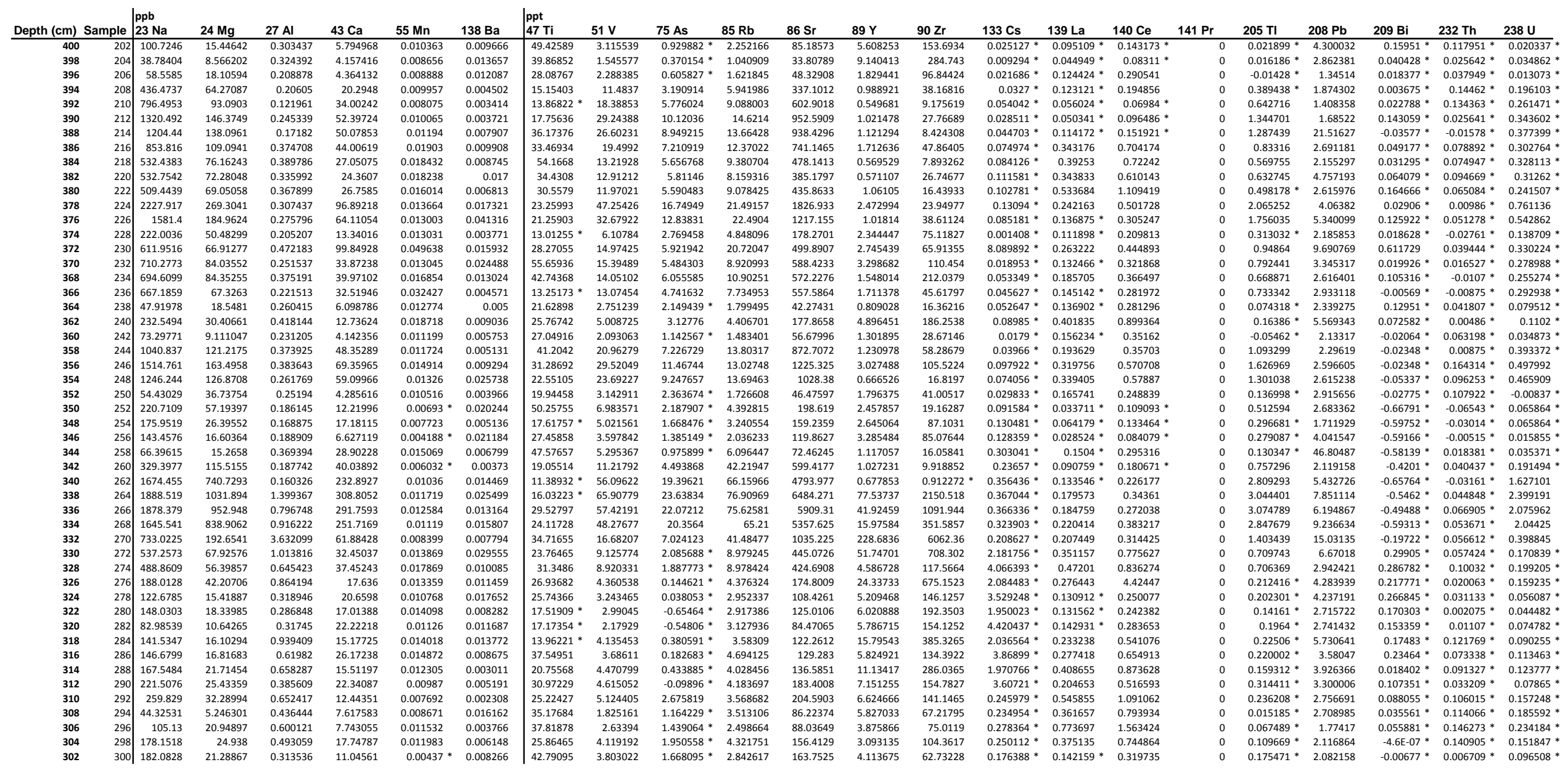


Table A.2 continued.

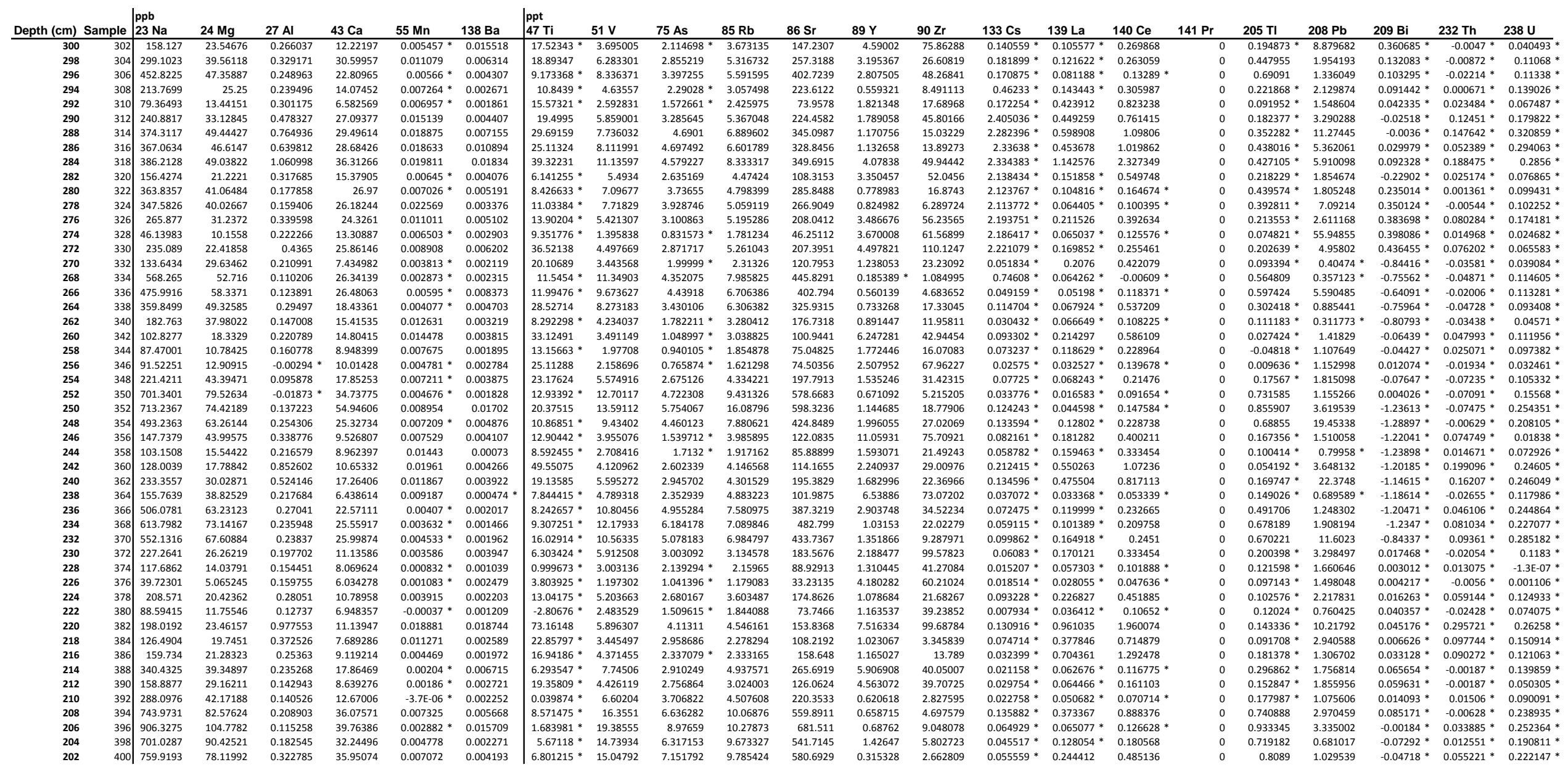


Table A.2 continued.

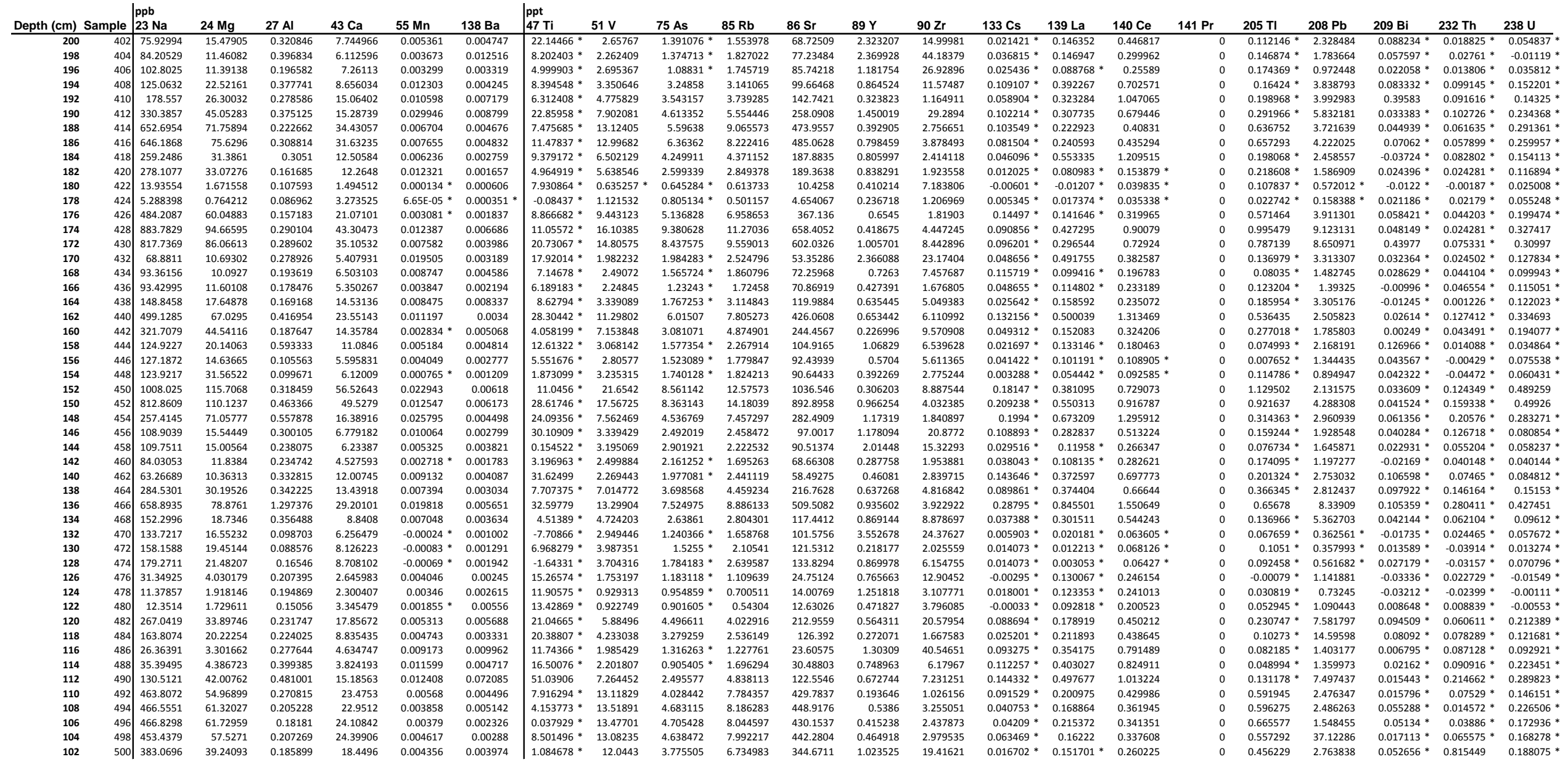


Table A.2 continued.

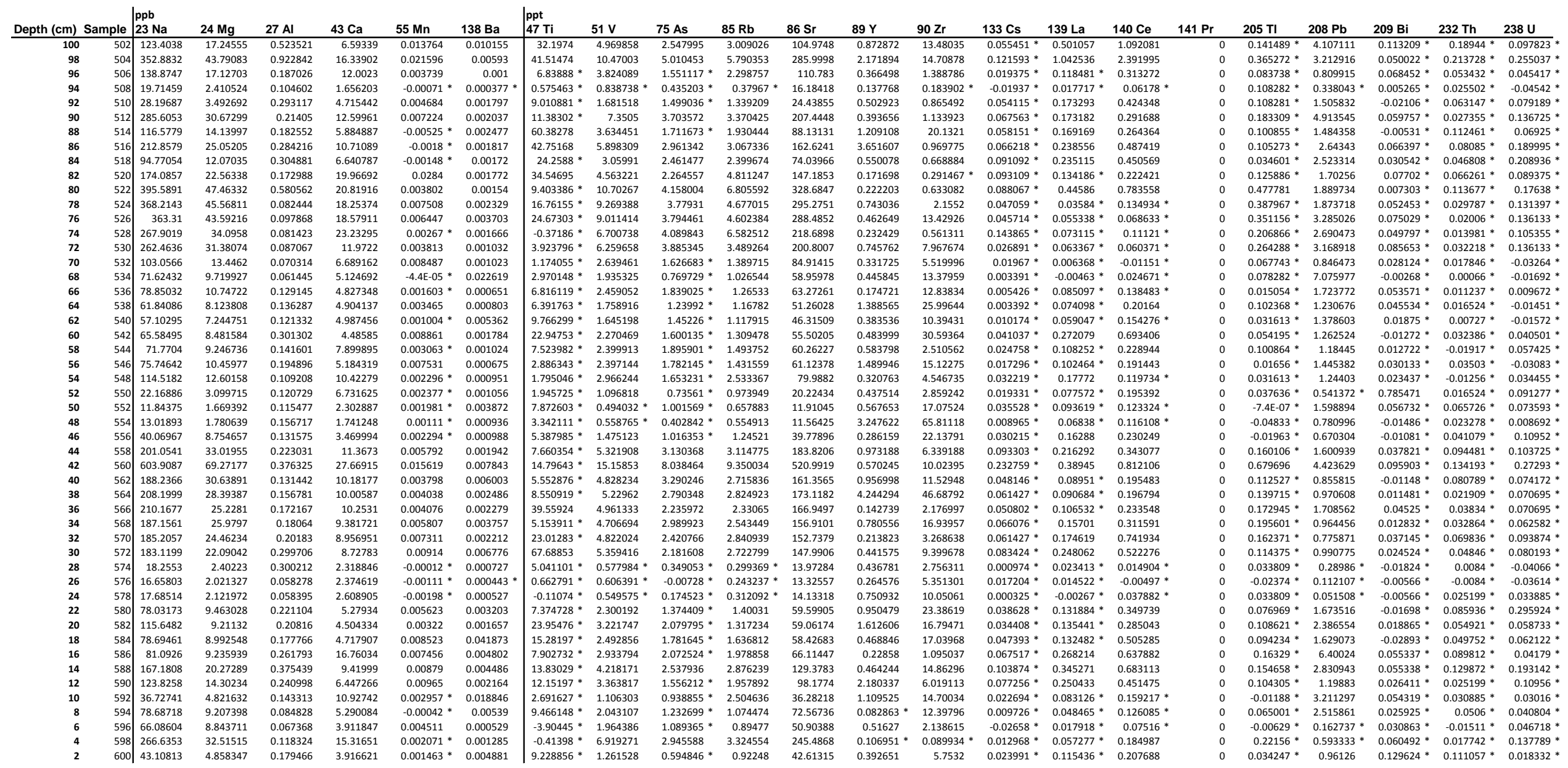




\section{Appendix B Roosevelt Island surface snow trace elements}

The surface snow samples taken during three storms at Roosevelt Island in November 2010 (presented as the basis for the isotope analysis in Chapter 5) were also analyzed for trace elements. Trace elements in these samples could be used to help further identify changes in source regions and circulation patterns for the three storms. This section presents preliminary results from this analysis.

The surface snow samples were analyzed for major, minor and trace elements using the Agilet inductively coupled plasma mass spectrometer (ICP-MS) at the geochemistry laboratory at Victoria University of Wellington. Further details on the three storms which were sampled and thesnow sampling procedure are described in Chapter 5. Each storm was sampled multiple times throughout the storm: four sampling events occurred during Storm 1 (1A-1D), five during Storm 2 (2A-2E) and four during Storm 3 (3A-3D). The time interval between samples varied between 8 and 24 hours. Each sample actually represents $0.5 \mathrm{~cm}$ to 2 $\mathrm{cm}$ of snow accumulation taken concurrently from between three to six different cleaned polypropylene surfaces (trays) laying on the snow surface.

The ICP-MS analysis for these samples is the same as described in Appendix A.3 and in Bull (2009) and Rhodes et al (2012). Because the surface samples were collected in Whirlpak bags instead of the pre-cleaned polypropylene bottles, nine blank samples of the Whirlpacks were analyzed to test for contaminants. Figure B.1 shows the averages and standard deviations of the Whirlpack blanks compared to 16 polypropylene bottles (which were cleaned using same methodology as in the snow pit samples). The contamination levels for the Whirlpaks are similar to those from the polypropylene bottles for most elements except for: $\mathrm{Pb}, \mathrm{Zr}, \mathrm{Sr}, \mathrm{As}, \mathrm{V}$, and Ti. Sodium (Na) contamination is also slightly higher for the Whirlpak blanks (Whirlpak blanks mean $=2.17, \sigma=0.97 \mathrm{ppb}$; bottle blanks mean $=0.21$, $\sigma=0.44 \mathrm{ppb}$ ), however these background values are still much lower than the levels measured in the surface snow samples (average $=183 \mathrm{ppb}$ ). This analysis indicatesthat, except for the elements mentioned above, the trace elements from these samples could be used for further analysis.

Table B.1 provides the trace element values measured for all the surface snow samples. 


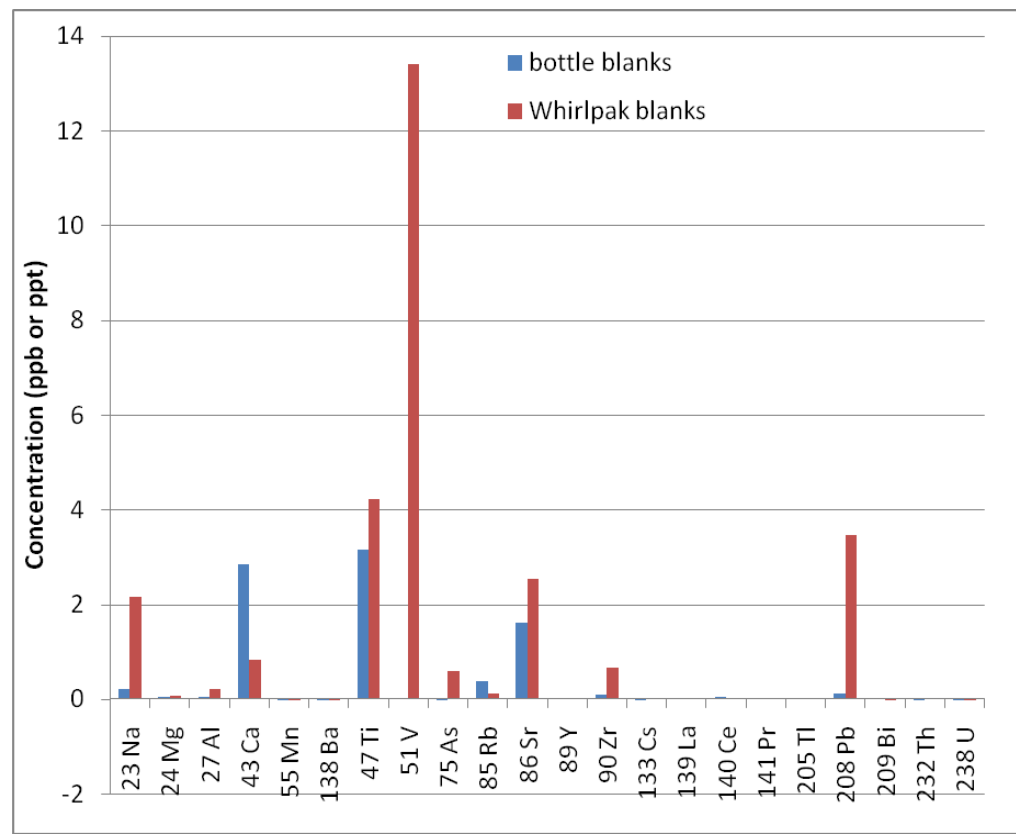

Figure B.1 Averages (top) and standard deviations (bottom) of the trace element concentrations for the Whirlpack versus polypropylene bottle blanks.

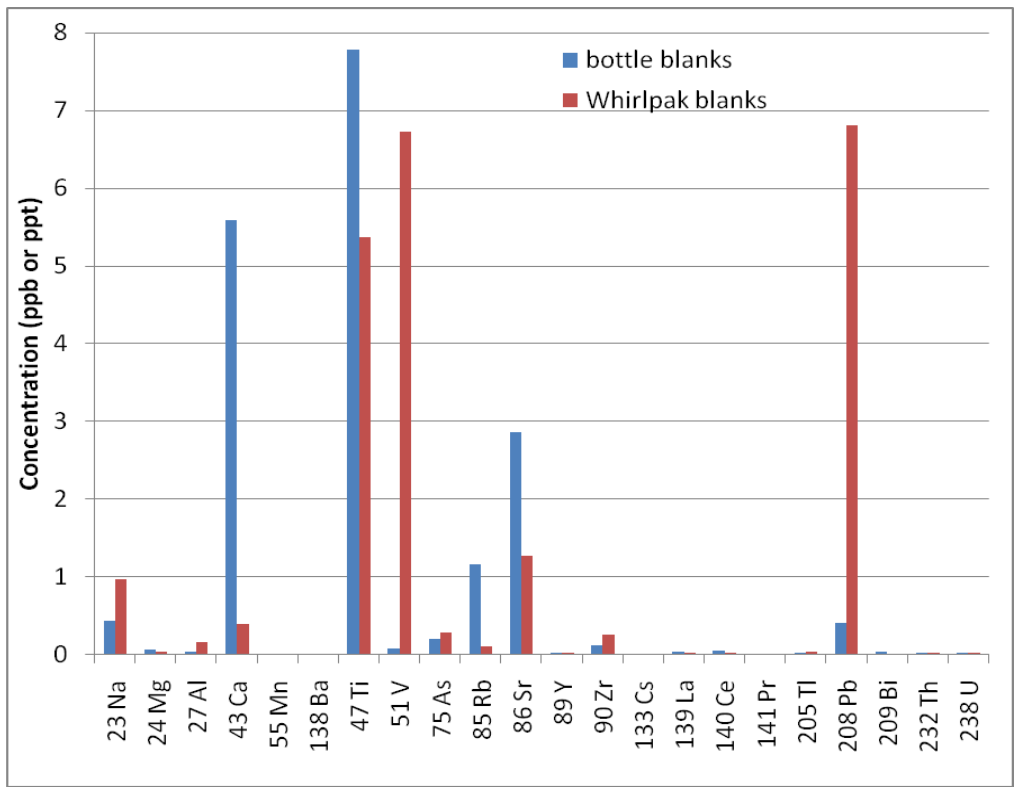


Table B.1 Trace element values from surface snow samples. Asterisks indicate values below the detection limit.

\begin{tabular}{|c|c|c|c|c|c|c|c|c|c|c|c|c|c|c|c|c|c|c|c|c|c|c|}
\hline \multirow{2}{*}{ Sample ID/\# } & \multicolumn{6}{|l|}{ ppb } & \multicolumn{16}{|l|}{ ppt } \\
\hline & $23 \mathrm{Na}$ & $24 \mathrm{Mg}$ & $27 \mathrm{Al}$ & $43 \mathrm{Ca}$ & $55 \mathrm{Mn}$ & $138 \mathrm{Ba}$ & $47 \mathrm{Ti}$ & $51 \mathrm{~V}$ & $75 \mathrm{As}$ & $85 \mathrm{Rb}$ & $86 \mathrm{Sr}$ & $89 \mathrm{Y}$ & $90 \mathrm{Zr}$ & $133 \mathrm{Cs}$ & $139 \mathrm{La}$ & $140 \mathrm{Ce}$ & $141 \mathrm{Pr}$ & $205 \mathrm{TI}$ & $208 \mathrm{~Pb}$ & $209 \mathrm{Bi}$ & $232 \mathrm{Th}$ & $238 \mathrm{U}$ \\
\hline Jam & $\begin{array}{lll}11 & 451.16818\end{array}$ & $\frac{24.99}{65.37654}$ & $\frac{21.322659}{1.62}$ & $\frac{15.6072}{15.10072}$ & 0.016398 * & 0.06736 & \begin{tabular}{|l}
74.86612 \\
\end{tabular} & 12.2478 & 6.027818 * & $\frac{05.499693}{0}$ & $\begin{array}{c}0001763 \\
410.1763\end{array}$ & 0.349037 & $-1.7216 *$ & 0.413738 * & 1.053615 & 3.466236 & 0 & -0.20801 * & 8.274842 & $\frac{10.04927}{-0.047}$ & $0.053428^{*}$ & 0.550112 \\
\hline & 67969 & 48.72735 & 1.800582 & 25.63257 & $0.043682 *$ & 0.186499 & 959.7204 & 11.78738 & $7.57698 *$ & 27.31847 & 324.179 & 1.262767 & 1.020891 & $0.513323 *$ & 3.337897 & & 0 & -0.225 * & & & & \\
\hline & 346.70156 & 49.20609 & 0.75976 & 8.721847 & $-0.01142 *$ & 0.070315 & 4.28853 & 8.990857 & 4.885518 * & 6.915413 & 305.3516 & 0.063012 * & -2.56651 * & 0.308555 * & 0.413922 & 08 & 0 & & & & & \\
\hline & 262.17032 & 39.12595 & 0.536089 & 10.6553 & 0.12507 & 0.124692 & .11.7929 & 6.837914 & $4.794268 *$ & 5.935433 & 248.3644 & $-0.01925 *$ & $-2.24325 *$ & $0.292781 *$ & $0.291129 *$ & & 0 & -0.16 & & & & 142515 \\
\hline & 28 & 41.32436 & 1.063575 & 28.49112 & 0.422145 & 0.173101 & 23.7263 & 8.249635 & $4.309102 *$ & 10.46781 & 272.6307 & 0.461686 & 4.912592 & 0.375866 * & 0.953725 & 02 & 0 & .057074 * & & & & \\
\hline & 284.21509 & 40.38702 & 1.041679 & 33.66686 & $-0.94327^{*}$ & 0.083392 & 117.7579 & 8.557396 & $3.700853 *$ & 13.73804 & 265.8615 & $0.166659 *$ & 3.232862 & $0.417076 *$ & 1.487125 & 1.168144 & & -0.21698 * & 2.116876 & $-0.08149 *$ & -0.03696 * & 0.576322 \\
\hline 1D & 44.806551 & 18.81765 & 0.564395 & $-3.4663 *$ & $0.07225 *$ & 0.144042 & 135.6518 & 5.270917 & $4.37847 *$ & 2070249 & 53.50503 & -0.13695 & -2.110 & & $-0.25554 *$ & 008982 & & 1217 & & & & \\
\hline & & 18.66786 & $\begin{array}{l}0.036776 \\
1.0676\end{array}$ & 0.480412 * & -2.34698 * & 154775 & 5.3141 & 2.131743 & 2.33626 * & & 49.56957 & $\begin{array}{l}-0.65569 \\
-0.059\end{array}$ & & & & & & & & & & \\
\hline & \begin{tabular}{|l|l}
55.169815 \\
\end{tabular} & 18.14223 & 2.5772 & $-0.0853 *$ & 0.724241 & 0.19182 & 126.0241 & 7.066542 & 2.605267 * & $\begin{array}{l}3.762344 \\
\end{array}$ & 67.01116 & 0.358621 & -2.06961 * & 0.140774 * & 1.726009 & 6.816977 & & .207547 * & 3.678229 & -0.1055 * & $-0.01454 *$ & 0.143735 \\
\hline 1B & 300.29833 & 46.41501 & & 9.746029 & 6.693953 & 0.170834 & 1.7202 & 14.63758 & 4.44137 & 8.060036 & 278.9587 & .211141 & -1.559 & & 2.563262 & & & & & & & \\
\hline & & & 2.065435 & & & 0.2019 & & 1.37201 & 5.533593 * & & 85.2574 & & & & & & & & & & & \\
\hline & $\begin{array}{lll}2 & 297.7382\end{array}$ & 46.19502 & 1.347114 & 8.648738 & $-0.04981 *$ & 0.095396 & 52.89337 & 9.981233 & $5.840217^{*}$ & 7.889313 & 276.9761 & 0.476654 & $-2.01046 *$ & $0.458313 *$ & 1.137692 & 4.217675 & & .149612 * & $=3.758432$ & 0.05108 * & $0.000633 *$ & 0.700026 \\
\hline 1C 13 & \begin{tabular}{l|l}
3 & 228.52312
\end{tabular} & 35.41248 & 0.597468 & 7.811988 & & & 187.654 & .415343 & & & & & & & & & & & & & & \\
\hline & $\begin{array}{lll}4 & 253.838029\end{array}$ & $\begin{array}{l}33.41248 \\
40.54376\end{array}$ & $\begin{array}{l}.599468 \\
1.106059\end{array}$ & $\begin{array}{l}7.811 \\
7.596\end{array}$ & $\begin{array}{c}-0.0645 \\
-0.0699 *\end{array}$ & 262089 & $\begin{array}{r}187.064 \\
336.2656\end{array}$ & $\begin{array}{l}.4113343 \\
8.744579\end{array}$ & $\begin{array}{l}.29035359 \\
4.241292 *\end{array}$ & $\begin{array}{l}6.576916 \\
6.402642\end{array}$ & $24.13 / 9$ & 0.219295 * & $\begin{array}{l}-1.9695 \\
-1.6908\end{array}$ & $0.348697 *$ & $\begin{array}{r}0.360609 \\
0.5919\end{array}$ & $\begin{array}{l}1.0486084 \\
2.995315\end{array}$ & c & 1 * & & 3 * & & $\begin{array}{l}.400211 \\
4.4021\end{array}$ \\
\hline & \begin{tabular}{l|l}
5 & 283.23141
\end{tabular} & 43.25543 & 0.910142 & 8.548501 & $-0.072 *$ & 0.367103 & 221.2229 & 8.856262 & 4.309175 * & 6.673164 & 268.8986 & 0.284908 & $-2.22369 *$ & 0.367027 * & 0.719433 & 2.779686 & & 0.105386 * & $\begin{array}{l}2.0 .044509 \\
3.96797\end{array}$ & $-0.07231 *$ & $0.057333 *$ & $\begin{array}{l}0.4551009 \\
0.551\end{array}$ \\
\hline 2A 16 & \begin{tabular}{l|l}
6 & 100.83354
\end{tabular} & 22.28211 & 0.95924 & 0.9899 * & -0.0593 & 0.085204 & 14.9464 & 6.299957 & $3.821281 *$ & & 102.4232 & $-0.22597 *$ & -1.959. & 0.202 & -0.079 & & & & & & & \\
\hline & & $\begin{array}{l}29.7811 \\
29.7911\end{array}$ & $\begin{array}{l}0.959924 \\
1.207372\end{array}$ & $\begin{array}{r}0.9899 \\
5.758177\end{array}$ & $\begin{array}{l}-0.0538512 * \\
-0.048\end{array}$ & 0 & $\begin{array}{l}4.9 .9464 \\
4.9259\end{array}$ & $\begin{array}{l}0.299951 \\
6.441541\end{array}$ & $5.758494 *$ & $\begin{array}{r}3.113513 \\
4.169572\end{array}$ & $\begin{array}{l}12.4232 \\
166.4063\end{array}$ & $\begin{array}{l}-0.225962 \\
-0.10622\end{array}$ & $\begin{array}{l}-1.095353 \\
-2.09737\end{array}$ & 0.28335 * & $2.03 E-05 *$ & & 0 & $0.161845 *$ & & $\begin{array}{l}-0.004 \\
-0.004\end{array}$ & & \\
\hline & \begin{tabular}{l|ll}
8 & 57.329131
\end{tabular} & 15.60731 & $0.031772 *$ & -4.63979 * & -0.07988 * & 0.061213 & 36.73981 & 4.169362 & 1.64648 * & 1.962569 & 44.14974 & -0.41357 * & 8.204437 & 0.115053 * & -0.38726 * & -1.30616 * & & 0.103506 * & 0.128818 * & -0.03184 * & $-0.06675 *$ & 0.028482 * \\
\hline $\begin{array}{ll}2 B & 19\end{array}$ & \begin{tabular}{l|l}
9 & 497.24628
\end{tabular} & 86.28506 & 5.942851 & 29.79512 & 0.08942 & 0.129466 & & 17.03832 & & & 5544802 & 0.9028 & & & & & & & & & & \\
\hline & & & $\begin{array}{l}5.944851 \\
1.360804\end{array}$ & & & & & 7. & $\begin{array}{l}13.396533 \\
6.755669 *\end{array}$ & & & $\begin{array}{l}0.102 \\
0.172\end{array}$ & $\begin{array}{l}-1.13 \\
-1.89\end{array}$ & & $\begin{array}{l}1.44 \\
0.60\end{array}$ & $\begin{array}{l}5.06 / \\
2.078\end{array}$ & 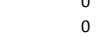 & & & $64 *$ & 58 * & 78476 \\
\hline 21 & $\begin{array}{lll}11 & 399.13784\end{array}$ & 71.56535 & 3.924379 & 18.70273 & & 0.102 & 39 & 12.2 & 9.035356 * & 9.274845 & 436. & & & & 1.185 & & & & & & & \\
\hline & & & 1.47488 & 7.915869 & & 0.02 & .34099 * & 7.2 & $6.122724 *$ & 6.245716 & & & & & 0.475454 & & & & & & & \\
\hline 23 & \begin{tabular}{|l|l}
3 & 167.5033
\end{tabular} & 29.16511 & 1.740172 & 6.458395 & $-0.00595 *$ & 0.0319 & .08341 & 8.300476 & $4.643082 *$ & 3.865083 & 174.637 & $0.066354 *$ & -1.41744 * & 0.197668 * & 0.505084 & $\begin{array}{l}1.530094 \\
\end{array}$ & & 0.09603 & 3.022078 & $0.072229 *$ & $-0.0252 *$ & 0.28993 \\
\hline 24 & \begin{tabular}{l|l}
4 & 213.44165
\end{tabular} & 37.12238 & 2.958223 & 12.63401 & $0.010195 *$ & 0.031712 & 9.8803 & 9.635157 & 3.66951 * & 5.519221 & 242.6171 & 0.364561 & $-1.36783 *$ & 0.291929 * & 0.867834 & 1.78014 & & $0.071936 *$ & 5.104869 & $-0.01094 *$ & -0.03425 * & 0.407229 \\
\hline 2C 25 & \begin{tabular}{l|l|l}
5 & 69.839742
\end{tabular} & 12.96723 & 0.362571 & 2.839 & & & & & & & & & & & & & & & & & & \\
\hline & & & & & & 0 & & & & & & & & & & & & & & & & \\
\hline 27 & & & & $\begin{array}{l}3.086 \\
-1.2\end{array}$ & & 0.005 & & 2. & & & & 3 * & $\begin{array}{r}-1.79 \\
-1.79\end{array}$ & & & & 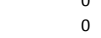 & & & & & \\
\hline & & & & $-0.36523 *$ & & 0.014418 & & 4.008522 & $0.264203 *$ & & & $-0.23836 *$ & -1.3898 * & $0.217541 *$ & & & & & & $-0.01376 *$ & -0.0168 * & $0.182474 *$ \\
\hline 29 & \begin{tabular}{l|l|l}
9 & 64.147893
\end{tabular} & 12.17354 & 0.317136 & $-2.7904 *$ & -0.03981 * & 0.005621 & -14.9679 * & 3.396413 & 1.562276 * & 1.996751 & 66.07765 & $-0.28344 *$ & -0.301 * & $0.21684 *$ & $-0.16913 *$ & -0.28564 * & ( & $0.058513 *$ & 1.126404 & $-0.0444 *$ & -0.07366 * & $0.12585 *$ \\
\hline $20 \quad 30$ & \begin{tabular}{l|l}
0 & 170.13856
\end{tabular} & 23.17 & 0.5 & & & & & & & & & & & & & & & & & & & \\
\hline & & & 1.754403 & & & & 246.5927 & $\begin{array}{r}15.46936 \\
\end{array}$ & 4.611634 * & 9.549768 & 331.7481 & 0.304926 & & & 0.946181 & & & & & & & \\
\hline & 480.76284 & $\begin{array}{l}59.861271 \\
58175\end{array}$ & $\begin{array}{l}1.1534003 \\
2.867101\end{array}$ & 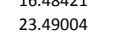 & 年 & $\begin{array}{l}0.0202475 \\
0.024202\end{array}$ & $\begin{array}{l}84.59571 \\
88.55074\end{array}$ & $\begin{array}{l}19.495360 \\
19.17793\end{array}$ & $\begin{array}{l}4.60110584 \\
6.104895\end{array}$ & $\begin{array}{l}9.8454968 \\
8.85463\end{array}$ & $\begin{array}{l}331.481 \\
398.4425\end{array}$ & $\begin{array}{l}0.301426 \\
0.616791\end{array}$ & $\begin{array}{l}-.453593 \\
-0.17127 \text { * }\end{array}$ & 0.308045 * & $\begin{array}{l}. .9466181 \\
1.965438\end{array}$ & $\begin{array}{l}-2.54142 \\
-5.87685\end{array}$ & & 0.102956 * & 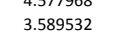 & -0.01968 * & $=0.0007066$ * & $\begin{array}{l}0.5304496 \\
0.70496\end{array}$ \\
\hline $2 \mathrm{E} \quad 33$ & \begin{tabular}{c|c|c}
3 & 373.92693
\end{tabular} & 46 & 2.2 & 2 & & & & 14 & & & & & & & & & & & & & & \\
\hline & & & 2.072609 & & & & 166.6751 & 16.24125 & $4.20619 *$ & 9.58512 & 378.2602 & 0.61271 & $0.059731 *$ & & $\begin{array}{l}1.573 \\
1.548\end{array}$ & $-4.09654 *$ & & & & & & $\begin{array}{l}0.42536 \\
0.487149\end{array}$ \\
\hline & $\begin{array}{l}444.51101 \\
374.62485\end{array}$ & $\begin{array}{l}54.085506 \\
46.085\end{array}$ & $\begin{array}{l}2.072609972 \\
1.669972\end{array}$ & $\begin{array}{l}30.64444 \\
31.38943\end{array}$ & 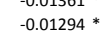 & $\begin{array}{l}0.025381 \\
0.030098\end{array}$ & $\begin{array}{r}160.6711 \\
180.96\end{array}$ & $\begin{array}{l}10.24425 \\
14.94336\end{array}$ & $\begin{array}{r}4.677538 * \\
\text { 4. }\end{array}$ & $\begin{array}{l}9.518512 \\
9.611068\end{array}$ & $\begin{array}{r}378.26062 \\
386.877\end{array}$ & $\begin{array}{l}0.6543111 \\
0.5439\end{array}$ & 0.807525 * & $\begin{array}{l}0.24341813 \\
0.242013\end{array}$ & $\begin{array}{l}1.5488124 \\
1.105001\end{array}$ & $\begin{array}{l}-4.0514054 \\
-3.41405\end{array}$ & & $\begin{array}{l}0.427657 \\
0.2767\end{array}$ & $=\begin{array}{l}.140444 \\
10.39366\end{array}$ & $\begin{array}{l}0.0526977 * \\
0\end{array}$ & $=0.020226 *$ & $\begin{array}{l}0.487149 \\
0.396638\end{array}$ \\
\hline $3 A \quad 36$ & & & & & & & & & & & & & & & & & & & & & & \\
\hline & & & $0.030784 *$ & & & & & 2.222143 & & 0.261564 * & $\begin{array}{l}13.05413 \\
13.75559\end{array}$ & $-0.35635 *$ & & & & & & & & & & \\
\hline & 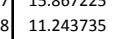 & $\begin{array}{l}1.4827141 \\
1.02901\end{array}$ & $\begin{array}{l}.0 .093014 \\
0.095032\end{array}$ & $\begin{array}{l}-4.4193999 \\
17.93983\end{array}$ & 0.475267 & $\begin{array}{l}0.021084 \\
0.02156\end{array}$ & $\begin{array}{l}44.5944 ! \\
51.56788\end{array}$ & $\begin{array}{l}3.2242143 \\
3.844182\end{array}$ & $\begin{array}{l}-.022534 \\
-0.05979\end{array}$ & $\begin{array}{l}0.21504 \\
3.612407\end{array}$ & $\begin{array}{l}294.1667 \\
29457\end{array}$ & $\begin{array}{l}-0.35353 \\
-0.1845\end{array}$ & 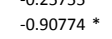 & 0.028199 * & -0.08363 * & $\begin{array}{l}-0.89561 \text { * } \\
0.0950\end{array}$ & & $\begin{array}{l}2.044 \\
2.366\end{array}$ & $\begin{array}{l}1.5007939 \\
2.184568\end{array}$ & $\begin{array}{l}-0.03536 \\
-0.03492\end{array}$ & $\begin{array}{l}-0.0351 \\
-0.02401 *\end{array}$ & 0.023061 * \\
\hline 3в & & & & & & & & & & & & & & & & & & & & & & \\
\hline & & & & & & & & & & & & & & & 0.827 & & & & & & & -0.01499 * \\
\hline 41 & $\begin{array}{ll}1198.775282\end{array}$ & 11.80907 & $-0.22234 *$ & -3.57464 * & $-0.02813 *$ & 0.155506 & $19.16763 *$ & 3.497081 & 1.684639 * & 1.407743 & 90.38061 & $-0.36868 *$ & -1.98844 * & 0.120659 * & -0.4768 & 1.0340 & & $0.032879 *$ & 0.317632 * & $-0.11044 *$ & $-0.06387 *$ & 0.085338 * \\
\hline $3 c$ & & & & & & & & & & & & & & & & & & & & & & \\
\hline & & & & & & & & & & & & & & & & & & & & & & \\
\hline 44 & \begin{tabular}{l|l}
4 & 101.08394
\end{tabular} & 12.33351 & 0.355888 & $-0.6214 *$ & -0.02251 * & 0.146007 & 176.9834 & 4.493129 & 2.19456 * & 2.172712 & 91.40268 & $-0.31139 *$ & -1.80191 * & 0.076048 * & -0.39559 * & 0.775264 * & & 0.209165 * & 1.45781 & $-0.10027 *$ & $-0.11033 *$ & 0.042955 \\
\hline 3D & & & & & & & & & & & & & & & & & & & & & & \\
\hline & & & & & & & & & & & & & & & & & & & & & & \\
\hline & & & & & & & & & & & & & & & & & & & & & & \\
\hline & \begin{tabular}{l|l|l|}
8 & 66.275
\end{tabular} & & & -0.50 & & & & & 1.210496 * & 2.07 & & & & & & & 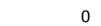 & & & & & \\
\hline & 59.56151 & & & 12.14319 & & & & & $1.57924 *$ & & & $-0.47837 *$ & $-1.15392 *$ & $0.066212 *$ & $-0.58561 *$ & 1.476344 & 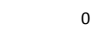 & 300309 * & 2.815428 & $-0.08435 *$ & -0.09496 * & 0.026346 \\
\hline & 59.576678 & 6.741877 & 0.102238 & -0.92769 * & $-0.02735 *$ & 0.015429 & 74.80041 & 2.496052 & $2.451157 *$ & 1.55635 & 71.36601 & -0.56021 * & $0.673813 *$ & 0.06516 * & -0.7044 * & 1.927541 & & 0.109066 * & 1.552553 & $-0.07148 *$ & $-0.08881 *$ & 0.007446 \\
\hline
\end{tabular}

